A route towards immune protection Milou Groat Nibbelink

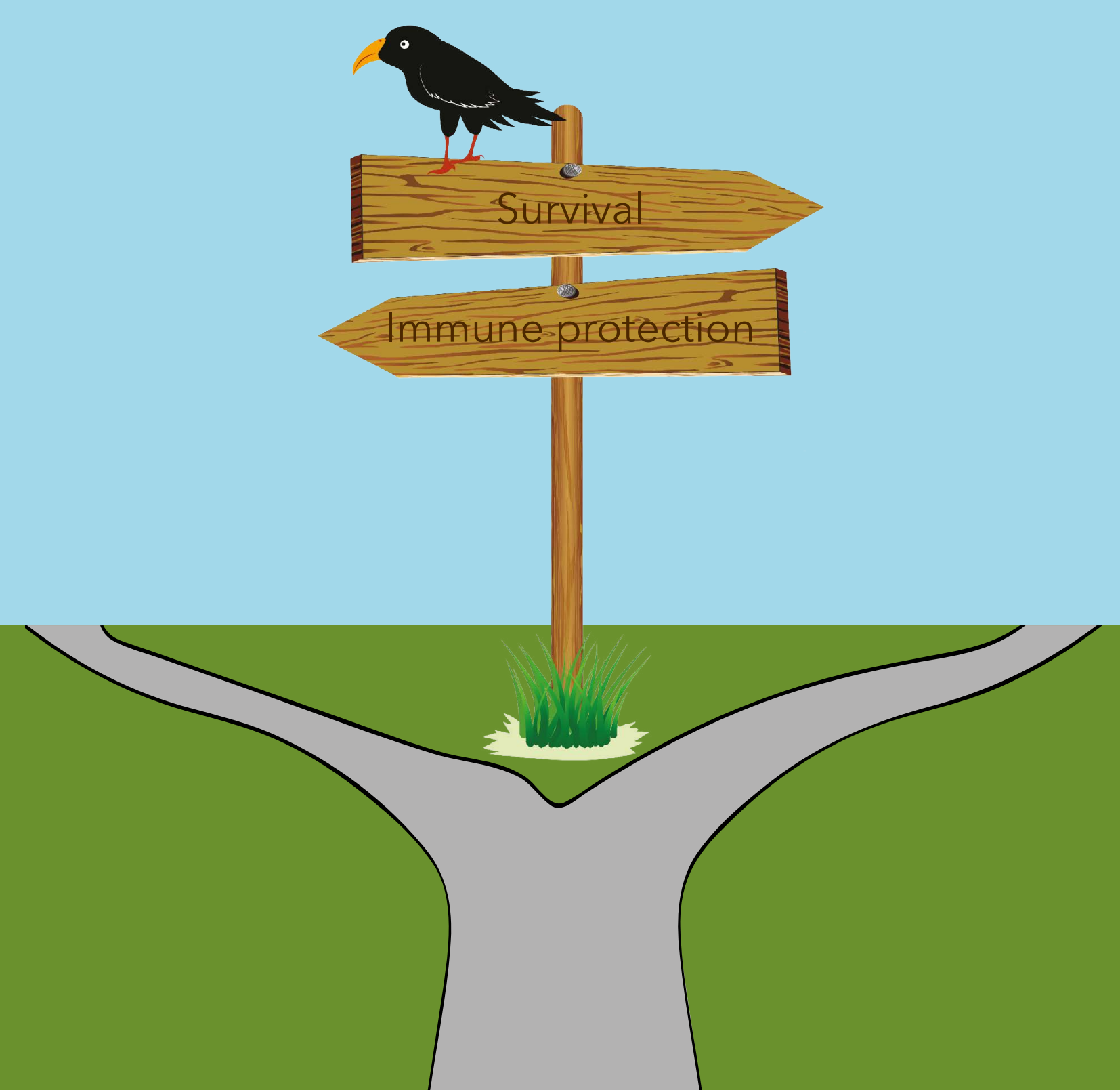




\section{A route towards immune protection}

Milou Groot Nibbelink

2016 


\section{Members of the Graduation Committee}

\section{Chairman:}

Prof. Dr. Ir. J. W. M. Hilgenkamp (University of Twente)

\section{Promoter:}

Prof. Dr. H. B. J. Karperien (University of Twente)

\section{Co-promoter:}

Dr. A. A. van Apeldoorn (University of Twente)

\section{Members:}

Prof. Dr. D. Stamatialis (University of Twente)

Prof. Dr. Ir. W. Steenbergen (University of Twente)

Prof. Dr. P. de Vos (University Medical Center Groningen)

Dr. Ir. S. le Gac (University of Twente)

Prof. Dr. D. W. Grijpma (University of Twente)

Dr. L. Moroni (Maastricht University)

Dr. F. Carlotti (Leiden University Medical Center)

\section{A route towards immune protection}

Milou Groot Nibbelink PhD Thesis, University of Twente, Enschede, The Netherlands

The research described in this thesis was supported by the Juvenile Diabetes Research Foundation (JDRF) (Grant key 17-2013-303).

ISBN: 978-90-365-4108-4

Copyright: Milou Groot Nibbelink 2016, Enschede, The Netherlands. Neither this thesis nor its parts may be reproduced without written permission of the author. Cover design: Linda Beving en Milou Groot Nibbelink 


\title{
A ROUTE TOWARDS IMMUNE PROTECTION
}

\section{DISSERTATION}

\author{
to obtain \\ the degree of doctor at the University of Twente, \\ on the authority of the rector magnificus, \\ Prof. Dr. H. Brinksma, \\ on account of the decision of the graduation committee, \\ to be publicly defended \\ on Friday, May $13^{\text {th }} 2016$ at 12.45
}

by

Milou Groot Nibbelink

Born on March $18^{\text {th }}, 1986$ in Apeldoorn, the Netherlands 
This dissertation has been approved by:

Prof. Dr. H. B. J. Karperien (Promoter)

Dr. A. A. van Apeldoorn (Co-promoter) 


\section{Table of Contents}

1 Thesis outline 1

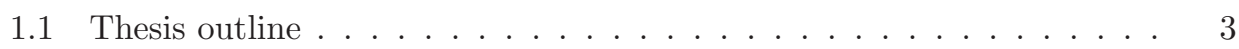

2 Immune protection in clinical islet of Langerhans transplantation 5

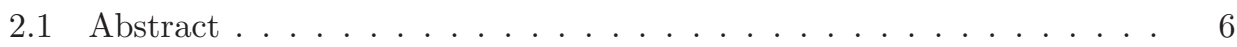

2.2 Type 1 Diabetes . . . . . . . . . . . . . . . . . 7

2.3 Clinical islet transplantation . . . . . . . . . . . . . . . . . 7

2.4 Immuno-suppressive drugs in islet transplantation . . . . . . . . . . 8

2.5 Encapsulation of islets for immune-protection . . . . . . . . . . . 9

2.6 Immune-protection; which immune responses are involved? . . . . . . 11

2.6.1 Instant Blood Mediated Immune Response . . . . . . . . . . . 11

2.6.2 Alloreactivity . . . . . . . . . . . . . . . 14

2.6.3 Autoimmune response . . . . . . . . . . . . . . 15

2.6.4 Xenograft rejection . . . . . . . . . . . . . 16

2.6.5 Inflammatory response . . . . . . . . . . . . . . . . . . 16

2.7 Finding the balance between immune protection and islet survival . . 17

2.7.1 The importance of oxygen for islet function and survival . . . . 18

2.7.2 Prevascularization of devices . . . . . . . . . . . . . 19

2.7.3 Immune protection by drug delivery . . . . . . . . . . . . . . . 19

3 A protocol to enhance INS1E and MIN6 functionality; the use of theophylline 


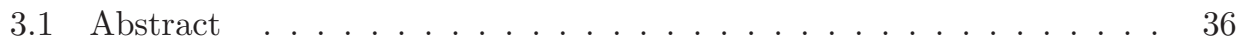

3.2 Introduction . . . . . . . . . . . . . . . . . . 37

3.3 Materials and Methods . . . . . . . . . . . . . . . . . . . 39

3.3.1 Cell culture . . . . . . . . . . . . . . . 39

3.3.2 Agarose microwell fabrication and controlled pseudo-islet formation ..................... 40

3.3.3 Glucose induced insulin secretion test . . . . . . . . . . . . . 40

3.3.4 The effect of theophylline on insulin secretion . . . . . . . . . . 41

3.3.5 Theophylline concentration dependent insulin secretion of MIN6 and INS1E pseudo-islets . . . . . . . . . . . . . . . 42

3.3.6 Statistical analysis . . . . . . . . . . . . . . . 42

3.4 Results. . . . . . . . . . . . . . . . . 42

3.4.1 The effect of theophylline on insulin secretion . . . . . . . . . 42

3.4.2 The effect of theophylline on the metabolic activity of MIN6 and INS1E cells . . . . . . . . . . . . . . . . . . 43

3.4.3 Theophylline concentration dependent insulin secretion of MIN6 and INS1E pseudo-islets . . . . . . . . . . . . . . . 43

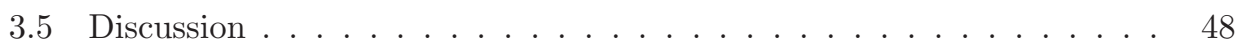

4 Diffusion properties, biocompatibility and function of encapsulated islets of Langerhans in a poly(ether sulfone) multibore hollow fiber

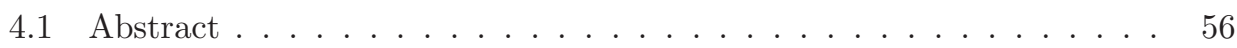

4.2 Introduction . . . . . . . . . . . . . . . . 57

4.3 Materials and methods . . . . . . . . . . . . . . . 59

4.3 .1 Cell culture . . . . . . . . . . . . . . 59

4.3.2 Pseudo-islet formation . . . . . . . . . . . . . 60

4.3.3 Multibore hollow fibers . . . . . . . . . . . . . . 60

4.3.4 Membrane permeance and diffusion characteristics . . . . . . 60

4.3.5 In vivo biocompatibility . . . . . . . . . . . . . 63 
4.3.6 Pseudo-islet seeding ..................... 64

4.3.7 Preventing pseudo-islet aggregation . . . . . . . . . . 65

4.3.8 In vitro MIN6 pseudo islet functionality . . . . . . . . . . . 65

4.3.9 Human donor islet functionality in vitro . . . . . . . . . . 66

4.3.10 Oxygen generation of PDMS calcium peroxide cylinders . . . . 67

4.4 Results.............................. 67

4.4.1 Membrane characteristics .............. 67

4.4.2 In-vivo biocompatibility of PESM multibore hollow fibers . . . 70

4.4.3 Preventing pseudo-islet clustering . . . . . . . . . . . . 72

4.4.4 In vitro MIN6 pseudo-islet functionality . . . . . . . . . . . . . 72

4.4.5 In vitro human islet functionality . . . . . . . . . . . . 73

4.4.6 Oxygen generation from PDMS calcium peroxide cylinders . . 75

4.5 Discussion . . . . . . . . . . . . . . . . . 77

5 Opening the white box in tissue engineering: visualization of cell aggregates in optically scattering scaffolds

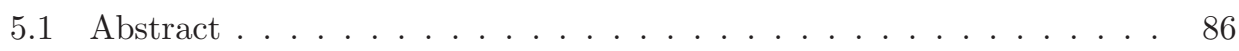

5.2 Introduction . . . . . . . . . . . . . . . . 87

5.3 Materials and methods . . . . . . . . . . . . . . . . 89

5.3.1 Cell culture . . . . . . . . . . . . . . 89

5.3 .2 Cell labeling . . . . . . . . . . . . . . . . 90

5.3.3 Agarose microwell fabrication and controlled cell aggregate formation ......................... 90

5.3.4 Multibore hollow fiber . . . . . . . . . . . . . . 91

5.3.5 Photoacoustic tomography ................. 91

5.3.6 Investigation into an optimum near-infrared (NIR) photoacoustic cell label . . . . . . . . . . . . . . . . . 93

5.3.7 End point photoacoustic imaging of labelled encapsulated cell

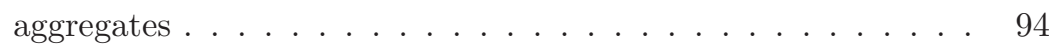


5.3.8 Photoacoustic serial imaging of encapsulated labelled INS1E cell aggregates ........................ 94

5.3.9 Statistical analysis . . . . . . . . . . . . . . 95

5.4 Results.............................. 95

5.4.1 Identification of an optimal near-infrared photoacoustic cell label 95

5.4.2 End point photoacoustic imaging of encapsulated cell aggregates 99

5.4.3 Longitudinal photoacoustic serial imaging of encapsulated labelled INS1E cell aggregates . . . . . . . . . . . . . . . . . . 101

5.5 Discussion . . . . . . . . . . . . . . . . . . 105

6 Evaluation of microwell PES/PVP membranes for islet encapsulation: A novel strategy for immune protection 113

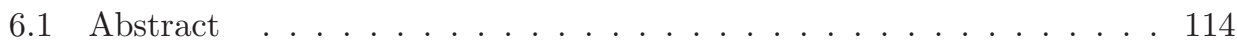

6.2 Introduction . . . . . . . . . . . . . . . . . . . 115

6.3 Materials and methods . . . . . . . . . . . . . . . . . 118

6.3.1 Microwell membrane fabrication . . . . . . . . . . . . . 118

6.3.2 Sodium hypochlorite treatment . . . . . . . . . . . . 118

6.3.3 In vivo biocompatibility . . . . . . . . . . . . . . . 119

6.3.4 Cell culture . . . . . . . . . . . . . . . . . . 120

6.3.5 Pseudo-islet formation . . . . . . . . . . . . . . . . 121

6.3.6 Pseudo islet viability in a closed system . . . . . . . . . . . . . 121

6.3.7 Human islet functionality in vitro in a closed system . . . . . . 123

6.3.8 Human islet functionality in vitro in a sealed device . . . . . . 124

6.4 Results. . . . . . . . . . . . . . . . . . . 126

6.4 .1 In vivo biocompatibility . . . . . . . . . . . . 126

6.4.2 Pseudo islet viability in a closed device . . . . . . . . . . 128

6.4.3 Human islet functionality in vitro in a closed system . . . . . . 128

6.4.4 Functionality of encapsulated human islets in a sealed device . 131

6.5 Discussion . . . . . . . . . . . . . . . . . . 133 
7 Mesenchymal stem cells and micropatterns of poly(ether sulfone)/ poly(vinylpyrrolidone) membranes accelerate vascularization

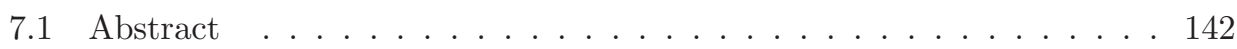

7.2 Introduction . . . . . . . . . . . . . . . . . 143

7.3 Materials and Methods . . . . . . . . . . . . . . . . 147

7.3.1 Membrane fabrication . . . . . . . . . . . . 147

7.3.2 Animal housing and cell culture . . . . . . . . . . . . . 147

7.3.3 Coating of membranes . . . . . . . . . . . . . . 148

7.3.4 Cell attachment on membranes . . . . . . . . . . . . . . 148

7.3.5 Cell alignment on micropatterned membranes . . . . . . . . . . 148

7.3.6 Micropatterned membranes and MSCs for in vivo vascularization in female Lewis rats . . . . . . . . . . . . . . . . . . 149

7.3.7 Statistical analysis . . . . . . . . . . . . . . 150

7.4 Results............................... 150

7.4.1 Cell attachment of MSCs to PES/PVP porous membranes . . . 150

7.4.2 MSC nucleus alignment on micropatterned membranes . . . . . 152

7.4.3 MSCs and micropatterns for in vivo vascularization in female Lewis rats . . . . . . . . . . . . . . . . . 153

7.5 Discussion . . . . . . . . . . . . . . . . 161

8 Oxygen generation for extrahepatic islet of Langerhans transplantation

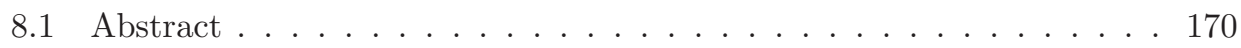

8.2 Introduction . . . . . . . . . . . . . . . . . . 171

8.3 Materials and methods . . . . . . . . . . . . . . . 173

8.3.1 Pancreatic islet isolation and culture . . . . . . . . . . 173

8.3.2 Microwell membrane fabrication . . . . . . . . . . . 173

8.3.3 $\mathrm{PDMS}-\mathrm{CaO}_{2}$ disk fabrication . . . . . . . . . . . . 174

8.3.4 Islet seeding and co-culture with PDMS disk . . . . . . . . . . 174

8.3.5 In vitro assessment of islet viability and metabolic activity . . 175 
8.3.6 In vitro assessment of glucose induced insulin secretion . . . . . 175

8.3.7 Statistical analysis . . . . . . . . . . . . . 176

8.4 Results. . . . . . . . . . . . . . . . 176

8.4.1 In vitro assessment of islet viability and metabolic activity . . 176

8.4.2 In vitro assessment of glucose induced insulin secretion . . . . . 180

8.5 Discussion . . . . . . . . . . . . . . . . . . 181

9 Summary and outlook $\quad 189$

9.1 Summary . . . . . . . . . . . . . . . . . . 190

9.2 Multibore hollow fiber for extrahepatic islet transplantation . . . . . . 192

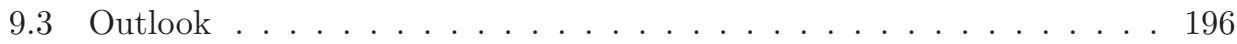

9.3.1 Improving the transplantation outcome by the induction of vessel formation . . . . . . . . . . . . . . . 196

9.3.2 Oxygen generating materials . . . . . . . . . . 202

9.3.3 Immune protection . . . . . . . . . . . . . . . . 205

9.3.4 The multibore hollow fiber or a flat microwell membrane? . . . 205

$\begin{array}{lr}\text { Curriculum Vitae } & 217\end{array}$

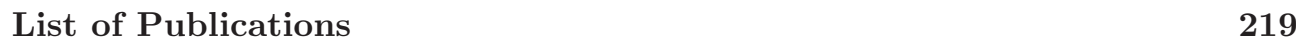

$\begin{array}{ll}\text { Acknowledgements } & 221\end{array}$ 


\section{Chapter 1}

\section{Thesis outline}

Milou Groot Nibbelink, Marcel Karperien, Aart van Apeldoorn 


\subsection{Thesis outline}

This work describes a route towards an immune protective device for islet of Langerhans transplantation. We developed a protocol to use MIN6 $\beta$ cells aggregates as pseudo-islets to overcome the donor shortage issue (chapter 3). In this thesis we explored two different immune protective strategies; a multibore hollow fiber and flat microwell membranes. In chapter 4 we investigated the possibility to use a commercial multibore hollow fiber. In this chapter we showed that we were capable to physically separate islets using agarose macrospheres. Photoacoustic imaging in chapter 5 confirmed these findings. The flat membrane microwell device was developed based on work of Buitinga et al.(1) who developed a poly(ethylene glycol terephthalate)-poly(butylene terephthalate) (PEOT/PBT) microwell scaffold, made by micro thermoforming of dense thin films. We developed a microwell device that consisted of a thin PES/PVP membrane for islet encapsulation and a $0.45 \mu \mathrm{m}$ pore sized PES lid (chapter 6). These membranes were sealed prior to seeding by a custom made seal device. Encapsulated human islets were still responsive to glucose stimulation after 7 days of culture.

As a lack of proper vascularization after transplantation and thereby hypoxia is a major contributor to islet death, we studied solutions to overcome this issue. In chapter 7 we showed that micropatterned membranes in combination with MSCs could be used to enhance vascularization in vivo. Finally, we combined the oxygen generating materials of Pedraza et al. (2) with the microwell membrane device of chapter 6 in chapter 8 . We showed, similar to Pedraza et al. that the oxygen generating disk had a positive effect on islet viability and function. In this thesis we took the first steps towards an immune protective device, although successful in many aspects additional work is needed to further optimize the devices developed in this work. Therefore in chapter 9 an outlook is presented of different options in order to reach a functional immune protective device for islet encapsulation. 


\section{References}

1. Buitinga, M., Truckenmller, R., Engelse, M.A., Moroni, L., Ten Hoopen, H.W.M., van Blitterswijk, C.A., de Koning, E.J.P., van Apeldoorn, A.A., and Karperien, M. Microwell Scaffolds for the Extrahepatic Transplantation of Islets of Langerhans. PLoS ONE 8, 2013.

2. Pedraza, E., Coronel, M.M., Fraker, C.A., Ricordi, C., and Stabler, C.L. Preventing hypoxia-induced cell death in beta cells and islets via hydrolytically activated, oxygen-generating biomaterials. Proc Natl Acad Sci U S A 109, 4245, 2012. 
Chapter 2

\section{Immune protection in clinical islet of Langerhans transplantation}

Milou Groot Nibbelink, Marcel Karperien, Aart van Apeldoorn 


\section{$2.1 \quad$ Abstract}

Although a promising therapy, in clinical islet of Langerhans transplantation $60-70 \%$ of the donor islets are lost within a few days after transplantation. This is due to mechanical stress, different immune-responses, and lack of vascularization. Much research has been performed on transplantation of islets in an extra hepatic location. Additionally, shielding the islets from the immune system by creating a so called immune-protective device has been of great interest. This review gives an overview of all immune responses involved in the loss of islets after transplantation. The focus lies on the properties needed for an immune protective device for extrahepatic islet transplantation based on these immune responses. Based on this, we show that finding the balance between optimal islet survival and immune-protection remains an enormous challenge. Therefore solutions to enhance islet survival in such immune protective devices are discussed. 


\subsection{Type 1 Diabetes}

Type 1 Diabetes mellitus is a chronic disease that manifests in children and young people (usually $<30$ years) and is caused by destruction of the insulin producing $\beta$ cells due to an autoimmune reaction(1-5). Diabetes mellitus is a disease characterized by hyperglycaemia as well as relative insulin deficiency. It is known for its severe acute and long-term complications due to micro- and macroangiopathic lesions and has a significant social and economic impact. Long term symptoms are retinopathy, neuropathy, and nephropathy(3, 6-12). As insulin is inadequately produced, type 1 Diabetes Mellitus patients need life-long insulin therapy and tight glucose monitoring, hence its name insulin-dependent Diabetes mellitus. Patients with severe glyceamic lability, recurrent hypoglycaemia, hypoglycaemia unawareness, or an insufficient response to the insulin therapy are in need for alternative therapies. Current alternatives for insulin injections are total pancreas transplantation or clinical islet transplantation $(3,6,7,9,11,13,14)$. Both alternatives have the disadvantage of limited donor availability and a need for life-long immunosuppressive drugs as both the pancreas and islets are of allogeneic origin. The advantages of islet transplantation over whole pancreas transplantation are the lower surgical risk and fewer complications(15). Due to a donor organ shortage, high costs of isolation procedures, and a life-long need for immunosuppressive agents, clinical islet transplantation is reserved for a selected group of patients. Only patients with severe glycaemic lability, recurrent hypoglycaemia, and hypoglycaemia unawareness are eligible for clinical islet transplantation $(3,6,7,9,11)$.

\subsection{Clinical islet transplantation}

Clinical islet transplantation (CIT) consists of the isolation of islets from a donor pancreas and transplantation in the patient via infusion in the portal vein. After infusion into the portal vein, islets travel to the liver where they will embolize in the microvasculature and perform their endocrine function. Although promising, studies have reported low numbers of patients that stay insulin dependent over time, from 
$24 \%$ after 2 years to only $15 \%$ after 5 years $(14,16)$. Many islets $(60 \%)$ are lost in the first days after transplantation $(17,18)$. This process starts already during isolation, where islets are exposed to a variety of cellular stresses such as mechanical, enzymatic, osmotic, and ischaemic stresses and disruption of cell matrix and vasculature(19). This has shown to have a great impact on islet survival, as islets are particularly wellperfused in the pancreas. Although islets consist of only $1 \%$ of the entire pancreas, they receive $5-15 \%$ of the total blood supply of the pancreas(20-22). Due to disruption of their vasculature and the exposure to only venous blood in the first days weeks after transplantation, transplanted islets are exposed to relative hypoxic conditions. This situation persists at least for 7 days after which angiogenesis starts eventually resulting in perfusion. It is known that hypoxia causes islets death and dysfunction(6, $7,16,23,24)$. In the liver, islets are immediately exposed to high concentrations of drugs and nutrients, such as glucose, negatively affecting islet function(11, 16, 24-29). The isolation procedure brings islets in a pro-inflammatory state as a consequence of cellular stresses(30). This induces the expression of pro-inflammatory cytokines which trigger different immune-responses involved in the loss of islets after transplantation.

\subsection{Immuno-suppressive drugs in islet transplantation}

To aid in preventing islet loss due to the attack of the immune system, immunosuppressive drugs are administered to the patients receiving islets. Although immunosuppressive drugs are necessary to enhance islet survival by decreasing the chance of acute rejection, life-long use of immunosuppressive drugs is associated with numerous complications such as; infections, neoplasms, and failure to control rejection. In addition some drugs have a negative effect on islet function by causing metabolic alterations or by direct drug toxicities. For example, calcineurin inhibitors and steroids have shown to interfere with $\beta$ cell function $(2,11,15,29,31-34)$. Consequently, multiple donor pancreata are necessary to obtain complete insulin dependency, which is again a problem with limited donor availability $(14,32)$. Additionally, the hepatic location for CIT increases the effect of toxic drugs, as their concentration is high in 
the liver as the liver metabolizes drugs(11).

To increase clinical islet transplantation efficacy, research has focused on developing devices for either immune-protection or improved islet survival. In addition, due to the disadvantages of the portal system as a transplantation site, a more favorable transplantation site is sought after. However, the ultimate solution has not yet been found. Either islets do not survive long enough or patients still need immunosuppressive drugs to avoid rejection(6).

\subsection{Encapsulation of islets for immune-protection}

Combining islet immune-protection while maintaining islet viability might be the ultimate solution. It is thought that membrane based scaffolds could both maintain islet viability and act as a barrier for the immune system. The most essential requirements for such a device, also known as a bioartificial pancreas, are; fast and efficient response to high glucose concentration in the blood, fast nutrient and oxygen transport, immune-protection, and biocompatibility. In detail, islets need to be separated from the blood stream, the device needs to be permeable for glucose, insulin, nutrients, and oxygen, and the device needs to be impermeable to the immune system to prevent cell-cell contact. However, the immune-protection should not compromise transport of glucose, insulin, oxygen, and nutrients as this will lead to islets necrosis and a dysfunctional bioartificial pancreas. In addition, the device should be sterilizable, implantable, and retrievable in an easy and safe manner(6-8, 16, 35-37). Components of the immune system have the same sizes as the necessary nutrients, insulin, and glucose. Consequently the development of an immune protective device is quite challenging due to these contradictory requirements. When designing an immune-protective encapsulation device for transplantation of islets, a balance needs to be found between optimal survival of islets and shielding the islets from the immune system(38). A device solely focused on islet survival will be as open as possible to prevent diffusion limitations and to optimally facilitate vessel ingrowth. On the other hand, when creating a device for immune-protection, the device will be more closed, 
often experiencing diffusion limitations, and does not allow for vessel infiltration towards the islets. To determine the criteria for immune-protection, it is important to understand the different immune responses involved in the destruction of the graft.

Much research has been done on encapsulating islets and protecting them from the immune system. There are different types of encapsulation starting from nanoencapsulation to macro-encapsulation.

One speaks of nano-encapsulation when islets are conformally coated(39, 40). Coating islets with polymer chains like Poly ethylene glycol (PEG) is frequently used(39, 40). The advantage of these coatings is that islets are less prone to hypoxia and nutrient deprivation as diffusion distances do not play a large role(39). Still the challenge remains to achieve an uniform coating. Furthermore, preserving long term stability is still largely unresolved since conformal coatings can be rapidly removed by endocytosis, and therefore immune protection decreases over time $(39,41)$.

Microcapsular devices consist mostly of islets encapsulated in hydrogels. Most common materials are; alginate, chitosan, agarose, HEMA-MMA, copolymers of acrylonitrile (AN69), and polyethylene glycol(17). Alginate has shown advantages over other materials, as it does not interfere with cell function, is mechanically stable, and capsules are easily manufactured at physiological conditions(17, 42, 43). Additionally, several coating materials for alginate are tested, such as PEG and different polycations, of which poly-L-lysine (PLL) seems to be the best option. Again the exact composition of the alginate-PLL beads are important as PLL can act pro-inflammatory $(7$, $17,42,44,45)$. As islets are fully embedded in the hydrogel, microcapsular devices are suitable for immune-protection. Problems with microcapsular devices include large diffusion distances due to thickness of the capsule, fragility, fouling of pores, limited islet viability, no connection to the vascular network, fibrosis, broad and ill-defined channel distributions, lot-to-lot variability in alginates. In addition, microcapsules are difficult to retrieve in case of implant failure $(6-8,16,17,46,47)$.

Islets can be encapsulated in different types of macro-encapsulation devices; for example an intravascular macrocapsular device (artery-vein shunt), an extravascular 
macrocapsular device, and an extravascular microcapsular device(6, 7). All these devices have their advantages and disadvantages and are frequently described in literature. Islets in an intravascular device are in close proximity of blood, giving them direct access to nutrients and oxygen. Consequently, they are able to react fast and efficient to molecular changes in stimulatory agents such as glucose. The disadvantages of an intravascular device include; a complex surgical intervention, high risk of thrombosis, and clot formation, and systemic administration of anticoagulation therapy(37, 40). Clot formation is caused by turbulence and damaged thrombocytes. Islets in extravascular devices experience diffusional limitations and the most important host responses responsible for graft failure are fibrosis and cellular adherence. On the other hand, extravascular devices are relatively easy to implant and retrieve. They can be re-seeded and they have flexibility in size $(6,7)$. In table 2.1 the advantages and disadvantages of the different encapsulation devices are summarized.

\subsection{Immune-protection; which immune responses are involved?}

\subsubsection{Instant Blood Mediated Immune Response}

The first innate immune response is related to the transplantation site; the portal system, where direct contact of islets with $\mathrm{ABO}$ blood components in the hepatic portal system triggers an Instant Blood Mediated Immune Response (IBMIR). Although reported before, Bennet et al.(48) reported this immune response in 1999 and give it the name IBMIR in 2000(49). They showed that when human islets were exposed to nonanticoagulated ABO-compatible human blood in a polyvinyl chloride tube, coated with heparin, a series of thrombotic and inflammatory events took place(49). They saw a reaction within 5 minutes upon reaction with the blood, where platelets started to coagulate to the surface of islets, contributing to fibrin formation. P-selectin was upregulated and $\beta$-thromboglobulin was secreted indicating activation of platelets. 
Table 2.1: Overview advantages and disadvantages of different encapsulation devices

\begin{tabular}{|c|c|c|}
\hline Device & Advantage & Disadvantage \\
\hline Nano encapsulation & $\begin{array}{l}\text { Hardly any diffusion dis- } \\
\text { tances }\end{array}$ & $\begin{array}{l}\text { Stability of the coating re- } \\
\text { mains a challenge, non- } \\
\text { retrievable }\end{array}$ \\
\hline Micro encapsulation & Easy to manufacture & $\begin{array}{l}\text { Large diffusion distances, } \\
\text { fragility, fouling of pores, } \\
\text { limited islet viability, no } \\
\text { connection to the vascular } \\
\text { network, fibrosis, broad } \\
\text { and ill-defined channel } \\
\text { distributions, lot-to-lot } \\
\text { variability of alginates, } \\
\text { and difficult to retrieve }\end{array}$ \\
\hline $\begin{array}{l}\text { Macro encapsulation (in- } \\
\text { travascular device) }\end{array}$ & $\begin{array}{l}\text { Close proximity of blood, } \\
\text { giving them direct access } \\
\text { to nutrients and oxygen, } \\
\text { can be reseeded, flexible in } \\
\text { size, retrievable }\end{array}$ & $\begin{array}{l}\text { Complex surgical in- } \\
\text { tervention, high risk of } \\
\text { thrombosis, and clot } \\
\text { formation, and systemic } \\
\text { administration of antico- } \\
\text { agulation therapy }\end{array}$ \\
\hline $\begin{array}{l}\text { Macro encapsulation (ex- } \\
\text { tra vascular device) }\end{array}$ & $\begin{array}{l}\text { Easy to implant and re- } \\
\text { trieve, they can be re- } \\
\text { seeded, flexible in size }\end{array}$ & Diffusion distances \\
\hline
\end{tabular}

Additionally, polymorphonuclear lymphocytes (PMNs) and monocytes started to cluster around the islets, leading to a disruption of islet morphology as quickly as 15-30 minutes after transplantation. The changed morphology showed condensed islet cell nuclei and infiltration of $\mathrm{CD}_{11 b^{+}}$cells. This indicates an absent of regulatory systems on the surface of an islet, as under physiological conditions, platelet activation is controlled by endothelial cells that inhibit aggregation of platelets via several mechanisms. For example; it is known that islets are surrounded by several types of collagens, a known mediator for platelet binding and activation(49, 50). In addition, complement systems are activated based on extensive generation of complement activation products(49). 
The findings from Bennet et al.(48) with their in vitro tubing loop model appeared to be correct, even before their publication, Sever et al.(51) published about the presence of a thrombus after transplantation seen in liver biopsies. Resulting in more studies and treatments to inhibit the IBMIR. Research found that isolated islets express at least 50 inflammation-associated genes, most likely up-regulated due to stress started before organ procurement till transplantation of the islets $(52,53)$. One important factor appeared to be the expression of coagulation factor III (thromboplastin, tissue factor) and thereby the production and secretion of tissue factor (TF) (47kDa) by islets $(27,29,52,54)$. TF activates coagulation, resulting in triggering and sequestration of platelets by thrombin generation(27, 54-56). Also the coagulation product thrombin-antithrombin (TAT) can be found furthermore substantiating a role of coagulation in the IBMIR (25).

Complement activation results in deposition of immunoglobulins (IgG and $\operatorname{IgM}$ ) and complement fragments (C4, C3, and C9) on the islet surface $(54,57)$. C9 on the islet surface is most likely responsible for the formation of the membrane attack complex (MAC). The formation of the MAC then leads to cell lysis and apoptosis(57).

Different components involved in IBMIR are responsible for the infiltration of the islets by several immune cells. Islets are infiltrated by $\mathrm{CD}_{11} \mathrm{~b}^{+}$neutrophilic granulocytes and macrophages after platelet activation, coagulation, and complement activation(49, 53, 54). However no B or $\mathrm{T}$ lymphocytes can be seen at this stage(53). $\mathrm{P}$-selecting is up-regulated by platelets, a receptor for neutrophil and monocyte interactions $(49,53)$. Granulocytes and monocytes could be stimulated by thrombin related protease-activated receptors on granulocytes and monocytes(53). Macrophages might be stimulated by TF, fibrin, and fibrinogen(53). Additionally, the complement activation anaphylatoxins C3a and C5a attract neutrophils and macrophages(48). Finally, the expression of monocyte chemotactic protein on the islet surface, likely triggered by the stress during isolation, attracts monocytes to the islets(30). As IBMIR triggers many different components of the immune system, it plays an important role in the activation/enhancement of other immune responses involved in islet loss(53). 


\subsubsection{Alloreactivity}

Recognition of the graft as foreign, triggers another immune response namely; allo- or xenorejection. A difference in criteria for immune-protection between allo-, or xenotransplantation is evident. When transplanting xenografts, the immune-protective device needs to meet stricter criteria then for $\operatorname{allografts}(58,59)$. Already in 1954, research was performed on immune-protective membranes by Algire et al.(60) and Prehn et al.(61), where they already showed the importance of cell impermeable membranes for allogeneic survival(60-62). In 1992 Loudovaris et al.(63) described a $0.45 \mu \mathrm{m}$ pore sized membrane that did not allow for cell infiltration but antibodies and complement (IgG, IgM, and C1q) could penetrate the membrane. They showed survival of the allogeneic cells, but not the xenogeneic cells. Suggesting that the infiltration of complement nor antibodies are involved in allorejection(63).

In clinical islet transplantation the pattern of allograft rejection is acute allorejection(15). Allograft rejection is a combination of the direct and indirect pathway. Gray et al. describe the knowledge on the discrimination between the direct and indirect presentation as routes of activation of the immune system(64-66). Where the direct pathway is based on cell-cell contact between the graft antigen presenting cells and the host T cells, also called donor MHC-restricted(15, 60, 64). When antigen presenting cells (APCs) present donor antigens followed by recognition of host T cells, one speaks of the indirect pathway, also called host MHC-restricted(15, 67, 68). Still it is thought that allograft rejection goes predominately via the direct antigen presentation by donor-type APC. For allograft rejection it is clear that this is mediated by $\mathrm{CD}^{+} \mathrm{T}$ cell activation by donor MHC complexes presented by $\operatorname{APCs}(59,60,65)$.

The immune response towards the allograft could be amplified by the previously described IBMIR, as activation of coagulation, the complement, and PMNs could make antigen recognition more efficient $(55,57)$. Complement activation helps in bridging innate immunity and specific immune responses(57). Additionally, the intraportal site contributes to the rate of alloreactivity as hepatic macrophages sequester many allogeneic cells. This process results in the secretion of many cytokines like IL-1 $\beta$, 
IL-2, IL-6, IL-10, IFN $\gamma$ which can influence the rate of rejection(15).

\subsubsection{Autoimmune response}

Besides the recognition for allo- and xenoantigens, the auto reactivity existing due to the autoimmune diabetes, also plays a role in rejection of the graft $(60,66,67,69$, 70). There are some indications that the autoreactivity plays a more prominent role in the allorejection than in xenograft rejection. Additionally, studies have shown that autoimmune reactivity could be species specific(67).

Genetic susceptibility and environmental triggers, for example viral infection, have shown to be required to develop Diabetes type $1(5,71-74)$. In response to these triggers, $\beta$ cells produce inflammatory mediators and up-regulate their expression of MHC class I. There are many different autoantigens involved in Diabetes type 1, most likely not all known. Insulin was the first known $\beta$ cell specific autoantigen, others targets of autoantibodies are carboxypeptidase $H$, the tyrosine phosphataselike proteins insulinoma antigen-2 (IA-2) and IA-2 $\beta$ (phogrin), and zinc transporter 8 , glutamic acid decarboxylase (GAD) $(71,72,75-82)$. Destruction of $\beta$ cells starts by the infiltration of mononuclear cells, like $\mathrm{CD} 4^{+} \mathrm{T}$ cells, $\mathrm{CD} 8^{+} \mathrm{T}$ cells, B lymphocytes, and macrophages with immune complex and complement deposition. These cells have a MHC class I hyperexpression on $\beta$ cells. The infiltration is started as $\beta$ cell autoantigens are released and taken up by antigen-presenting cells (APC). These APCs present the autoantigens and release cytokines and chemokines. The presented autoantigens are then recognized by $\mathrm{CD} 4^{+} \mathrm{T}$ cells, followed by a stimulation of APC secretion of cytokines and nitric oxide (NO). The secreted chemokines and cytokines enhance recruitment of immune cells and activate $\mathrm{CD}^{+} \mathrm{T}$ cells $(56)$. This infiltration is known as insulitis $(4,21,71-73,79,81,83,84)$. Ultimately, $\beta$ cell apoptosis is induced via multiple pathways and cytokines such as Interleukin-1 $\beta$ (IL-1 $\beta$ ), Tumor necrosis factor $\alpha(\mathrm{TNF} \alpha)$, and Interferon $\gamma(\operatorname{IFN} \gamma)(1,2,12,73,75,85-89)$. 


\subsubsection{Xenograft rejection}

For xenotransplantation it is clear that both antibodies and complement infiltration are omvolved. Additionally, Loudovaris et al.(62) showed by depleting CD4 ${ }^{+}, \mathrm{CD}^{+}$ cells, and/or B cells, that the xenografts did not survive when only CD4 ${ }^{+}$cells were present, thereby highlighting the important role of $\mathrm{CD}^{+}$cells in rejection(62). As these cells were not able to infiltrate their membranes, it suggests that they are most likely to be involved in the indirect antigen recognition and subsequent stimulation of inflammatory cells(62). The role of $\mathrm{CD}^{+}$cells in rejection of xenogeneic cells is described in detail elsewhere $(50,65,90-93)$. The activation of $\mathrm{T}$ cells seems to be indeed an indirect process. When xenoantigens are processed and presented by the presenting cells in association with major histocompatibility complex (MHC) molecules, $\mathrm{CD}^{+}$cells are activated(61, 90, 91).

\subsubsection{Inflammatory response}

When transplanting an immune-protective device the surgery itself and the device will induce the final immune response involved in rejection of islets. For many years it has been known that injury to the vascularized connective tissue induces an inflammatory response. An increase in inflammatory cells, plasma proteins, and bioactive factors such as cytokines and nitric oxide (NO) is seen. In addition, as a response to the foreign polymers, bioactive proteins such as fibrinogen are released and adsorbed by the polymers. This will then facilitate adherence of inflammatory cells and thus the production of IL-1 $\beta$, TNF $\alpha$ and Transforming growth factor $\beta$ (TGF $\beta$ ). Similar to the autoimmune destruction of $\beta$ cells, these cytokines will also induce apoptosis in $\beta$-cells once transported through the encapsulation material. In addition, it is thought that adsorption of immunoglobulins, such as IgG, IgM, and IgA acts as opsonins to immune cells $(24,94-97)$.

Finally, the inflammatory response limits graft survival and function of encapsulated islets. This response could be mediated by a foreign body response to the transplanted immune-protective device, the surgical intervention, and the release of inflammatory 
mediators of the transplanted cells themselves $(65,98,99)$. Besides graft failure due to the extra physical barrier created by this inflammatory response, secreted cytotoxic molecules could potentially penetrate the device and have a detrimental effect on the encapsulated cells(65). Activated macrophages have shown to also play a role in rejection of encapsulated islets as they are the source of detrimental factors such as NO and cytokines such as IL-1b (17.5 kDa), TNF- $\alpha$ (51 kDa), and IFN $\gamma(81 \mathrm{kDa})(33$, $65,92)$. Based on the sizes of these factors, one can easily understand the problem associated with these factors as these cannot be shielded by the immune-protective device while still allowing for proper nutrient/insulin $(5.8 \mathrm{kDa})$ transport over the membrane(33, 98, 100, 101).

\subsection{Finding the balance between immune protection and islet survival}

As it seems to be impossible to exclude diffusion of small molecules involved in the different immune responses through the device while allowing diffusion of nutrients, the question rises how small the pores need to be/ how big the molecular weight cutoff should be for an effective immune-protective device. Finding the balance between survival and immuneprotection remains difficult but needs to be found(38). As it is a compromise/balance between two extremes.

The search for the optimal molecular weight cut off when using membrane based immune-protective devices resulted in different opinions. Usually the molecular weight cut off lies between $50-150 \mathrm{kDa}(58)$. The $150 \mathrm{kDa}$ cut off is often based on the size of the smallest immunoglobulin; IgG. With such a membrane, IgG should not permeate across the membrane. Beside the use of the molecular weight cut off, researchers describe the pore size used for immune-protective devices. Loudovaris et al. showed that an $0.45 \mu \mathrm{m}$ pore size comprising membrane was successful in shielding allogeneic cells from the immune system(63). A very well-known device in the field of islet encapsulation is the Baxter immunoisolation device, otherwise known as the TheraCyte ${ }^{\mathrm{TM}}$ system, where islets are shielded by a $0.4 \mu \mathrm{m}$ pore membrane laminated to a $5 \mu \mathrm{m}$ 
pore membrane to allow for vascularization(102-104). Still IgG and IgM were able to infiltrate the device while the allogenic tissue survived. Therefore the question rises if an immune-protective device should have a molecular weight cut off of below 150 $\mathrm{kDa}$ or if the pore size could be increased to enhance islet survival(3, 102, 103, 105).

\subsubsection{The importance of oxygen for islet function and survival}

Besides looking for the optimal pore size of an immune-protective device, researchers use different approaches to enhance islet survival while encapsulated like enhancing oxygen generation, induction of vascularization or the addition of drug delivery systems(106). Enhancement of islet survival and prevention of cell death on itself has also a beneficial effect on the immune-protection of the islets. As it is known that antigens from dead or dying islets are important in immune recognition(37, 107). Additionally, the activated immune cells can form an elaborate response around the device, thereby lower the local $\mathrm{pO}_{2}(37)$.

A very important facilitator to islet death is hypoxia and therefore solutions to overcome hypoxia have been studied for many years(19). Hypoxia occurs as the vasculature of the normally highly vascularized islet it disrupted during isolation but also as islets are exposed to the relatively deoxygenated blood in the portal vein of the liver(37, 106, 108, 109). Hypoxia, in an early stage, already influences the glucose homeostasis in islets, as the glucose pathway thrives on oxidative phosphorylation(37, 108, 110). Consequently, hypoxia or other mechanisms that reduce the aerobic capacity of an islet will most likely have an effect on insulin secretion upon glucose stimulation(37, 108, 110-112). Hypoxia is known to induce expression of various genes regulated by hypoxia-inducible factor-1 (HIF1)(113). HIF-1 consists of two subunits; HIF $1 \alpha$ and HIF $1 \beta$. HIF $1 \alpha$ activates target genes and consequently is involved in the secretion of $\operatorname{VEGF}(108,109,112,113)$.

To overcome hypoxia researchers add oxygen generating materials to their device, introduce PEG-conjugated hemoglobin as an oxygen carrier or add an oxygen generator based on electrolysis of water to form oxygen and hydrogen, or use microalgae-based 
photosynthetic oxygen generators $(37,106,107,111,114,115)$. Even gene therapy to enhance islet survival has been applied by for example increasing HIF-1 $\alpha$ levels(37).

\subsubsection{Prevascularization of devices}

Besides adding an external source of oxygen to an immune-protective device, hypoxia could also be overcome by prevascularization of the device or by induction of vascularization in vivo $(22,106)$. Increasing the blood supply can be achieved by release of angiogenic factors by drugs or cells, the use of materials with microarchitecture (discovered by Baxter Healthcare in 1990), and the reduction of the immune response that is responsible for the formation of the fibrous capsule(37). One of the most used angiogenic factors is vascular endothelial growth factor (VEGF) $(37,38)$. Even $\beta$ cells themselves are known to secrete VEGF as it plays an important role in regulating islet vascularization and function(116) However, it is known that the process of isolation impairs the expression of VEGF-A in $\beta$ cells $(116,117)$. Adding VEGF to the device has shown to enhance the vascularization locally and provides a stable vasculature around the device $(22,37,118)$. Other used angiogenic factors are; endothelial cell growth factor, and basic fibroblast growth factor(38). Vascularization could also be achieved by implantation of islets combined with other cell types, like mesenchymal stromal cells (MSCs), fibroblasts, endothelial (progenitor) cells, and bone marrow progenitor cells(19, 37, 40, 116, 117, 119-122).

\subsubsection{Immune protection by drug delivery}

Drug delivery can be focused on enhancing islet survival by inducing vascularization, as described above, but also to prevent/decrease the immune response. For example drugs have been administered to control the IBMIR like thrombin inhibitor Melagatran, activated protein $\mathrm{C}$, dextran sulfate, and the water soluble domain of complement receptor I(15, 25, 123-126). As these are all systemic drugs, with consequently a high risk of bleeding, locally administered drug delivery systems have been developed. Examples of these local drug delivery systems are; the coating of islets with heparin to inhibit surface thrombosis formation or by coating the islets with PEG and hep- 
$\operatorname{arin}(40,123,127)$. Drugs based on the use of monoclonal antibodies have also been used successfully in the treatment of allorejection and in autoimmune disease $(15,69)$. Although MSCs are frequently used to induce vascularization, they are also known for their immunosuppressive capabilities on $\mathrm{T}$ cells. Therefore, encapsulation islets together with MSCs might decrease the immune response(117, 128-132). They work on different subsets of immune cells thereby inhibiting $\mathrm{T}$ cell proliferation, cytotoxic T lymphocyte activity, and decreasing IFN $\gamma$ production(128).

In conclusion, although clinical islet transplantation seems to be very promising, encapsulating islets in an immune-protective device for extra hepatic transplantation might enhance the transplantation outcome. The most difficult part is finding the balance between immune-protection and islet survival as components of the immunesystem are in the same size range as nutrients and glucose and insulin. The most optimal dimensions have yet to be discovered. Still, overcoming important factors involved in islet death, could enhance islet survival. Enhancement of prevascularization by local administration of drugs or the use of other cell types could be beneficial for islet survival. Also the local administration of oxygen is promising to overcome the highly detrimental hypoxia islets often experience after transplantation. This all combined with a decrease in immune-response, by drugs delivery systems or immune modulatory cells, might be the solution for encapsulation of islets. Still, it will always be a compromise in a certain direction. When adding oxygen generating materials, the islets will sense less hypoxia, consequently the vascularization rate will decrease as hypoxic islets express HIF1- $\alpha$ with vascularization as a result.

Based on this, we propose that the ideal device is a macro-encapsulation device which physically separates islets from each other to prevent aggregation and thereby diffusion limitations. As a macroencapsulation device can also be easily retrieved when necessary, this aids in patients wellbeing. Using membrane based scaffolds, islets should be in close proximity to the blood stream to survive and function, this means that the membrane needs to be as thin as possible so islets are within $200 \mu \mathrm{m}$ distance from blood vessels. For optimal islet survival the membrane should be as open 
as possible however, the membrane should exclude infiltration of immune cells. Additionally, the focus should not lie on exclusion of all other components of the immune system as this will decrease diffusion of nutrients in such a way that islet survival is compromised. When looking for a material for islet encapsulation, one should consider a material that allows for fast diffusion of glucose and insulin and should not be susceptible to fouling as this will decrease the rate of diffusion. One of the major hurdles to overcome are the first weeks after transplantation before the device is completely vascularized. We propose the addition of oxygen generating materials to the device, however understanding that this will decrease the rate of vascularization. Finally, by using cells, like MSCs, to increase the rate of vascularization, the change of islet survival in the first weeks after transplantation will be increased. Additionally, their immune modulatory capabilities will also enhance islet survival. 


\section{References}

1. Mathis, D., Vence, L., and Benoist, C. $\beta$-cell death during progression to diabetes. Nature 414, 792, 2001.

2. Van Belle, T.L., Coppieters, K.T., and Von Herrath, M.G. Type 1 diabetes: Etiology, immunology, and therapeutic strategies. Physiological Reviews 91, 79, 2011.

3. Steele, J.A.M., Halle, J.P., Poncelet, D., and Neufeld, R.J. Therapeutic cell encapsulation techniques and applications in diabetes. Adv Drug Deliv Rev 6768, 74, 2014 .

4. Foulis, A.K. The pathology of the endocrine pancreas in type 1 (insulin-dependent) diabetes mellitus. APMIS 104, 161, 1996.

5. Hornum, L., and Markholst, H. New autoimmune genes and the pathogenesis of type 1 diabetes. Curr Diabetes Rep 4, 135, 2004.

6. Silva, A.I., de Matos, A.N., Brons, I.G., and Mateus, M. An overview on the development of a bio-artificial pancreas as a treatment of insulin-dependent diabetes mellitus. Medicinal Research Reviews 26, 181, 2006.

7. Beck, J., Angus, R., Madsen, B., Britt, D., Vernon, B., and Nguyen, K.T. Islet encapsulation: Strategies to enhance islet cell functions. Tissue Engineering 13, 589, 2007.

8. Silva, A.I., and Mateus, M. Development of a polysulfone hollow fiber vascular bio-artificial pancreas device for in vitro studies. Journal of Biotechnology 139, 236, 2009.

9. Kumar, P., and Clark, M. Diabetes mellitus and other disorders of metabolism. In: Saunders W.B., ed. 5 ed2002. pp. 1069.

10. Boron, W.F., Boulpaep, E.L., and Barret, E.J. The endocrine pancreas. Elsevier; 2005. pp. 1066.

11. Kort, H.D., Koning, E.J.D., Rabelink, T.J., Bruijn, J.a., and Bajema, I.M. Islet transplantation in type 1 diabetes. Bmj 342, d217, 2011.

12. Pirot, P., Cardozo, A.K., and Eizirik, D.L. Mediators and mechanisms of pancreatic beta-cell death in type 1 diabetes. Arq Bras Endocrinol Metabol 52, 156, 2008. 
13. Shapiro, A.M.J., Ricordi, C., Hering, B.J., Auchincloss, H., and Lindblad, R. Islet transplantation in seven patients with type 1 diabetes mellitus using a glucocorticoidfree immunosuppressive regimen. New England Journal of Medicine 343, 230, 2000. 14. Shapiro, a.M.J., Ricordi, C., Hering, B.J., Auchincloss, H., Lindblad, R., Robertson, R.P., Secchi, A., Brendel, M.D., Berney, T., Brennan, D.C., Cagliero, E., Alejandro, R., Ryan, E.a., DiMercurio, B., Morel, P., Polonsky, K.S., Reems, J.-A., Bretzel, R.G., Bertuzzi, F., Froud, T., Kandaswamy, R., Sutherland, D.E.R., Eisenbarth, G., Segal, M., Preiksaitis, J., Korbutt, G.S., Barton, F.B., Viviano, L., Seyfert-Margolis, V., Bluestone, J., and Lakey, J.R.T. International trial of the Edmonton protocol for islet transplantation. The New England journal of medicine 355, 1318, 2006.

15. White, S.A., James, R.F.L., Swift, S.M., Kimber, R.M., and Nicholson, M.L. Human islet cell transplantation - Future prospects. Diabetic Med 18, 78, 2001.

16. Grundfest-Broniatowski, S.F., Tellioglu, G., Rosenthal, K.S., Kang, J., Erdodi, G., Yalcin, B., Cakmak, M., Drazba, J., Bennett, A., Lu, L., and Kennedy, J.P. A new bioartificial pancreas utilizing amphiphilic membranes for the immunoisolation of porcine islets a pilot study in the canine. ASAIO Journal 55, 400, 2009.

17. de Vos, P., Faas, M.M., Strand, B., and Calafiore, R. Alginate-based microcapsules for immunoisolation of pancreatic islets. Biomaterials 27, 5603, 2006.

18. Biarnes, M., Montolio, M., Nacher, V., Raurell, M., Soler, J., and Montanya, E. $\beta$-cell death and mass in syngeneically transplanted islets exposed to short- and long-term hyperglycemia. Diabetes 51, 66, 2002.

19. Deters, N.A., Stokes, R.A., and Gunton, J.E. Islet transplantation: Factors in short-term islet survival. Arch Immunol Ther Exp 59, 421, 2011.

20. Ballian, N., and Brunicardi, F.C. Islet vasculature as a regulator of endocrine pancreas function. World J Surg 31, 705, 2007.

21. Homo-Delarche, F., and Boitard, C. Autoimmune diabetes: The role of the islets of Langerhans. IMMUNOL TODAY 17, 456, 1996.

22. Trivedi, N., Steil, G.M., Colton, C.K., Bonner-Weir, S., and Weir, G.C. Improved vascularization of planar membrane diffusion devices following continuous infusion of vascular endothelial growth factor. Cell Transplant 9, 115, 2000. 
23. Daoud, J., Petropavlovskaia, M., Rosenberg, L., and Tabrizian, M. The effect of extracellular matrix components on the preservation of human islet function in vitro. Biomaterials 31, 1676, 2010.

24. Barshes, N.R., Wyllie, S., and Goss, J.A. Inflammation-mediated dysfunction and apoptosis in pancreatic islet transplantation: Implications for intrahepatic grafts. J Leukocyte Biol 77, 587, 2005.

25. Özmen, L., Ekdahl, K.N., Elgue, G., Larsson, R., Korsgren, O., and Nilsson, B. Inhibition of thrombin abrogates the instant blood-mediated inflammatory reaction triggered by isolated human islets: Possible application of the thrombin inhibitor Melagatran in clinical islet transplantation. Diabetes 51, 1779, 2002.

26. Nanji, S.A., and Shapiro, A.M.J. Advances in pancreatic islet transplantation in humans. Diabetes Obes Metab 8, 15, 2006.

27. Moberg, L., Johansson, H., Lukinius, A., Berne, C., Foss, A., Kallen, R., Ostraat, O., Salmela, K., Tibell, A., Tufveson, G., Elgue, G., Nilsson Ekdahl, K., Korsgren, O., and Nilsson, B. Production of tissue factor by pancreatic islet cells as a trigger of detrimental thrombotic reactions in clinical islet transplantation. Lancet 360, 2039, 2002.

28. Citro, A., Cantarelli, E., and Piemonti, L. Anti-inflammatory strategies to enhance islet engraftment and survival. Curr Diabetes Rep 13, 733, 2013.

29. Harlan, D.M., Kenyon, N.S., Korsgren, O., and Roep, B.O. Current advances and travails in islet transplantation. Diabetes 58, 2175, 2009.

30. Azzi, J., Geara, A.S., El-Sayegh, S., and Abdi, R. Immunological aspects of pancreatic islet cell transplantation. Expert Rev Clin Immunol 6, 111, 2010.

31. Monaco, A.P., Maki, T., Ozato, H., Carretta, M., Sullivan, S.J., Borland, K.M., Mahoney, M.D., Chick, W.L., Muller, T.E., Wolfrum, J., and Solomon, B. Transplantation of islet allografts and xenografts in totally pancreatectomized diabetic dogs using the Hybrid Artificial Pancreas. Annals of Surgery 214, 339, 1991.

32. Naftanel, M.A., and Harlan, D.M. Pancreatic islet transplantation. PLoS Med 1, $198,2004$.

33. De Groot, M., Schuurs, T.A., and Van Schilfgaarde, R. Causes of limited survival 
of microencapsulated pancreatic islet grafts. J Surg Res 121, 141, 2004.

34. Scharp, D.W. Encapsulated Human Islet Allografts: Providing Safety with Efficacy. Cellular Transplantation: Elsevier Inc.; 2007. pp. 135.

35. Lacy, P.E., Hegre, O.D., Gerasimidi-vazeou, A., Gentile, F.T., Dionne, E., Science, S., Series, N., Dec, N., and Dionne, K.E. Maintenance of Normoglycemia in Diabetic Mice by Subcutaneous Xenografts of Encapsulated Islets . Science 254, $1782,1991$.

36. Risbud, M.V., and Bhonde, R.R. Islet immunoisolation: Experience with biopolymers. J Biomater Sci Polym Ed 12, 1243, 2001.

37. Colton, C.K. Oxygen supply to encapsulated therapeutic cells. Adv Drug Deliv Rev 67-68, 93, 2014.

38. Tilakaratne, H.K., Hunter, S.K., Andracki, M.E., Benda, J.A., and Rodgers, V.G.J. Characterizing short-term release and neovascularization potential of multiprotein growth supplement delivered via alginate hollow fiber devices. Biomaterials 28, 89, 2007.

39. Fotino, N., Fotino, C., and Pileggi, A. Re-engineering islet cell transplantation. Pharmacol Res 98, 76, 2015.

40. Teramura, Y., and Iwata, H. Bioartificial pancreas. Microencapsulation and conformal coating of islet of Langerhans. Adv Drug Deliv Rev 62, 827, 2010.

41. Teramura, Y., Oommen, O.P., Olerud, J., Hilborn, J., and Nilsson, B. Microencapsulation of cells, including islets, within stable ultra-thin membranes of maleimideconjugated PEG-lipid with multifunctional crosslinkers. Biomaterials 34, 2683, 2013. 42. De Vos, P., Spasojevic, M., and Faas, M.M. Treatment of diabetes with encapsulated islets. In: Pedraz J.L., Orive G., eds. Advances in Experimental Medicine and Biology2010. pp. 38.

43. Soon-Shiong, P., Heintz, R.E., Merideth, N., Yao, Q.X., Yao, Z., Zheng, T., Murphy, M., Moloney, M.K., Schmehl, M., Harris, M., Mendez, R., and Sandford, P.A. Insulin independence in a type 1 diabetic patient after encapsulated islet transplantation. The Lancet 343, 950, 1994.

44. Kendall Jr, W.F., Darrabie, M.D., El-Shewy, H.M., and Opara, E.C. Effect of 
alginate composition and purity on alginate microspheres. J Microencapsulation 21, $821,2004$.

45. Ponce, S., Orive, G., Hernandez, R., Gascon, A.R., Pedraz, J.L., de Haan, B.J., Faas, M.M., Mathieu, H.J., and de Vos, P. Chemistry and the biological response against immunoisolating alginate-polycation capsules of different composition. Biomaterials 27, 4831, 2006.

46. Desai, T.A., Hansford, D.J., and Ferrari, M. Micromachined interfaces: New approaches in cell immunoisolation and biomolecular separation. Biomol Eng 17, 23, 2000 .

47. Daoud, J., Rosenberg, L., and Tabrizian, M. Pancreatic islet culture and preservation strategies: Advances, challenges, and future outlook. Cell Transplant 19, 1523, 2010.

48. Bennet, W., Sundberg, B., Groth, C.G., Brendel, M.D., Brandhorst, D., Brandhorst, H., Bretzel, R.G., Elgue, G., Larsson, R., Nilsson, B., and Korsgren, O. Incompatibility between human blood and isolated islets of langerhans: A finding with implications for clinical intraportal islet transplantation? Diabetes 48, 1907, 1999.

49. Bennet, W., Groth, C.G., Larsson, R., Nilsson, B., and Korsgren, O. Isolated human islets trigger an instant blood mediated inflammatory reaction: Implications for intraportal islet transplantation as a treatment for patients with type 1 diabetes. Upsala J Med Sci 105, 125, 2000.

50. O'Connell, P.J., Cowan, P.J., Hawthorne, W.J., Yi, S., and Lew, A.M. Transplantation of xenogeneic islets: Are we there yet? Curr Diabetes Rep 13, 687, 2013. 51. Sever, C.E., Demetris, A.J., Zeng, Y., Tzakis, A., Fung, J.J., Starzl, T.E., and Ricordi, C. Islet cell allotransplantation in diabetic patients: Histologic findings in four adults simultaneously receiving kidney or liver transplants. Am J Pathol 140, $1255,1992$.

52. Johansson, H., Lukinius, A., Moberg, L., Lundgren, T., Berne, C., Foss, A., Felldin, M., Kallen, R., Salmela, K., Tibell, A., Tufveson, G., Ekdahl, K.N., Elgue, G., Korsgren, O., and Nilsson, B. Tissue factor produced by the endocrine cells of the islets of langerhans is associated with a negative outcome of clinical islet transplan- 
tation. Diabetes 54, 1755, 2005.

53. Van Der Windt, D.J., Bottino, R., Casu, A., Campanile, N., and Cooper, D.K.C. Rapid loss of intraportally transplanted islets: An overview of pathophysiology and preventive strategies. Xenotransplantation 14, 288, 2007.

54. Nilsson, B., Ekdahl, K.N., and Korsgren, O. Control of instant blood-mediated inflammatory reaction to improve islets of Langerhans engraftment. Curr Opin Organ Transplant 16, 620, 2011.

55. Inverardi, L., and Ricordi, C. Therapeutic approaches to counteract immediate blood-mediated inflammatory reaction in islet transplantation. Transplantation 82, 312, 2006.

56. Reffet, S., and Thivolet, C. Immunology of pancreatic islet transplantation. Diabetes Metab 32, 523, 2006.

57. Tjernberg, J., Ekdahl, K.N., Lambris, J.D., Korsgren, O., and Nilsson, B. Acute antibody-mediated complement activation mediates lysis of pancreatic islets cells and may cause tissue loss in clinical islet transplantation. Transplantation 85, 1193, 2008. 58. Li, R.H. Materials for immunoisolated cell transplantation. Adv Drug Deliv Rev 33, 87, 1998.

59. Scharp, D.W., and Marchetti, P. Encapsulated islets for diabetes therapy: History, current progress, and critical issues requiring solution. Adv Drug Deliv Rev 67-68, 35, 2014.

60. Algire, G.H., Weaver, J.M., and Prehn, R.T. Growth of cells in vivo in diffusion chambers. I. Survival of homografts in immunized mice. J Natl Cancer Inst 15, 493, 1954.

61. Prehn, R.T., Weaver, J.M., and Algire, G.H. The diffusion-chamber technique applied to a study of the nature of homograft resistance. J Natl Cancer Inst 15, 509, 1954.

62. Loudovaris, T., Mandel, T.E., and Charlton, B. CD $4^{+}$T cell mediated destruction of xenografts within cell-impermeable membranes in the absence of $\mathrm{CD}^{+} \mathrm{T}$ cells and B cells. Transplantation 61, 1678, 1996.

63. Loudovaris, T., Charlton, B., Hodgson, R.J., and Mandel, T.E. Destruction of 
xenografts but not allografts within cell impermeable membranes. Transplant Proc 24, 2291, 1992.

64. Gray, D.W.R. Encapsulated islet cells: The role of direct and indirect presentation and the relevance to xenotransplantation and autoimmune recurrence. BR MED BULL 53, 777, 1997.

65. Wilson, J.T., and Chaikof, E.L. Challenges and emerging technologies in the immunoisolation of cells and tissues. Adv Drug Deliv Rev 60, 124, 2008.

66. Bosi, E., Braghi, S., Maffi, P., Scirpoli, M., Bertuzzi, F., Pozza, G., Secchi, A., and Bonifacio, E. Autoantibody Response to Islet Transplantation in Type 1 Diabetes. Diabetes 50, 2464, 2001.

67. Rayat, G.R., and Gill, R.G. Pancreatic islet xenotransplantation: Barriers and prospects. Curr Diabetes Rep 3, 336, 2003.

68. Gill, R.G. Antigen presentation pathways for immunity to islet transplants. Relevance to immunoisolation. Annals of the New York Academy of Sciences1999. pp. 255.

69. Kuttler, B., Rasing, K., Lehmann, M., Brock, J., andHahn, H.J. Prevention of autoimmune but not allogeneic destruction of grafted islets by different therapeutic strategies. J Mol Med 77, 226, 1999.

70. Makhlouf, L., Kishimoto, K., Smith, R.N., Abdi, R., Koulmanda, M., Winn, H.J., Auchincloss Jr, H., and Sayegh, M.H. The role of autoimmunity in islet allograft destruction: Major histocompatibility complex class II matching is necessary for autoimmune destruction of allogeneic islet transplants after T-cell costimulatory blockade. Diabetes 51, 3202, 2002.

71. Lambert, P., and Bingley, P.J. What is type 1 diabetes? Medicine 34, 47, 2006.

72. Thrower, S.L., and Bingley, P.J. What is type 1 diabetes? Medicine 38, 592, 2010. 73. Richardson, S.J., Willcox, A., Bone, A.J., Morgan, N.G., and Foulis, A.K. Immunopathology of the human pancreas in type-I diabetes. SeminImmunopathol 33, $9,2011$.

74. Stankov, K., Benc, D., and Draskovic, D. Genetic and epigenetic factors in etiology of diabetes mellitus type 1. Pediatrics 132, 1112, 2013. 
75. Roep, B.O., and Peakman, M. Diabetogenic T lymphocytes in human Type 1 diabetes. Curr Opin Immunol 23, 746, 2011.

76. Payton, M.A., Hawkes, C.J., and Christie, M.R. Relationship of the 37,000- and 40,000-Mr tryptic fragments of islet antigens in insulin-dependent diabetes to the protein tyrosine phosphatase-like molecule IA-2 (ICA512). J Clin Invest 96, 1506, 1995. 77. Wenzlau, J.M., Juhl, K., Yu, L., Moua, O., Sarkar, S.A., Gottlieb, P., Rewers, M., Eisenbarth, G.S., Jensen, J., Davidson, H.W., and Hutton, J.C. The cation efflux transporter ZnT8 (Slc30A8) is a major autoantigen in human type 1 diabetes. Proc Natl Acad Sci U S A 104, 17040, 2007.

78. Palmer, J.P., Asplin, C.M., Clemons, P., Lyen, K., Tatpati, O., Raghu, P.K., andPaquette, T.L. Insulin antibodies in insulin-dependent diabetics before insulin treatment. Science 222, 1337, 1983.

79. Knip, M., and Siljander, H. Autoimmune mechanisms in type 1 diabetes. Autoimmunity Reviews 7, 550, 2008.

80. Marino, E., andGrey, S.T. A new role for an old player: Do B cells unleash the self-reactive $\mathrm{CD}^{+} \mathrm{T}$ cell storm necessary for the development of type 1 diabetes? J Autoimmun 31, 301, 2008.

81. Morran, M.P., Omenn, G.S., and Pietropaolo, M. Immunology and genetics of type 1 diabetes. Mt Sinai J Med 75, 314, 2008.

82. Winter, W.E., andSchatz, D.A. Autoimmune markers in diabetes. Clin Chem 57, $168,2011$.

83. Homo-Delarche, F., and Drexhage, H.A. Immune cells, pancreas development, regeneration and type 1 diabetes. Trends Immunol 25, 222, 2004.

84. Rabinovitch, A., and Suarez-Pinzon, W.L. Cytokines and their roles in pancreatic islet $\beta$-cell destruction and insulin-dependent diabetes mellitus. Biochem Pharmacol 55, 1139, 1998.

85. Uno, S., Imagawa, A., Okita, K., Sayama, K., Moriwaki, M., Iwahashi, H., Yamagata, K., Tamura, S., Matsuzawa, Y., Hanafusa, T., Miyagawa, J., and Shimomura, I. Macrophages and dendritic cells infiltrating islets with or without beta cells produce tumour necrosis factor- $\alpha$ in patients with recent-onset type 1 diabetes. Diabetologia 
$50,596,2007$.

86. Yoon, J.W., and Jun, H.S. Autoimmune destruction of pancreatic $\beta$ cells. Am J Ther 12, 580, 2005.

87. Atkinson, M.A., and Eisenbarth, G.S. Type 1 diabetes: New perspectives on disease pathogenesis and treatment. Lancet 358, 221, 2001.

88. Coppieters, K.T., Roep, B.O., and Von Herrath, M.G. Beta cells under attack: Toward a better understanding of type 1 diabetes immunopathology. SeminImmunopathol 33, 1, 2011.

89. Roep, B.O., and Peakman, M. Antigen targets of type 1 diabetes autoimmunity. Cold Spring Harb Perspect Med 22012.

90. Solomon, M.F., Kuziel, W.A., Mann, D.A., and Simeonovic, C.J. The role of chemokines and their receptors in the rejection of pig islet tissue xenografts. Xenotransplantation 10, 164, 2003.

91. Jones, K.S., Sefton, M.V., and Gorczynski, R.M. In vivo recognition by the host adaptive immune system of microencapsulated xenogeneic cells. Transplantation 78, $1454,2004$.

92. Kobayashi, T., Harb, G., Rajotte, R.V., Korbutt, G.S., Mallett, A.G., Arefanian, H., Mok, D., and Rayat, G.R. Immune mechanisms associated with the rejection of encapsulated neonatal porcine islet xenografts. Xenotransplantation 13, 547, 2006.

93. Rayat, G.R., Johnson, Z.A., Beilke, J.N., Korbutt, G.S., Rajotte, R.V., and Gill, R.G. The degree of phylogenetic disparity of islet grafts dictates the reliance on indirect CD4 T-cell antigen recognition for rejection. Diabetes 52, 1433, 2003.

94. De Vos, P., Van Hoogmoed, C.G., De Haan, B.J., and Busscher, H.J. Tissue responses against immunoisolating alginate-PLL capsules in the immediate posttransplant period. J Biomed Mater Res 62, 430, 2002.

95. Tam, S.K., De Haan, B.J., Faas, M.M., Halla, J.P., Yahia, L., and De Vos, P. Adsorption of human immunoglobulin to implantable alginate-poly-L-lysine microcapsules: Effect of microcapsule composition. J Biomed Mater Res Part A 89, 609, 2009.

96. Yang, K.C., Wu, C.C., Cheng, Y.H., Kuo, T.F., and Lin, F.H. Chitosan/Gelatin 
Hydrogel Prolonged the Function of Insulinoma/Agarose Microspheres In Vivo During Xenogenic Transplantation. Transplant Proc 40, 3623, 2008.

97. Kessler, L., Jesser, C., Lombard, Y., Karsten, V., Belcourt, A., Pinget, M., andPoindron, P. Cytotoxicity of peritoneal murine macrophages against encapsulated pancreatic rat islets: In vivo and in vitro studies. J Leukocyte Biol 60, 729, 1996.

98. Vaithilingam, V., andTuch, B.E. Islet transplantation and encapsulation: An update on recent developments. Rev Diabetic Stud 8, 51, 2011.

99. Dang, T.T., Thai, A.V., Cohen, J., Slosberg, J.E., Siniakowicz, K., Doloff, J.C., Ma, M., Hollister-Lock, J., Tang, K.M., Gu, Z., Cheng, H., Weir, G.C., Langer, R., and Anderson, D.G. Enhanced function of immuno-isolated islets in diabetes therapy byco-encapsulation with an anti-inflammatory drug. Biomaterials 34, 5792, 2013.

100. Krishnan, R., Alexander, M., Robles, L., Foster, C.E., and Lakey, J.R.T. Islet and stem cell encapsulation for clinical transplantation. Rev Diabetic Stud 11, 84, 2014.

101. Schweicher, J., Nyitray, C., and Desai, T.A. Membranes to achieve immunoprotection of transplanted islets. Front Biosci Landmark 19, 49, 2014.

102. Loudovaris, T., Jacobs, S., Young, S., Maryanov, D., Brauker, J., and Johnson, R.C. Correction of diabetic nod mice with insulinomas implanted within Baxter immunoisolation devices. J Mol Med 77, 219, 1999.

103. Brauker, J., Martinson, L.A., Young, S.K., and Johnson, R.C. Local inflammatory response around diffusion chambers containing xenografts: Nonspecific destruction of tissues and decreased local vascularization. Transplantation 61, 1671, 1996.

104. Barkai, U., Weir, G.C., Colton, C.K., Ludwig, B., Bornstein, S.R., Brendel, M.D., Neufeld, T., Bremer, C., Leon, A., Evron, Y., Yavriyants, K., Azarov, D., Zimermann, B., Maimon, S., Shabtay, N., Balyura, M., Rozenshtein, T., Vardi, P., Bloch, K., De Vos, P., and Rotem, A. Enhanced oxygen supply improves islet viability in a new bioartificial pancreas. Cell Transplant 22, 1463, 2013.

105. Omer, A., Duvivier-Kali, V., Fernandes, J., Tchipashvili, V., Colton, C.K., and Weir, G.C. Long-term normoglycemia in rats receiving transplants with encapsulated islets. Transplantation 79, 52, 2005. 
106. Bloch, K., Papismedov, E., Yavriyants, K., Vorobeychik, M., Beer, S., and Vardi, P. Photosynthetic oxygen generator for bioartificial pancreas. Tissue Engineering 12, $337,2006$.

107. Evron, Y., Zimermann, B., Ludwig, B., Barkai, U., Colton, C.K., Weir, G.C., Arieli, B., Maimon, S., Shalev, N., Yavriyants, K., Goldman, T., Gendler, Z., Eizen, L., Vardi, P., Bloch, K., Barthel, A., Bornstein, S.R., and Rotem, A. Oxygen supply by photosynthesis to an implantable islet cell device. Horm Metab Res 47, 24, 2015. 108. Cantley, J., Grey, S.T., Maxwell, P.H., and Withers, D.J. The hypoxia response pathway and $\beta$-cell function. Diabetes Obes Metab 12, 159, 2010. 109. Moritz, W., Meier, F., Stroka, D.M., Giuliani, M., Kugelmeier, P., Nett, P.C., Lehmann, R., Candinas, D., Gassmann, M., and Weber, M. Apoptosis in hypoxic human pancreatic islets correlates with HIF-1alpha expression. FASEB J 16, 745, 2002.

110. Sato, Y., Endo, H., Okuyama, H., Takeda, T., Iwahashi, H., Imagawa, A., Yamagata, K., Shimomura, I., and Inoue, M. Cellular hypoxia of pancreatic $\beta$-cells due to high levels of oxygen consumption for insulin secretion in vitro. J Biol Chem 286, $12524,2011$.

111. Chae, S.Y., Kim, S.W., and Bae, Y.H. Effect of cross-linked hemoglobin on functionality and viability of microencapsulated pancreatic islets. Tissue Engineering 8, 379, 2002.

112. Bensellam, M., Duvillia, B., Rybachuk, G., Laybutt, D.R., Magnan, C., Guiot, Y., Pouyssegur, J., and Jonas, J.C. Glucose-induced O 2 consumption activates hypoxia inducible factors 1 and 2 in rat insulin-secreting pancreatic beta-cells. PLoS ONE 72012.

113. Miao, G., Ostrowski, R.P., Mace, J., Hough, J., Hopper, A., Peverini, R., Chinnock, R., Zhang, J., and Hathout, E. Dynamic production of hypoxia-inducible factor- $1 \alpha$ in early transplanted islets. Am J Transplant 6, 2636, 2006.

114. Wu, H., Avgoustiniatos, E.S., Swette, L., Bonner-Weir, S., Weir, G.C., and Colton, C.K. In situ electrochemical oxygen generation with an immunoisolation device. Annals of the New York Academy of Sciences1999. pp. 105.

115. Pedraza, E., Coronel, M.M., Fraker, C.A., Ricordi, C., and Stabler, C.L. Pre- 
venting hypoxia-induced cell death in beta cells and islets via hydrolytically activated, oxygen-generating biomaterials. Proc Natl Acad Sci U S A 109, 4245, 2012.

116. Wang, X., Meloche, M., Verchere, C.B., Ou, D., Mui, A., and Warnock, G.L. Improving islet engraftment by gene therapy. Journal of transplantation 20112011.

117. Borg, D.J., and Bonifacio, E. The use of biomaterials in islet transplantation. Curr Diabetes Rep 11, 434, 2011.

118. Vallbacka, J.J., and Sefton, M.V. Vascularization and improved in vivo survival of VEGF-secreting cells microencapsulated in HEMA-MMA. Tissue Engineering 13, $2259,2007$.

119. Kang, S., Park, H.S., Jo, A., Hong, S.H., Lee, H.N., Lee, Y.Y., Park, J.S., Jung, H.S., Chung, S.S., and Park, K.S. Endothelial progenitor cell cotransplantation enhances islet engraftment by rapid revascularization. Diabetes 61, 866, 2012.

120. Veriter, S., Gianello, P., Igarashi, Y., Beaurin, G., Ghyselinck, A., Aouassar, N., Jordan, B., Gallez, B., and Dufrane, D. Improvement of subcutaneous bioartificial pancreas vascularization and function by coencapsulation of pig islets and mesenchymal stem cells in primates. Cell Transplant 23, 1349, 2014.

121. Veriter, S., Aouassar, N., Adnet, P.Y., Paridaens, M.S., Stuckman, C., Jordan, B., Karroum, O., Gallez, B., Gianello, P., and Dufrane, D. The impact of hyperglycemia and the presence of encapsulated islets on oxygenation within a bioartificial pancreas in the presence of mesenchymal stem cells in a diabetic Wistar rat model. Biomaterials 32, 5945, 2011.

122. Penko, D., Rojas-Canales, D., Mohanasundaram, D., Peiris, H.S., Sun, W.Y., Drogemuller, C.J., Keating, D.J., Coates, P.T.H., Bonder, C.S., and Jessup, C.F. Endothelial progenitor cells enhance islet engraftment, influence $\beta$-cell function, and modulate islet connexin 36 expression. Cell Transplant 24, 37, 2015.

123. Teramura, Y., and Iwata, H. Islets surface modification prevents blood-mediated inflammatory responses. Bioconjugate Chem 19, 1389, 2008.

124. Contreras, J.L., Eckstein, C., Smyth, C.A., Bilbao, G., Vilatoba, M., Ringland, S.E., Young, C., Thompson, J.A., Fernandez, J.A., Griffin, J.H., and Eckhoff, D.E. Activated protein $\mathrm{C}$ preserves functional islet mass after intraportal transplantation: 
A novel link between endothelial cell activation, thrombosis, inflammation, and islet cell death. Diabetes 53, 2804, 2004.

125. Johansson, H., Goto, M., Siegbahn, A., Elgue, G., Korsgren, O., and Nilsson, B. Low molecular weight dextran sulfate: A strong candidate drug to block IBMIR in clinical islet transplantation. Am J Transplant 6, 305, 2006.

126. Bennet, W., Sundberg, B., Lundgren, T., Tibell, A., Groth, C.G., Richards, A., White, D.J., Elgue, G., Larsson, R., Nilsson, B., and Korsgren, O. Damage to porcine islets of Langerhans after exposure to human blood in vitro, or after intraportal transplantation to cynomologus monkeys: Protective effects of sCR1 and heparin. Transplantation 69, 711, 2000.

127. Cabric, S., Sanchez, J., Lundgren, T., Foss, A., Felldin, M., Kallen, R., Salmela, K., Tibell, A., Tufveson, G., Larsson, R., Korsgren, O., and Nilsson, B. Islet surface heparinization prevents the instant blood-mediated inflammatory reaction in islet transplantation. Diabetes 56, 2008, 2007.

128. Ding, Y., Bushell, A., and Wood, K.J. Mesenchymal stem-cell immunosuppressive capabilities: Therapeutic implications in islet transplantation. Transplantation 89, 270, 2010.

129. Jiang, X.X., Zhang, Y., Liu, B., Zhang, S.X., Wu, Y., Yu, X.D., and Mao, N. Human mesenchymal stem cells inhibit differentiation and function of monocytederived dendritic cells. Blood 105, 4120, 2005.

130. Spaggiari, G.M., Capobianco, A., Becchetti, S., Mingari, M.C., and Moretta, L. Mesenchymal stem cell-natural killer cell interactions: Evidence that activated NK cells are capable of killing MSCs, whereas MSCs can inhibit IL-2-induced NK-cell proliferation. Blood 107, 1484, 2006.

131. Brusko, T.M. Mesenchymal stem cells: A potential border patrol for transplanted islets? Diabetes 58, 1728, 2009.

132. Ding, Y., Xu, D., Feng, G., Bushell, A., Muschel, R.J., and Wood, K.J. Mesenchymal stem cells prevent the rejection of fully allogenic islet grafts by the immunosuppressive activity of matrix metalloproteinase-2 and -9. Diabetes 58, 1797, 2009. 


\section{Chapter 3}

\section{A protocol to enhance INS1E and MIN6 functionality; the use of theophylline}

Milou Groot Nibbelink, Giulia Marchioli, Lorenzo Moroni, Marcel Karperien, Aart van Apeldoorn 


\subsection{Abstract}

The aim of this study was to develop a protocol to use MIN6 and INS1E pseudo-islets as model for islets of Langerhans for in vitro Type I Diabetes research by the addition of theophylline. This methodical study was composed of the step by step development of a new protocol. Both the effect on metabolic activity and functionality of INS1E and MIN6 cells to the addition of theophylline to glucose buffers was tested. A dose-dependent study finalized the development of this protocol. We found high responsiveness of MIN6 and INS1E pseudo-islets when adding theophylline. This response was dose- and cell line dependent, resulting in a minimal stimulation index of 5 followed by a rapid return to base-line insulin secretion by reducing glucose concentrations after a first high glucose stimulation. In conclusion, using this protocol pseudo-islets demonstrate high responsiveness to glucose by the addition of theophylline to glucose buffers. This protocol solves issues concerning in vitro research for Type I Diabetes as pancreas donor shortage and availability of primary islets of Langerhans is limited. To avoid the limitations of using human donor material, cell lines represent a valid alternative. Many different beta-cell lines have been reported, but the lack of reproducible responsiveness to glucose stimulation remains a challenge. We propose that complementing glucose stimulation buffers with theophylline is an effective strategy to obtain reproducible and physiologic relevant glucose responses in INS1E and MIN6 cells. 


\subsection{Introduction}

In vitro research in the field of Type I Diabetes is frequently limited by the availability of a functional model for islets of Langerhans. The development of a protocol for Type I Diabetes in vitro research is therefore highly desired. In vitro research is hampered as available cell lines do not have a similar responsiveness to glucose stimulation as islets (Fig 3.1 left panel). Cell lines are needed as the use of primary cells is limited due to donor shortage. In addition, islet isolation and their transport to the research facility affect the viability and functionality of the donor material. Moreover, another common problem for the in vitro testing of human islets is represented by the donor variability, which limits the comparison between different donors and different sets of experiments. All these limitations suggest the need of a reliable and easily available method to produce pseudo-islets for in vitro research purposes. For this reason many different cell lines have been created over the last decades(1). Of all these beta cell lines, mouse insulinoma MIN6 and rat insulinoma INS1E cell lines best reflect the physiological conditions, as both cell lines are responsive to glucose stimuli and they both express glucokinase(1). The MIN6 cell line originates from a transgenic C57BL/6 mouse insulinoma(2), while INS1E cells were generated from rat insulinoma induced by X-ray irradiation(3). Although beta cell lines are commonly used, a major issue is the reproducible responsiveness to glucose stimulation. In particular a low-highlow insulin secretion profile needs to be detected in response to low-high-low glucose stimulation, as seen in functional islet of Langerhans(4). This is often not the case for both INS1E and MIN6 cells, as their insulin secretion does not return to basal level after stimulation with low glucose for the second time. Therefore either just the stimulation index or only the amount of insulin secreted in the first low glucose stimulation is shown in literature(5-8). The stimulation index is a measure to express islet functionality. It is defined as the amount of insulin secreted under high glucose stimulation, divided by the basal insulin secreted in low glucose conditions. For islets of Langerhans, a threshold stimulation index of at least 2 defines a functional response and often these cell lines do not reach this threshold level nor display a reproducible 
behavior(9).

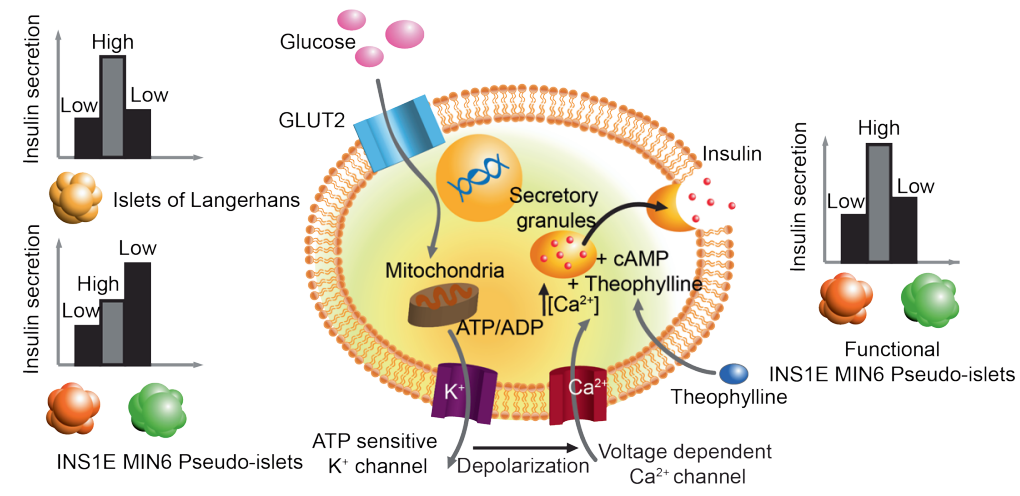

Figure 3.1: Schematic representation of this study. Islets of Langerhans secrete more insulin upon stimulation with higher concentration of glucose. Beta cell lines do not have this reproducible secretion profile (left). Theophylline acts on cAMP, thereby enhancing insulin secretion in a glucose dependent manner (middle). MIN6 and INS1E pseudo-islets can be functionalized by the addition of theophylline to the glucose buffers (right).

In adult islets insulin secretion is a complex process. When the extracellular glucose rises, glucose enters the beta cell via the GLUT2 glucose transporter. Glucose is phosphorylated by a glucokinase, enters in the glycolysis and leads to an increased concentration of ATP. This increase of ATP closes the K+ channels and consequently depolarizes the plasma membrane of the beta cell. This makes an influx of $\mathrm{Ca}^{2+}$ possible via the voltage dependent L-type $\mathrm{Ca}^{2+}$ channel. The influx of $\mathrm{Ca}^{2+}$ induces insulin secretion from the secretory granules(1, 10-13).

Ways to functionalize cells to secrete insulin upon glucose stimulation have been frequently explored in the field of fetal and neonatal islets. It is known that these cells hardly secrete insulin upon glucose stimulation(14-16). Different components have been tested which act on different molecules/channels in the insulin secretion pathway, like leucine, glipizide, theophylline, nicotinamide, and sodium butyrate(14-17). Theophylline, a methylxanthine, has been described to enhance insulin secretion by stimulation of cAMP (Fig 3.1 middle)(14, 15, 17-23). Theophylline inhibits phospho- 
diesterase activity, which leads to an increase in intracellular $\operatorname{cAMP}(14,19,22,23)$. Adding theophylline to glucose buffers has already been applied in primary, fetal and neonatal islets as well as for the administration in Type I Diabetes patients, in order to enhance their responsiveness to glucose stimulation $(14,15,17,19,20)$. However until now the effect of theophylline has not been examined using INS1E and MIN6 cell lines. In this study, theophylline was applied to increase functional response of MIN6 and INS1E beta cell lines, both in monolayer and in an aggregate configuration to mimic islets of Langerhans response.

Research has already shown that the response to glucose stimulation differs between monolayers and cell clusters $(4,24-27)$. In the case of primary islets there is an impaired insulin secretion in dispersed islets compared to intact islets. However, upon reaggregation insulin secretion is enhanced again $(4,24,27)$. Research on beta cell lines, like MIN6 cells, also showed significant enhanced insulin secretion when cell clusters, or so-called pseudo-islets, were used compared to monolayers $(4,24,27,28)$.

The aim of this study as depicted in figure 3.1, was to develop a protocol to functionalize MIN6 and INS1E cell lines so they can be used as in vitro models for Diabetes research. With the addition of theophylline, we show that MIN6 and INS1E aggregates cells become responsive to glucose stimulation in a reproducible manner and show stimulation indices $>5$ and a proper low-high-low insulin secretion profile. Additionally, we show a dose dependent and cell-line dependent response. Since previous research has shown that insulin secretion is enhanced in pseudo-islets compared to cells in monolayers, our protocols were developed on MIN6 and INS1E pseudo-islets.

\subsection{Materials and Methods}

\subsubsection{Cell culture}

INS1E rat insulinoma cells (provided by Dr. B. Guigas, LUMC, Leiden, the Netherlands and Dr. P. Maechler, University Medical Center, Geneva, Switzerland) were 
cultured in RMPI (Gibco) with $2.05 \mathrm{~mm}$ Glutamax (Invitrogen) supplemented with $5 \%(\mathrm{v} / \mathrm{v})$ fetal bovine serum (FBS, Lonza), $100 \mathrm{U} / \mathrm{mL}$ penicillin and $100 \mathrm{mg} / \mathrm{mL}$ streptomycin (Gibco), $10 \mathrm{~mm}$ HEPES, $1 \mathrm{~mm}$ sodium pyruvate, and $50 \mu \mathrm{M}$ freshly added beta-mercaptoethanol (Gibco) at $37^{\circ} \mathrm{C}$ and $5 \% \mathrm{CO}_{2}$. Mouse insulinoma MIN6-B1 cells (provided by Dr. P. Halban, University Medical Center, Geneva, Switzerland) were cultured in Dulbecco's Modified Eagle's Medium (DMEM, Gibco) supplemented with $10 \%$ (v/v) FBS (Lonza), $100 \mathrm{U} / \mathrm{mL}$ penicillin and $100 \mathrm{mg} / \mathrm{mL}$ streptomycin, and $70 \mu \mathrm{M}$ freshly added beta-mercaptoethanol (Gibco) $\left(37^{\circ} \mathrm{C}, 5 \% \mathrm{CO}_{2}\right)$.

\subsubsection{Agarose microwell fabrication and controlled pseudo-islet formation}

For controlled pseudo-islet formation, cells were cultured in sterile agarose microwells. These agarose microwells were fabricated as described previously(29). In short, polydimethylsiloxane (PDMS) negative Molards containing micro pillars (200 $\mu \mathrm{m})$ were sterilized (70\% ethanol). A 3\% agarose (UltraPure ${ }^{\mathrm{TM}}$ Gibco Invitrogen) PBS solution was heated to $100^{\circ} \mathrm{C}$ in a microwave oven. PDMS Molards were placed inside 6 wells plate and filled with $6 \mathrm{~mL}$ of agarose solution. Air bubbles were removed by centrifuging the plates $(300 \mathrm{~g}, 1 \mathrm{~min})$. Solidification of the agarose was established by storing the plates at $4{ }^{\circ} \mathrm{C}(>30 \mathrm{~min})$. Next, the Molards were removed from the agarose using a sterile spatula. The agarose chips were punched out leaving a thin agarose wall on all sides to fit into a 12 wells plate. Stable pseudo-islets were then created based on the work of Hilderink et al.(30). MIN6 cells or INS1E cells were then seeded onto the agarose chips (250 cells per aggregate). The plates were centrifuged (150 g, $1 \mathrm{~min}$ ) and $1 \mathrm{~mL}$ of medium was carefully added to the chips. After $48 \mathrm{~h}$ at $37^{\circ} \mathrm{C}$ pseudo-islets (average size of $100 \mu \mathrm{m}$ ) were flushed out of the chips.

\subsubsection{Glucose induced insulin secretion test}

A tailor made Krebs buffer (115 mm NaCl, 5 mm KCl, 24 mm $\mathrm{NaHCO}_{3}$ Sigma) supplemented with $2.2 \mathrm{mM} \mathrm{CaCl}_{2}, 20 \mathrm{~mm}$ HEPES (Gibco), $2 \mathrm{mg} / \mathrm{mL}$ bovine serum albumin, 
and $1 \mathrm{mM} \mathrm{MgCl}_{2}$ was prepared at $\mathrm{pH} 7.4$ with different concentrations of theophylline (Sigma) (concentration range from $0.1 \mathrm{~mm}$ to $20 \mathrm{~mm}$ ). Subsequently, the buffer was split into low $(1.67 \mathrm{~mm})$ and high glucose $(16.7 \mathrm{~mm})$. Cells were washed three times in low glucose buffer followed by a pre-incubation of $90 \mathrm{~min}$ in low glucose buffer. Cells were stimulated for $45 \mathrm{~min}$ in subsequent low, high and low glucose buffer with a three time wash step in low glucose between the high and second low. Samples were taken after each incubation, spun down (300g, $3 \mathrm{~min})$ and the supernatant was stored at $-20^{\circ} \mathrm{C}$. Samples were analyzed using a rat insulin Elisa (Mercodia) for INS1E samples and mouse insulin ELISA (Mercodia) for MIN6 samples.

\subsubsection{The effect of theophylline on insulin secretion}

MIN6 cells were seeded in a 12 well plate at a cell density of 30.000 cells $/ \mathrm{cm}^{2}$. After $48 \mathrm{~h}$ insulin secretion upon glucose stimulation with the addition of theophylline $(10 \mathrm{~mm})$ in both low $(1.67 \mathrm{~mm})$ and high glucose $(16.7 \mathrm{~mm})$ Krebs buffers or only the high glucose $(16.7 \mathrm{~mm})$ Krebs buffer was tested. Insulin secretion was quantified by ELISA as described above.

The effect of theophylline on the metabolic activity of MIN6 and INS1E cells MIN6 and INS1E pseudo-islets were prepared as described above. Per condition approximately 950 pseudo-islets were seeded in a 96 transwell plate $(40 \mu \mathrm{m}$, Millipore). A Presto blue assay (Invitrogen) was performed following manufacturer's protocol (1.5 h incubation) to determine their basal level of metabolic activity, before theophylline treatment. After the first presto blue, the pseudo-islets were washed three times in low glucose buffer with different theophylline concentrations $(0,5,10$, and $20 \mathrm{~mm}$ ) and incubated for $5 \mathrm{~h}$ in the same low glucose buffer with added theophylline. After these $5 \mathrm{~h}$ of incubation, a second presto blue assay was performed (1.5 h incubation). 


\subsubsection{Theophylline concentration dependent insulin secretion of MIN6 and INS1E pseudo-islets}

MIN6 and INS1E pseudo-islets were prepared as described above. Per condition approximately 285 pseudo-islets were seeded in a 96 transwell plate (40 $\mu \mathrm{m}$, Millipore). Six theophylline concentrations were tested $(0,0.1,0.5,1,5$, and $10 \mathrm{~mm})$ by dissolving the theophylline in both low $(1.67 \mathrm{~mm})$ and high glucose $(16.7 \mathrm{~mm})$ Krebs buffers. Insulin secretion upon glucose stimulation was tested as described above.

\subsubsection{Statistical analysis}

One-way ANOVA statistical analysis was performed followed by a Bonferroni posthoc test. Data is expressed as mean \pm standard deviation and significant differences are indicated with $*(\mathrm{p} \leq 0.05)$. The analysis was performed using IBM SPSS statistic 20 software.

\subsection{Results}

\subsubsection{The effect of theophylline on insulin secretion}

Figure 3.2 shows the insulin secretion of MIN6 cells when stimulated with glucose. Cells were either stimulated with standard glucose buffers (1.67 mM and $16.7 \mathrm{~mm})$ or with glucose buffers with $10 \mathrm{~mm}$ theophylline. Theophylline was added either in all buffers $(\mathrm{T})$ or just in the high glucose buffer $(\mathrm{T}(\mathrm{hg}))$. Figure 3.2B shows the differences in stimulation indices between the different groups. The control group appeared to be non-functional whereas both theophylline groups exhibited functional insulin secretion profiles. Furthermore, no difference was seen in insulin secretion patterns between the two different theophylline groups. Although the low high low profile was visible when using theophylline compared to the control, only a marginal improvement in stimulation index was seen. As these experiments were performed on monolayers, and the beneficial effect on function of cell aggregation has already been 
described in literature, further experiments were conducted with pseudo-islets $(4,24$, $27)$.
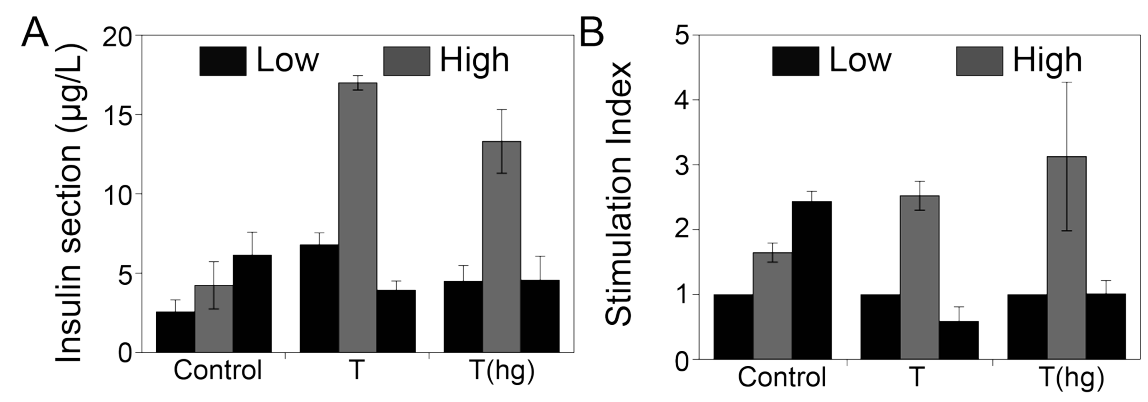

Figure 3.2: The effect of theophylline on insulin secretion. Insulin secretion ( $\mu \mathrm{g} / \mathrm{L})$ (A) and stimulation index (B) of MIN6 cells cultured on tissue culture plastic (monolayer) without theophylline, with theophylline $10 \mathrm{~mm}$ in all the incubation buffers $(\mathrm{T})$ and with theophylline $10 \mathrm{~mm}$ added only in the high glucose buffer ( $\mathrm{T}(\mathrm{hg}))$. Error $=$ mean SD

\subsubsection{The effect of theophylline on the metabolic activity of MIN6 and INS1E cells}

The effect on metabolic activity was assessed on both MIN6 (Fig 3.3A) and INS1E (Fig 3.3B) pseudo-islets for the duration of a glucose induced insulin secretion test.

Figure 3.3 shows the fold change of the metabolic activity after 5 h incubation compared to the initial basal activity. Again no significant effect of theophylline was seen in both cell types and for none of the concentrations tested, confirming that theophylline exerted no toxic effect on MIN6 and INS1E pseudo-islets, for an incubation time of the duration of a standard function test.

\subsubsection{Theophylline concentration dependent insulin secretion of MIN6 and INS1E pseudo-islets}

After establishing that theophylline did not impair viability and metabolic activity of both MIN6 and INS1E cells, the effect on insulin secretion was tested in MIN6 

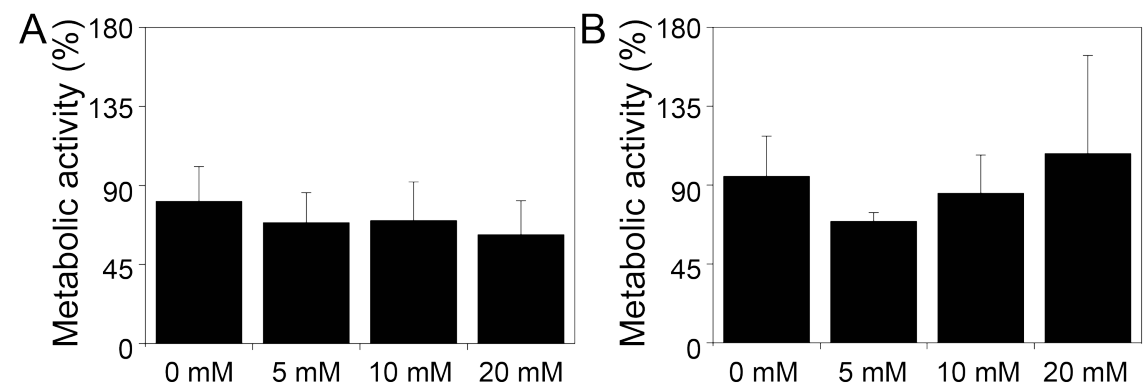

Figure 3.3: The effect of theophylline on the metabolic activity of MIN6 and INS1E cells. Metabolic activity of MIN6 (A) or INS1E (B) pseudo-islets cultured for $5 \mathrm{~h}$ in presence of different concentrations of Theophylline. Data are presented as percentage of the metabolic activity at $\mathrm{t}=0$. Error $=$ mean $\mathrm{SD}$

pseudo-islets (Fig 3.4) and INS1E pseudo-islets (Fig 3.5). Pseudo-islets were stimulated with different concentrations of theophylline to find the optimal concentration. Functionality is expressed as stimulation index and it is defined as the amount of insulin secreted under high glucose stimulation, divided by the basal insulin secreted in low glucose conditions. Pseudo-islets were determined as functional when stimulation indices were above 2 , and a decrease in insulin secretion was seen when stimulated with low glucose buffer for the second time(9). Figure 3.4 shows pseudo-islets functionality of MIN6 cells when stimulated with different concentrations of theophylline. Both the insulin secretion in $\mu \mathrm{g} / \mathrm{L}$ (Fig 3.4A) and stimulation indices (Fig 3.4B) are depicted. To compare the efficiency of different theophylline concentrations on cell stimulation, statistical analysis compared the stimulation indices in high glucose conditions, all concentrations had a significantly higher insulin secretion compared to the control $(\mathrm{p}<0.05)$. Additionally, when MIN6 pseudo-islets were stimulated with $0.1 \mathrm{mM}$, they secreted significantly more insulin compared to the pseudo-islets stimulated with $1 \mathrm{~mm}$ to $10 \mathrm{~mm}$. The MIN6 pseudo-islets clearly showed a dose-dependent insulin secretion pattern. When looking at the insulin secretion $(\mu \mathrm{g} / \mathrm{L})$, the maximal effect appeared to be between $0.5 \mathrm{~mm}$ and $5 \mathrm{~mm}$. However, when looking at the stimulation indices, the optimal concentration seems to be $0.1 \mathrm{~mm}$. This was due to a lower insulin secretion when stimulated with low glucose for the $0.1 \mathrm{~mm}$ condition 
compared to the other concentrations of theophylline rather than a lower insulin production under high glucose stimulation, therefore resulting in a higher stimulation index. Despite the remarkable increase in insulin secretion by the addition of theophylline, insulin secretion returned to base line after replacing the high glucose buffer with a low glucose buffer mimicking normal physiology.

Hilderink et al. showed an average stimulation index of $1.86 \pm 0.7$ for INS1E pseudoislets(30). This is comparable to the control group (Fig 3.5). Compared to the MIN6 pseudo-islets, INS1E pseudo-islets showed a similar insulin secretion pattern as MIN6 pseudo-islets. However, they seemed to be less sensitive to theophylline as they secreted less insulin when stimulated with $0.1 \mathrm{mM}$ of theophylline compared to the MIN6 pseudo-islets (Fig 3.5A). Additionally, no detectable difference in the stimulation index was seen in the $0.5 \mathrm{~mm}$ to $10 \mathrm{~mm}$ range of theophylline concentration. Compared to MIN6 pseudo-islets, insulin secretion in INS1E pseudo-islets did not decrease as effectively to base line when stimulated with the second low glucose buffer particular at the highest concentrations used. To compare the efficiency of different theophylline concentrations on cell stimulation, statistical analysis compared the stimulation indices in high glucose conditions, only INS1E pseudo-islets stimulated with $0.1 \mathrm{mM}$ theophylline did not have a significantly higher insulin secretion compared to the control. 
A

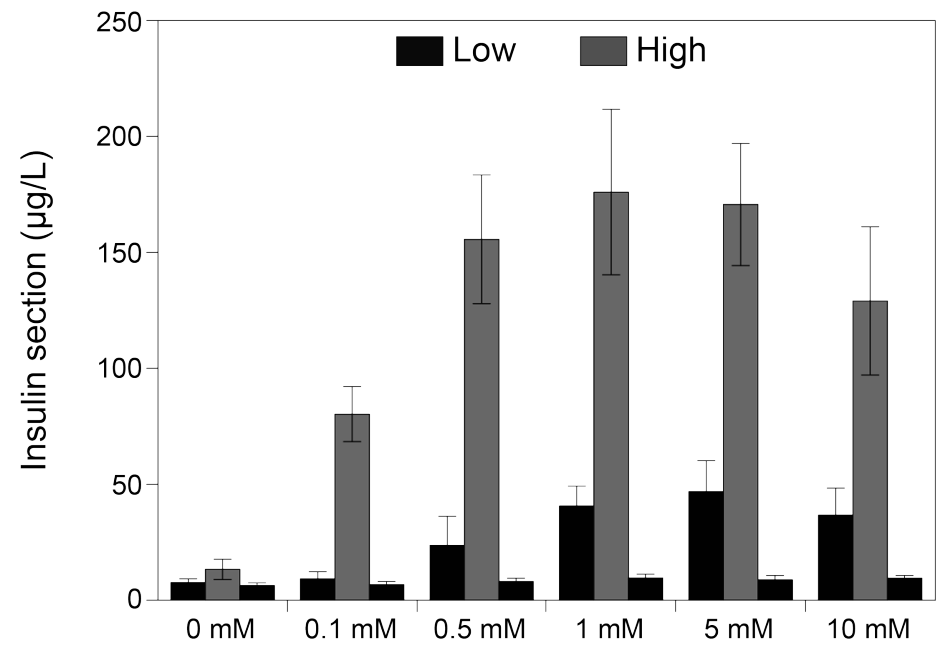

B

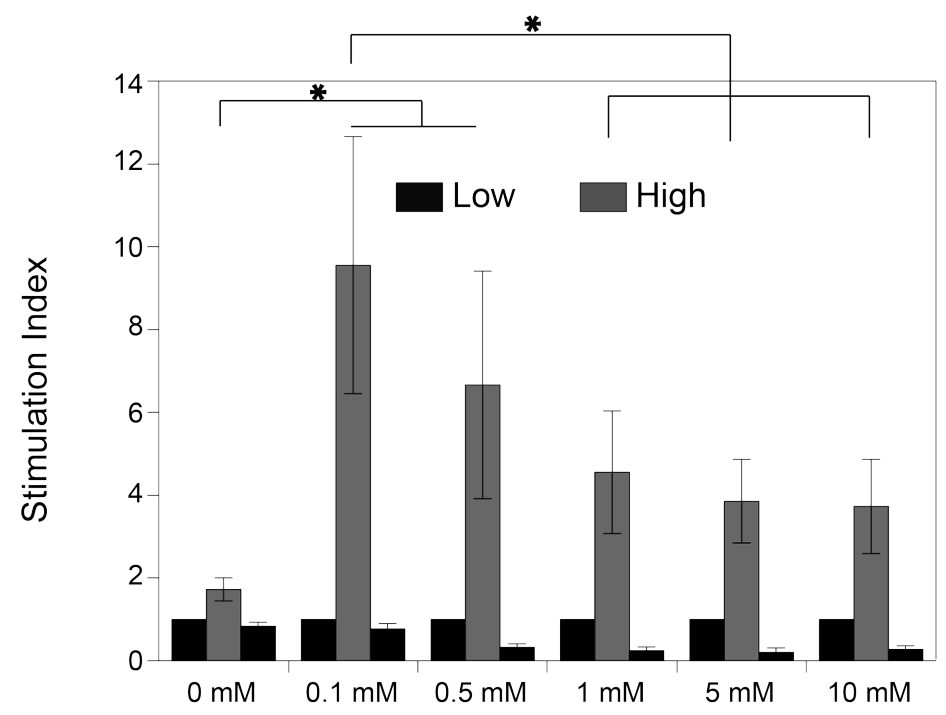

Figure 3.4: Theophylline concentration dependent insulin secretion of MIN6 pseudo-islets. Dose-response results of the glucose induced insulin secretion test on MIN6 pseudo-islets at different concentrations of theophylline. (A) secreted amount of insulin $(\mu \mathrm{g} / \mathrm{L})$ is shown, in (B) data are normalized by the amount of insulin secreted in low glucose condition (stimulation index). Data are expressed as mean \pm standard deviation and significant differences are indicated with $*(\mathbf{p} \leq 0.05)$. 
A

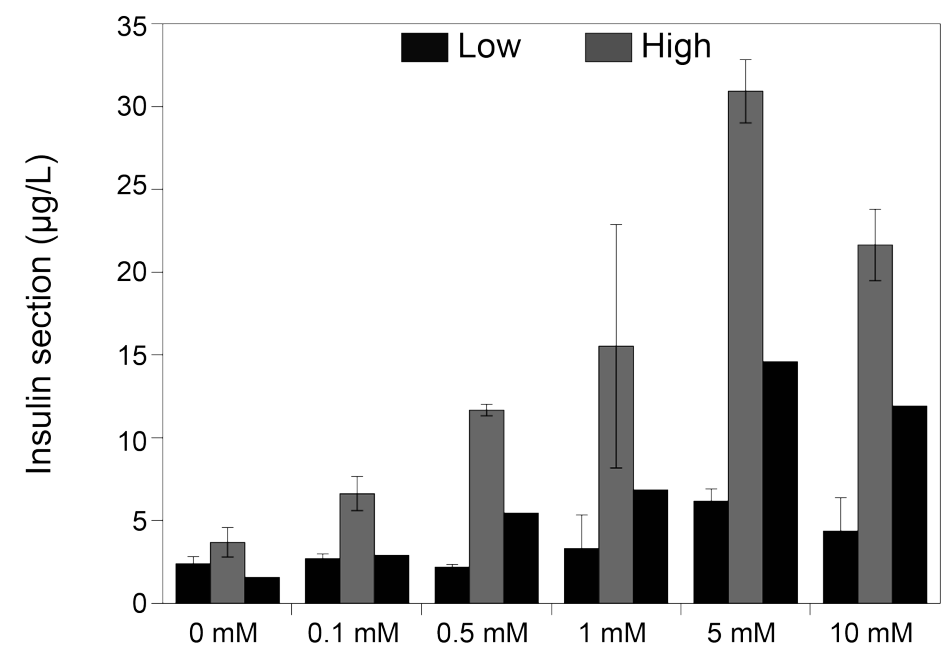

B

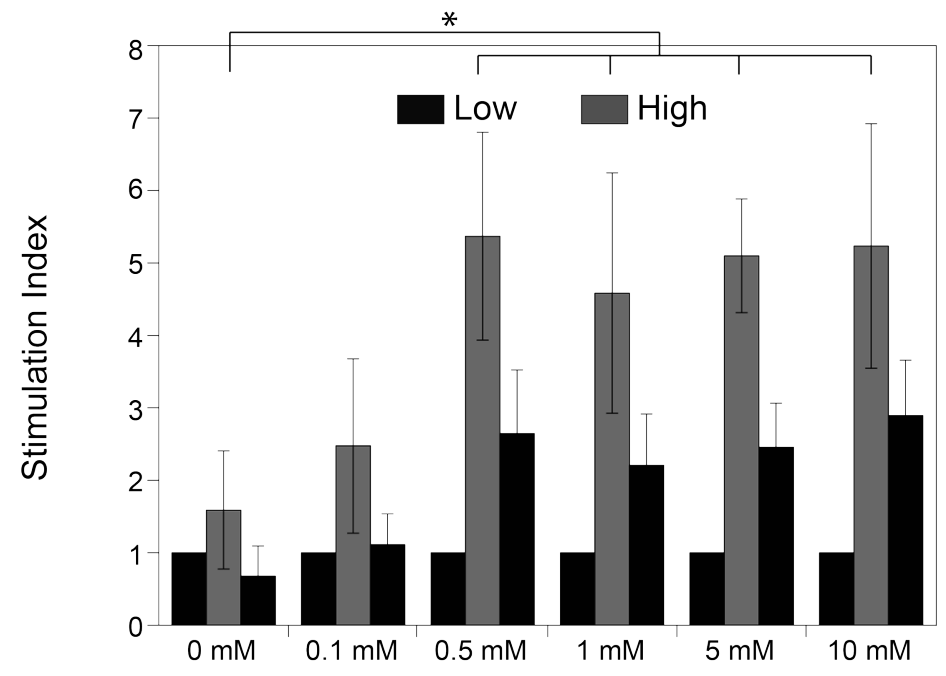

Figure 3.5: Theophylline concentration dependent insulin secretion of INS1E pseudo-islets. Dose-response results of the glucose induced insulin secretion test of INS1E pseudo-islets at different concentrations of theophylline. (A)secreted amount of insulin $(\mu \mathrm{g} / \mathrm{L})$ is shown, (B) data are normalized by the amount of insulin secreted in low glucose condition (stimulation index). Data are expressed as mean \pm standard deviation and significant differences are indicated with $*(\mathbf{p} \leq \mathbf{0 . 0 5})$. 


\subsection{Discussion}

In this work, we demonstrated that the addition of theophylline to the glucose stimulation buffer is necessary to achieve a proper stimulation index both for MIN6 and INS1E pseudo-islets. Thereby developing an in vitro protocol for Diabetes research using cell-lines instead of primary islets.

The generation of functional pseudo-islets for in vitro testing has been widely addressed in literature and many authors report aggregation as a way to increase insulin secretion and functionality. Both islets and beta cell line aggregates showed an increased glucose responsiveness in an aggregate configuration when compared to their dispersed counterpart $(4,24-27)$. This enhancement in insulin secretion is provided by a specific cell-cell contact mediated by many components such as the ephrin-A5 receptor and the adhesion Molarecule E-cadherin(24, 25, 27, 31). Aggregation of pancreatic beta-cells ensure that the basal level of insulin secretion in starvation conditions $(1.67 \mathrm{~mm})$ is reduced, while the glucose stimulated secretion is enhanced(31). An improvement in both INS1E and MIN6 functionality is therefore already provided by the aggregation procedure $(5,24)$. In this work, we show that aggregation itself is not sufficient to generate a functional pseudo-islet, with a stimulation index comparable to native human tissue. As the stimulation index in the control condition, without theophylline stimulation, is below 2 both for INS1E and MIN6 aggregates, which is considered the lowest threshold for defining an islet as functional(9). Reproducible stimulation indices and a consistent return to basal level of insulin secretion upon second stimulation with low glucose condition is still a major issue. Many authors only publish first low and high stimulation, but neglect the importance of return to basal level, which is essential for defining an islet functional $(5,7,8)$. In other papers only the amount of insulin secreted in different conditions were compared among each other, but this does not give any indication about the proper functional response (low-high-low) of the tested cells $(6)$.

With the addition of theophylline, we show that MIN6 and INS1E pseudo-islets are responsive with stimulation indices around 5 and a proper return to basal level in low 
glucose conditions. This return to baseline was more effective in MIN6 pseudo islets than in INS1E pseudo islets. Theophylline, a phosphodiesterase inhibitor, increases the intracellular cAMP levels by blocking its degradation and making it longer available for the increase of cytosolic calcium concentration(32). A mechanism proposed by Malaisse, suggests that theophylline acts by mobilizing an intracellular source of calcium, originally located into the vacuolar system into the cytosol. In absence of glucose, most of the calcium still escapes from the cytoplasm, but the simultaneous presence of glucose blocks this outward flux of calcium(32). This mechanism explains why theophylline's action is dependent on glucose stimulation and does not exert its effect in low glucose conditions, at least at low theophylline concentrations $(0.1 \mathrm{~mm})$ (32). In fact, we show a dose dependent response of MIN6 pseudo-islets to theophylline stimulation. In particular for MIN6 pseudo-islets, the stimulation at a lower dose, induced insulin secretion only in high glucose conditions and did not induce insulin release in basal medium (low glucose). On the contrary, higher theophylline concentrations stimulated insulin release also in low glucose condition, thus lowering the overall stimulation index. For this reason, the action of theophylline on insulin secretion stimulation is glucose-dependent. Our results show that the addition of theophylline has no detrimental effect on the metabolic activity of INS1E and MIN6 pseudo-islets. This behavior was relatively different for INS1E pseudo-islets showing a lower sensitivity to theophylline action and highlighting a cell-line dependent response. More research would be necessary to understand in depth the different behavior of MIN6 and INS1E pseudo-islets: the difference could reside in speciesspecific characteristics or in a distinct fine-tuning regulation in the cAMP level in insulin secretion mechanism. This difference might be explained by the higher glucokinase activity in MIN6 cells compared to INS1E cells. As shown by Arden and Co-workers, the glucokinase activity in MIN6 cells is higher because of the higher insulin granule content in MIN6 cells(33). Based on these results, we propose the use of $0.1 \mathrm{mM}$ theophylline in glucose induced insulin secretion test of MIN6 pseudoislets, since in these conditions the functional behavior of islets of Langerhans is best resembled. In addition we found that theophylline stimulated MIN6 pseudo-islets 
showed a higher stimulation index and a better return to basal level, upon second low glucose conditions. For INS1E pseudo-islets a higher theophylline concentration $(5 \mathrm{mM})$ was necessary to significantly increase the stimulation index compared to the control $(0 \mathrm{~mm})$ but its subsequent return to basal level was sub optimal. For in vitro purposes we therefore recommend the use of pseudo islets of MIN6 cells. 


\section{References}

1. Skelin, M., Rupnik, M., and Cencic, A. Pancreatic beta cell lines and their applications in diabetes mellitus research. ALTEX 27, 105, 2010.

2. Miyazaki, J.I., Araki, K., Yamato, E., Ikegami, H., Asano, T., Shibasaki, Y., Oka, Y., and Yamamura, K.I. Establishment of a pancreatic $\beta$ cell line that retains glucose-inducible insulin secretion: Special reference to expression of glucose transporter isoforms. Endocrinology 127, 126, 1990.

3. Asfari, M., Janjic, D., Meda, P., Li, G., Halban, P.A., and Wollheim, C.B. Establishment of 2-mercaptoethanol-dependent differentiated insulin-secreting cell lines. Endocrinology 130, 167, 1992.

4. Hauge-Evans, A.C., Squires, P.E., Persaud, S.J., and Jones, P.M. Pancreatic $\beta$ cell-to- $\beta$-cell interactions are required for integrated responses to nutrient stimuli: Enhanced $\mathrm{Ca} 2^{+}$and insulin secretory responses of MIN6 pseudoislets. Diabetes 48, $1402,1999$.

5. Chowdhury, A., Satagopam, V.P., Manukyan, L., Artemenko, K.A., Fung, Y.M.E., Schneider, R., Bergquist, J., and Bergsten, P. Signaling in insulin-secreting MIN6 pseudoislets and monolayer cells. J Proteome Res 12, 5954, 2013.

6. Weber, L.M., and Anseth, K.S. Hydrogel encapsulation environments functionalized with extracellular matrix interactions increase islet insulin secretion. Matrix Biol $27,667,2008$.

7. Poy, M.N., Eliasson, L., Krutzfeldt, J., Kuwajima, S., Ma, X., MacDonald, P.E., Pfeffer, S., Tuschl, T., Rajewsky, N., Rorsman, P., and Stoffel, M. A pancreatic isletspecific microRNA regulates insulin secretion. Nature 432, 226, 2004.

8. Vetterli, L., Brun, T., Giovannoni, L., Bosco, D., and Maechler, P. Resveratrol potentiates glucose-stimulated insulin secretion in INS-1E $\beta$-cells and human islets through a SIRT1-dependent mechanism. J Biol Chem 286, 6049, 2011.

9. Benhamou, P.Y., Oberholzer, J., Toso, C., Kessler, L., Penfornis, A., Bayle, F., Thivolet, C., Martin, X., Ris, F., Badet, L., Colin, C., and Morel, P. Human islet transplantation network for the treatment of Type I diabetes: first data from the 
Swiss-French GRAGIL consortium (1999-2000). Groupe de Recherche Rhin Rhjne Alpes Geneve pour la transplantation d'Ilots de Langerhans. Diabetologia 44, 859, 2001.

10. Straub, S.G., andS harp, G.W.G. Glucose-stimulated signaling pathways in biphasic insulin secretion. Diabetes/Metabolism Research and Reviews 18, 451, 2002.

11. MacDonald, P.E., Joseph, J.W., and Rorsman, P. Glucose-sensing mechanisms in pancreatic $\beta$-cells. Philos Trans R Soc B Biol Sci 360, 2211, 2005.

12. Henquin, J.C. Triggering and amplifying pathways of regulation of insulin secretion by glucose. Diabetes 49, 1751, 2000.

13. Rorsman, P., and Renstrom, E. Insulin granule dynamics in pancreatic beta cells. Diabetologia 46, 1029, 2003.

14. Weinhaus, A.J., Poronnik, P., Cook, D.I., and Tuch, B.E. Insulin secretagogues, but not glucose, stimulate an increase in $\left[\mathrm{Ca}_{2}{ }^{+}\right] \mathrm{i}$ in the fetal rat -cell. Diabetes 44 , $118,1995$.

15. Korbutt, G.S., Elliott, J.F., Ao, Z., Smith, D.K., Warnock, G.L., and Rajotte, R.V. Large scale isolation, growth, and function of porcine neonatal islet cells. J Clin Invest 97, 2119, 1996.

16. Otonkoski, T., Ustinov, J., Rasilainen, S., Kallio, E., Korsgren, O., and Hayry, P. Differentiation and maturation of porcine fetal islet cells in vitro and after transplantation. Transplantation 68, 1674, 1999.

17. Korsgren, O., Andersson, A., and Sandler, S. In vitro screening of putative compounds inducing fetal porcine pancreatic beta-cell differentiation: implications for cell transplantation in insulin-dependent diabetes mellitus. Ups J Med Sci 98, 39, 1993.

18. Charles, M.A., Lawecki, J., Pictet, R., and Grodsky, G.M. Insulin secretion. Interrelationships of glucose, cyclic adenosine, 3',5' monophosphate, and calcium. J Biol Chem 250, 6134, 1975.

19. Hvidberg, A., Rosenfalck, A., Christensen, N.J., and Hilsted, J. Long-term administration of theophylline and glucose recovery after hypoglycaemia in patients with type 1 diabetes mellitus. Diabetic Medicine 15, 608, 1998.

20. Murray, H.E., Paget, M.B., and Downing, R. Preservation of glucose responsive- 
ness in human islets maintained in a rotational cell culture system. Molecular and Cellular Endocrinology 238, 39, 2005.

21. Hoffman, L., Mandel, T.E., Carter, W.M., Koulmanda, M., and Martin, F.I.R. Insulin secretion by fetal human pancreas in organ culture. Diabetologia 23, 426, 1982.

22. Brisson, G.R., Malaisse-Lagae, F., and Malaisse, W.J. The stimulus-secretion coupling of glucose-induced insulin release. VII. A proposed site of action for adenosine3',5'-cyclic monophosphate. J Clin Invest 51, 232, 1972.

23. Tuch, B.E., Osgerby, K.J., andTurtle, J.R. The role of calcium in insulin release from the human fetal pancreas. Cell Calcium 11, 1, 1990.

24. Luther, M.J., Hauge-Evans, A., Souza, K.L.A., Jorns, A., Lenzen, S., Persaud, S.J., andJones, P.M. MIN6 $\beta$ cell- $\beta$-cell interactions influence insulin secretory responses to nutrients and non-nutrients. Biochemical and Biophysical Research Communications 343, 99, 2006.

25. Nyitray, C.E., Chavez, M.G., and Desai, T.A. Compliant 3D microenvironment improves $\beta$-cell cluster insulin expression through mechanosensing and $\beta$-catenin signaling. Tissue Engineering - Part A 20, 1888, 2014.

26. Pipeleers, D., In t Veld, P., Maes, E., and Van De Winkel, M. Glucose-induced insulin release depends on functional cooperation between islet cells. PROC NATL ACAD SCI U S A 79, 7322, 1982.

27. Kelly, C., McClenaghan, N.H., and Flatt, P.R. Role of islet structure and cellular interactions in the control of insulin secretion. Islets 3, 41, 2011.

28. Hauge-Evans, A.C., Squires, P.E., Belin, V.D., Roderigo-Milne, H., Ramracheya, R.D., Persaud, S.J., and Jones, P.M. Role of adenine nucleotides in insulin secretion from MIN6 pseudoislets. Molecular and Cellular Endocrinology 191, 167, 2002.

29. Rivron, N.C., Vrij, E.J., Rouwkema, J., Gac, S.L., Van Berg, A.D., Truckenmuller, R.K., andVan Blitterswijk, C.A. Tissue deformation spatially modulates VEGF signaling and angiogenesis. Proc Natl Acad Sci U S A 109, 6886, 2012.

30. Hilderink, J., Spijker, S., Carlotti, F., Lange, L., Engelse, M., van Blitterswijk, C., de Koning, E., Karperien, M., and van Apeldoorn, A. Controlled aggregation of 
primary human pancreatic islet cells leads to glucose-responsive pseudoislets comparable to native islets. J Cell Mol Med 17, 12555, 2015.

31. Konstantinova, I., Nikolova, G., Ohara-Imaizumi, M., Meda, P., Kucera, T., Zarbalis, K., Wurst, W., Nagamatsu, S., and Lammert, E. EphA-Ephrin-A-mediated beta cell communication regulates insulin secretion from pancreatic islets. Cell 129, $359,2007$.

32. Malaisse, W.J. Insulin secretion: multifactorial regulation for a single process of release. The Minkowski award lecture delivered on September 7, 1972 before the European Association for the study of Diabetes at Madrid, Spain. Diabetologia 9, 167, 1973.

33. Arden, C., Harbottle, A., Baltrusch, S., Tiedge, M., and Agius, L. Glucokinase is an integral component of the insulin granules in glucose-responsive insulin secretory cells and does not translocate during glucose stimulation. Diabetes 53, 2346, 2004. 


\section{Chapter 4}

\section{Diffusion properties,}

\section{biocompatibility and function of}

encapsulated islets of Langerhans in a poly(ether sulfone) multibore

\section{hollow fiber}

Milou Groot Nibbelink, Katarzyna Skrzypek, Maria Coronel, Irayme Labrada, Cherie Stabler, Maaike Braham, Eelco de Koning, Marcel Karperien, Dimitrios Stamatialis, Aart van Apeldoorn 


\subsection{Abstract}

In the early stages of clinical islet of Langerhans transplantation by injection in the portal vein, $60-70 \%$ of the donor islets are lost in the liver. This loss is mainly due to mechanical stresses, immune-responses, and low oxygen supply. As an alternative approach, encapsulating islets in an implantable poly(ether sulfone) multibore bore hollow fiber was studied as a concept for islets transplantation. These fibers comprising seven bores with a diameter of $0.9 \mathrm{~mm}$ exert good mechanical properties and the selective layer has an average membrane pore size of $20 \mathrm{~nm}$. Membrane sieving coefficients for water, glucose and insulin were 1 at pressures ranging from 0.01 to 0.05 bar, but were lower for BSA and IgG. To provide sufficient oxygen for the encapsulated islets part of the bores were filled with cylinders of a composite of poly(dimethyl siloxane) and calcium peroxide as an oxygen generating material. The small dimensions of the cylinders and the fast diffusion of water only allowed sufficient oxygen be generated during a few days. Moreover, islets seeded in the bores of the fiber aggregated rapidly inhibiting their long-term survival. A seeding method using agarose spheres with a size distribution ranging from 150 to $350 \mu \mathrm{m}$ was shown a methodology to avoid islet aggregation. Opposite to free floating islets, in vitro function tests of encapsulated MIN6 pseudo-islets as well as human islets at consecutively low and high glucose levels revealed a minimal change in response in the release of insulin. No functional behavior of the encapsulated islets was seen both after 1 and 7 days of culture. An in vivo study on fibers with islets encapsulated showed the material was biocompatible, allowed infiltration of cells and formation of tissue up to the selective layer surrounding the bores. Histology of explanted fibers revealed only few insulin positive cells and some TUNEL positive cells were present. 


\subsection{Introduction}

Although clinical islet transplantation has proven an effective treatment for patients with Type I Diabetes, and a valuable low-risk alternative for total pancreas transplantation, more than $60-70 \%$ of the islets are lost immediately after transplantation in the portal vein(1). This loss is mainly due to complex immune responses, predominantly the instant blood mediated inflammatory reaction (IBMIR), and hypoxia due to the lack of adequate vascularization $(2,3)$. The immunogenicity of transplanted allogeneic islets requires a life-long use of immunosuppressive drugs, which are in general only partly effective in controlling rejection and are associated with numerous complications such as infections and neoplasms. In addition, some immunosuppressive drugs cause metabolic alterations, which have a negative effect on islet function, or induce toxicity due to their accumulation in the liver(2-5).

A strategy to avoid the use of immunosuppressive drugs is to encapsulate islets, thereby introducing a physical barrier between islets and the immune system(6-14). If successful, such a so called immune protective device could not only decrease the risks of complications involved, but also provides opportunities for future use of stem cell derived $\beta$ cells or xenotransplantation.

A few immune protective devices have been described in literature. The Baxter immunoisolation device, also known as the TheraCyte ${ }^{\mathrm{TM}}$ system, is well-known and was studied for islet encapsulation. In this device islets are shielded by a $0.4 \mu \mathrm{m}$ pore inner membrane laminated to a $5 \mu \mathrm{m}$ pore outer membrane that induces tissue ingrowth vascularization $(13,15,16)$. No immune responses were observed to allogeneic islets, which indicated that a pore size of $0.4 \mu \mathrm{m}$ affords sufficient protection $(13,15$, 16). A similar method of encapsulating islets of Langerhans is by using hollow fibers. Hollow fibers provide a combination of a large surface area with small dimensions, which is regarded advantageous for implantation devices. In previous research it was shown that allogeneic islets were shielded from rejection because of the membranes small pore size $(8,12,14)$. However, low long term survival rates and impaired function of encapsulated islets in these devices, related to diffusion limitations were the 
general drawbacks encountered(3, 17). Moreover, the low survival of islets in these devices may be due to islet clustering. Clustering increases the distance for diffusion of small molecules and when becoming too large will lead to cell death(3, 18). From these literature data it could be concluded that the porosity and the pore size of the membrane applied, diffusion rates and distance of embedded islets to the surrounding vasculature are of prime importance. To overcome the problems associated with diffusion limitations more recently multibore hollow fibers have been considered for extrahepatic islet transplantation(19-21). These fibers have a higher mechanical stability compared to single fibers allowing easier handling upon implantation. Importantly, different functionalities can be appointed to the different bores of the multibore hollow fiber, like islet encapsulation, vascularization, oxygen supply, and delivery of bioactive components (Fig 4.1).

In this paper we describe macro encapsulation of islets in commercially available modified poly(ether sulfone) (PESM) Multiboreß hollow fibers. These fibers have been successfully used as hepatocyte bioreactors and a medium perfusion system for three-dimensional tissue engineered constructs $(19,22)$. It was also shown that PESM multibore hollow fibers were non-fouling and in vitro tests revealed the material biocompatible. To potentially use these fibers for islet encapsulation the in-vivo biocompatibility of the device and membrane permeance of water, glucose, insulin and proteins was determined. An easy and reliable seeding method to load islets into the bores was developed. The physical separation of encapsulated islets, their viability and functionality were subsequently studied. Finally, the effectiveness of short term and localized oxygen supply on cell survival, by incorporating calcium peroxide PDMS composites cylinders as developed by Pedraza et al.(23) in the bores of the multibore hollow fiber was evaluated. 


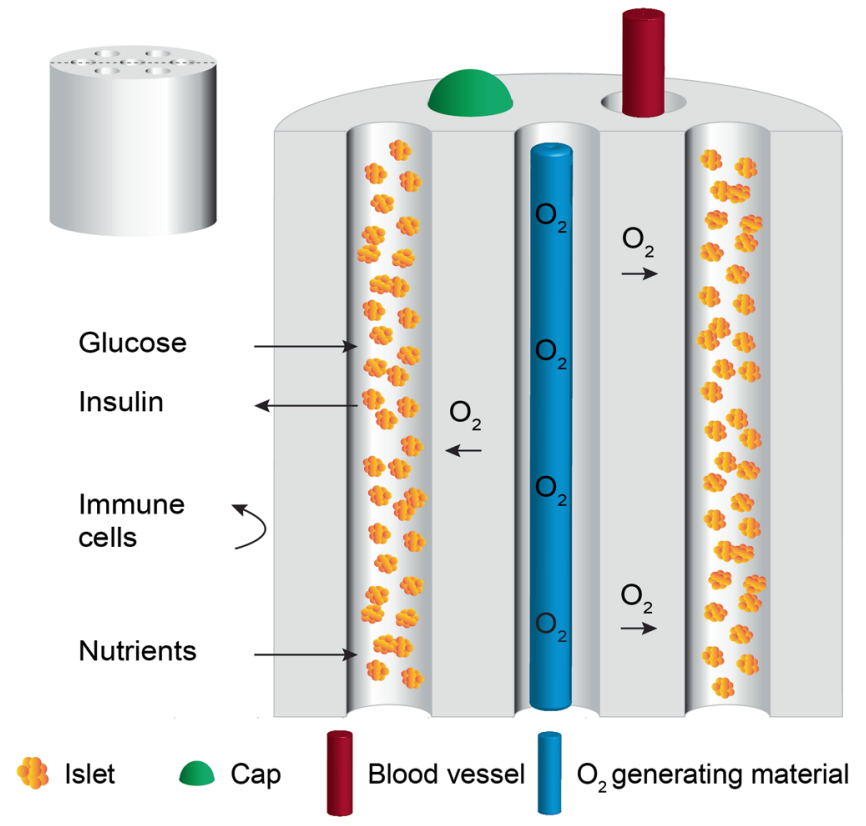

Figure 4.1: A multibore hollow fiber for encapsulation of islets of Langerhans. The bores can be used for different purposes like; islet encapsulation, vascularization, and oxygen generation. The device needs to be permeable for nutrients, glucose, and insulin, but impermeable for immune cells.

\subsection{Materials and methods}

\subsubsection{Cell culture}

MIN6-B1 mouse insulinoma cells (kindly provided by Dr. P. Halban, University Medical Center, Geneva, Switzerland) were cultured at $37^{\circ} \mathrm{C}$ and $5 \% \mathrm{CO}_{2}$ in Dulbecco's Modified Eagle's Medium (DMEM, Gibco) supplemented with 10\% (v/v) FBS (Lonza), $100 \mathrm{U} / \mathrm{mL}$ penicillin, $100 \mathrm{mg} / \mathrm{mL}$ streptomycin (Gibco), and $70 \mu \mathrm{M}$ freshly added beta-mercaptoethanol (Gibco). Human islets of Langerhans pooled from 2 pancreata of organ donors were provided by the Human Islet Isolation Center of the Leiden University Medical Center (Leiden, The Netherlands). The islet isolation center is permitted to provide donor tissue, not eligible for clinical transplantation, for 
research purposes in agreement with the Dutch law and institutional requirements. Islets were cultured in CMRL 1066 medium ( $5.5 \mathrm{~mm}$ glucose) containing 10\% FCS, $20 \mathrm{mg} / \mathrm{mL}$ ciprofloxacin, $50 \mathrm{mg} / \mathrm{mL}$ gentamycin, $2 \mathrm{mM}$ L-glutamin, $0.25 \mathrm{mg} / \mathrm{mL}$ fungizone, $10 \mathrm{~mm}$ HEPES, and $1.2 \mathrm{mg} / \mathrm{mL}$ nicotinamide(24).

\subsubsection{Pseudo-islet formation}

Pseudo-islets were formed as described in chapter 3(25). In short, single MIN6 cells were seeded in agarose microwells (250 cells per microwell). After 2 days incubation in normal culture medium, stable pseudo-islets were obtained (chapter 3).

\subsubsection{Multibore hollow fibers}

Porous poly(ether sulfone) (PESM) Multiboreß hollow fibers (Inge AG) were used to encapsulate pseudo-islets or human islets in individual bores. Single fibers $(4 \mathrm{~mm}$ in diameter) consisted of 7 bores with a diameter of approximately $0.9 \mathrm{~mm}$. The average pore size of the PESM multibore hollow fiber membrane was $20 \mathrm{~nm}(19)$.

\subsubsection{Membrane permeance and diffusion characteristics}

Membrane modules containing one PESM multibore hollow fiber (Fig 4.2), used for permeance and diffusion measurements, were prepared using $8 \mathrm{~mm}$ polyethylene tubes and Kartell T connectors (VNW). Both ends were glued using two-component epoxy glue (Griffon $囚)$. After hardening of the glue all bores were opened again by cutting off the edges. During the experiment one side of the module was closed using an end cap.

Permeance of glucose $(n=3)$ and insulin $(n=3)$ was measured in an inside-out deadend manner. Prior to the start of the measurements, the membrane was wetted using MilliQ water for $30 \mathrm{~min}$ ( 0.5 bar, RT) and flushed with a glucose ( $5.5 \mathrm{~mm}$, Sigma) or insulin (138 pM, Sigma) solution depending on the experiment for $30 \mathrm{~min}$ (RT, 0.5 bar). The weight of the permeate was measured for $30 \mathrm{~min}$ with a $3 \mathrm{sec}$ interval 


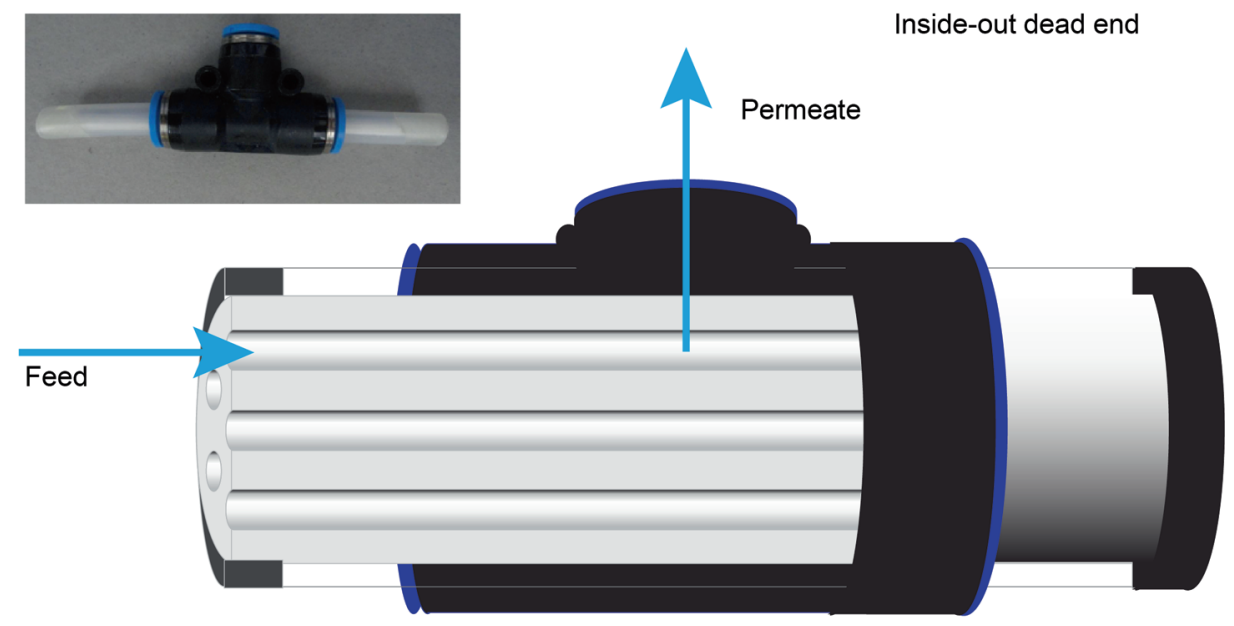

Figure 4.2: Module used for inside-out dead end permeance measurements. The PESM multibore hollow fiber was glued (dark grey) into the polyethylene tubing. Both ends were cut to open the bores. During the measurements, one end was closed with an end cap. Measurements were performed at different pressures.

at different pressures ranging from 0.1 to 0.5 bar. Permeance of water $(n=8)$, culture medium (DMEM, Gibco) (n=3), bovine serum albumin (BSA, Sigma) $(n=6)$, and Immunoglobulin IgG (Sigma) ( $\mathrm{n}=3$ ) was measured using a cross flow set-up. Before the experiments, MilliQ was flushed through the membrane at 0.3 bar for at least one hour in order to check if all bores of hollow fiber membrane were open and to wet the membrane. Subsequently $100 \mathrm{~mL}$ of a feed containing, depending on the experiment, water, medium, $1 \mathrm{mg} / \mathrm{mL}$ BSA or $0.02 \mathrm{mg} / \mathrm{mL}$ IgG solution in PBS was recirculated through the membrane module. Experiments were performed at different pressures ranging from 0.01 to 0.1 bar. A SpectrumLabs automatic back pressure valve (JM separations) was used to achieve a constant transmembrane pressure during the experiments. For all cross flow measurements, at the indicated time points, the weight of permeate was measured for $1 \mathrm{~h}$. The permeance was graphically determined from the slope of the flux $\left(J=L / m^{2} h\right)$ versus transmembrane pressure. Samples from the feed were taken at the start of each measurement and from the feed and permeate at the end of each measurement. Samples were analyzed for glucose (VITROS 
medium analyzer), insulin (Mercodia human insulin ELISA), BSA (UV-VIS), and IgG (UV-VIS). The Sieving coefficient was determined according Eq 4.1 ( $\mathrm{Sc}=$ Sieving Coefficient, $\mathrm{Cf}=$ concentration in the feed, $\mathrm{Cp}=$ concentration in the permeate).

$$
S_{c}=\frac{C_{p}}{C_{f}}
$$

Diffusion of insulin was measured using a cross flow set-up composed of membrane modules containing two T connectors (Fig 4.3).

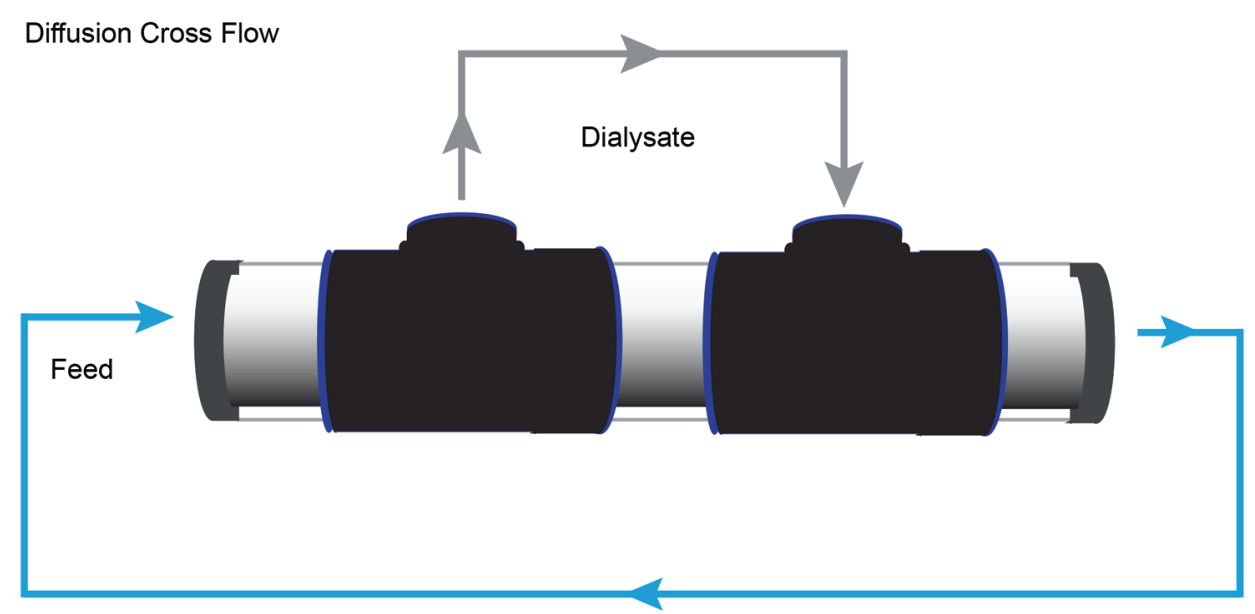

Figure 4.3: Module used for cross flow diffusion measurements. The PESM multibore hollow fiber was glued (dark grey) into the polyethylene tubing. Both ends were cut to open the bores. Measurements were performed at different pressures.

First, MilliQ was flushed through the membrane at 0.03 bar for at least one hour in order to wet the membrane and remove air bubbles trapped inside the pores. Subsequently, all water was removed from the system and $60 \mathrm{~mL}$ of a feed containing $20 \mathrm{mU} / \mathrm{L}$ insulin solution was recirculated through the bores of the fiber, while $60 \mathrm{~mL}$ of dialysate containing PBS was recirculated around the fiber in the counter current direction. The feed and dialysate were pumped at $4 \mathrm{~mL} / \mathrm{min}$ and $8 \mathrm{~mL} / \mathrm{min}$, 
respectively. At these flow rates no transmembrane pressure could be detected. After $30 \mathrm{~min}, 2 \mathrm{~mL}$ samples were collected from both feed and dialysate and analyzed for insulin using an ELISA assay (Mercodia). The flux was calculated using equation 4.2 $\left(\mathrm{C}_{\text {acceptor }}\right.$ is the insulin concentration in the dialysate, $\mathrm{V}_{\text {acceptor }}$ is the volume of the dialysate solution and $\mathrm{S}$ is the surface area of the membrane):

$$
\operatorname{flux}\left(\mathrm{gm}^{-2} \mathrm{~s}^{-1}\right)=\frac{C_{\text {acceptor }}\left(\mathrm{gm}^{-3}\right) \cdot V_{\text {acceptor }}\left(\mathrm{m}^{3}\right) / \mathrm{s}\left(\mathrm{m}^{2}\right)}{\operatorname{time}(\mathrm{s})}
$$

The permeability of insulin, as a measure of the diffusion over time, was calculated using equation $4.3(\Delta \mathrm{C}$ is the concentration difference between the feed and the dialysate and $\mathrm{l}$ is the thickness of the membrane):

$$
\operatorname{permeability}\left(m^{2} s^{-1}\right)=\frac{\operatorname{flux}\left(\mathrm{gm}^{-2} \mathrm{~s}^{-1}\right)}{\Delta C\left(\mathrm{gm}^{-3}\right)} \cdot l(m)
$$

From the permeability, the diffusion coefficient were determined using equation 4.4(where $\mathrm{K}$ is the partition coefficient. Since insulin is relatively small compared to the pore size, $\mathrm{K}$ can be assumed equal to one):

$$
\text { diffusion coefficient }\left(m^{2} s^{-1}\right)=\frac{\operatorname{permeability}\left(m^{2} s^{-1}\right)}{K}
$$

\subsubsection{In vivo biocompatibility}

The in vivo biocompatibility of PESM multibore hollow fibers was determined by implantation in 9 week old male C57BL/6 mice (Jackson Laboratories) $(n=2-4)$. The study was reviewed and approved by the University of Miami, Miami Institutional Animal Care and Use Committee. All procedures were conducted according to the guidelines of the Committee on Care and Use of Laboratory Animals, Institute of Laboratory Animal Resources (National Research Council). The mice were housed in micro-isolated cages in virus antibody-free rooms with free access to autoclaved food and water at the Department of Veterinary Resources of the University of Mi- 
ami. Before implantation the PESM multibore hollow fibers $(1 \mathrm{~cm})$ were sterilized by incubation in $70 \%$ ethanol for 30 min and thereafter washed thoroughly with PBS.

Mice were anesthetized by isoflurane $(2 \%)$ and after shaving the abdomen and sterilizing the skin, a midline incision was made and the epididymal fat pads (EFP) were exposed (Fig 4.4A). Multibore hollow fibers were placed on the EFP (Fig 4.4B), wrapped in the EFP (Fig 4.4C), and sealed with fibrin glue. Subsequently, the wrapped scaffolds were placed in the abdominal cavity, the muscle was sutured and the skin was closed using staples. Animals received pain medication, buprenorphine $(20 \mu \mathrm{g} / \mathrm{mL})$, immediately after surgery, and twice a day for the first 2 days after implantation.

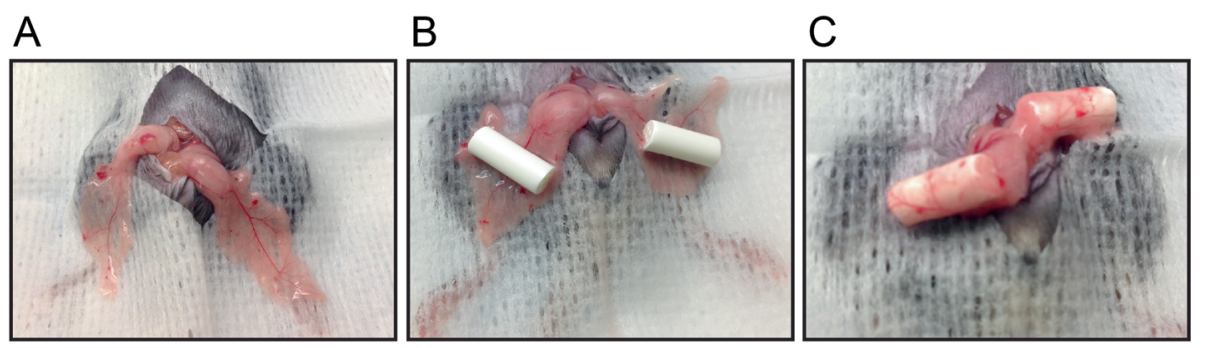

Figure 4.4: Implantation of the PESM multibore hollow fibers in epididymal fat pads (EFP) of a mouse. The EFPs were exposed (A), the hollow fibers were placed on the EFPs (B), wrapped and sealed with fibrin glue (C) after which the wrapped fibers were placed in the abdominal cavity.

The PESM multibore hollow fibers were explanted after 7, 21 or 28 days. The samples were fixed in $10 \%$ formalin, processed for paraffin sectioning and sections were stained with hematoxylin and eosin.

\subsubsection{Pseudo-islet seeding}

Prior to seeding pseudo-islets or human islets, PESM multibore hollow fibers were sterilized in $70 \%$ ethanol for at least $30 \mathrm{~min}$, washed with PBS (3x), placed under reduced pressure to remove air from the pores for at least $1 \mathrm{~h}$, and pre-incubated with culture medium overnight. Pseudo-islets were seeded in the bores of $1 \mathrm{~cm}$ multibore 
hollow fibers. One end of the fiber was closed using surgical staples. The seeding method was derived from the general known kidney capsule implantation method(26). In short, islets were centered in a petri dish, taken up by a Hamilton syringe and pipetted into PE-50 tubing (Intramedic). The tube was centrifuged (1000 rpm, $1 \mathrm{~min}$ ) in order to form a pellet, thereby reducing the volume for seeding. The pellet was divided over the different bores by injecting the islets into the bores using a syringe and PE-50 tubing as described by Szot et al.(26). After seeding the multibore hollow fiber was closed by surgical staples and cultured in an excess of medium in 6 well plates.

\subsubsection{Preventing pseudo-islet aggregation}

To prevent aggregation, pseudo-islets were mixed with agarose macrospheres (4\%, Agarose Bead Technologies, $150 \mu \mathrm{m}$ to $350 \mu \mathrm{m}$ ) prior to seeding into the individual bores. After $24 \mathrm{~h}$ of culture the multibore hollow fibers were fixed in $10 \%$ formalin (24h, RT) and processed for paraffin sectioning. Sections were stained with hematoxylin and eosin. To compare the effect of mixing pseudo-islets with agarose macrospheres, a similar experiment was conducted with only pseudo-islets.

\subsubsection{In vitro MIN6 pseudo islet functionality}

MIN6 pseudo-islets with and without agarose macrospheres (4\%, Agarose Bead Technologies, $150 \mu \mathrm{m}$ to $350 \mu \mathrm{m}$ ) were seeded into the PESM multibore hollow fiber as described above. After 1 day of culture, a glucose induced insulin secretion test (GIIST) was performed as described in chapter 3. In short; a tailor made Krebs buffer (115 mm NaCl,5 mm KCl, $24 \mathrm{~mm} \mathrm{NaHCO}_{3}$, Sigma) supplemented with $2.2 \mathrm{~mm}$ $\mathrm{CaCl}_{2}, 20 \mathrm{~mm}$ HEPES (Gibco), $2 \mathrm{mg} / \mathrm{mL}$ bovine serum albumin, $1 \mathrm{~mm} \mathrm{MgCl}_{2}$, and $0.1 \mathrm{~mm}$ theophylline (Sigma) was prepared at pH 7.4. From this Krebs buffer a low (1.67 mM) and high $(16.7 \mathrm{~mm})$ glucose buffer was prepared, by adding glucose. Both free floating pseudo-islets and hollow fibers were washed $(3 \times 5 \mathrm{~min})$ with low glucose buffer followed by a pre-incubation of $90 \mathrm{~min}$ in low glucose buffer. All samples were 
then stimulated for $60 \mathrm{~min}$ in subsequent low, high and low glucose buffer with a 3 times 5 min wash step with low glucose buffer between the high and second low. Samples were taken after each incubation, spun down $(300 \mathrm{~g}, 3 \mathrm{~min})$ and the supernatant was stored at $-20^{\circ} \mathrm{C}$. Samples were analyzed using a mouse insulin ELISA (Mercodia). Free floating pseudo-islets with and without agarose macrospheres in a transwell system (MilliPore) were used as control. The functionality of pseudo-islets was determined by the stimulation index which is defined as the insulin secretion after stimulation with high glucose relative to the insulin secretion when stimulated with the first low glucose buffer. Pseudo-islets with a stimulation index higher than 2 were regarded functional.

\subsubsection{Human donor islet functionality in vitro}

Viability and functionality of islets seeded in the bores of a multibore hollow fiber were determined after 1 and 7 days of culturing. To assess islet function within the bores, a GIIST was performed. Free floating islets in a transwell system (MilliPore) $(\mathrm{n}=3)$ were used as a positive control. Multibore hollow fibers with encapsulated islets, and the free floating islets were pre-incubated in a low glucose buffer $(115 \mathrm{~mm}$ $\mathrm{NaCl}, 5 \mathrm{~mm} \mathrm{KCl}, 24 \mathrm{~mm} \mathrm{NaHCO} 3,2.2 \mathrm{M} \mathrm{CaCl}_{2}, 1 \mathrm{M} \mathrm{MgCl}, 1 \mathrm{M} \mathrm{HEPES,} 10 \%$ Human Serum Albumin (HSA), and $1.67 \mathrm{~mm}$ glucose (pH7.4) for $1.5 \mathrm{~h}$ at $37^{\circ} \mathrm{C}$. All samples were then stimulated for $90 \mathrm{~min}$ in subsequent low $(1.67 \mathrm{~mm})$, high $(20.5 \mathrm{~mm})$ and low $(1.67 \mathrm{~mm})$ glucose buffer with a three times 5 min wash step with low glucose buffer between the high and second low. Samples were taken after each incubation, spun down (300g, $3 \mathrm{~min}$ ) and the supernatant was stored at $-20^{\circ} \mathrm{C}$. Samples were analyzed using a human insulin ELISA kit (Mercodia). The PESM multibore hollow fibers were fixed in $10 \%$ formalin (RT, $1 \mathrm{~h}$ ). Paraffin sections of the samples were stained for apoptosis using a TUNEL assay (Roche), $\beta$ cells were stained for insulin (Santa Cruz), and Dapi (Invitrogen) was used as a nuclear stain. A hematoxylin and eosin staining was performed to determine cell morphology. 


\subsubsection{Oxygen generation of PDMS calcium peroxide cylinders}

Oxygen generation was based on the method described by Pedraza et al(23). Calcium peroxide particles embedded in PDMS generate oxygen upon reaction with water via the following reaction:

$2 \mathrm{CaO}_{2}+4 \mathrm{H}_{2} \mathrm{O} \rightarrow 2 \mathrm{Ca}(\mathrm{OH})_{2}+2 \mathrm{H}_{2} \mathrm{O}_{2} \rightarrow 2 \mathrm{Ca}(\mathrm{OH})_{2}+2 \mathrm{H}_{2} \mathrm{O}+\mathrm{O}_{2}$

Calcium peroxide particles with a maximum size of $74 \mu \mathrm{m}$ were mixed with uncured PDMS (4:1 vol/vol PDMS silicone/platinum catalyst) in a 1:4 ratio (wt/wt) and degassed. The PDMS calcium peroxide mixture was pipetted into the bores of a $2 \mathrm{~cm}$ PESM multibore hollow fiber and cured at $37^{\circ} \mathrm{C}$ for $24 \mathrm{~h}$. The PDMS/calcium peroxide cylinders were then removed from the PESM multibore hollow fiber. Before measurements the constructs were sterilized with $70 \%$ ethanol for $30 \mathrm{~min}$ and subsequently washed 3 times with PBS for 5 min. Oxygen release measurements were performed using a closed chamber system at $0.2 \mathrm{~mm}$ oxygen and PreSens non-invasive, ruthenium-based oxygen sensors. All samples were incubated in PBS at $37^{\circ} \mathrm{C}$. Data were collected every 15 seconds during 4 days and PBS was refreshed every day to prevent saturation. The following samples were measured; PDMS/calcium peroxide cylinders, an open hollow fiber with three cylinders, a hollow fiber with three cylinders closed with surgical staples, and an empty multibore hollow fiber.

\subsection{Results}

\subsubsection{Membrane characteristics}

The linear increase in the flux of water, culture medium, insulin, glucose, BSA and IgG at various pressures revealed that no compaction of the membrane occurred (Fig 4.5). 

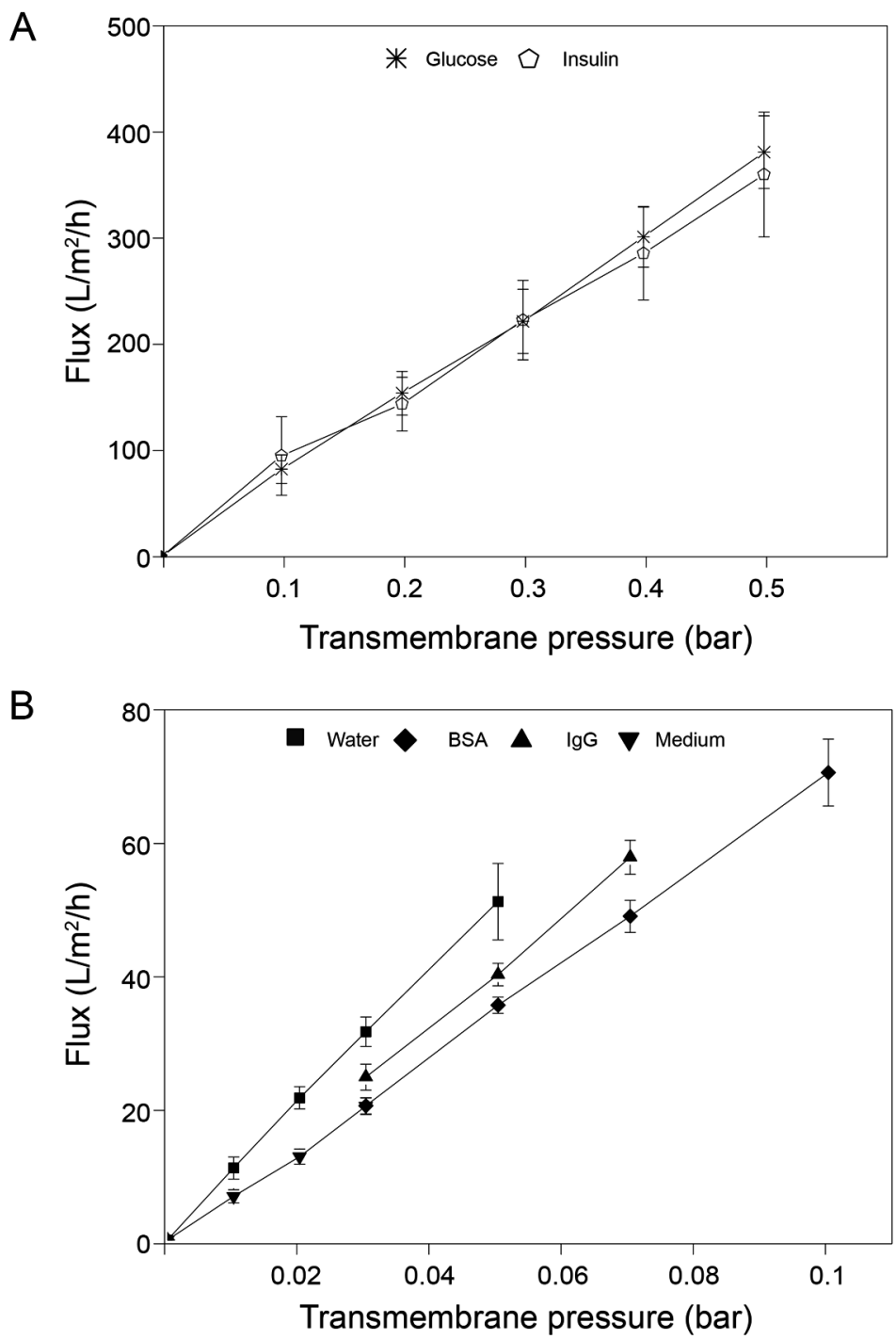

Figure 4.5: A) Flux of glucose (*) and insulin ( $\square)$ as a function of pressure, measured in an inside-out dead-end manner. B) Flux of water $(\boldsymbol{\square})$, BSA $(\diamond)$, IgG $(\Delta)$, and medium $(\nabla)$ measured using a cross flow set-up. 
The convective water permeance (Table 4.1) was calculated from the slope of the flux versus the transmembrane pressure.

Table 4.1: Convection transport of water, BSA, IgG, Insulin, Glucose, and medium across a PESM multibore hollow fiber. Sieving Coefficients at different pressures ranging form 0.01 to 0.1 bar. ${ }^{a} \mathrm{~S}_{c}$ is the Sieving Coefficient, $\mathrm{C}_{p}$ is the concentration in the permeate, and $\mathrm{C}_{f}$ is the concentration in the feed. ${ }^{*} \mathrm{ND}$ $=$ not determined

\begin{tabular}{|l|l|l|l|l|l|l|}
\hline & \multicolumn{2}{|l|}{$\begin{array}{l}\text { Permeability } \\
\left(L / m^{2} h \text { bar }\right)\end{array}$} & \multicolumn{2}{l|}{ Sieving Coefficient $\left(S_{c}=C_{p} / C_{f}\right)^{a}$} \\
\cline { 2 - 7 } & & $\begin{array}{l}\text { De } \\
\text { Bartelo } \\
\text { et } \\
\text { al. }(19)\end{array}$ & 0.01 bar & 0.02 bar & 0.03 bar & 0.1 bar \\
\hline Water & $1027 \pm 134$ & 1067 & 1 & 1 & 1 & 1 \\
\hline BSA & $697 \pm 158$ & 845 & 0.38 & 0.65 & 0.71 & 0.95 \\
\hline IgG & $811 \pm 33$ & 724 & 0.78 & 0.79 & 0.8 & 0.93 \\
\hline Insulin & $730 \pm 69$ & ND* & 1 & 1 & 1 & 1 \\
\hline Glucose & $758 \pm 78$ & ND* $^{*}$ & 1 & 1 & 1 & 1 \\
\hline $\begin{array}{l}\text { Culture } \\
\text { medium }\end{array}$ & $655 \pm 13$ & ND* $^{*}$ & ND* & ND* & ND* & ND* \\
\hline
\end{tabular}

A value of $1027 \pm 134 \mathrm{~L} / \mathrm{m}^{2} h$ bar $(\mathrm{n}=8)$ was found which is similar to the value determined by De Bartolo et al. (1067 L/ $\mathrm{m}^{2}$ hbar) (19). Additionally, similar values of BSA and IgG permeance were detected compared to De Bartelo et al.(19). Insulin and glucose transport through the membrane was comparable and a Sieving Coefficient of 1 was found for both molecules, indicating that mass transport was not hindered by the membrane (Table 4.1). Additionally, the estimated diffusion coefficient of insulin was $1.01 \times 10^{-10} \mathrm{~m}^{2} / \mathrm{sec}$, a value in the same order of magnitude than the insulin diffusion coefficient in water $\left(1.5 \times 10^{-10} \mathrm{~m}^{2} / \mathrm{sec}\right)$. For BSA and $\operatorname{IgG}$ the Sieving Coefficient decreased when the pressure was lowered (Table 4.1). Still, both compounds were able to cross the membrane albeit slightly less efficient. 


\subsubsection{In-vivo biocompatibility of PESM multibore hollow fibers}

The in-vivo biocompatibility of the PESM multibore hollow fibers was tested by implantation in mice. One centimeter pieces of the hollow fiber were implanted in the EFP of B6 mice and explanted on day $7(n=2), 21(n=4)$ or $28(n=2)$. Representative HE sections are shown in figure 4.6. Already after 7 days of implantation a fibrous capsule was present (Fig 4.6A), suggesting a tissue response to the material. The fibrous capsule increased in thickness between day 7 and 21. However, the thickness of the fibrous capsule remained stable after 21 days. Additionally, cells infiltrated the pores only from the edge of the PESM multibore hollow fiber up to the selective inner layer of the bores. The sections prepared from explants retrieved after 21 days (Fig 4.6B) and 28 days (Fig 4.6C) of implantation revealed an increased tissue infiltration compared to samples explanted 7 days after implantation. At none of the time points cell infiltration in the shell of the membrane was observed. 


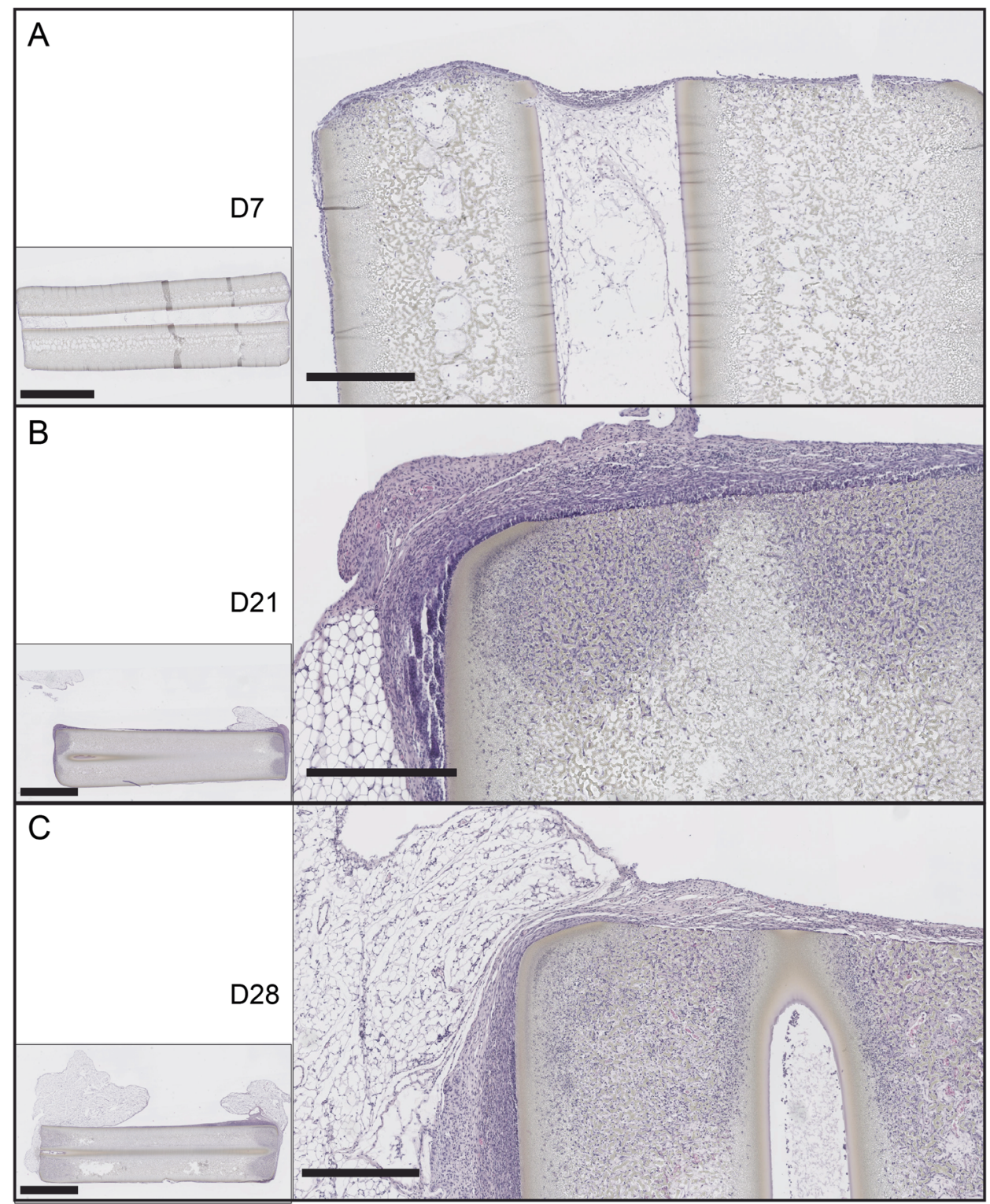

Figure 4.6: PESM multibore hollow fibers implanted in the EFP of B6 mice and explanted at day 7 (A), day 21 (B), and day 28 (C). Paraffin sections were stained with hematoxilin and eosin. Scale bars on the left are $2.5 \mathrm{~mm}$. Scale bars on the right are $500 \mu \mathrm{m}$. 


\subsubsection{Preventing pseudo-islet clustering}

A newly developed seeding method, derived from the kidney capsule seeding method by Szot et al.(26) allowed to randomly distribute pseudo-islets in the bores of the PESM multibore hollow fiber. As pseudo-islets were not able to attach to the wall of the bores, clustering occurred (Fig 4.7A). Due to this clustering the distance of the center of the pseudo-islets to the wall of the bore became larger than $200 \mu \mathrm{m}$ which limits diffusion of nutrients and waste products. As a result disintegration of the pseudo-islets appeared, which was clearly visible in Figure 4.7B. Cell clustering was prevented by mixing the pseudo-islets with agarose macrospheres (diameter $150 \mu \mathrm{m}$ to $350 \mu \mathrm{m}$ ) as depicted in Figure 4.7C. Pseudo-islets in the presence of the agarose macrospheres remained intact.
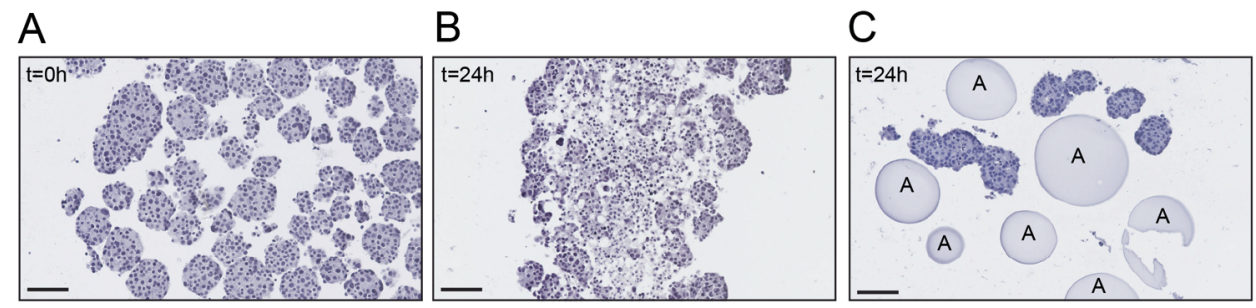

Figure 4.7: A) MIN6 pseudo-islets inside a single bore of a PESM multibore hollow fiber directly after seeding $(t=0 \mathrm{~h})$. B) Clustering of pseudo-islets at $24 \mathrm{~h}$ and C) pseudo-islets separated by mixing with agarose macrospheres at $24 \mathrm{~h}$. Scale bar $100 \mu \mathrm{m}$.

\subsubsection{In vitro MIN6 pseudo-islet functionality}

To study the effect of encapsulation and physically separating pseudo-islets in a PESM multibore hollow fiber the so called stimulation index of the islets was determined. By placing the fibers with encapsulated islets in subsequently low, high and low glucose buffers changes in insulin secretion were determined. This method, also known as the Glucose Induced Insulin Secretion Test (GIIST) provides a stimulation index defined as the insulin secretion after exposure to the high glucose buffer relative to pre-incubation in the low glucose buffer. Islets are regarded functional when the ratio 
is higher than 2. As a control free floating islets seeded in transwells were used. The results presented in figure 4.8 showed that free floating pseudo-islets with or without added agarose macrospheres appeared functional as their stimulation index was higher than 2. Although insulin was secreted from the pseudo-islets encapsulated in the hollow fibers, only a slightly non-significant change in stimulation index was observed indicating a loss in functionality already after 1 day. Moreover, no difference was observed in the stimulation index for these islets in the presence of absence of agarose microspheres.

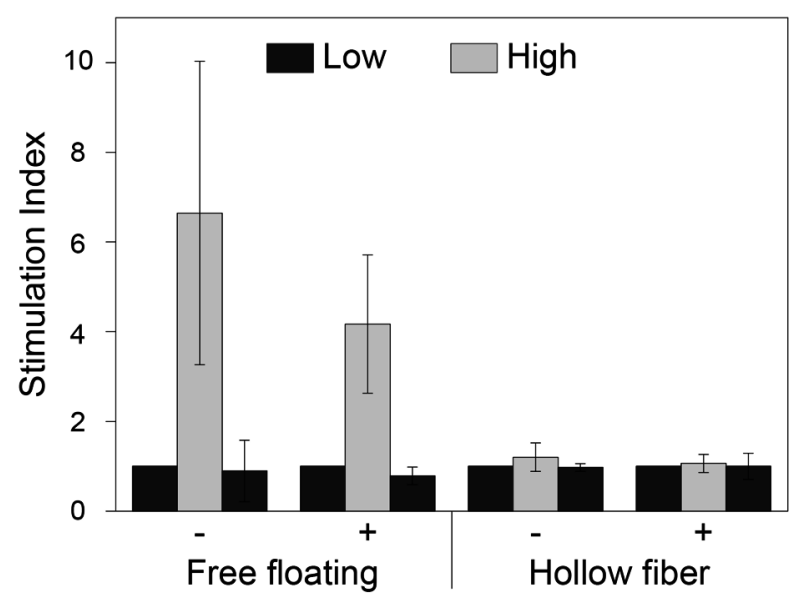

Figure 4.8: MIN6 pseudo-islet functionality in-vitro. Stimulation indexes of free floating MIN6 pseudo-islets and encapsulated pseudo-islets in PESM multibore hollow fibers with (+) and without (-) agarose macrospheres.

\subsubsection{In vitro human islet functionality}

Similarly as determined for MIN6 aggregates, which served merely as a model, the functionality of human islets encapsulated in PESM multibore hollow fibers was as- 
sessed. A glucose induced insulin secretion test (GIIST) was performed after 1 and 7 days incubation in medium. Free floating human islets appeared functional and, compared to day 1 , even showed an increase in the stimulation index at day 7 . Contrary, encapsulated human islets showed no functional behavior both at day 1 and 7 (Fig 4.9A). Histological sections stained with hematoxylin and eosin revealed that islets encapsulated were intact (Fig 4.9B). Staining histological sections for cell apoptosis using a TUNEL assay (green) and insulin (red) revealed that the islets contain cells positive for TUNEL but only a few cells positive for insulin (Figure 4.9C).
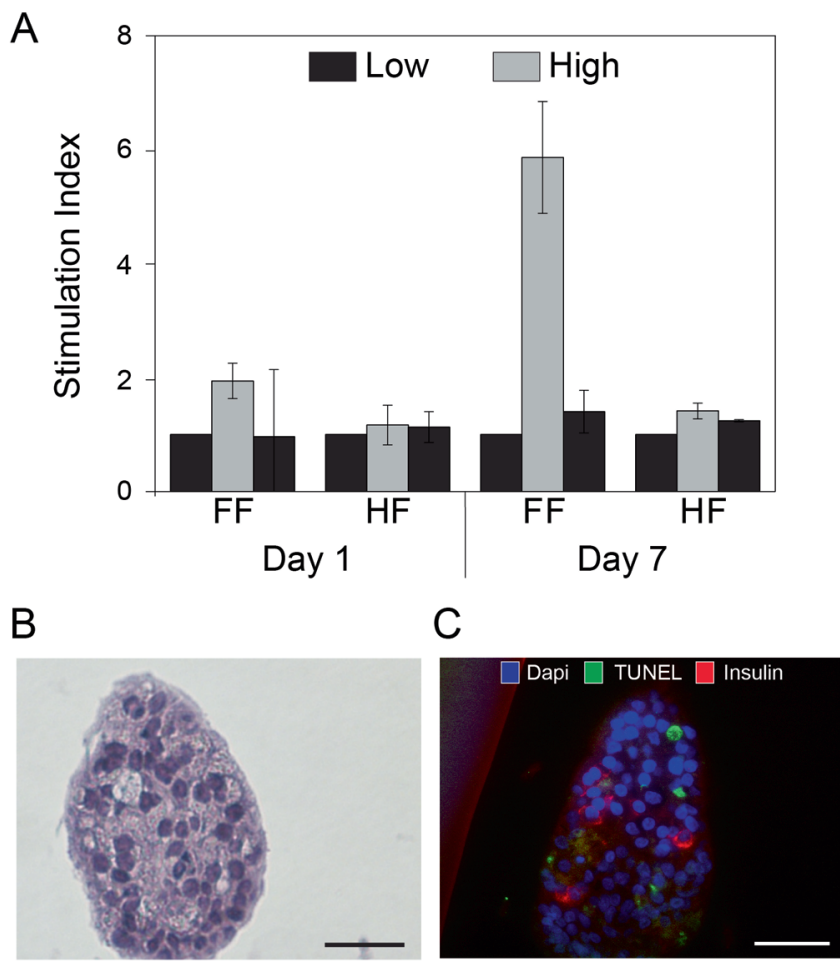

Figure 4.9: Human islet functionality in vitro. A) Stimulation indexes of free floating (FF) and islets encapsulated in the PESM multibore hollow fiber (HF) at day 1 and 7. B) Hematoxylin and eosin stained encapsulated islet. Scale bar $25 \mu \mathrm{m}$. C) Islet stained with TUNEL (green), insulin (red), and Dapi (blue). Scale bar $25 \mu \mathrm{m}$. 


\subsubsection{Oxygen generation from PDMS calcium peroxide cylinders}

The results described above reveal a low functionality of islets encapsulated in the bores of the hollow fibers which may be due to a low oxygen supply. As depicted in figure 4.1 some of the bores may be filled with an oxygen generating material to overcome the time necessary for adequate oxygen supply by vascularization. Based on the method Pedraza et al.(23) who applied calcium peroxide particles embedded in PDMS disks as oxygen generating composites, PDMS/calcium peroxide cylinders fitting the bores of the multibore hollow fiber were prepared (Fig 4.10A). The generation of oxygen from these cylinders placed in the multibore fiber and incubation in PBS was measured using an oxygen sensor (Fig 4.10B).

The geometries of the cylinders prepared and disk as described by Pedraza et al. have differentt surface to volume ratios and for comparison data were presented in table 4.2 .

Table 4.2: Surface and volume of the PDMS calcium peroxide disk and cylinder

\begin{tabular}{|c|c|c|c|c|c|}
\hline & \multicolumn{2}{|l|}{ Surface } & \multicolumn{2}{|l|}{ Volume } & \multirow{2}{*}{ Surface to volume ratio } \\
\hline & Per unit & $\begin{array}{ll}\% & \text { of } \\
\text { disk } & \end{array}$ & Per unit & $\begin{array}{ll}\% & \text { of } \\
\text { disk } & \end{array}$ & \\
\hline disk & $188.5 \mathrm{~mm}^{2}$ & 100 & $\begin{array}{l}78.5 \\
\mathrm{~mm}^{3}\end{array}$ & 100 & $1: 0.42$ \\
\hline cylinder & $39.5 \mathrm{~mm}^{2}$ & 16 & $6.4 \mathrm{~mm}^{3}$ & 8 & $1: 0.21$ \\
\hline
\end{tabular}

As shown in Figure 4.10C no differences were observed in the release rate of oxygen from cylinders incubated in PBS or a construct in which cylinders were inserted in the multibore hollow fiber and subsequently incubated in PBS. The fast diffusion of water induces a high rate of oxygen generation which likely may only have a positive effect in the short term but was insufficient to give a positive effect on islet function at longer implantation times. 
A

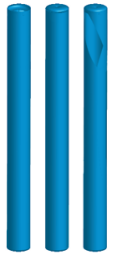

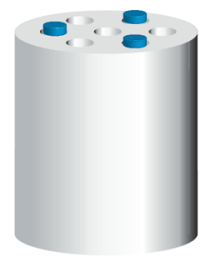

B
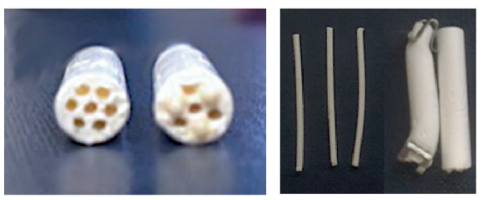

Cylinder with $\mathrm{O}_{2}$ generating material

C

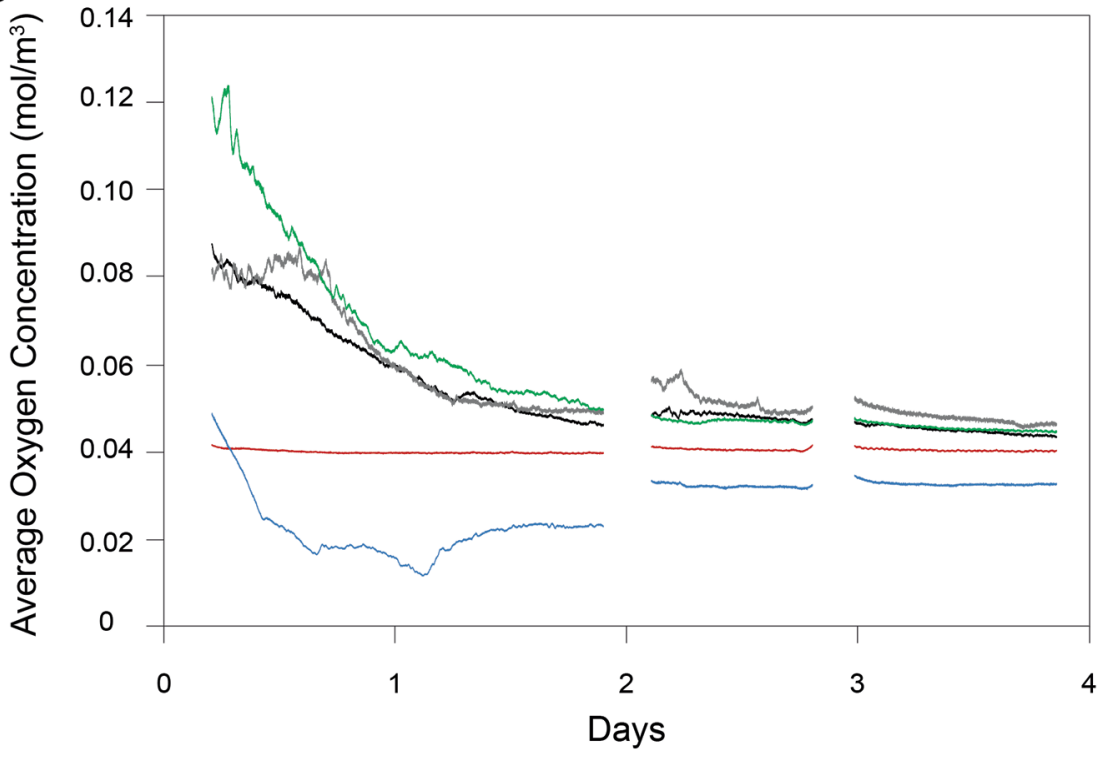

- HF - Blank - Cylinder - HF with cylinder - HF with cylinder and staples

Figure 4.10: A) Schematic overview of the oxygen generating PDMS/calcium peroxide cylinders and their insertion into the multibore hollow fiber (HF). B) Overview of the different conditions applied in oxygen release measurements (from left to right); empty multibore hollow fiber, multibore hollow fiber with three cylinders, three cylinders, and a closed multibore. C) Oxygen concentration as a function of time for the different devices incubated in PBS (empty hollow fiber in blue, three cylinders in black, multibore hollow fiber containing three cylinders in grey, closed multibore hollow fiber with three cylinders in green). PBS oxygen concentration at the measuring conditions in red 


\subsection{Discussion}

Encapsulation of islets of Langerhans in a PESM multibore hollow fiber was evaluated as an approach towards the development of an implantable glucose responsive device. Such a device may meet the requirements of: 1) protection against immunological reactions to donor islets 2) protection to induced stresses which lead to cell death and 3) avoiding hypoxia conditions by induction of a well-integrated microvasculature or by the generation of oxygen. Meeting these requisites would overcome the $60-70 \%$ loss of functional donor islets in current clinical practice by injection in the portal vein and their residence in the liver(1). In applying this transplantation method islets are exposed to blood which initiates the instant blood mediated inflammatory reaction leading to cell death. Additionally, high concentrations of immunosuppressive drugs, lipids, and glucose in the liver have a detrimental effect on islet survival(2-5).

In the development of implantable devices for the encapsulation of islets research has mainly focused on hollow fibers and a sealed pouch known as the TheraCyte ${ }^{\mathrm{TM}}$ system $(15,16,27)$. In all cases islets are surrounded by a protective membrane with small pore size. The design protects islets from contact with host immune cells and thus avoids the use of immunosuppressive drugs. Importantly, the diffusion of molecules like glucose and insulin, nutrients and waste products and oxygen should be high in order to retain viable islets. A major problem encountered in the viability of encapsulated islets is related to diffusion distances. When these distances are larger than $200 \mu \mathrm{m}$ cell death readily occurs $(28,29)$. A way to reduce diffusion distances in the application of hollow fibers is the use of multibore hollow fibers. Such fibers combine large surface areas with small dimensions, good mechanical properties, and the implant design is versatile for different functions may be allocated to the bores. The PESM fiber investigated for islet encapsulation had a diameter of $4 \mathrm{~mm}$ and contained 7 bores with a diameter of $900 \mu \mathrm{m}$. The diffusion rate through the fiber is determined by the pore size of $20 \mathrm{~nm}$ at the wall of the bores. Convection experiments revealed no limitations of permeance of water, glucose or insulin and somewhat lower convection of proteins like BSA or IgG at pressures in between 0.01 bar to 0.5 bar. 
Although the in vitro biocompatibility of the poly(ether sulfone) was shown, the in vivo tissue response was unknown. Implantation of fibers $(1 \mathrm{~cm})$ in the EFP of mice revealed fast cell infiltration in the membrane up to the selective layer of the bore walls. However, also a fibrous capsule was formed around the fiber suggesting a tissue response to the material.

An important factor affecting cell survival is the diffusion distance of nutrients to the cells. When this exceeds more than $200 \mu \mathrm{m}$, it is known that cell survival could be negatively affected $(28,29)$. Clustering of islets in a macro encapsulation device can lead to the formation of a large (millimeter size) tissue clumps, which negatively influences efficient mass transport ultimately detrimental for islet survival and $\beta$ cell function(30). Encapsulation of pseudo-islets in the multibore hollow fiber resulted in clustering of islets, leading to increased diffusion distances of molecules and consequently to disintegration of the islets. Disintegration of islets was observed already within $24 \mathrm{~h}$ and the GIIST revealed that the islets were not responding to changes in glucose concentrations. Combining agarose macrospheres $(150 \mu \mathrm{m}$ to $350 \mu \mathrm{m})$ with islets before seeding prevented clustering leading to a more homogeneous distribution of islets throughout the bores. Although islets were better dispersed the GIIST showed that islets were not able to react adequately to changes in glucose levels as no increase in insulin secretion could be detected.

The function test revealed the islets non-functional response, which might be related to low oxygen levels present under the in vitro conditions applied. The distribution of islets in the bores, could have caused too high cell density with consequently too low oxygen levels. More recently Pedraza et al. developed a method for local oxygen supply using composites of calcium peroxide and PDMS(23). Cylinders fitting the bores of the hollow fiber were prepared and a device with the oxygen releasing cylinders was made. The oxygen concentration over time was determined and results showed a full release of oxygen within $24 \mathrm{~h}$. The small dimensions of the cylinders and the fast oxygen release was considered not suitable and no further tests were performed. 
In conclusion, although insulin and glucose are able to pass the PESM multibore hollow fiber membrane and selective layer of the bores, the GIIST on macroencapsulated pseudo-islets showed that the diffusion distances hindered an efficient exchange of glucose and insulin. Even when clustering was prevented by the addition of the macrospheres, no improvement in the GIIST was obtained. The design of the commercial multibore hollow fiber only provides oxygen generated from the PDMS $\mathrm{CaO}_{2}$ cylinders for a period of $24 \mathrm{~h}$. Because oxygen supply should be provided for at least 2 weeks a redesign accounting for the diffusion properties for oxygen and water is necessary in order to obtain a macro encapsulation device suitable for clinical islet transplantation. 


\section{References}

1. de Vos, P., Faas, M.M., Strand, B., and Calafiore, R. Alginate-based microcapsules for immunoisolation of pancreatic islets. Biomaterials 27, 5603, 2006.

2. Kort, H.D., Koning, E.J.D., Rabelink, T.J., Bruijn, J.a., and Bajema, I.M. Islet transplantation in type 1 diabetes. Bmj 342, d217, 2011.

3. Beck, J., Angus, R., Madsen, B., Britt, D., Vernon, B., and Nguyen, K.T. Islet encapsulation: Strategies to enhance islet cell functions. Tissue Engineering 13, 589, 2007.

4. Silva, A.I., and Mateus, M. Development of a polysulfone hollow fiber vascular bio-artificial pancreas device for in vitro studies. Journal of Biotechnology 139, 236, 2009 .

5. Van Belle, T.L., Coppieters, K.T., and Von Herrath, M.G. Type 1 diabetes: Etiology, immunology, and therapeutic strategies. Physiological Reviews 91, 79, 2011.

6. Kang, J., Erdodi, G., Kennedy, J.P., Chou, H., Lu, L., and Grundfest-Broniatowski, S. Toward a bioartificial pancreas: Diffusion of insulin and IgG across immunoprotective membranes with controlled hydrophilic channel diameters. Macromolecular Bioscience 10, 369, 2010.

7. Ikeda, H., Kobayashi, N., Tanaka, Y., Nakaji, S., Yong, C., Okitsu, T., Oshita, M., Matsumoto, S., Noguchi, H., Narushima, M., Tanaka, K., Miki, A., Rivas-Carrillo, J.D., Soto-Gutierrez, A., Navarro-Alvarez, N., Jun, H.S., Tanaka, N., and Yoon, J.W. A newly developed bioartificial pancreas successfully controls blood glucose in totally pancreatectomized diabetic pigs. Tissue Engineering 12, 1799, 2006.

8. Figliuzzi, M., Cornolti, R., Plati, T., Rajan, N., Adobati, F., Remuzzi, G., and Remuzzi, A. Subcutaneous xenotransplantation of bovine pancreatic islets. Biomaterials $26,5640,2005$.

9. Erdodi, G., Kang, J., Yalcin, B., Cakmak, M., Rosenthal, K.S., GrundfestBroniatowski, S., andKennedy, J.P. A novel macroencapsulating immunoisolatory device: The preparation and properties of nanomat-reinforced amphiphilic co-networks deposited on perforated metal scaffold. Biomed Microdevices 11, 297, 2009. 
10. Suzuki, K., Bonner-Weir, S., Trivedi, N., Yoon, K.H., Hollister-Lock, J., Colton, C.K., and Weir, G.C. Function and survival of macroencapsulated syngeneic islets transplanted into streptozocin-diabetic mice. TRANSPLANTATION 66, 21, 1998.

11. Grundfest-Broniatowski, S.F., Tellioglu, G., Rosenthal, K.S., Kang, J., Erdodi, G., Yalcin, B., Cakmak, M., Drazba, J., Bennett, A., Lu, L., and Kennedy, J.P. A new bioartificial pancreas utilizing amphiphilic membranes for the immunoisolation of porcine islets a pilot study in the canine. ASAIO Journal 55, 400, 2009.

12. Monaco, A.P., Maki, T., Ozato, H., Carretta, M., Sullivan, S.J., Borland, K.M., Mahoney, M.D., Chick, W.L., Muller, T.E., Wolfrum, J., and Solomon, B. Transplantation of islet allografts and xenografts in totally pancreatectomized diabetic dogs using the Hybrid Artificial Pancreas. Annals of Surgery 214, 339, 1991.

13. Loudovaris, T., Jacobs, S., Young, S., Maryanov, D., Brauker, J., and Johnson, R.C. Correction of diabetic nod mice with insulinomas implanted within Baxter immunoisolation devices. Journal of molecular medicine (Berlin, Germany) 77, 219, 1999.

14. Lacy, P.E., Hegre, O.D., Gerasimidi-vazeou, A., Gentile, F.T., Dionne, E., Science, S., Series, N., Dec, N., and Dionne, K.E. Maintenance of Normoglycemia in Diabetic Mice by Subcutaneous Xenografts of Encapsulated Islets Science 254, 1782, 1991.

15. Brauker, J., Martinson, L.A., Young, S.K., and Johnson, R.C. Local inflammatory response around diffusion chambers containing xenografts: Nonspecific destruction of tissues and decreased local vascularization. TRANSPLANTATION 61, 1671, 1996.

16. Barkai, U., Weir, G.C., Colton, C.K., Ludwig, B., Bornstein, S.R., Brendel, M.D., Neufeld, T., Bremer, C., Leon, A., Evron, Y., Yavriyants, K., Azarov, D., Zimermann, B., Maimon, S., Shabtay, N., Balyura, M., Rozenshtein, T., Vardi, P., Bloch, K., De Vos, P., and Rotem, A. Enhanced oxygen supply improves islet viability in a new bioartificial pancreas. Cell Transplant 22, 1463, 2013.

17. Silva, A.I., de Matos, A.N., Brons, I.G., and Mateus, M. An overview on the development of a bio-artificial pancreas as a treatment of insulin-dependent diabetes mellitus. Medicinal Research Reviews 26, 181, 2006. 
18. Lehmann, R., Zuellig, R.A., Kugelmeier, P., Baenninger, P.B., Moritz, W., Perren, A., Clavien, P.A., Weber, M., and Spinas, G.A. Superiority of small islets in human islet transplantation. Diabetes 56, 594, 2007.

19. De Bartolo, L., Morelli, S., Rende, M., Campana, C., Salerno, S., Quintiero, N., and Drioli, E. Human hepatocyte morphology and functions in a multibore fiber bioreactor. Macromolecular Bioscience 7, 671, 2007.

20. Altman, J.J. The bioartificial pancreas: Macroencapsulation of insulin secreting cells in hollow fibers. Journal of Diabetic Complications 2, 68, 1988.

21. Meneghello, G., Parker, D.J., Ainsworth, B.J., Perera, S.P., Chaudhuri, J.B., Ellis, M.J., and De Bank, P.A. Fabrication and characterization of poly(lactic-co-glycolic acid)/polyvinyl alcohol blended hollow fibre membranes for tissue engineering applications. Journal of Membrane Science 344, 55, 2009.

22. Bettahalli, N.M.S. Membrane supported scaffold architectures for tissue engineering Narasimha Murthy Srivatsa Bettahalli 2011.

23. Pedraza, E., Coronel, M.M., Fraker, C.A., Ricordi, C., and Stabler, C.L. Preventing hypoxia-induced cell death in beta cells and islets via hydrolytically activated, oxygen-generating biomaterials. Proc Natl Acad Sci U S A 109, 4245, 2012.

24. Spijker, H.S., Ravelli, R.B.G., Mommaas-Kienhuis, A.M., Van Apeldoorn, A.A., Engelse, M.A., Zaldumbide, A., Bonner-Weir, S., Rabelink, T.J., Hoeben, R.C., Clevers, H., Mummery, C.L., Carlotti, F., and De Koning, E.J.P. Conversion of Mature Human $\beta$-Cells into Glucagon- Producing $\alpha$-Cells. Diabetes 62, 2471, 2013.

25. Hilderink, J., Spijker, S., Carlotti, F., Lange, L., Engelse, M., van Blitterswijk, C., de Koning, E., Karperien, M., and van Apeldoorn, A. Controlled aggregation of primary human pancreatic islet cells leads to glucose-responsive pseudoislets comparable to native islets. J Cell Mol Med 17, 12555, 2015.

26. Szot, G.L., Koudria, P., and Bluestone, J.A. Transplantation of pancreatic islets into the kidney capsule of diabetic mice. J Visualized Exp 2007.

27. Loudovaris, T., Jacobs, S., Young, S., Maryanov, D., Brauker, J., and Johnson, R.C. Correction of diabetic nod mice with insulinomas implanted within Baxter immunoisolation devices. J Mol Med 77, 219, 1999. 
28. Pareta, R.A., Farney, A.C., and Opara, E.C. Design of a bioartificial pancreas. Pathobiology 80, 194, 2013.

29. Schweicher, J., Nyitray, C., and Desai, T.A. Membranes to achieve immunoprotection of transplanted islets. Front Biosci Landmark 19, 49, 2014.

30. Lehmann, R., Zuellig, R.A., Kugelmeier, P., Baenninger, P.B., Moritz, W., Perren, A., Clavien, P.A., Weber, M., and Spinas, G.A. Superiority of small islets in human islet transplantation. DIABETES 56, 594, 2007. 



\section{Chapter 5}

\section{Opening the white box in tissue}

engineering: visualization of cell aggregates in optically scattering scaffolds

Milou Groot Nibbelink, Khalid Daoudi, Sanne Slegers, Diederik Grootendorst, Maura Dantuma, Wiendelt Steenbergen, Marcel Karperien, Srirang Manohar, Aart van Apeldoorn 


\subsection{Abstract}

The non-invasive and longitudinal imaging of cells or cell aggregates in large optically scattering scaffolds is still a largely unresolved problem in tissue engineering. In this work, we investigated the potential of near-infrared (NIR) photoacoustic tomography imaging to address this issue. We used clinically relevant sizes of highly light scattering polyethersulfone (PESM) multibore hollow fiber scaffolds seeded with cells. Since cells have little optical absorption at NIR wavelengths, we studied labelling of cells with absorbers. Four NIR labels were examined for their suitability based on absorption characteristics, resistance to bleaching, and influence on cell viability. On the basis of these criteria, carbon nanoparticles proved most suitable in a variety of cells. For photoacoustic imaging, we used a research setup, based on a computed tomography geometry. As proof of principle, using this imager we monitored the distribution and clustering of labelled rat insulinoma $\beta$ (INS1E) cell aggregates in the scaffolds. This was performed for the duration of one week in a non-destructive manner. The results were validated using fluorescence imaging, histology and light microscopy imaging. Based on our findings, we conclude that photoacoustic tomography is a powerful tool for the non-destructive imaging of cells in optically scattering tissue-engineered scaffolds. 


\subsection{Introduction}

Depending on their clinical application, tissue engineered scaffolds vary widely in shape and dimensions, and comprise different types of polymeric biomaterials. Studying cell behavior and distribution within such tissue engineered scaffolds is important. While many methods are available today, none are able to perform this adequately. Histology, only allows for endpoint analysis since it is a destructive technique. Scanning electron microscopy is also not applicable for real-time monitoring since measurements are performed in vacuum, and further can only visualize the surface layers of the scaffold due to scattering, and attenuation of the electron beam. Optical techniques like confocal fluorescence microscopy, optical coherence tomography(OCT), and fluorescent mediated diffuse optical tomography have the main advantage of being non-destructive and show high contrast for appropriately labelled specimens. However, these optical techniques are less useful in scattering media such as most porous scaffolds $(1,2)$ and usually only allow imaging inside scaffolds up to maximally a few hundred micrometers deep with sufficient resolution.

A method that is attracting great interest in imaging optical absorption contrast in highly scattering media is photoacoustic (PA) also called optoacoustic imaging(3-5). In this method a short pulse of light is used to irradiate the sample of interest. The instantaneous absorption of light by naturally occurring chromophores, or extraneously added dyes, induces a localized temperature rise, which results in the generation of ultrasound pulses via the thermoelastic effect. Using ultrasound transducers placed outside the medium it is possible to detect these ultrasound waves even those arising from large depths, thanks to their weak scattering and attenuation in soft tissues(3, 4). An image reconstruction algorithm is then utilized to ascertain the location of the ultrasound sources, allowing for three-dimensional visualization of absorber distribution $(3,4)$. The PA technique in a microscopic variant (PAM) has been applied for high resolution imaging of scaffold degradation of polylactic glycolic acid (PLGA) inverse opal scaffolds, and for the visualization of melanoma cells inside these scaffolds $(6,7)$. In addition, in similar scaffolds the neovascularization in a mouse model 
was monitored by combining PAM with OCT (8). Zhang et al. described the addition of a contrast agent to cells in order to visualize them with $\operatorname{PAM}(9)$. The addition of the contrast agent based in 1-(4,5-dimethyl-2-thiazolyl)-3,5-diphenylformazan (MTT formazan) to encapsulated cells in their PLGA inverse opal scaffolds, showed enhanced visualization of the cells using PAM. Zhang et al. describe that the use of other tetrazolium-formazan system could enable PAM imaging at other wavelengths. This is necessary as MTT formazan crystals have a strong absorption in the region of $500 \mathrm{~nm}$ to $700 \mathrm{~nm}(9)$.

Using different wavelengths for imaging is possible with photoacoustic imaging. This opens the door to imaging of co-cultures and the evaluation of (immune) histochemistry in both 2D and 3D dimensions. Zhang et al. showed the use of OR-PAM for visualization of different types of cells in a co-culture samples with imaging depths of $1 \mathrm{~mm}(10)$. PAM provides excellent resolutions but is limited to shallow depth imaging. Recently, a commercially available hybrid photoacoustic/ultrasound system (11) was used to image single-walled carbon nanotube (SWCNT)-incorporated PLGA (SWCNT-PLGA) implanted $2 \mathrm{~mm}$ deep in a rats. The scaffolds were successfully visualized using PA imaging at 7 and 14 days post-surgery. While this study showed clearly the capability of PA imaging to visualize the scaffold in vivo at two time points, it did not image cells and their fate inside the scaffold.

In this work, we use a PA computed tomography (CT) imager based on acquiring multiple projections around the object, to image cell aggregates inside large tissue engineered scaffolds over time. We used a polyethersulfone (PESM) multibore hollow fiber as the scaffold. This PESM scaffold possesses clinically relevant thickness of $4 \mathrm{~mm}$ in diameter (and centimeters in length). These specific multibore hollow fibers are commercially available and used for water treatment. In literature they are described as a hepatocyte bioreactor and a medium perfusion system for three-dimensional tissue engineered constructs $(12,13)$. These studies showed that the multibore hollow fiber was biocompatible and did not foul $(12,13)$. 
The scaffold is developed for macro-encapsulation of Islets of Langerhans for extrahepatic transplantation in patients with Type I Diabetes. The scaffolds were seeded with rat insulinoma cells or primary bovine chondrocytes, as a model for Islets of Langerhans, to investigate the performance of the imaging approach and optimize it for future in vivo applications. Near infrared (NIR) wavelengths showed low scaffold signal background and deep penetration depths compared to visible wavelengths. Since cells show low optical absorption at these wavelengths, prior labeling of the cells is required. We therefore, investigated four NIR dyes for their optical absorption characteristics, resistance to bleaching, signal intensity and influence on cell viability, to select the most optimal label for PA tomography. The PA images of the labeled cells in the scaffolds were validated using fluorescence imaging, histology and light microscopy imaging.

\subsection{Materials and methods}

\subsubsection{Cell culture}

As Islets of Langerhans are not abundantly available, cell aggregates with a diameter of 100 or $200 \mu \mathrm{m}$ of either rat insulinoma (INS1E) $\beta$ cells or primary bovine chondrocytes were used as a model for islets. The INS1E cells (provided by Dr. B. Guigas, LUMC, Leiden, the Netherlands and Dr. P. Maechler, University Medical Center, Geneva, Switzerland) were cultured in RMPI (Gibco) with 2.05 mM L-glutamine (Invitrogen) supplemented with $5 \%$ (v/v) fetal bovine serum (FBS, Lonza), $100 \mathrm{U} / \mathrm{mL}$ penicillin and $100 \mathrm{mg} / \mathrm{mL}$ streptomycin (Gibco), $10 \mathrm{mM}$ HEPES, $1 \mathrm{~mm}$ sodium pyruvate, and $50 \mu \mathrm{M}$ freshly added beta-mercaptoethanol (Gibco). Primary bovine chondrocytes, obtained from calves collected from the local abattoir, were cultured in Dulbecco's Modified Eagle's Medium (DMEM, Gibco) supplemented with $10 \%$ (v/v) FBS (Lonza), $0.1 \mathrm{~mm}$ non-essential amino acids (Sigma), $0.02 \mathrm{~mm}$ Ascorbic-Acid-2Phosphate (ASAP), $100 \mathrm{U} / \mathrm{mL}$ penicillin and $100 \mathrm{mg} / \mathrm{mL}$ streptomycin (Gibco), 1\% Proline (Sigma) $\left(37^{\circ} \mathrm{C}, 5 \% \mathrm{CO}_{2}\right)$. 


\subsubsection{Cell labeling}

Performances of four cell labels were evaluated: DiR, carbon nanoparticles (CNP), Sienna $^{+}$, and Endorem(14-17). DiR (Invitrogen) is near IR fluorescent, lipophilic carbocyanine $\mathrm{DiOC}_{1} 8(7)(\mathrm{DiR})$ with a fluorescence excitation at $750 \mathrm{~nm}$ and an emission at $780 \mathrm{~nm}$. and two superparamagnetic iron oxide particles. DiR diffuses laterally with the plasma membrane of cells. CNP (India Ink, Rotring) were collected from Indian ink. Only particles smaller than $0.22 \mu \mathrm{m}$ were used as the Indian ink was filtered through a $0.22 \mu \mathrm{m}$ filter. Both Sienna ${ }^{+}$and Endorem are superparamagnetic iron oxide particles (SPIOs). Sienna ${ }^{+}$(EndoMagnetics Ltd. Cambridge) are carboxydextran-coated iron oxide particles. Endorem (Guerbet) are dextran coated iron oxide particles. Cells were labelled with $4 \mu \mathrm{M}$ DiR following manufacturers protocol (Invitrogen). Cells were incubated overnight with Sienna ${ }^{+}(200 \mu \mathrm{g} / \mathrm{mL})$ and Endorem $(200 \mu \mathrm{g} / \mathrm{mL})$ and CNP (diluted 5000x in medium). The same protocols were maintained for all cell types.

\subsubsection{Agarose microwell fabrication and controlled cell aggregate formation}

These agarose microwell chips are a platform to create cell aggregates in a controlled manner. They were used for validation, as their properties are well known. Sterile agarose microwells were fabricated as described previously(18). In short, polydimethylsiloxane (PDMS) negative molds containing either $200 \mu \mathrm{m}$ or $400 \mu \mathrm{m}$ wells were sterilized with $70 \%$ ethanol. $3 \%$ UltraPure $^{\mathrm{TM}}$ agarose (Gibco Invitrogen) was dissolved in PBS. The solution was heated to $100^{\circ} \mathrm{C}$ in a microwave oven. Molds were placed inside 6 wells plate and filled with $8 \mathrm{~mL}$ of $3 \%$ agarose solution. The plates were centrifuged at $300 \mathrm{~g}$ for $1 \mathrm{~min}$ to remove air bubbles and stored at $4{ }^{\circ} \mathrm{C}$ for at least $30 \mathrm{~min}$. After the gel is formed, the molds were gently removed from the agarose using a sterile spatula. Using a sterile punching device, chips were punched out leaving a thin agarose wall on all sides to fit into a 12 wells plate. Chondrocytes or INS1E cells were then seeded onto the agarose chips (1.5 million chondrocytes/chip, 
and 1 million INS1Es/chip). To understand how many cells gave rise to the signal of 1 aggregate we calculated the amount of cells per aggregate. As the total amount of wells is known (2865 for $200 \mu \mathrm{m}$ wells in a chip and 1465 for $400 \mu \mathrm{m}$ wells in a chip) the total cell per aggregate could be determined exactly. This means that one chondrocyte aggregate contained 524 cells $(200 \mu \mathrm{m})$ or 1023 cells $(400 \mu \mathrm{m})$ and one INS1E aggregates contained 350 cells $(200 \mu \mathrm{m})$ or 683 cells $(400 \mu \mathrm{m})$. The plates were centrifuged at $150 \mathrm{~g}$ for a maximum of $1 \mathrm{~min}$ and $1 \mathrm{~mL}$ of medium was carefully added to the chips. After $24 \mathrm{~h}$ (Chondrocytes) or $48 \mathrm{~h}$ (INS1E) at $37^{\circ} \mathrm{C}$, if needed, aggregates were flushed out of the chips and used for seeding in the multibore hollow fiber.

\subsubsection{Multibore hollow fiber}

A modified poly(ether sulfone) (PESM) Multiboreßhollow fiber (Inge AG, Germany) was used to encapsulate the cells ( $1 \mathrm{~cm}$ pieces). The $4 \mathrm{~mm}$ single fiber consists of 7 bores with a diameter of approximately $0.9 \mathrm{~mm}$ each. The membrane has pores of $20 \mathrm{~nm}(12)$.

\subsubsection{Photoacoustic tomography}

The imager uses a 32-element curvilinear ultrasound detector array (Imasonic, Besancon) with a central frequency of $6.25 \mathrm{mHz}$ and $80 \%$ bandwidth. A 32-channel pulserreceiver system (Lecoeur Electronique, Paris) was used for data acquisition(19) at sampling rate of $80 \mathrm{mHz}$ and $60 \mathrm{~dB}$ gain. The detector is placed inside the water tank and connected to rotator stage (Fig 5.1A and B). 


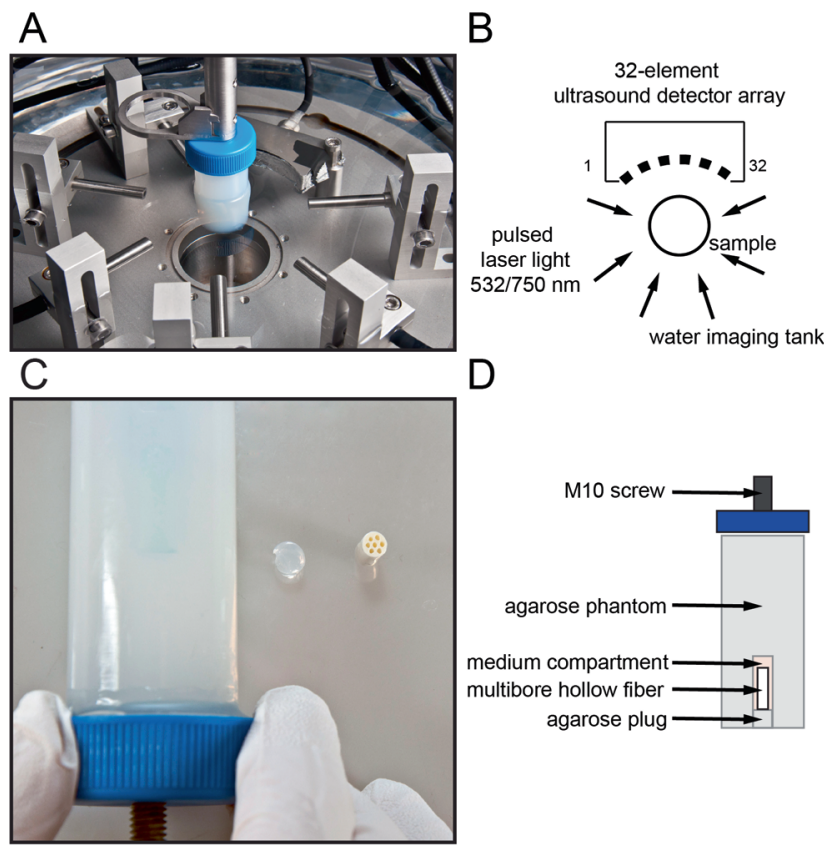

Figure 5.1: Overview of experimental set-up. A) Left agarose phantom, specially designed with a medium compartment. In the middle the agarose plug used to close the medium compartment. PESM multibore hollow fiber on the right. B) Schematic overview of the specially designed agarose phantom. C) Picture of the photoacoustic tomography setting, illumination from six fibers, agarose phantom in the middle, and the detector. The sample is fixed while ultrasound array and fibers are rotating. D) Schematic overview of the photoacoustic tomography setting.

Illumination is achieved using light from an optical parametric oscillator (Opotek, $700 \mathrm{~nm}$ to $950 \mathrm{~nm}$ ) pumped by a Q-switched Nd:YAG laser (Quanta-Ray, Spectra Physics) operating at $10 \mathrm{~Hz}$ repetition rate(19, 20) and delivering $5 \mathrm{n}$ sec pulses of about $28 \mathrm{~mJ}$. The laser is coupled into a fiber bundle, which splits into 7 branches of about $9 \mathrm{~mm}$ diameter. One fiber is used to monitor the delivered energy and the others are distributed around the sample (Fig 5.1A and B). The data are stored and reconstructed off line using back-projection algorithm(21).

Prior to each set of measurements, a calibration measurement was performed, using a phantom containing four horsetail hairs, to determine the CT imaging geometry 
such as center of rotation, position of detector elements and also the speed of sound in water $(20,21)$. The images of the scaffolds and their contents were obtained by performing 20 projections with 18 degrees steps.

\subsubsection{Investigation into an optimum near-infrared (NIR) photoacoustic cell label}

INS1Es were labelled with DiR, CNP, Sienna ${ }^{+}$, and Endorem. Then they were seeded (865.000 cells/chip) in a chip containing $400 \mu \mathrm{m}$ agarose microwells. After 1 day, agarose chips were fixed in 10\% Formalin (1h, RT) and washed with PBS $(3 \mathrm{x})$. To prevent loss of aggregates, a layer of agarose was placed on top of the chips. Agarose phantoms were made by embedding the agarose chips inside agarose containing $0.5 \%(\mathrm{v} / \mathrm{v})$ of IntraLipid@ $20 \%$. Chips were imaged with a pulsed laser energy of $20 \mathrm{~mJ} / \mathrm{cm}^{2}$ split over six fibers, using 20 projections of 18 degrees, 25 averages per image, and 1 slice.

Photostability examination of different labels was performed by illuminating different label solutions using a pulsed laser. The variation in the absorption spectra of DiR, CNP, Sienna ${ }^{+}$, and Endorem were measured using a spectrophotometer (UV probe 2.21). Labelling solutions were diluted to prevent oversaturation of the spectophotometer; DiR 1000x in ethanol, CNP 5000x in $\mathrm{dH}_{2} \mathrm{O}$, Sienna ${ }^{+}$and Endorem 1000x in $\mathrm{dH} 2 \mathrm{O}, 100 \%$ Ethanol or $100 \% \mathrm{dH}_{2} \mathrm{O}$ was used as reference and baseline, based on the solvent used. A cuvet was filled with $1.5 \mathrm{~mL}$ diluted label solution. Prior to the irradiation, a spectrum of each solution is measured, then the cuvet was illuminated using a $748 \mathrm{~nm}$ pulsed laser with an energy of $20 \mathrm{~mJ} / \mathrm{cm}^{2}$. Samples were illuminated 3 times during $15 \mathrm{~min}$. After each time interval, samples were mixed and the absorption spectrum was measured.

To test the effect of the labels on cell proliferation and activity, labelled INS1E cells were cultured for 1,3 or 7 days $(n=3)$. At day 1,3 , and 7 a Presto blue assay (Invitrogen) was performed following manufactures protocol (1h incubation). 


\subsubsection{End point photoacoustic imaging of labelled encapsulated cell aggregates}

DiR labelled bovine chondrocyte aggregates were seeded into six different PESM multibore hollow fibers by placing a $4 \mathrm{~mL}$ polyethylene tube on the tip of a $5 \mathrm{~mL}$ glass pipet. The cell suspension was then loaded followed by placing the hollow fiber inside the polyethylene tube. The end of the hollow fiber was closed by a surgical staple (Horizon, ligating clips). Finally the cell suspension was pipetted into the hollow fiber. This process was repeated at least 3 times, till all bores were filled. Finally, the other end of the hollow fiber was closed with surgical staples. Each time point (day 0 and 7) one hollow fiber containing DiR labelled cells were fixed in 10\% Formalin. Prior to imaging, the hollow fiber is placed in the agarose sample and imaged in transverse plane with a pulsed laser energy of $25 \mathrm{~mJ} / \mathrm{cm}^{2}$ split over 6 fibers. Hollow fibers were imaged using fluorescent cryotome (excitation $640 \mathrm{~nm}$, emission $712 \mathrm{~nm}$, slice thickness $30 \mu \mathrm{m}$, and exposure time of $5000 \mathrm{~m} \mathrm{sec})(22,23)$.

\subsubsection{Photoacoustic serial imaging of encapsulated labelled INS1E cell aggregates}

DiR and CNP labelled INS1E aggregates, with or without agarose macrospheres to prevent cell clustering (4\%, Agarose Bead Technologies, $150 \mu \mathrm{m}$ to $350 \mu \mathrm{m}$ ), were seeded into a four PESM multibore hollow fibers as described previously. A specially designed agarose phantom containing a medium compartment was created at each measurement day in a sterile environment and filled with normal culture medium without phenol red (Figure 5.1C). Each time the hollow fibers were placed inside the medium compartment (Figure 5.1D). For each hollow fiber an agar sample with medium compartment was made. The phantoms were closed using an agarose plug and sealed with a layer of agarose. Samples were imaged at day 0, 3, and 7 (Fluence is $20 \mathrm{~mJ} / \mathrm{cm}^{2}, 10$ slices in transverse plane, 25 averages, 20 projections, and 18 degrees). Right after each measurement point the hollow fiber was placed back into the culture medium to prevent any cells apoptosis. After one week, hollow fibers were fixed in 
10\% Formalin and embedded in paraffin. Sections were deparaffinized. Hydrated, and incubated with proteinase K ( 5 min, RT). After which they were stained for insulin using a rabbit anti insulin (Santa Cruz) primary antibody and a goat anti rabbit alexa 568 (Invitrogen) secondary antibody. Subsequently sections were stained for cell apoptosis using a TUNEL assay (Roche) according to manufacturer's protocol. Sections were then mounted using a Dapi aqueous mounting medium (Vectashield hard set with Dapi). Thereby directly counterstaining the nuclei of the cells with Dapi. A paraffin section was treated with Pulmozyme as a positive control for the TUNEL assay.

\subsubsection{Statistical analysis}

A two paired Student's t-test was performed to assess statistical differences for Presto blue results $(\mathrm{p}<0.05)$.

\subsection{Results}

\subsubsection{Identification of an optimal near-infrared photoacoustic cell label}

The relative performances of four cell labels were evaluated: DiR, carbon nanoparticles (CNP), and two superparamagnetic iron oxide particles (SPIOs): Sienna ${ }^{+}$and Endorem(14-17) with their respective absorbance spectrum depicted in figure 5.2. 


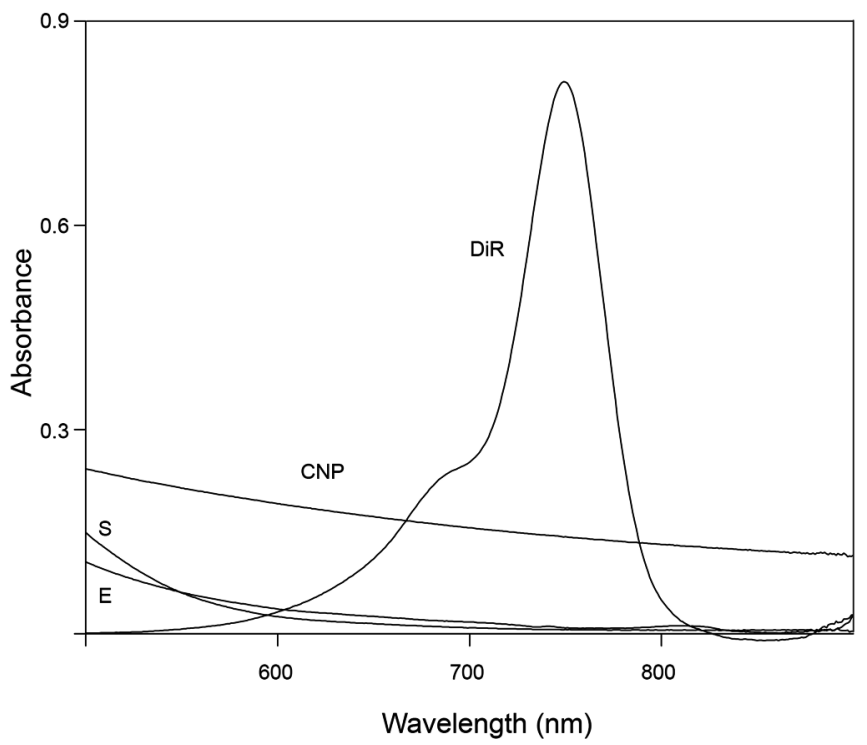

Figure 5.2: Absorption spectra of the 4 NIR labels (DiR, CNP, Sienna $^{+}$, Endorem).

Figure 5.3A shows the PA image of the complete field-of-view of an agarose microwell chip seeded with DiR labelled primary bovine chondrocytes. The region marked by the rectangle is magnified in figure 5.3B. Individual wells containing approximately 960 cells are seen as individual spots with a diameter of approximately $200 \mu \mathrm{m}$ in the PA image. These cell numbers per aggregate were based on the total amount of cells seeded divided by the number of well in each chip. The PA signal of each individual aggregate accurately co-localized with the light microcopy image (Fig 5.3C). The results showed that labeling chondrocytes with $\mathrm{DiR}$ was successful, and the DiR labeled cells produced PA signals. Similar PA images of agarose chips were obtained using the other 3 labels, but with different average spot intensities from CNP with the highest signal to Sienna ${ }^{+}$and Endorem with the lowest signal (Fig 5.3D). 

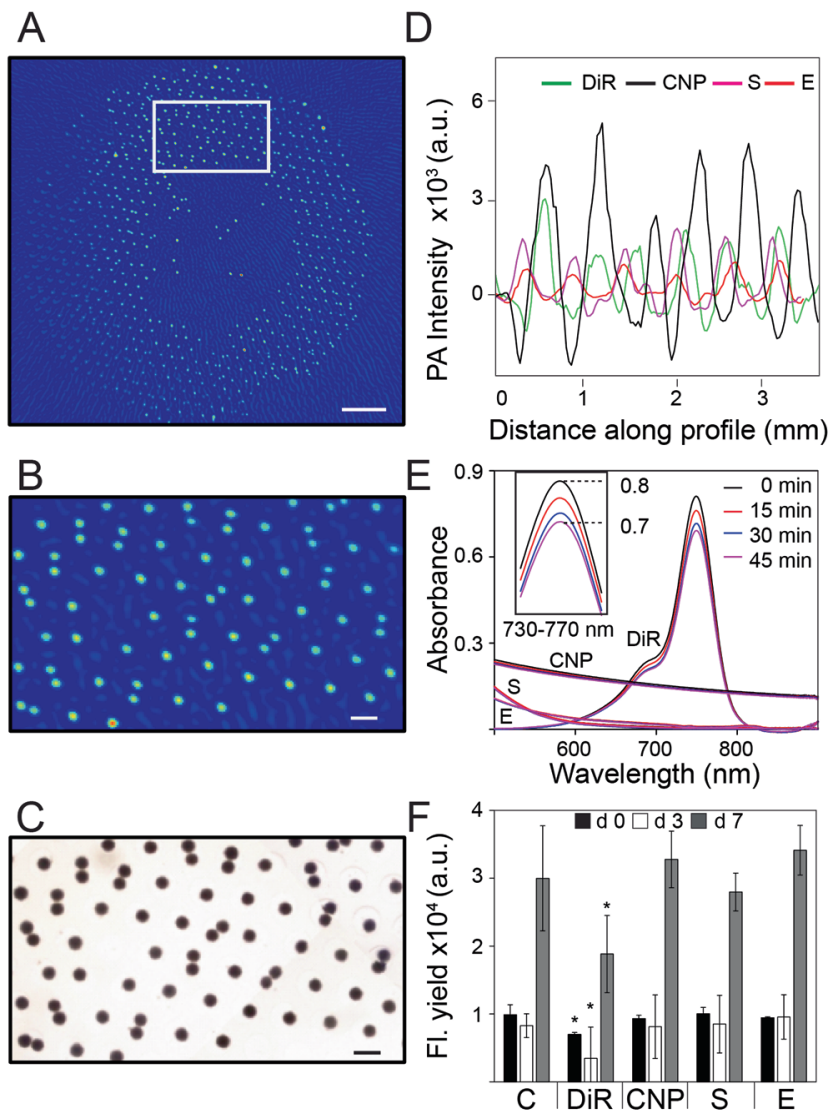

Figure 5.3: Finding the optimal near-infrared photoacoustic (PA) cell label. A) PA image of complete field-of-view of agarose microwell chip seeded with DiR labelled chondrocytes. Scale bar $2 \mathrm{~mm}$ B) Magnification of boxed area in figure A. Scale bar $400 \mu \mathrm{m} \mathrm{C)}$ Corresponding light microscopy image of the same agarose chip area. Scale bar $400 \mu \mathrm{m}$ D) Profile along rows of wells within the agarose chip, with signal intensities for DiR (green), CNP (black), Sienna $^{+}$(red), and Endorem (purple) labelled INS1E cell aggregates. E) Photoinstability of DiR as the time evolution of optical absorption spectra with pulsed light exposure. F) Presto Blue assay on labelled INS1E cells showing cell activity in terms of fluorescence signal after 0 (black), 3 (white), and 7 (grey) days of culture. (* $\mathbf{p}<0.05$, compared to control of corresponding day). 
For the most optimal PA signal, one should take cell type dependent label efficiencies into account. Figure 5.3D depicts the profile of PA intensities from a row of INS1E aggregates obtained per label. For INS1E cell aggregates the PA response from CNP labelled cells showed the highest signal intensity compared to the other labels from CNP with the highest signal to Sienna ${ }^{+}$and Endorem with the lowest signal. We also performed comparable measurements using primary bovine chondrocytes to assess cell type dependent effects (Fig 5.4).

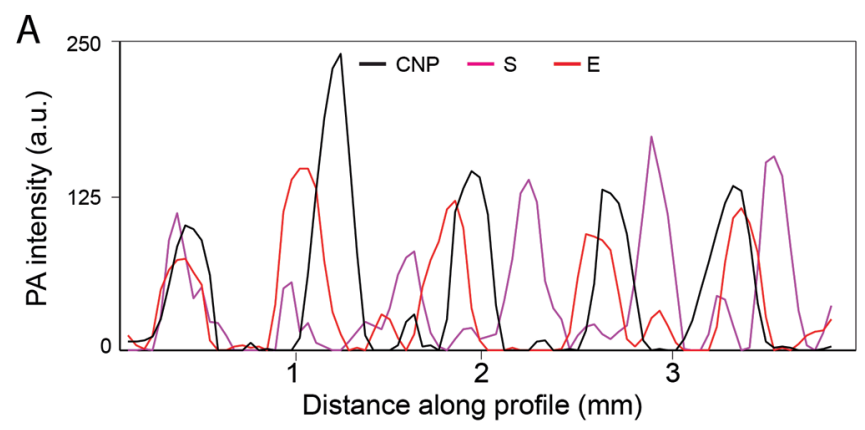

Figure 5.4: Cell type dependent phenomena. Profile along a row off aggregates within the agarose chip, with signal intensities for CNP (black), Sienna ${ }^{+}$(red), and Endorem (purple) labelled bovine articular chondrocyte aggregates

Figure 5.3E shows bleaching of DiR, where a drop of approximately $12.5 \%$ in the absorption of DiR was seen after 45 minutes of illumination. The inset in figure 5.3E shows details of the absorption changes in the wavelength range $730 \mathrm{~nm}$ to $770 \mathrm{~nm}$ for DiR. Figure 5.2 shows the complete overview of the photostability of the 4 labels of optical absorption spectra with pulsed light exposure over time. CNPs and the SPIOs showed no perceivable changes in absorption after 45 minutes of illumination.

Fluorescence yield from a Presto Blue assay that indicates cell activity, after labelling with the 4 labels, is shown in figure 5.3F for days 0,3 and 7 . An initial drop in fluorescence signal was seen on day 3 for all cases. This might be due to slow attachment of cells to the tissue culture plastic, decreasing their activity. Of the 4 labels, only DiR negatively affected cell metabolism. 


\subsubsection{End point photoacoustic imaging of encapsulated cell aggregates}

Prior to serial photoacoustic imaging, these experiments were performed for the sake of validation using fluorescence imaging on slices of the scaffold made using a cryomicrotome(22, 23). Figure 5.5A shows PA cross-sectional images of a hollow fiber with encapsulated DiR labelled primary bovine chondrocyte aggregates fixed directly after cell seeding at day 0. Corresponding fluorescence cryomicrotome image is depicted in figure 5.5B. Hollow fiber containing DiR labelled cells were also imaged after 7 days of culture. PA image after 7 days of culture is shown in figure $5.5 \mathrm{C}$ and the corresponding fluorescence cryomicrotome images is shown in figure 5.5D. The PA images showed high intensity regions corresponding to cell distributions inside the bores of the PESM scaffolds (Fig 5.5A and C). The PA and fluorescence cryomicrotome images demonstrate excellent co-localization, by comparing figure $5.5 \mathrm{~A}$ and $\mathrm{B}$ and figure $5.5 \mathrm{C}$ and D. In both PA and fluorescence cryotome images individual aggregates are seen. At day 0 the images appeared overall grainy with a dense distribution of cells at the walls of each bore in the multibore hollow fiber (Fig. 5.5A). At day 7 however, in the PA images a condensation of the intensity was observed (Fig 5.5C). Additionally, the signal becomes more localized in the bores and has a more homogenous appearance between the bores(Fig 5.5C). This is also seen in the fluorescence cryotome images, indicating the clustering of cell aggregates (Fig 5.5D). 
A

\section{Photoacoustic tomography}

C

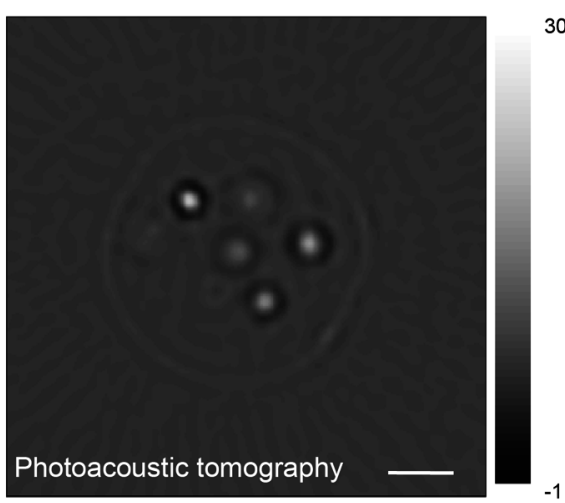

B

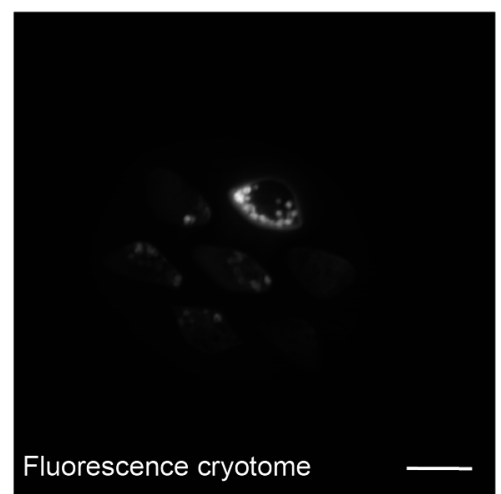

D

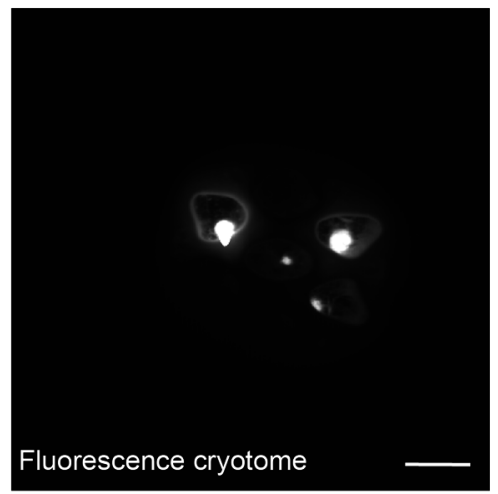

Figure 5.5: End point photoacoustic imaging of labelled encapsulated chondrocyte aggregates. The same multibore hollow fiber with DiR labelled cells was imaged with fluorescence cryotomicrotome to compare the images. A) PA tomography images of day 0 and B) corresponding fluorescence cryotome image. C) PA tomography images of day 7 and D) corresponding fluorescence cryotome image. (scale bars $1 \mathrm{~mm}$ ). 


\subsubsection{Longitudinal photoacoustic serial imaging of encapsulated labelled INS1E cell aggregates}

We investigated the real time possibilities of longitudinal PA tomography. At specific time-points during seven days of culture, the same encapsulated INS1E aggregates were imaged by PA tomography, instead of imaging three different PESM scaffolds at three different time points. Due to cumulative photobleaching of DiR, it was not possible to image DiR labelled samples over time (data not shown). We found no detectable PA signal after 3 days. On the contrary, the CNP labelled cells could be imaged even at 7 days without apparent drop in PA signal intensity (Fig 5.6).

Figure 5.6A shows one representative slice per time point of encapsulated CNP labelled INS1E aggregates. Directly after cell seeding (day 0), hotspots were visible in the PA images representing separate aggregates. With time, the PA images showed compaction of the signal within the bores indicating clustering of the individual INS1E aggregates.

Figure 5.6B shows the PA images of encapsulated INS1E aggregates in combination with agarose macrospheres into the PESM scaffold. These are used to prevent cell aggregate clustering. PA images in Figure 5.6B retained the graininess of the image on day 0 , days 3 and 7 in a contrast to the situation without the agarose macrospheres. This suggested that the macrospheres prevented cell aggregates from clustering.

After the PA measurements, comparative histology of the specimens at day 7 was done to confirm the PA findings. Figure 5.7A shows the H\&E stained histological images of the scaffold. The top image represents the scaffold without the macrospheres, and the bottom image represents the one containing a mixture of labelled cells and agarose macrospheres. In the top image cell clustering is observed in contrast to the bottom image, which coincides with the PA imaging results. Using agarose macrospheres helped maintaining the original size of the aggregates (100 $\mu \mathrm{m}$ to $200 \mu \mathrm{m})$, without these agarose macrospheres the aggregates size increased. 
A

INS1E aggregates

(without macro-spheres) $\times 10^{4}$

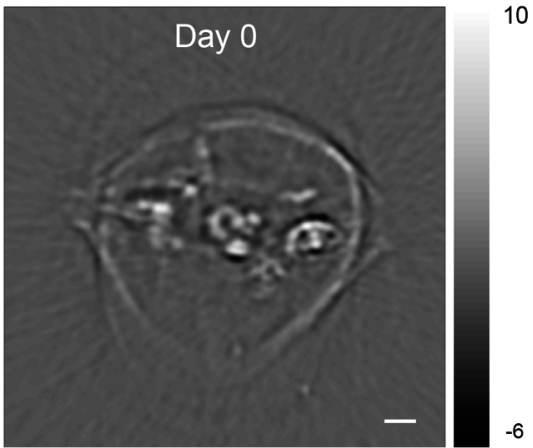

$x 10^{4}$

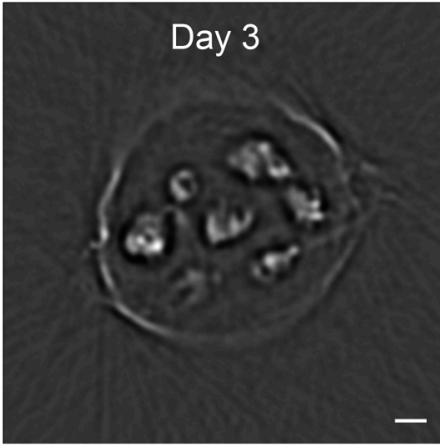

6

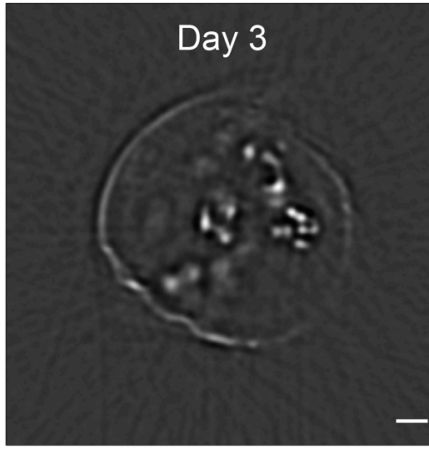

$x 10^{4}$

6

$\times 10^{4}$

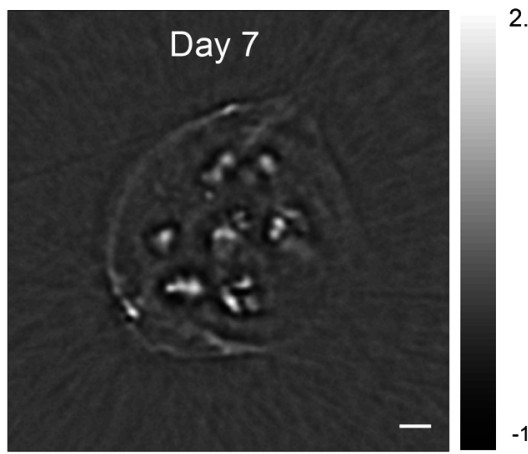

$\times 10^{4}$

(with macrospheres)

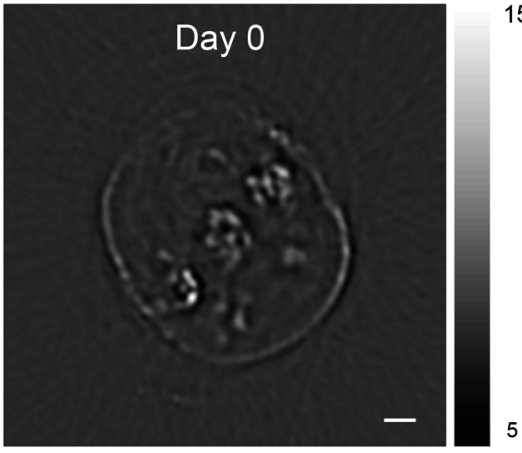

$10^{4}$ 
To assess potential detrimental effects of prolonged illumination on cell apoptosis, we investigated apoptosis by a TUNEL assay. In addition, the presence of insulin positive cells was determined with immunohistochemistry. Figure 5.7B shows hardly any apoptotic INS1E cells (green) in samples with and without the agarose macrospheres compared to a positive control section (Pulmozyme treated sections, white square). In addition, the INS1E aggregates stained positive for insulin without any noticeable differences between the conditions (red). This shows that even prolonged imaging does not harm the cells which is important for longitudinal imaging. 

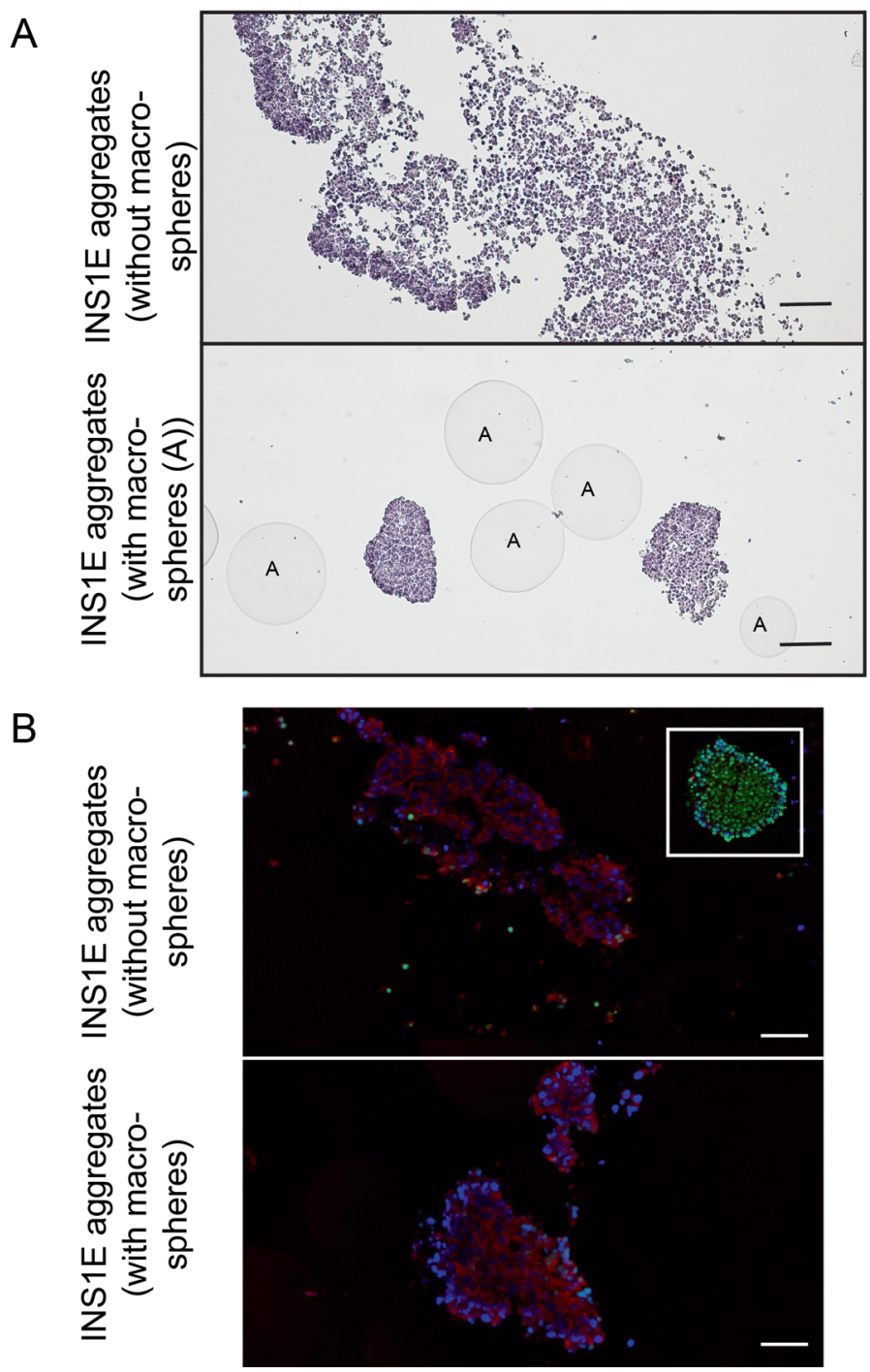

Figure 5.7: Photoacoustic serial imaging of encapsulated labelled INS1E cell aggregates. A) Hematoxilin and Eosin staining of the aggregates alone (top), and aggregates mixed with macropheres (bottom) after 7 days of culture. The circles with letter $A$ in the lower image are the agarose macrospheres. Scale bars $100 \mu \mathrm{m} \mathrm{B)}$ Tunel assay (green), insulin (red), and DAPI (blue) staining of aggregates alone (top) and aggregates mixed with beads (bottom) after 7 days of culture. Positive control, Pulmozyme treated section, for TUNEL in white square. Scale bars $50 \mu \mathrm{m}$ 


\subsection{Discussion}

Visualizing cells in large highly scattering scaffolds is hampered when common imaging techniques are used. In this work, we report that this challenge could be met by using a less conventional imaging technique based on PA tomography. We tested to which extent we could use PA tomography to follow cells in time and with what resolution. We studied a specific scaffold modality engineered for macro-encapsulation of islets of Langerhans used as an islet delivery vehicle in Type I Diabetes. Such scaffolds are generally large in size, $\mathrm{mm}$ to $\mathrm{cm}$ range, since they have to house a considerable large mass of islet tissue $(24,25)$. Moreover, in case of macro-encapsulation for immunoprotective applications, these devices are closed and do not allow for observation of cell behavior given the optically scattering nanoporous polymer layers which comprise these scaffolds.

We show that a number of NIR labels could be used for PA imaging in optically scattering scaffolds. Of these labels, DiR affected cell metabolism in long-term culture. In addition, DiR was sensitive for bleaching, a known and undesirable phenomenon related to fluorescent labels(26). In contrast, high signal intensities were obtained using CNP. This label was not sensitive for bleaching and did not show evidence of cell toxicity making it ideally suited for non-invasive imaging over time. We demonstrate that signal intensity with each of these labels is cell type dependent. The differences in signal intensities between different labels could be explained by the difference in labelling method and label type between DiR and both SPIOs and CNP. While DiR is incorporated into the membrane of the cells, both SPIOs and CNP are phagocytized by the cells. Furthermore, the amplitude of PA signal depends on the optical absorption coefficient of the labels that is higher for CNP and DiR at the imaging wavelength used than for the SPIOs. In addition, part of the absorbed light by DiR will be converted to the fluorescence emission, which contributes to the lower PA signal compared to CNP. Additionally to the difference in signal intensity between the different cell types and labels, one could expect a difference in time span where cells can be followed. This difference is determined by the dilution of the labels while cells 
proliferate. Hence the labelling efficiency, the absorption coefficient, and the proliferate rate of cells play a big role in the difference in PA intensity. These last two aspects are very interesting to investigate further. Comparing PA images of DiR labeled cells in scaffolds with images obtained by fluorescence cryomicrotomy, we showed a visually excellent co-localization between PA images and fluorescence cryomicrotome images of DiR labeled cells. This visual co-localization could not be substantiated by image overlay since PA slices represent $1 \mathrm{~mm}$ thick slices of the multibore hollow fibers, while slices of $30 \mu \mathrm{m}$ were imaged by fluorescence cryomicrotome.

The great advantage of PA imaging is the ability to visualize cells in a non-destructive manner. This allowed us to follow cell distribution over a period of 7 days, of encapsulated INS1E aggregates in the same hollow fiber. A special sample holder of agarose gel with a medium compartment needed to be developed. This container helped in maintaining sterility, an important condition for longitudinal imaging. Cell aggregates were imaged over time, making it possible to follow cell behavior. Without agarose macropheres, cell aggregate clustering was seen as the aggregates size increased on the images. On the other hand we noticed that the macrospheres were able to prevent cell aggregate. These results were validated by histology, where the effect of addition of microspheres to cell distribution was clearly visible and in full agreement with the PA imaging. Importantly, a TUNEL assay showed hardly any apoptotic cells, indicating that PA tomography is harmless for cells.

The next step in cell imaging would be functional imaging by taking advantage of the PA ability to image at multiple wavelengths. Functional imaging would give more information of cell behavior and cell type specific function. One of the major drawbacks when using relatively large scaffolds is the occurrence of hypoxia in the core of the scaffold. PA imaging could help answering these fundamental questions in a noninvasive manner, for example by using cells labelled with an hypoxia sensitive probe. More specifically for evaluation of beta cells in the PESM multibore hollow fiber, $\beta$-cell specific probes are needed $(27,28)$. This could be achieved by transfection of $\beta$ cells with an appropriate NIR fluorescent reporter gene(28). In the end, the ultimate 
goal would be to perform in vivo functional imaging using PA tomography. Different studies using PA imaging and even specifically PA tomography to image in vivo have been previously reported $(8,11,29-32)$. These studies focus on different imaging targets such as cancer, photothermal therapy, vascularization, and oxygen saturation. This indicates the possibility to continue this work in vivo, thereby following encapsulated cells after transplantation. Especially in combination with functional imaging this would be highly interesting.

Overall this study demonstrates that PA tomography can be used to follow distribution of cells encapsulated in highly scattering scaffolds of clinically relevant size without sample destruction. Further CNP is found to be a suitable NIR PA contrast agent for labelling cells. With this combination, it is possible to achieve a $100 \mu \mathrm{m}$ to $200 \mu \mathrm{m}$ resolution in imaging the aggregates at few $\mathrm{mm}$ deep and over a period of 7 days. This resolution allows the study of global cell behavior rather than following of individual. One of the main challenges of PA tomography remains a lack of quantification due to the unknown optical fluence. Some directions to improve quantification is to use either photon propagation models $(33,34)$ or a combination with other optical techniques $(35,36)$. 


\section{References}

1. Thevenot, P., Nair, A., Dey, J., Yang, J., and Tang, L. Method to analyze threedimensional cell distribution and infiltration in degradable scaffolds. Tissue Engineering - Part C: Methods 14, 319, 2008.

2. Sun, Y., Tan, H.Y., Lin, S.J., Lee, H.S., Lin, T.Y., Jee, S.H., Young, T.H., Lo, W., Chen, W.L., and Dong, C.Y. Imaging tissue engineering scaffolds using multiphoton microscopy. Microscopy Research and Technique 71, 140, 2008.

3. Wang, L.V., and $\mathrm{Hu}, \mathrm{S}$. Photoacoustic tomography: In vivo imaging from organelles to organs. Science 335, 1458, 2012.

4. Lutzweiler, C., and Razansky, D. Optoacoustic imaging and tomography: Reconstruction approaches and outstanding challenges in image performance and quantification. Sensors (Switzerland) 13, 7345, 2013.

5. Taruttis, A., and Ntziachristos, V. Advances in real-time multispectral optoacoustic imaging and its applications. Nature Photonics 9, 219, 2015.

6. Zhang, Y., Cai, X., Choi, S.W., Kim, C., Wang, L.V., and Xia, Y. Chronic label-free volumetric photoacoustic microscopy of melanoma cells in three-dimensional porous Scaffolds. Biomaterials 31, 8651, 2010.

7. Zhang, Y.S., Cai, X., Yao, J., Xing, W., Wang, L.V., and Xia, Y. Non-invasive and in situ characterization of the degradation of biomaterial scaffolds by volumetric photoacoustic microscopy. Angew Chem Int Ed 53, 184, 2014.

8. Cai, X., Zhang, Y., Li, L., Choi, S.W., MacEwan, M.R., Yao, J., Kim, C., Xia, Y., and Wang, L.V. Investigation of neovascularization in three-dimensional porous scaffolds in vivo by a combination of multiscale photoacoustic microscopy and optical coherence tomography. Tissue Engineering - Part C: Methods 19, 196, 2013.

9. Zhang, Y., Cai, X., Wang, Y., Zhang, C., Li, L., Choi, S.W., Wang, L.V., and Xia, Y. Noninvasive photoacoustic microscopy of living cells in two and three dimensions through enhancement by a metabolite dye. Angew Chem Int Ed 50, 7359, 2011.

10. Zhang, Y.S., Yao, J., Zhang, C., Li, L., Wang, L.V., and Xia, Y. Optical-resolution photoacoustic microscopy for volumetric and spectral analysis of histological and im- 
munochemical samples. Angew Chem Int Ed 53, 8099, 2014.

11. Talukdar, Y., Avti, P., Sun, J., and Sitharaman, B. Multimodal ultrasoundphotoacoustic imaging of tissue engineering scaffolds and blood oxygen saturation in and around the scaffolds. Tissue Engineering - Part C: Methods 20, 440, 2014.

12. De Bartolo, L., Morelli, S., Rende, M., Campana, C., Salerno, S., Quintiero, N., and Drioli, E. Human hepatocyte morphology and functions in a multibore fiber bioreactor. Macromolecular Bioscience 7, 671, 2007.

13. Bettahalli, N.M.S. Membrane supported scaffold architectures for tissue engineering Narasimha Murthy Srivatsa Bettahalli 2011.

14. Grootendorst, D.J., Jose, J., Fratila, R.M., Visscher, M., Velders, A.H., Ten Haken, B., Van Leeuwen, T.G., Steenbergen, W., Manohar, S., and Ruers, T.J.M. Evaluation of superparamagnetic iron oxide nanoparticles (Endorem (R)) as a photoacoustic contrast agent for intra-operative nodal staging. Contrast Media and Molecular Imaging 8, 83, 2013.

15. Eisenblatter, M., Ehrchen, J., Varga, G., Sunderkotter, C., Heindel, W., Roth, J., Bremer, C., and Wall, A. In vivo optical imaging of cellular inflammatory response in granuloma formation using fluorescence-labeled macrophages. Journal of Nuclear Medicine 50, 1676, 2009.

16. Kruyt, M.C., De Bruijn, J., Veenhof, M., Oner, F.C., Van Blitterswijk, C.A., Verbout, A.J., and Dhert, W.J.A. Application and limitations of chloromethyl- benzamidodialkylcarbocyanine for tracing cells used in bone tissue engineering. Tissue Engineering 9, 105, 2003.

17. Matuszewski, L., Persigehl, T., Wall, A., Sehwindt, W., Tombach, B., Fobker, M., Poremba, C., Ebert, W., Heindel, W., and Bremer, C. Cell tagging with clinically approved iron oxides: Feasibility and effect of lipofection, particle size, and surface coating on labeling efficiency. Radiology 235, 155, 2005.

18. Rivron, N.C., Vrij, E.J., Rouwkema, J., Gac, S.L., Van Berg, A.D., Truckenmuller, R.K., and Van Blitterswijk, C.A. Tissue deformation spatially modulates VEGF signaling and angiogenesis. Proceedings of the National Academy of Sciences of the United States of America 109, 6886, 2012. 
19. Jose, J., Grootendorst, D.J., Vijn, T.W., Wouters, M., Van Boven, H., Van Leeuwen, T.G., Steenbergen, W., Ruers, T.J.M., and Manohar, S. Initial results of imaging melanoma metastasis in resected human lymph nodes using photoacoustic computed tomography. Journal of Biomedical Optics 16, 2011.

20. Jose, J., Willemink, R.G.H., Resink, S., Piras, D., Van Hespen, J.C.G., Slump, C.H., Steenbergen, W., Van Leeuwen, T.G., and Manohar, S. Passive element enriched photoacoustic computed tomography (PER PACT) for simultaneous imaging of acoustic propagation properties and light absorption. Optics Express 19, 2093, 2011.

21. Jose, J., Willemink, R.G.H., and Steenbergen, W. Speed-of-sound compensated photoacoustic tomography. Medical Physics 39, 7262, 2012.

22. Spaan, J.A.E., Siebes, M., ter Wee, R., Kolyva, C., van Teeffelen, J.W.G.E., Vink, H., Fokkema, D.S., Streekstra, G., and VanBavel, E. Visualisation of intramural coronary vasculature by an imaging cryomicrotome suggests compartmentalisation of myocardial perfusion areas. Medical and Biological Engineering and Computing 43, 431, 2005.

23. van den Wijngaard, J.P.H.M., Schwarz, J.C.V., van Horssen, P., van Lier, M.G.J.T.B., Dobbe, J.G.G., Spaan, J.A.E., and Siebes, M. 3D Imaging of vascular networks for biophysical modeling of perfusion distribution within the heart. Journal of Biomechanics 46, 229, 2013.

24. Figliuzzi, M., Cornolti, R., Plati, T., Rajan, N., Adobati, F., Remuzzi, G., and Remuzzi, A. Subcutaneous xenotransplantation of bovine pancreatic islets. Biomaterials $26,5640,2005$.

25. Lacy, P.E., Hegre, O.D., Gerasimidi-vazeou, A., Gentile, F.T., Dionne, E., Science, S., Series, N., Dec, N., and Dionne, K.E. Maintenance of Normoglycemia in Diabetic Mice by Subcutaneous Xenografts of Encapsulated Islets Maintenance of Normoglycemia in Diabetic Mice by Subcutaneous Xenografts of Encapsulated Islets. Science 254, 1782, 1991.

26. Bernas, T., Zarebski, M., Cook, R.R., and Dobrucki, J.W. Minimizing photobleaching during confocal microscopy of fluorescent probes bound to chromatin: Role 
of anoxia and photon flux. Journal of Microscopy 215, 281, 2004.

27. Kang, N.Y., Lee, S.C., Park, S.J., Ha, H.H., Yun, S.W., Kostromina, E., Gustavsson, N., Ali, Y., Chandran, Y., Chun, H.S., Bae, M., Ahn, J.H., Han, W., Radda, G.K., and Chang, Y.T. Visualization and isolation of langerhans islets by a fluorescent probe PiY. Angew Chem Int Ed 52, 8557, 2013.

28. Reiner, T., Kohler, R.H., Liew, C.W., Hill, J.A., Gaglia, J., Kulkarni, R.N., and Weissleder, R. Near-infrared fluorescent probe for imaging of pancreatic $\beta$ cells. Bioconjugate Chemistry 21, 1362, 2010.

29. Lu, W., Huang, Q., Ku, G., Wen, X., Zhou, M., Guzatov, D., Brecht, P., Su, R., Oraevsky, A., Wang, L.V., and Li, C. Photoacoustic imaging of living mouse brain vasculature using hollow gold nanospheres. Biomaterials 31, 2617, 2010.

30. Li, W., Rong, P., Yang, K., Huang, P., Sun, K., and Chen, X. Semimetal nanomaterials of antimony as highly efficient agent for photoacoustic imaging and photothermal therapy. Biomaterials 45, 18, 2015.

31. Jing, L., Liang, X., Deng, Z., Feng, S., Li, X., Huang, M., Li, C., and Dai, Z. Prussian blue coated gold nanoparticles for simultaneous photoacoustic/CT bimodal imaging and photothermal ablation of cancer. Biomaterials 35, 5814, 2014.

32. Nam, S.Y., Ricles, L.M., Suggs, L.J., and Emelianov, S.Y. In vivo ultrasound and photoacoustic monitoring of mesenchymal stem cells labeled with gold nanotracers. PLoS ONE 72012.

33. Yao, L., Sun, Y., and Jiang, H. Transport-based quantitative photoacoustic tomography: Simulations and experiments. Physics in Medicine and Biology 55, 1917, 2010 .

34. Laufer, J., Cox, B., Zhang, E., and Beard, P. Quantitative determination of chromophore concentrations from 2D photoacoustic images using a nonlinear model-based inversion scheme. Applied Optics 49, 1219, 2010.

35. Daoudi, K., Hussain, A., Hondebrink, E., and Steenbergen, W. Correcting photoacoustic signals for fluence variations using acousto-optic modulation. Optics Express 20, 14117, 2012.

36. Bauer, A.Q., Nothdurft, R.E., Erpelding, T.N., Wang, L.V., and Culver, J.P. 
Quantitative photoacoustic imaging: Correcting for heterogeneous light fluence distributions using diffuse optical tomography. Journal of Biomedical Optics 162011. 


\section{Chapter 6}

\section{Evaluation of microwell PES/PVP}

\section{membranes for islet encapsulation:}

\section{A novel strategy for immune protection}

Katarzyna Skrzypek, Milou Groot Nibbelink, Maria Coronel, Irayme Labrada, Cherie Stabler, Jéré van Lente, Marcel Karperien, Aart van Apeldoorn, Dimitrios Stamatialis 


\subsection{Abstract}

Encapsulating islets of Langerhans for extrahepatic transplantation, might help overcome the multifactorial inflammatory response associated with cell death after intrahepatic islet transplantation. However, encapsulation for immune protection remains a difficult challenge as secretory components of the immune system have usually a similar size as nutrients, insulin, and glucose. Therefore when designing an immune protective device for the transplantation of islets, a compromise needs to be found between optimal mass transport of nutrients and hormones to enable survival and function of islets, and shielding the donor islets from the immune system. An encapsulation device should also provide physical separation of islets as clustering has been shown to decrease cell survival as a consequence of increased diffusion distances. Buitinga et al., described a microwell device created from non degradable, non celladhesive, block copolymer, poly(ethylene glycol terephthalate)-poly(butylene terephthalate) (PEOT/PBT). They were able to prevent islet clustering and cell attachment within this device by capturing individual islets in separate microwells. However, since this particular device is designed to be an entirely open structure which facilitates blood vessel ingrowth into the islets, it does not provide adequate immune protection. The aim of this study was to adapt the design of the microwell device in such a way that it could be used as an immune protective macroencapsulation device for extrahepatic islet transplantation. In this study we used a combination of solvent-non solvent phase separation and micro-molding technology using poly(ether sulfone)/ poly(vinylpyrrolidone) (PES/PVP) to create a microwell membrane. In vitro glucose stimulated insulin secretion showed that islets encapsulated in a closed device comprising a PES/PVP microwell membrane and a $0.45 \mu \mathrm{m}$ PES lid can adequately respond to changes in glucose. Moreover, in vivo implantation of the microwell membrane showed minimal fibrous capsule $( \pm 50 \mu \mathrm{m})$ formation around the membrane and that cells were not able to penetrate the selectivelayer on the outside of the microwell membrane. In conclusion, this study suggests that a PES/PVP microwell device can potentially serve as an immune protective macroencapsulation device. 


\subsection{Introduction}

Intrahepatic transplantation of islets of Langerhans is associated with a high degree of islet loss within the two weeks after the intervention(1). Extrahepatic transplantation of islets using biomaterials as a carrier for islets could increase the outcome of the transplantation by providing a more optimal environment(1-4). When these same biomaterials are engineered in such a way that they offer immune protection the use of immunosuppressive drugs can be omitted. This also opens a route for use of xenogenic, or stem cell derived beta cell therapy. However when encapsulating islets inside a marcoencapsulation device, diffusion limitations often leads to cell death(5-8). These diffusion limitations are not only a result of the thickness, or porosity, of the device, but can also result from the clustering of islets, as often no physical separation between the islets is present in macroencapsulation devices described in literature, leading to a loss of function and cell death. The clustering of islets negatively affects islet structure and consequently leads to diffusion-limited nutrient deprivation(9). A large islet size has shown to be associated with apoptosis and necrosis in the core of these islets. Other studies showed that large islets are less efficient in secreting insulin compared to small islets(5, 9-12). Another important parameter to consider when designing an immune protective islet encapsulation device is to prevent cell attachment to the biomaterial at hand, which can ultimately result in dedifferentiation of endocrine cells leading to loss of islet function $(10,13)$. Both in vitro and in vivo studies which observed attachment of islets to different substrates leading to a change in the native morphology caused a subsequent loss of insulin positive cells likely induced by beta cell dedifferentiation $(13,14)$.

Creating an encapsulation device that facilitates physical separation with minimal cell attachment to the surrounding biomaterial might therefore be the solution to overcome these issues. Buitinga et al., described a microwell islet tissue engineered scaffold for transplantation of islets which allows for capturing individual islets in separate microwell pockets thus providing a physical separation between each islet(15). The authors used films consisting of a non-cell-adhesive and biocompatible poly(ethylene 
glycol terephthalate)-poly(butylene terephthalate) (PEOT/PBT) block copolymer to create macroporous microwell devices. Islet clustering was prevented in this device due to the confinement of individual islets inside separate islet size microwells while preserving the natural morphology of the islets (15).

The aim of this study is to create an immune protective device based on a microwell array. We set a few important design criteria; islets need to be separated from the blood stream, the device needs to be permeable for glucose, insulin, nutrients, and oxygen, and the device needs to be impermeable to the immune system to prevent cell-cell contact. However, the immune-protection should not compromise transport of glucose, insulin, oxygen, and nutrients as this will lead to islets necrosis and a dysfunctional immune protective device $(5,8,16-20)$. Engineering the optimal immune protective device is quite challenging as components of the immune system have a similar size as essential nutrients, insulin, and glucose necessary for islet function and metabolism. Therefore when designing an immune protective encapsulation device for the transplantation of islets, a proper balance needs to be found between optimal survival of islets and shielding the islets from the immune system(21).

We adapted the design of Buitinga et al. to create an immune protective device. However since this device allows for revascularization of islets due to its open macroporous design it does not provide adequate protection from the host immune cells. Previous studies have shown that a pore size of $0.4 \mu \mathrm{m}$ to $0.45 \mu \mathrm{m}$ is sufficient for immune protection(22-24).

We developed an immune protective macro encapsulation device where islets are confined between two membranes, of a tailored porosity that permits nutrient inflow and metabolite outflow. Additionally the device protects the islets from the immune system by preventing direct cell-cell contact with the protected islets (Fig 6.1). 


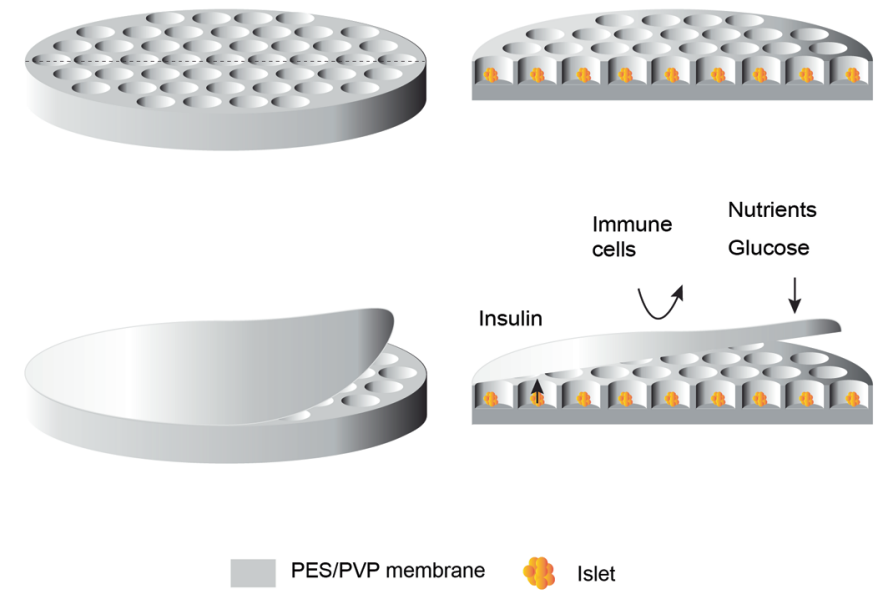

Figure 6.1: A schematic overview of the PES/PVP flat membrane encapsulation device. When sealed with a lid (bottom), an immune protective device is created. Insulin, glucose, and nutrients pass through the membrane while immune cells are blocked.

The microwell textured membrane allows for physical separation of the islets. Poly(ether sulfone)/ poly(vinylpyrrolidone) (PES/PVP), an inert material, was used for the microwell textured membranes as it prevents islet attachment, spreading, and clustering while maintaining islets rounded morphology. The addition of PVP to PES is used to obtain hydrophilized PES membranes, thereby decreasing the fouling properties of the membrane $(25,26)$. Additionally the ratio of PES/PVP determines the pore size of the membranes when solvent non-solvent induced phase separation is used(26). Porosity of PES/PVP can be further fine-tuned using sodium hypochlorite (25, 27, 28). Using a phase separation micro-molding method, we were able to control the porosity of the PES/PVP membranes while creating microwells for islet encapsulation(22-24, 29-31). We optimized the thickness of the microwell membrane and the pore size of the PES membrane used as a lid by analyzing glucose responsiveness of encapsulated (pseudo)-islets. In conclusion, this study suggests that a nanoporous PES/PVP microwell device with a similar design as presented by Buitinga et al. can potentially serve as an immunoprotective islet macroencapsulation device. 


\subsection{Materials and methods}

\subsubsection{Microwell membrane fabrication}

Micropatterned membranes were fabricated using phase separation micro-molding method $(\mathrm{PS} \mu \mathrm{M})(29-31)$. Membranes were prepared using a $15 \mathrm{wt} \%$ polyethersulfone (PES)(Ultrason, E6020P) and a $5 \mathrm{wt} \%$ polyvinylpyrrolidone (PVP) $(\mathrm{MW}=40000$, Sigma Aldrich) in N-Methylpyrrolidone (NMP)(Acros organic) polymer solution which was stirred at the roller bank (ON at RT). The polymer solution was casted on the custom made, silicon, micropatterned mold with shapes and sizes of the features presented in figure 6.2. A custom-made casting machine with micrometric screws to regulate the casting thickness was used to obtain a casting thickness of $100 \mu \mathrm{m}$ and $250 \mu \mathrm{m}$. Casting was followed by immersion into the demineralized water coagulation bath. When the polymer became turbid and precipitated, membranes were demolded from the wafer. Finally, the membranes were rinsed with demineralized water in order to remove remaining solvent traces and stored in demineralized water till further use.

\subsubsection{Sodium hypochlorite treatment}

In order to increase the porosity of the membranes, after extensive washing of the membranes, they were treated for $24 \mathrm{~h}$ with 4000 ppm sodium hypochlorite aqueous solution (Fluka). Subsequently, the membranes were washed and stored in demineralized water. 
A

Top view
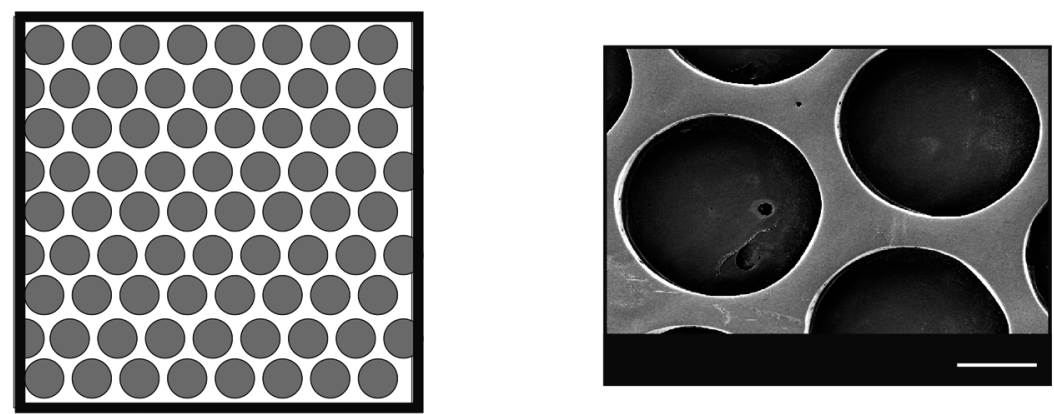

$\mathrm{B}$

Side view

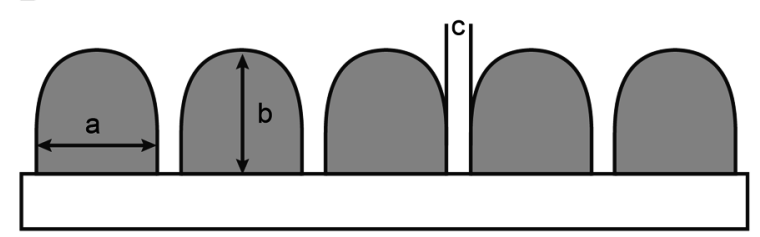

$a=500 \mu \mathrm{m} \quad b=500 \mu \mathrm{m} \quad c=100 \mu \mathrm{m}$

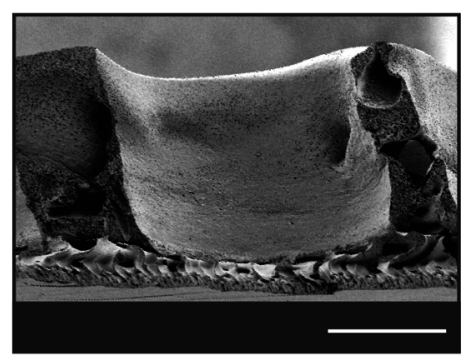

Figure 6.2: A schematic overview of the wafer and corresponding SEM images of the microwell membrane. A) A top view of the silicon, micropatterned mold, with on the right a SEM image of the microwell membrane. B) A side view of the silicon, micropatterned mold, with on the right a cross section of the microwell membrane. Scale bars $200 \mu \mathrm{m}$

\subsubsection{In vivo biocompatibility}

The in vivo biocompatibility of the microwell membranes was determined by implantation in 9 week old male C57BL/6 mice (Jackson Laboratories) $(n=2)$. The study was reviewed and approved by the University of Miami, Miami Institutional Animal Care and Use Committee. All procedures were conducted according to the guidelines of the Committee on Care and Use of Laboratory Animals, Institute of Laboratory Animal Resources (National Research Council). The mice were housed in microisolated cages in virus antibody-free rooms with free access to autoclaved food and water at the Department of Veterinary Resources of the University of Miami. Before 
implantation the microwell membranes (diameter $10 \mathrm{~mm}$ ) were sterilized by incubation in $70 \%$ ethanol for $30 \mathrm{~min}$ and thereafter washed thoroughly with PBS. Mice were anesthetized by isoflurane $(2 \%)$ and after shaving the abdomen and sterilizing the skin, a midline incision was made and the epididymal fat pads (EFP) were exposed (Fig 6.3A). A microwell membrane was placed on the EFP (Fig 6.3B), wrapped in the EFP (Fig 6.3C), and sealed with fibrin glue. Subsequently, the wrapped membranes were placed in the abdominal cavity, the muscle was sutured and the skin was closed using staples. Animals received pain medication, buprenorphine $(20 \mu \mathrm{g} / \mathrm{mL})$, immediately after surgery, and twice a day for the first 2 days after implantation. The microwell membranes were explanted after 7, 15, 21 or 28 days. The samples were fixed in $10 \%$ formalin, processed for paraffin sectioning and sections were stained with hematoxylin and eosin.
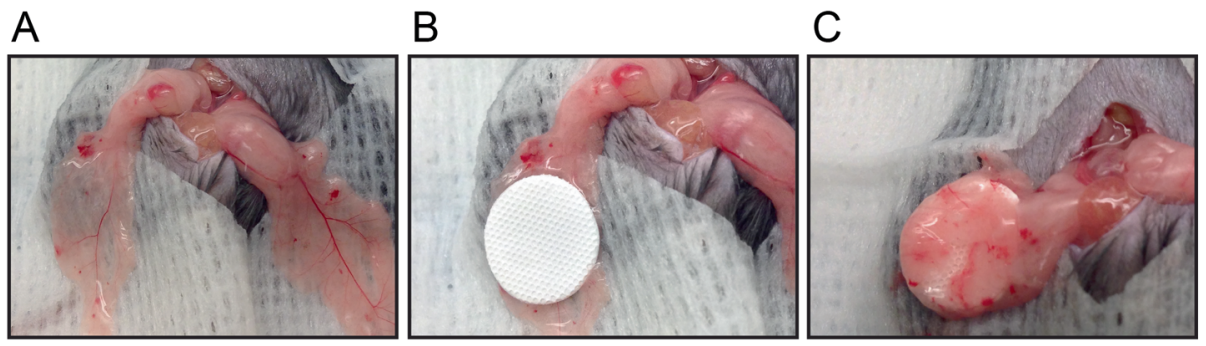

Figure 6.3: Implantation of the microwell membranes in epididymal fat pads (EFP) of a mouse. The EFPs were exposed (A), the microwell membrane was placed on the EFPs (B), wrapped and sealed with fibrin glue $(C)$ after which the wrapped membranes were placed in the abdominal cavity.

\subsubsection{Cell culture}

MIN6-B1 mouse insulinoma cells (kindly provided by Dr. P. Halban, University Medical Center, Geneva, Switzerland) were cultured at $37^{\circ} \mathrm{C}$ and $5 \% \mathrm{CO}_{2}$ in Dulbecco's Modified Eagle's Medium (DMEM, Gibco) supplemented with 10\% (v/v) FBS (Lonza), $100 \mathrm{U} / \mathrm{mL}$ penicillin, $100 \mathrm{mg} / \mathrm{mL}$ streptomycin (Gibco), and $70 \mu \mathrm{M}$ freshly added beta-mercaptoethanol (Gibco). Human islets of Langerhans from 3 pancreata 
of organ donors were provided by the Human Islet Isolation Center of the Leiden University Medical Center (Leiden, The Netherlands). The islet isolation center is permitted to provide donor tissue, not eligible for clinical transplantation, for research purposes in agreement with the Dutch law and institutional requirements. Islets were cultured in CMRL 1066 medium (5.5 mM glucose) containing 10\% FBS (Lonza), 2 mM GlutaMAX (Invitrogen), $100 \mathrm{mu} / \mathrm{mL}$ penicillin and $1 \mathrm{mg} / \mathrm{mL}$ streptomycin (Gibco), $10 \mathrm{~mm}$ HEPES (Invitrogen), and $1.2 \mathrm{mg} / \mathrm{mL}$ nicotinamide (Sigma-Aldrich) at $37^{\circ} \mathrm{C}$ and $5 \% \mathrm{CO}_{2}$.

\subsubsection{Pseudo-islet formation}

Pseudo-islets were formed as described in chapter 3(32). In short, single MIN6 cells were seeded in agarose microwells (250 cells per microwell). After 2 days incubation in normal culture medium, stable pseudo-islets were obtained (chapter 3).

\subsubsection{Pseudo islet viability in a closed system}

Before seeding the pseudo-islets, the membranes were sterilized with $70 \%$ ethanol for 30 min, washed 3 times in PBS and pre incubated in culture medium overnight. In order to create a closed system to mimic an immune protective encapsulation device a transwell construct was used (figure 6.4). In short the microwell membrane was assembled within transwell construct (insert and sealing ring) and the pseudo-islets (150) where seeded on the top. Medium was aspirated leaving pseudo-islets inside the wells of the membrane and insert (blue) was taken off, letting membrane stay within the sealing ring (brown). A PES membrane (Sterlitech) was used as a lid and was placed on the top of the microwell membrane and these two membranes were sealed with the transwell construct. The transwell construct containing the encapsulated pseudo-islets was placed in a 24 well plate. 


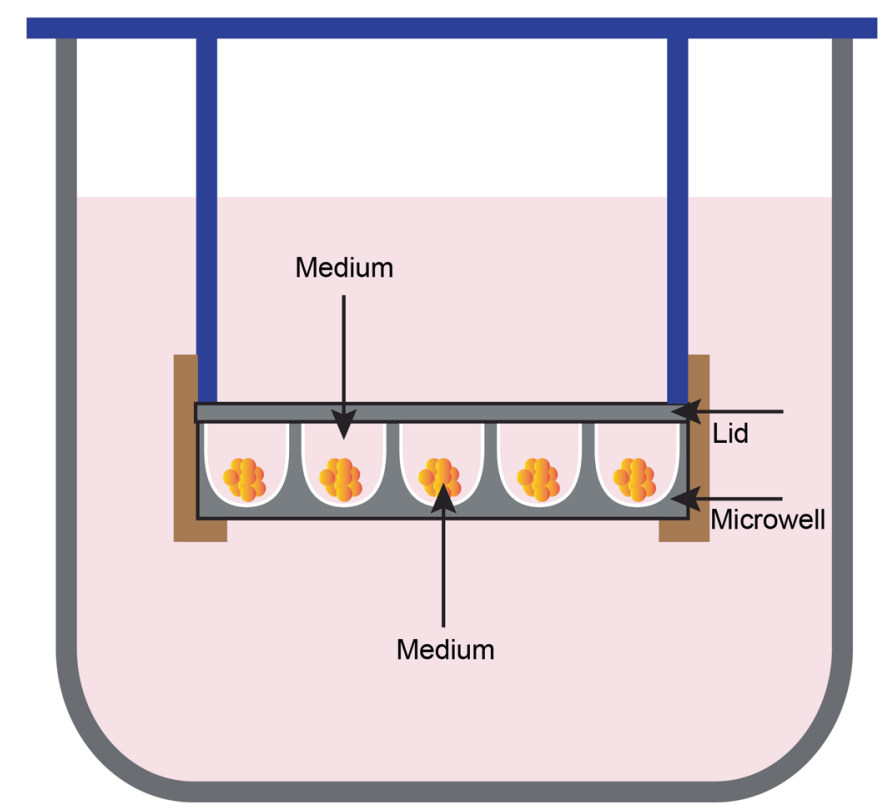

Medium (pseudo) islet

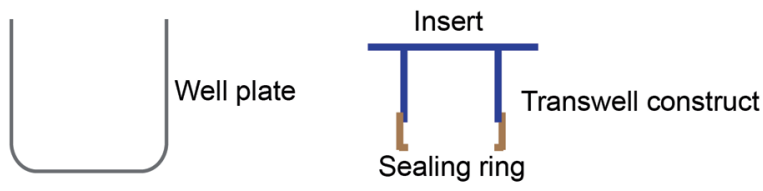

Figure 6.4: Islets (orange) were seeded in the microwell flat membrane. A PES lid was placed on top. Subsequently, the microwell/lid construct (dark grey) was closed by a transwell construct. This transwell construct consisted of an insert (blue) and a sealing ring (brown). Combined a tightly sealed construct was created; thereby medium was only able to diffuse through the membranes (pink). 
After 1 day of culture the transwell construct was opened and the lid was removed. A live/dead analysis was performed in order to determine the pseudo-islet viability. Membranes with pseudo islets inside the microwells were placed in a solution containing $0.25 \mu \mathrm{L} / \mathrm{mL}$ Calcein (Sigma-Aldrich) and $3 \mu \mathrm{L} / \mathrm{mL}$ Ethidium Homodimer (Sigma-Aldrich) in PBS $\left(30 \mathrm{~min}\right.$ at $\left.37^{\circ} \mathrm{C}\right)$. Green-fluorescent live cells and red fluorescent dead cells were imaged using EVOS digital inverted fluorescence microscope.

\subsubsection{Human islet functionality in vitro in a closed system}

In order to use the microwell membranes as an encapsulation device, a closed system containing the microwell membrane covered with a flat PES membrane with different porosities $(0.45 \mu \mathrm{m}$ and $5 \mu \mathrm{m}$, Sterlitech) as a lid was used. This closed system was created using the transwell construct as depicted in figure 6.4. Before seeding the islets, the membranes were sterilized with $70 \%$ ethanol for $30 \mathrm{~min}$, washed 3 times in PBS and pre incubated in culture medium overnight. A closed system was created by the following steps; the microwell membrane was assembled within the transwell construct (insert and sealing ring) and the human islets (150 IEQ) where seeded on the top. Medium was aspirated leaving the islets inside the wells of the membrane and the insert (blue) was taken off, letting membrane stay within the sealing ring (brown). A PES membrane (Sterlitech) was used as a lid and was placed on the top of the microwell membrane and these two membranes were sealed with the transwell construct. The transwell construct containing the encapsulated islets was placed in a 24 well plate. After 1 day of culture the islets were stimulated with glucose to assess their glucose responsiveness. A glucose induced insulin secretion test (GIIST) was used to assess the glucose responsiveness (chapter 3). In Short; a tailor made Krebs buffer (115 mm NaCl, $5 \mathrm{~mm} \mathrm{KCl,} 24 \mathrm{~mm} \mathrm{NaHCO}_{3}$, Sigma) supplemented with $2.2 \mathrm{~mm}$ $\mathrm{CaCl}_{2}, 20 \mathrm{~mm}$ HEPES (Gibco), $2 \mathrm{mg} / \mathrm{mL}$ bovine serum albumin, $1 \mathrm{~mm} \mathrm{MgCl}_{2}$, and $0.1 \mathrm{~mm}$ theophylline (Sigma) was prepared at pH 7.4. From this Krebs buffer a low (1.67 mm) and high $(16.7 \mathrm{~mm})$ glucose buffer was prepared, by adding glucose. Both free floating human-islets and the transwell constructs containing the encapsulated islets were washed ( $3 \times 5 \mathrm{~min})$ with low glucose buffer followed by a pre-incubation of 
$90 \mathrm{~min}$ in low glucose buffer. All samples were then stimulated for $60 \mathrm{~min}$ in subsequent low, high, low, high, and low glucose buffer with a 3 times 5 min wash step with low glucose buffer after each high glucose stimulation step. Samples were taken after each incubation, spun down $(300 \mathrm{~g}, 3 \mathrm{~min})$ and the supernatant was stored at $-20^{\circ} \mathrm{C}$. Samples were analyzed using a mouse insulin ELISA (Mercodia). Free floating human islets (150 IEQ) were used as control $(n=3)$. The functionality of human islets was determined by the stimulation index that is defined as the insulin secretion after stimulation with high glucose relative to the insulin secretion when stimulated with the first low glucose buffer.

In order to find the optimal encapsulation device, two different microwell membranes were used; membranes casted with a $100 \mu \mathrm{m}$ casting thickness (thin) and with a $250 \mu \mathrm{m}$ casting thickness (normal). Additionally, two different PES lids were tested; $0.45 \mu \mathrm{m}$ and $5 \mu \mathrm{m}$ pore size.

\subsubsection{Human islet functionality in vitro in a sealed device}

The next step was to seal the lids and microwell membranes together to create an immune protective barrier. A thin (100 $\mu \mathrm{m}$ casting thickness) microwell membrane and a $0.45 \mu \mathrm{m}$ PES membrane were sealed together for these experiments. We developed a custom-made heat sealing device in which the top and bottom half can be placed and compressed at the rim at variable temperature and pressure(Fig 6.5). In order to create a sealed device, the Teflon coated heating elements were heated to $90^{\circ} \mathrm{C}$. Using an inbuilt calibrated thermocouple the temperature can be accurately controlled during sealing. The seal device containing the two membranes can be closed at a fixed pressure resulting in a reliable seal within 10 seconds. This way the membranes were sealed only at the rim, leaving a small opening as inlet for cell seeding. 
A

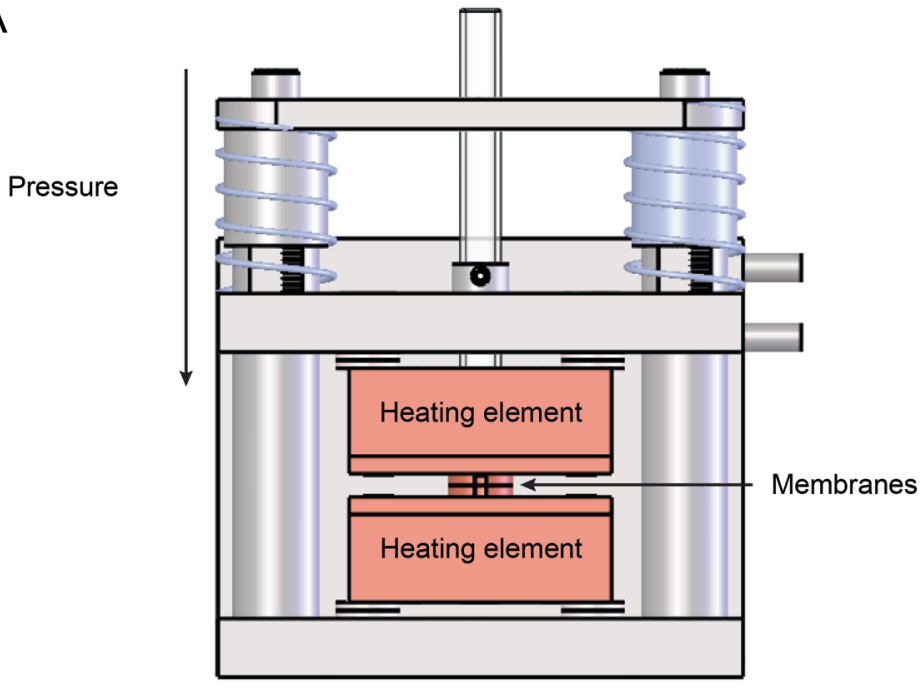

B

C
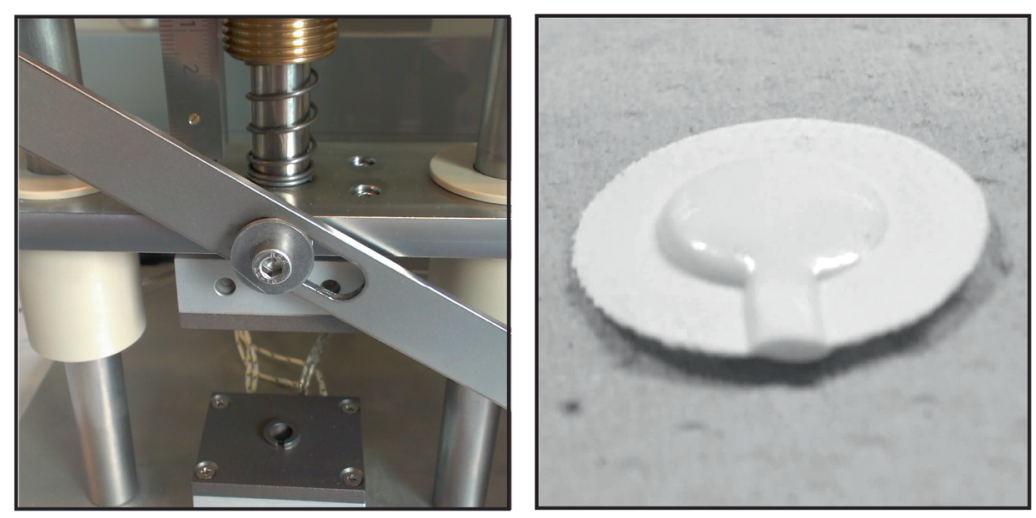

Figure 6.5: A) Schematic overview of the custom made seal device. Two Teflon coated heating elements with a circle with a small opening were used to obtain a seal between the microwell membrane and the PES lid. The two membranes were in between the two elements. A spring was used to apply pressure. B) The actual seal device. C) The sealed construct after sealing.

Sealed device was sterilized with $70 \%$ ethanol (30 min), washed 3 times 5 min in PBS and pre incubated in culture medium overnight. Human islets (150 IEQ) were seeded inside the device via the small inlet that was closed after seeding using sterile surgical staples (HORIZON, Ligating clips). After which the sealed constructs were placed in 
a 24 well plate containing culture medium. After 1 and 7 days of culture a GIIST was performed to assess the encapsulated islets' response to a glucose stimulation. The GIIST was performed as described for the closed system.

\subsection{Results}

\subsubsection{In vivo biocompatibility}

PES/PVP microwell membranes for islet encapsulation were implanted in the epididymal fat pads (EFP) of a mouse. After 7, 15, 21 and 28 days, samples were explanted, sectioned, and stained with hematoxylin and eosin (HE). In figure 6.6 HE stained sections of a representative sample explanted after 28 days is shown. Cell infiltration into the pores of the membrane can be seen as well as the formation of a fibrous capsule around the entire scaffold (Fig 6.6A). The fibrous capsule has a thickness of approximately $50 \mu \mathrm{m}$ (Fig 6.6B and C). The microwells are indicated with red lines in figure $6.6 \mathrm{C}$. Cells were found to be able to infiltrate into the pores of the membrane (Fig 6.6D). However, cellular infiltration was not seen in the selective submicrometer layer on the outside of the membrane (red box) (Fig 6.6E). 
A

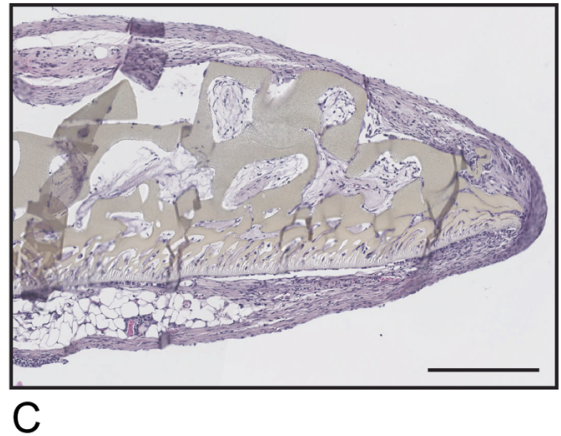

B
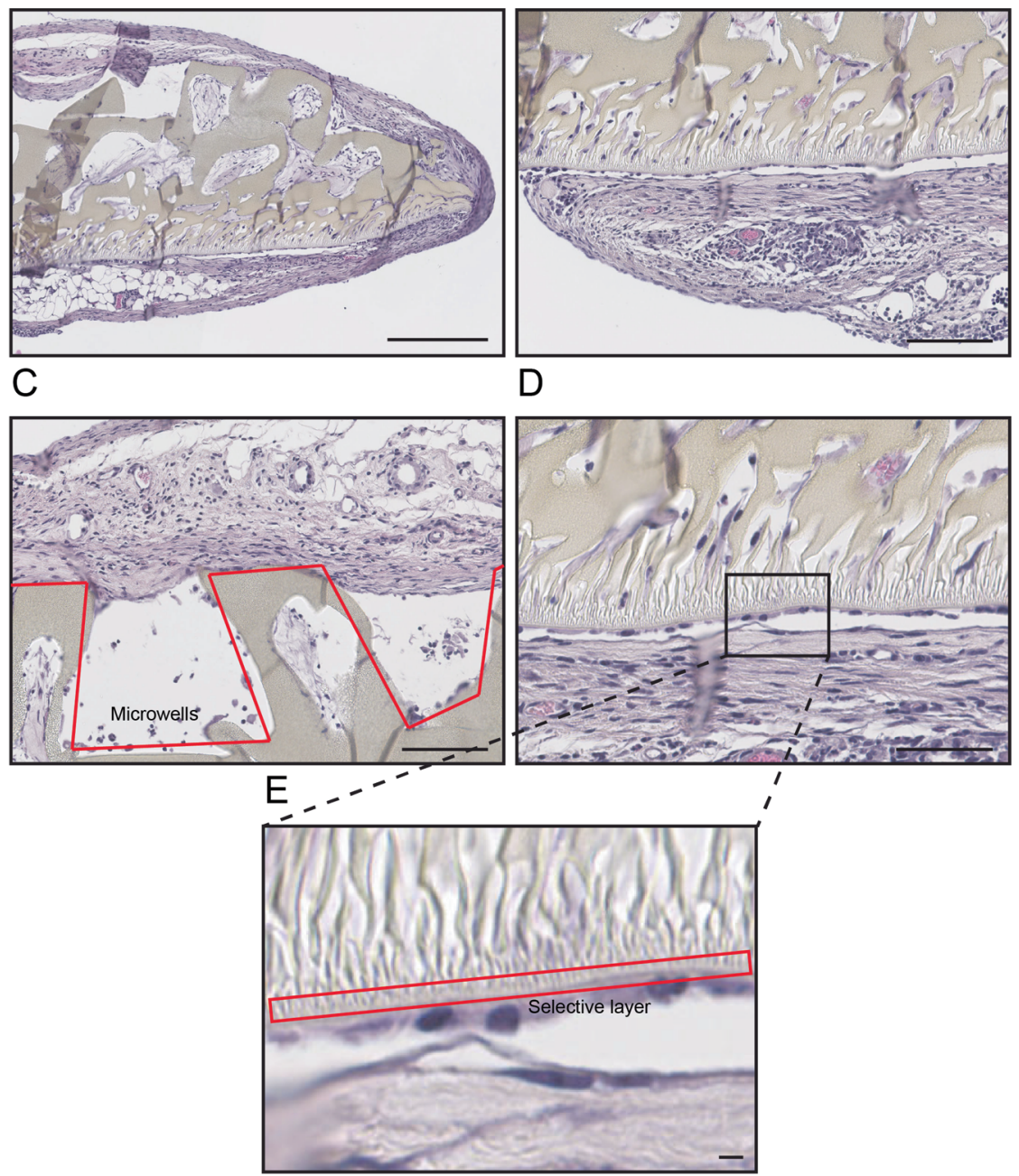

Figure 6.6: In vivo biocompatibility. Flat membranes were implanted in the epididymal fat pads (EFP) of a mouse. After 28 days, samples were explanted, sectioned, and stained with hematoxylin and eosin (HE). A) An overview of the HE section, scale bar $250 \mu \mathrm{m}$. B) Tissue formation on the bottom part of the membrane, a fibrous capsule of approximately $50 \mu \mathrm{m}$ is surrounding the membrane, scale bar $100 \mu \mathrm{m}$. C) Tissue formation around the top part of the membrane, the microwells are indicated with the red lines. Scale bar $100 \mu \mathrm{m}$. D) A high magnification of the HE stain shows cell infiltration up to the selective layer, scale bar $50 \mu \mathrm{m}$. E) The selective layer in more detail, indicated by the red box, scale bar $50 \mu \mathrm{m}$. 


\subsubsection{Pseudo islet viability in a closed device}

Pseudo-islets cultured inside the closed system were analyzed for cell survival after 1 day of culture. A live dead assay was performed to assess cell viability after 1 day of culture inside the closed system. In figure 6.7 viable pseudo-islets residing in the microwell membrane are shown, hardly any dead cells were found. Additionally, the pseudo-islets remained their rounded morphology and cells did not attach to the membrane.

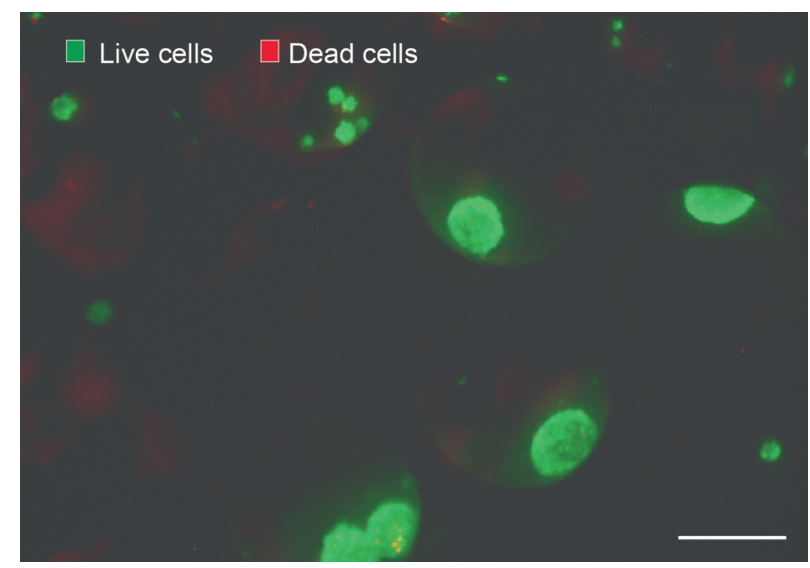

Figure 6.7: Pseudo-islets were cultured for 1 day in a closed system. After 1 day of culture, the transwell construct was opened, the PES membrane lid was removed and the pseudo-islets were stained with Calcein (live cells in green) and Ethidium homodimer (dead cells in red). Scale bar $250 \mu \mathrm{m}$

\subsubsection{Human islet functionality in vitro in a closed system}

As pseudo-islets remained viable inside the closed system, we continued with human islets inside the closed system. Microwell membranes with a $250 \mu \mathrm{m}$ casting thickness (normal) were used for encapsulation of human islets. Two different PES membranes were used as a lid for the closed system; $0.45 \mu \mathrm{m}$ and $5 \mu \mathrm{m}$ pore sized membranes. These membranes were chosen to compare the difference between a pore size known to be immune protective $(0.45 \mu \mathrm{m})$ and pores too big for immune protection $(5 \mu \mathrm{m})$ 
(22-24). After 1 day of culture a GIIST was performed to assess islets responsiveness to glucose stimulation. The results of the GIIST are depicted in figure 6.8.

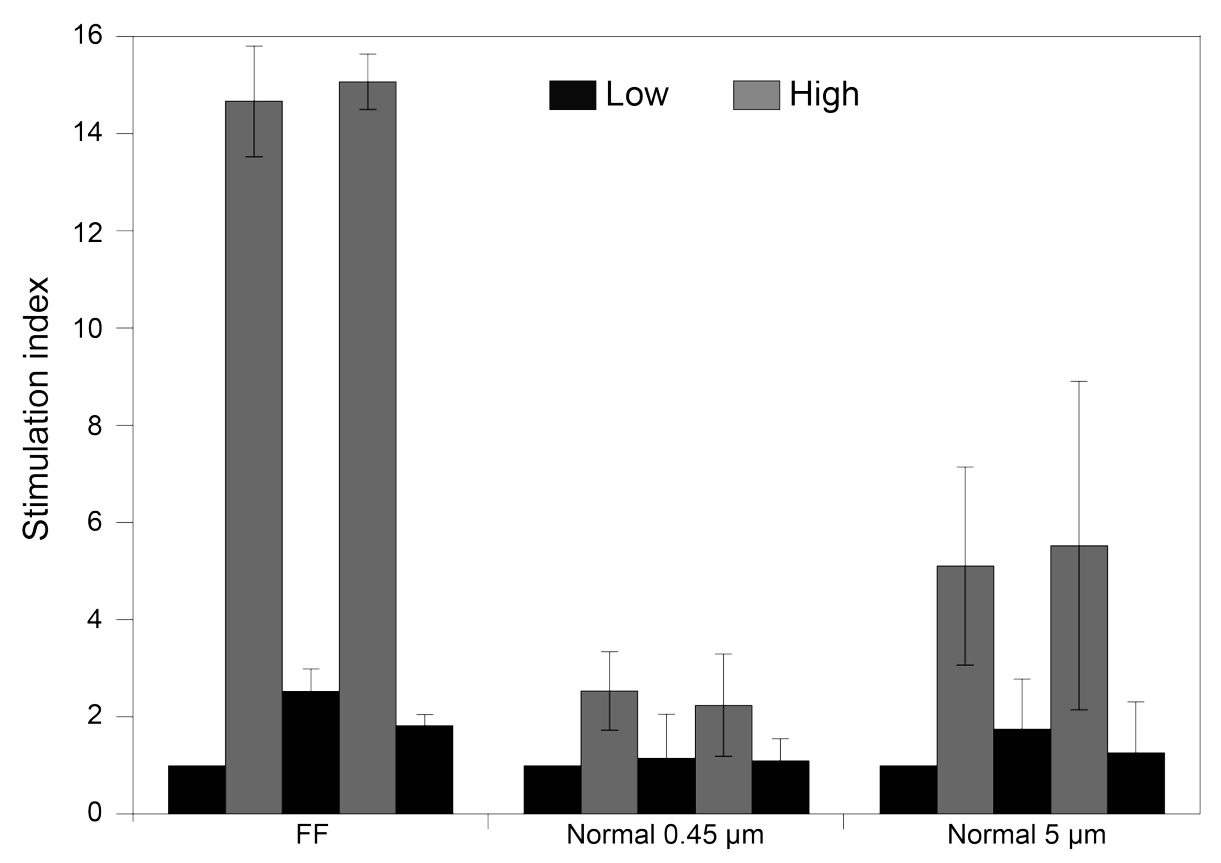

Figure 6.8: Islets encapsulated in a closed system comprising of a $250 \mu \mathrm{m}$ casting thickness (normal) microwell membrane and a $0.45 \mu \mathrm{m}$ or $5 \mu \mathrm{m}$ PES membrane lid. After 1 day of culture, glucose responsiveness was tested via a GIIST. Insulin secretion is depicted as the stimulation index by normalizing the insulin secretion to the first low glucose stimulation. Error $=\mathrm{SD}$

Insulin secretion is depicted as the stimulation index, where the insulin secretion is normalized to the first low glucose stimulation. Free floating islets were used as a control. Overall the stimulation index of encapsulated islets was found to be 6 times lower than the free floating control $(14.7 \pm 1.1$ and $15.1 \pm 0.6)$. Islets encapsulated in the normal microwell membrane with a $0.45 \mu \mathrm{m}$ lid have the lowest stimulation index $(2.5 \pm 0.8$ and $2.2 \pm 1.1)$. Although a slightly higher stimulation index was seen when islets were encapsulated with the $5 \mu \mathrm{m}$ lid $(5.1 \pm 2.0$ first high and $5.5 \pm$ 3.4 second high), still the stimulation index was lower than the free floating control. 
This indicates mass transport limitations in both conditions.

As the glucose responsiveness decreased by 6 fold, we changed the casting thickness of the microwell membrane from $250 \mu \mathrm{m}$ (normal) to $100 \mu \mathrm{m}$ (thin). Again islets were cultured in a closed system for 1 day, after which a GIIST was performed. Similar to the closed system containing a normal microwell membrane, we closed the microwell membrane with either the $0.45 \mu \mathrm{m}$ or $5 \mu \mathrm{m}$ pore sized PES lid. In figure 6.9 the glucose responsiveness of the encapsulated human islets are is shown.

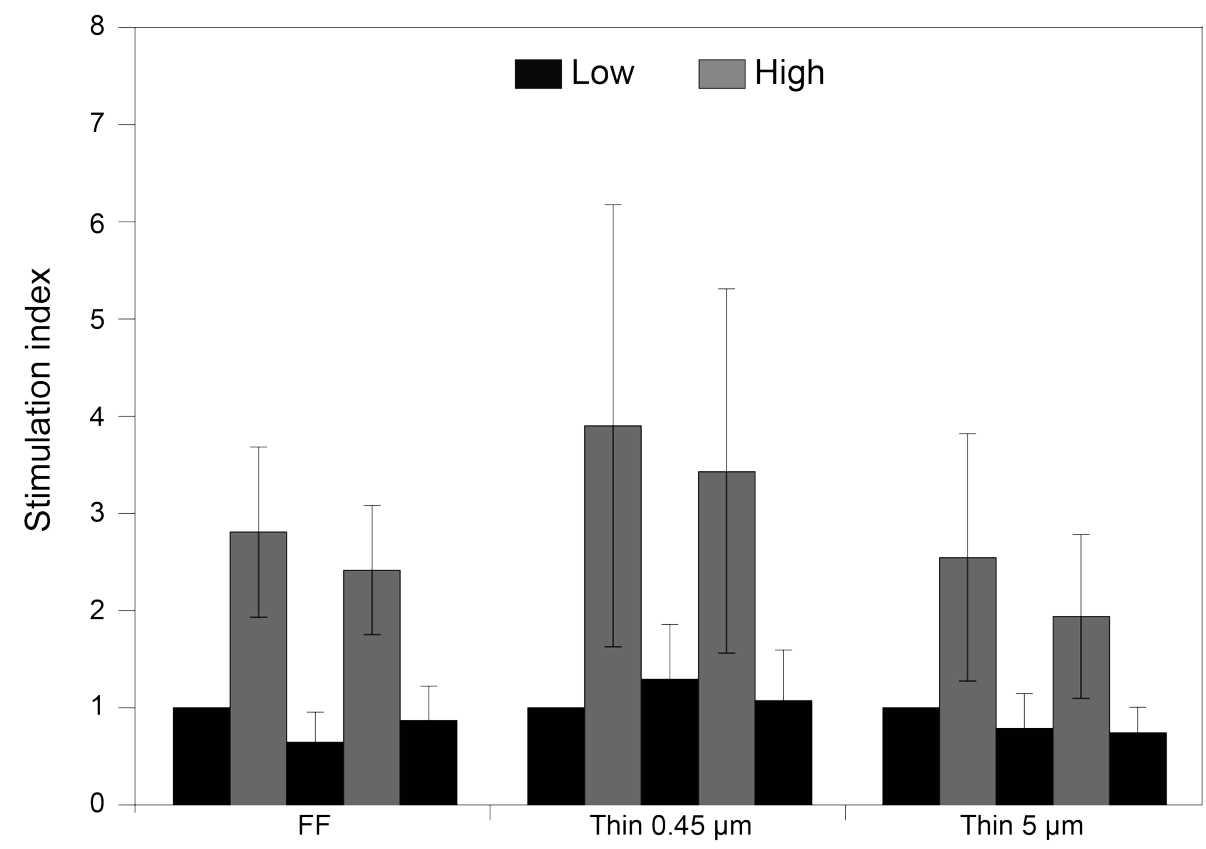

Figure 6.9: Islets encapsulated in a closed system comprising of a $100 \mu \mathrm{m}$ casting thickness (thin) microwell membrane and a $0.45 \mu \mathrm{m}$ or $5 \mu \mathrm{m}$ PES membrane lid. After 1 day of culture, glucose responsiveness was tested via a GIIST. Insulin secretion is depicted as the stimulation index by normalizing the insulin secretion to the first low glucose stimulation. Error $=\mathrm{SD}$

Again the insulin secretion is depicted as the stimulation index. Interestingly, all conditions showed similar stimulation indices. The free floating islets had a stimulation index of $2.8 \pm 0.9$ for the first high and $2.4 \pm 0.7$ for the second high. Both pore sized 
lids gave similar stimulation indices, the islets encapsulated in the $0.45 \mu \mathrm{m}$ pore sized lid had a stimulation index of $3.9 \pm 2.3$ for the first high and $3.4 \pm 1.9$ for the second high. Islets encapsulated in the $5 \mu \mathrm{m}$ pore sized lid had a stimulation index of $2.5 \pm$ 1.3 for the first high and $1.9 \pm 0.8$ for the second high. This indicates the beneficial effect of the thinner casting thickness of the microwell membrane. By decreasing the casting thickness, mass transport was increased leading to functional islets similar to the free floating islets.

\subsubsection{Functionality of encapsulated human islets in a sealed device}

The closed system showed that islets, encapsulated in thin microwell membranes combined with a $0.45 \mu \mathrm{m}$ lid, remained functional after 1 day of culture. The next step was an actual sealed device comprising of these two different membranes. With a custom designed seal device (Fig 6.5), we were able to create such a sealed device. Human islets of two donors were seeded inside these sealed devices and cultured for 7 days. After 1 day and 7 days of culture a GIIST was performed to assess islet functionality (Fig 6.10).

Similar to the closed system, insulin secretion is depicted as the stimulation index. For both human donors an increase in stimulation index was observed between day 1 and day 7. This effect was seen for both the free floating islets as well as the encapsulated islets. Where stimulation indices lied in the range of 2-3 for day 1, they increased to 4-7 for day 7 . 


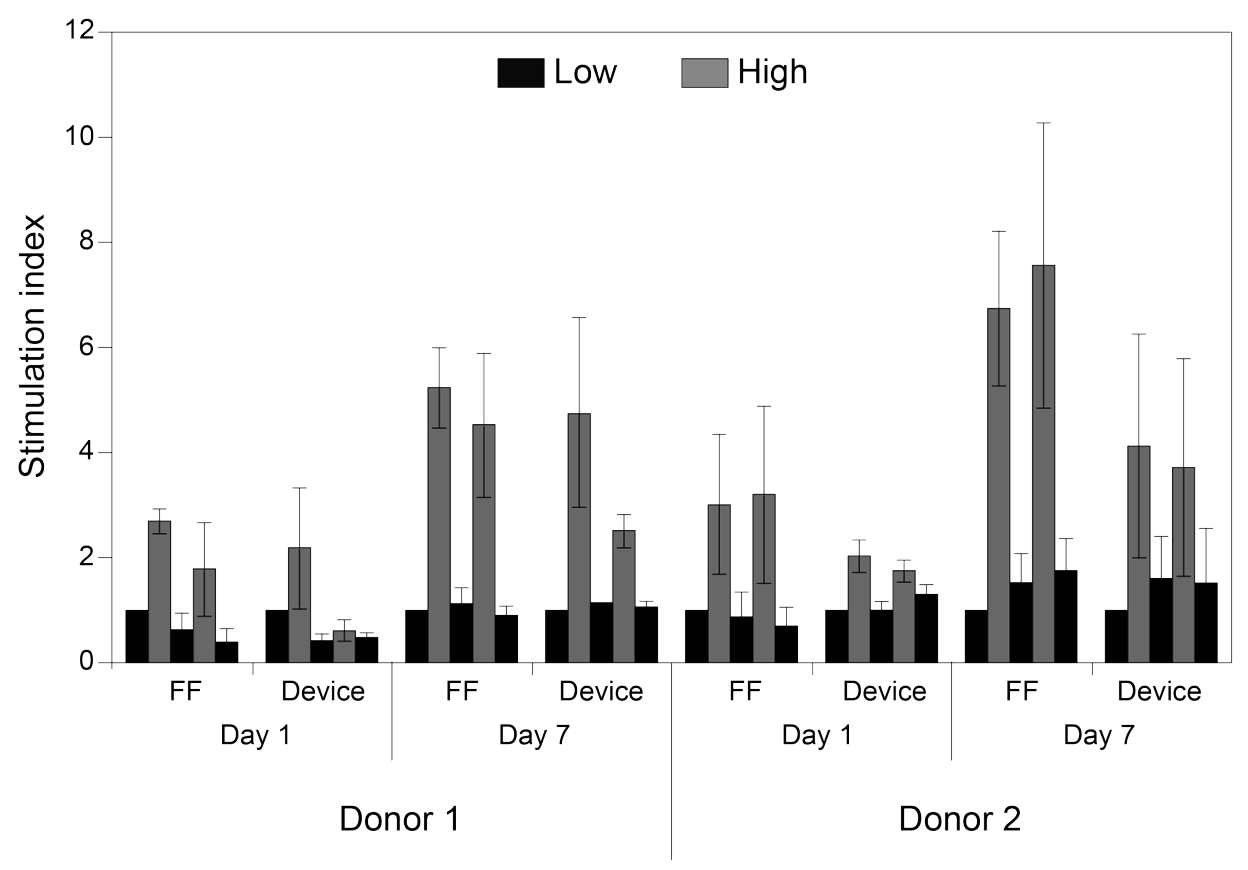

Figure 6.10: Islets encapsulated in a sealed device comprising of a $100 \mu \mathrm{m}$ casting thickness (thin) microwell membrane and a $0.45 \mu \mathrm{m}$ PES membrane lid. After 1 and 7 days of culture, the glucose responsiveness was tested via a GIIST. Insulin secretion is depicted as the stimulation index by normalizing the insulin secretion to the first low glucose stimulation. Error $=\mathrm{SD}$

Similar to the closed system, the stimulation indices of the encapsulated islets tended to be slightly lower than the free floating islets but this did not reach significance. After 7 days of culture the encapsulated islets of donor 1 had a stimulation index of $4.7 \pm 1.8$ for the first high and $2.5 \pm 0.3$ for the second high. While the free floating of the same donor had a stimulation index of $5.2 \pm 0.8$ for the first high and $4.5 \pm 1.3$ for the second high. Free floating islets from donor 2 had stimulation indices of 6.7 \pm 1.5 and $7.6 \pm 2.7$ after 7 days of culture. In comparison, encapsulated islets from the same donor showed stimulation indices of $4.1 \pm 2.1$ and $3.7 \pm 2.0$ after 7 days of culture. These results indicate that the process of sealing did not influence the mass transport. 


\subsection{Discussion}

In vivo biocompatibility of the PES/PVP microwell encapsulation device was tested by implantation in the EFP of mice. After 7, 15, 21, and 28 days the EFP containing the device was explanted and analyzed for fibrous capsule formation. After 28 days of explantation, a small fibrous capsule of $50 \mu \mathrm{m}$ present around the entire device. The influence of this fibrous capsule on islet survival and function in vivo should be examined further. One of the properties of an immune protective device is the ability to prevent infiltration of immune cells towards the islets(22-24). We showed that the microwell membrane of the device was able to prevent cell infiltration as no cells penetrated the selective layer of the membrane in the in vivo biocompatibility study.

A viability study of pseudo-islets in a closed system, indicated that pseudo-islets were able to stay viable inside the device. Additionally, the rounded morphology of islets was obtained and no cell attachment was observed. These two parameters are of great importance for a successful device $(5,9-11,13)$.

The microwell encapsulation device was further optimized using two different microwell membranes; a normal (250 $\mu$ m casting thickness) and a thin (100 $\mu \mathrm{m}$ casting thickness) microwell membrane. Additionally, two different PES lids were used to close the microwell membrane; membranes with either $0.45 \mu \mathrm{m}$ or $5 \mu \mathrm{m}$ pores. With the PES lids we wanted to determine the effect of an immune protective membrane ( $0.45 \mu \mathrm{m}$ pores) on the function of human islets compared to a more open structure (5 $\mathrm{mm}$ pores). As the development of an immune protective device is quite challenging, and a balance needs to be found between optimal survival of islets and shielding the islets from the immune system(21). A clear discrimination between human islets function was seen when islet were encapsulated in the normal microwell membrane with the two different lids. A decrease in function was seen when a $0.45 \mu \mathrm{m}$ lid was used compared to the $5 \mu \mathrm{m}$ lid. As the latter has a 100 times more open structure, this was as expected. In both conditions the stimulation index was lower than the free floating islets. However, these effects disappeared when the casting thickness of 
the membrane was decreased from $250 \mu \mathrm{m}$ to $100 \mu \mathrm{m}$. The porosity of the lids did not seem to influence the functionality of the islets anymore as in both conditions similar stimulation indices were found. This could be explained by the decrease in thickness of the microwell membrane from $250 \mu \mathrm{m}$ to $100 \mu \mathrm{m}$. Additionally, the stimulation index of both closed systems were comparable to the free floating islets. Indicating that the closed device comprising of a thin microwell membrane and a PES membrane lid does not hamper diffusion of nutrients, glucose, and insulin.

A custom made seal device made it possible to effectively seal the thin microwell membrane to the $0.45 \mu \mathrm{m}$ membrane. Human islets of 2 donors were seeded inside this sealed construct. After 1 and 7 days the functionality of the encapsulated islets was compared to the free floating islets. For both the sealed device and the free floating islet we even showed an increase in stimulation index after 7 days of culture compared to the day 1 stimulation index. Additionally, comparable stimulation indices were seen in the sealed device compared to the free floating islets. This confirmed the results from the closed system, that the device does not impede diffusion of nutrients, glucose, and insulin. Furthermore, the heat generated by the seal device and the process of sealing did not influence the properties of both membranes.

Further in vivo studies are necessary to determine the survival of islets encapsulated in the sealed PES/PVP microwell device. Additionally, in vivo studies in immune competent animals will show if the device is actually immune protective.

One important issue while transplanting islets encapsulated in an immune protective device is the lack of vascularization. Islets, normally highly vascularized, have shown to become hypoxic and necrotic when vasularization is not sufficient $(5,33)$. We propose to combine the sealed PES/PVP microwell device with mesenchymal stem cells (MSCs) to enhance vessel formation in vivo thereby increasing the change of graft survival. MSCs are known for their vessel formation potential. Interestingly, they also possess immunemodulatory properties(34-38). The PES membrane lid could be used as a carrier material for the MSCs. 
In conclusion, the PES/PVP micro encapsulation device was able to prevent cell attachment and remain the rounded morphology of islets. As $0.45 \mu \mathrm{m}$ pore size membranes have shown to be immune protective, we chose a $0.45 \mu \mathrm{m}$ pore sized PES lid to close the microwell membrane(22-24). The in vitro data suggests no diffusion limitations due to the pore sizes of the sealed construct. Furthermore, the in vivo biocompatibility study of the microwell membrane suggests that we were able to prevent cell infiltration, as the selective layer of the membrane was not infiltrated by cells. This combined with the in vitro data, we have shown that we were able to create an immune protective macro encapsulation device where islets were physically separated in microwells. 


\section{References}

1. Kheradmand, T., Wang, S., Gibly, R.F., Zhang, X., Holland, S., Tasch, J., Graham, J.G., Kaufman, D.B., Miller, S.D., Shea, L.D., and Luo, X. Permanent protection of PLG scaffold transplanted allogeneic islet grafts in diabetic mice treated with ECDIfixed donor splenocyte infusions. Biomaterials 32, 4517, 2011.

2. Dufour, J.M., Rajotte, R.V., Zimmerman, M., Rezania, A., Kin, T., Dixon, D.E., and Korbutt, G.S. Development of an ectopic site for islet transplantation, using biodegradable scaffolds. Tissue Eng 11, 1323, 2005.

3. Gibly, R.F., Zhang, X., Graham, M.L., Hering, B.J., Kaufman, D.B., Lowe, W.L., and Shea, L.D. Extrahepatic islet transplantation with microporous polymer scaffolds in syngeneic mouse and allogeneic porcine models. Biomaterials 32, 9677, 2011.

4. Gibly, R.F., Zhang, X., Lowe Jr, W.L., and Shea, L.D. Porous scaffolds support extrahepatic human islet transplantation, engraftment, and function in mice. Cell Transplant 22, 811, 2013.

5. Beck, J., Angus, R., Madsen, B., Britt, D., Vernon, B., and Nguyen, K.T. Islet encapsulation: Strategies to enhance islet cell functions. Tissue Eng 13, 589, 2007.

6. Pareta, R.A., Farney, A.C., and Opara, E.C. Design of a bioartificial pancreas. Pathobiology 80, 194, 2013.

7. Schweicher, J., Nyitray, C., and Desai, T.A. Membranes to achieve immunoprotection of transplanted islets. Front Biosci Landmark 19, 49, 2014.

8. Silva, A.I., de Matos, A.N., Brons, I.G., and Mateus, M. An overview on the development of a bio-artificial pancreas as a treatment of insulin-dependent diabetes mellitus. Medicinal Research Reviews 26, 181, 2006.

9. Lehmann, R., Zuellig, R.A., Kugelmeier, P., Baenninger, P.B., Moritz, W., Perren, A., Clavien, P.A., Weber, M., and Spinas, G.A. Superiority of small islets in human islet transplantation. DIABETES 56, 594, 2007.

10. Andersson, A. Isolated mouse pancreatic islets in culture: Effects of serum and different culture media on the insulin production of the islets. Diabetologia 14, 397, 1978. 
11. MacGregor, R.R., Williams, S.J., Tong, P.Y., Kover, K., Moore, W.V., and Stehno-Bittel, L. Small rat islets are superior to large islets in in vitro function and in transplantation outcomes. Am J Physiol Endocrinol Metab 290, E771, 2006.

12. Nam, K.H., Yong, W., Harvat, T., Adewola, A., Wang, S., Oberholzer, J., and Eddington, D.T. Size-based separation and collection of mouse pancreatic islets for functional analysis. Biomed Microdevices 12, 865, 2010.

13. Weinberg, N., Ouziel-Yahalom, L., Knoller, S., Efrat, S., and Dor, Y. Lineage tracing evidence for in vitro dedifferentiation but rare proliferation of mouse pancreatic $\beta$-cells. DIABETES 56, 1299, 2007.

14. Rackham, C.L., Jones, P.M., and King, A.J.F. Maintenance of Islet Morphology Is Beneficial for Transplantation Outcome in Diabetic Mice. PLoS ONE 82013.

15. Buitinga, M., Truckenmuller, R., Engelse, M.A., Moroni, L., Ten Hoopen, H.W.M., van Blitterswijk, C.A., de Koning, E.J.P., van Apeldoorn, A.A., and Karperien, M. Microwell Scaffolds for the Extrahepatic Transplantation of Islets of Langerhans. PLoS ONE 82013.

16. Silva, A.I., and Mateus, M. Development of a polysulfone hollow fiber vascular bio-artificial pancreas device for in vitro studies. Journal of Biotechnology 139, 236, 2009.

17. Grundfest-Broniatowski, S.F., Tellioglu, G., Rosenthal, K.S., Kang, J., Erdodi, G., Yalcin, B., Cakmak, M., Drazba, J., Bennett, A., Lu, L., and Kennedy, J.P. A new bioartificial pancreas utilizing amphiphilic membranes for the immunoisolation of porcine islets a pilot study in the canine. ASAIO Journal 55, 400, 2009.

18. Lacy, P.E., Hegre, O.D., Gerasimidi-vazeou, A., Gentile, F.T., Dionne, E., Science, S., Series, N., Dec, N., and Dionne, K.E. Maintenance of Normoglycemia in Diabetic Mice by Subcutaneous Xenografts of Encapsulated Islets Science 254, 1782, 1991.

19. Risbud, M.V., and Bhonde, R.R. Islet immunoisolation: Experience with biopolymers. J Biomater Sci Polym Ed 12, 1243, 2001.

20. Colton, C.K. Oxygen supply to encapsulated therapeutic cells. Adv Drug Deliv Rev 67-68, 93, 2014. 
21. Tilakaratne, H.K., Hunter, S.K., Andracki, M.E., Benda, J.A., and Rodgers, V.G.J. Characterizing short-term release and neovascularization potential of multiprotein growth supplement delivered via alginate hollow fiber devices. Biomaterials 28, 89, 2007.

22. Barkai, U., Weir, G.C., Colton, C.K., Ludwig, B., Bornstein, S.R., Brendel, M.D., Neufeld, T., Bremer, C., Leon, A., Evron, Y., Yavriyants, K., Azarov, D., Zimermann, B., Maimon, S., Shabtay, N., Balyura, M., Rozenshtein, T., Vardi, P., Bloch, K., De Vos, P., and Rotem, A. Enhanced oxygen supply improves islet viability in a new bioartificial pancreas. Cell Transplant 22, 1463, 2013.

23. Brauker, J., Martinson, L.A., Young, S.K., and Johnson, R.C. Local inflammatory response around diffusion chambers containing xenografts: Nonspecific destruction of tissues and decreased local vascularization. TRANSPLANTATION 61, 1671, 1996.

24. Loudovaris, T., Jacobs, S., Young, S., Maryanov, D., Brauker, J., and Johnson, R.C. Correction of diabetic nod mice with insulinomas implanted within Baxter immunoisolation devices. Journal of molecular medicine (Berlin, Germany) 77, 219, 1999.

25. Hanafi, Y., Szymczyk, A., Rabiller-Baudry, M., and Baddari, K. Degradation of poly(ether sulfone)/polyvinylpyrrolidone membranes by sodium hypochlorite: Insight from advanced electrokinetic characterizations. Environ Sci Technol 48, 13419, 2014. 26. Pellegrin, B., Gaudichet-Maurin, E., and Causserand, C. Mechano-chemical ageing of PES/PVP ultrafiltration membranes used in drinking water production. Water Science and Technology: Water Supply2013. pp. 541.

27. Rouaix, S., Causserand, C., and Aimar, P. Experimental study of the effects of hypochlorite on polysulfone membrane properties. J Membr Sci 277, 137, 2006.

28. Wienk, M., Meuleman, E.E.B., Borneman, Z., Van Den Boomgaard, T., and Smolders, C.A. Chemical treatment of membranes of a polymer blend: mechanism of the reaction of hypochlorite with poly(vinyl pyrrolidone). J Polym Sci Part A 33, 49, 1995.

29. Papenburg, B.J., Vogelaar, L., Bolhuis-Versteeg, L.A.M., Lammertink, R.G.H., Stamatialis, D., and Wessling, M. One-step fabrication of porous micropatterned scaf- 
folds to control cell behavior. Biomaterials 28, 1998, 2007.

30. Vogelaar, L., Barsema, J.N., Van Rijn, C.J.M., Nijdam, W., and Wessling, M. Phase Separation Micromolding - PSuM. Adv Mater 15, 1385, 2003.

31. Vogelaar, L., Lammertink, R.G.H., Barsema, J.N., Nijdam, W., Bolhuis-Versteeg, L.A.M., Van Rijn, C.J.M., and Wessling, M. Phase separation micromolding: A new generic approach for microstructuring various materials. Small 1, 645, 2005.

32. Hilderink, J., Spijker, S., Carlotti, F., Lange, L., Engelse, M., van Blitterswijk, C., de Koning, E., Karperien, M., and van Apeldoorn, A. Controlled aggregation of primary human pancreatic islet cells leads to glucose-responsive pseudoislets comparable to native islets. J Cell Mol Med 17, 12555, 2015.

33. Ballian, N., and Brunicardi, F.C. Islet vasculature as a regulator of endocrine pancreas function. World J Surg 31, 705, 2007.

34. Brusko, T.M. Mesenchymal stem cells: A potential border patrol for transplanted islets? DIABETES 58, 1728, 2009.

35. Ding, Y., Bushell, A., and Wood, K.J. Mesenchymal stem-cell immunosuppressive capabilities: Therapeutic implications in islet transplantation. TRANSPLANTATION 89, 270, 2010.

36. Ding, Y., Xu, D., Feng, G., Bushell, A., Muschel, R.J., and Wood, K.J. Mesenchymal stem cells prevent the rejection of fully allogenic islet grafts by the immunosuppressive activity of matrix metalloproteinase-2 and -9. DIABETES 58, 1797, 2009.

37. Jiang, X.X., Zhang, Y., Liu, B., Zhang, S.X., Wu, Y., Yu, X.D., and Mao, N. Human mesenchymal stem cells inhibit differentiation and function of monocyte-derived dendritic cells. Blood 105, 4120, 2005.

38. Spaggiari, G.M., Capobianco, A., Becchetti, S., Mingari, M.C., and Moretta, L. Mesenchymal stem cell-natural killer cell interactions: Evidence that activated NK cells are capable of killing MSCs, whereas MSCs can inhibit IL-2-induced NK-cell proliferation. Blood 107, 1484, 2006. 



\title{
Chapter 7
}

\section{Mesenchymal stem cells and micropatterns of poly(ether}

\author{
sulfone)/ poly(vinylpyrrolidone)
}

\section{membranes accelerate}

\section{vascularization}

Milou Groot Nibbelink, Katarzyna Skrzypek, Lisanne Karbaat, Sanne Both, Jacqueline Plass, Bettie Klomphaar, Jéré van Lente, Sieger Henke, Marcel Karperien, Dimitrios Stamatialis, Aart van Apeldoorn 


\subsection{Abstract}

Extrahepatic transplantation of islets of Langerhans could aid in better survival of islets after transplantation. When islets are transfused into the liver $60-70 \%$ of donor islets of Langerhans are lost immediately after transplantation. An important factor for a successful extrahepatic transplantation is a well-vascularized network surrounding the device. There are many strategies known to enhance vessel formation around a device like the addition of cells with endothelial potential, the combination with angiogenic factors, and the use of micropatterns at the exposed surface of the device. The aim of this paper was to test the additive effect of combining two strategies, MSCs and micropatterns, to enhance scaffold vascularization. Inert poly(ether sulfone)/poly(vinylpyrrolidone) (PES/PVP) membranes are normally non cell adherent. Cell growth to PES/PVP membranes was achieved by coating the membranes with fibronectin. Already in vitro we showed a positive effect of the micropatterned membranes on MSC alignment and organization, an important contributor to vessel formation. A subcutaneous rat model was used to address if MSCs and micropatterns separately had an effect on the rate of vascularization. Additionally, we analyzed the additive effect of these two strategies. However, when combined there seemed to be no additive effect of the micropatterns. In conclusion, we were able to enhance in vivo vessel formation with micropatterned PES/PVP membranes and MSCs. 


\subsection{Introduction}

In clinical islet transplantation (CIT) 60-70\% of the donor islets of Langerhans are lost immediately after transplantation. This is due to many different factors such as mechanical stress, different immune-responses, and lack of vascularization. After intraportal infusion, islets are immediately exposed to high concentrations of drugs and nutrients, such as glucose, negatively affecting islet function(1-8). Additionally, islets are in a pro-inflammatory state at the moment of transplantation due to the isolation procedure(9). In this state islets express inflammatory mediators, leading to the onset of different immune-responses, like Instant Blood Mediated Immune Response (IBMIR) and alloresponse(9).

Previous research has focused on improving the transplantation outcome by immuneprotective strategies that prevent immune cells from reaching encapsulated islets while maintaining islet viability as best as possible. Good examples of this are membrane based scaffolds as they could both maintain islet viability and act as a physical barrier for the immune system. These scaffolds need to meet the following stringent requirements; islets need to be kept separated from the blood stream, the device needs to be permeable for glucose, insulin, nutrients, and oxygen, and the device needs to be impermeable to the immune cells to prevent cell-cell contact. However, the transport of glucose, insulin, oxygen, and nutrients should not be compromised by the immune-protection as this will lead to islet necrosis and a loss of function(2, 10-15). It is therefore important to find a proper balance between optimal survival of islets on one hand and immune protection on the other(16). When solely focusing on islet survival, the device should be as open as possible to prevent diffusion limitations and to allow for vessel ingrowth. However, when creating a device for immune-protection, the device needs to be more closed consequently preventing islet vascularization and impeding diffusion limitations.

One of the focus points while designing an immune protective scaffold for extrahepatic islet transplantation is the possibility to prevascularize the scaffold or to enhance vascularization directly after implantation. It is important to provide blood supply 
as close to the islets as possible as for one, the isolation process disrupts their own vasculature and two, islets are normally highly vascularized in the pancreas. In fact they receive $5-15 \%$ of the total blood supply of the pancreas while they only consist of $1 \%$ of the entire pancreas mass(17-19). Normally, islets become hypoxic due to the disruption of their vasculature during isolation. Neo-angiogenesis will allow perfusion of islets, however this generally starts 7 days post transplantation. It is known that hypoxia leads to a loss of viability and glucose responsiveness $(1-3,10,11,20)$.

There are many different ways to enhance vascularization of the encapsulated islets, either by prevascularization of the device or by induction of vascularization in vivo(19, 21). This can be achieved by the release of angiogenic factors by drugs or cells, but also using materials with specific micropatterns, and the reduction of the immune response that is responsible for the formation of the fibrous capsule(15). Baxter Healthcare discovered that micropatterns could positively influence vessel formation already in 1990. More recently, Song et al. showed that MSCs on micropatterned PDMS had a positive effect on vessel formation in vivo(22). Micropatterns aid in alignment and organization of cells, which has shown to be an important contributor to vessel formation(23). Vascular endothelial growth factor (VEGF) is one of the most used angiogenic factors $(15,16)$. Interestingly, VEGF is also known to play an important role in regulating islet vascularization and function(24). VEGF is even secreted by the $\beta$ cells themselves. Unfortunately, the process of islet isolation impairs the expression of VEGF-A in $\beta$ cells $(24,25)$. Therefore, the addition of VEGF to the a device has shown to enhance the vascularization locally $(15,19,26)$. There are also other angiogenic factors used for the induction of vascularization, like endothelial cell growth factor and basic fibroblast growth factor(16). Vascularization could also be achieved by adding cell types with endothelial potential, like mesenchymal stromal cells (MSCs), fibroblasts, endothelial (progenitor) cells, and bone marrow progenitor cells to the islet implant. Addition of cells could be achieved by seeding cells on the scaffold or by coating islets with cells(15, 24, 25, 27-32). Using MSCs in an immuneprotective device does not only aid in vessel formation but they have the additional advantage of being immune modulatory. Therefore MSCs could reduce the immune 
response against the encapsulated islets. Finally autologous MSCs can be derived from a bone marrow aspirate taken from the patients, a huge advantage for clinical islet transplantation(33-37).

We tested three different micropatterns as depicted in figure 7.1: Non - patterned membranes, membranes with an intermittent pattern (bricks), and membranes with an intermittent pattern of bricks in combination with continuous parallel lines (channels) for the induction of vessel formation. The difference in patterns lies in the full intermittent pattern and the pattern with continuous lines. The first goal of these patterns was to obtain cell alignment and orientation as this enhances vessel formation(23). We therefore choose a distance of $100 \mu \mathrm{m}$ between the bricks on both patterns as studies had shown that alignment occurs in channels as small as $20 \mu \mathrm{m}$ to $130 \mu \mathrm{m}[38]$. Additionally, when creating a vascular device, it is important to create a sufficient vascular network for the application(39). As islets would be homogenously distributed inside a flat immune protective device, we aimed at an interconnected dense vascular network. Therefore the design of the micropatterns contained intermittent bricks.

The aim of this paper was to test the effect of two strategies, micropatterns and MSCs, on vascularization. Additionally, the additive effect of combining these two strategies to enhance scaffold vascularization was tested. We hypothesized that the combination of MSCs and micropatterns could potentially enhance vascularization in vivo. The material of choice was PES/PVP, an inert material with good biocompatibility properties. In order to achieve cell growth, cell attachment to PES/PVP was achieved using a coating of fibronectin. The different membranes were implanted in a subcutaneous rat model to address if micropatterns had an effect on the rate of vascularization. Additionally, we investigated the effect of MSCs on the rate of vascularization. 


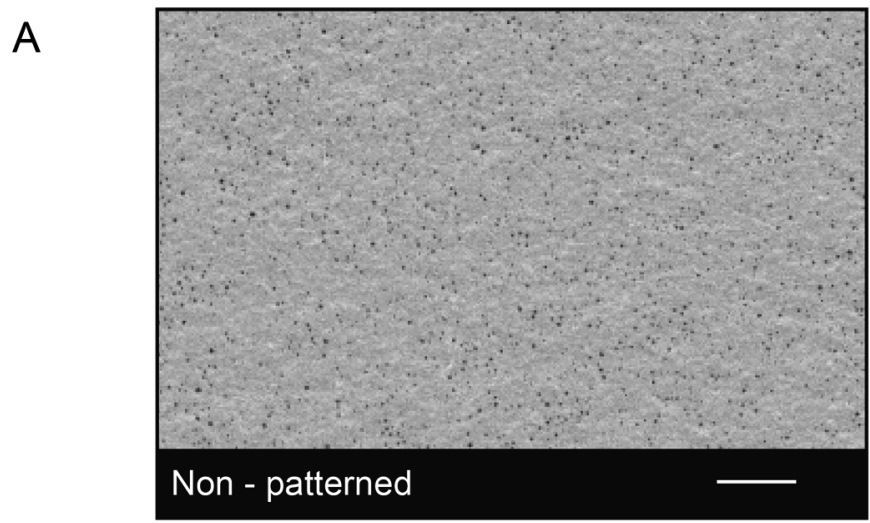

B

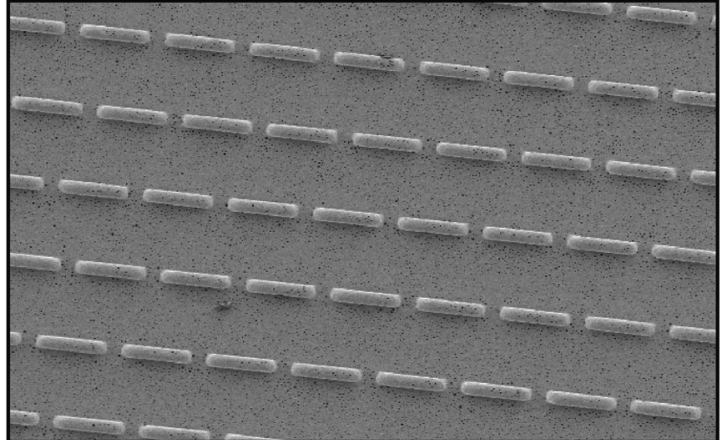

Bricks

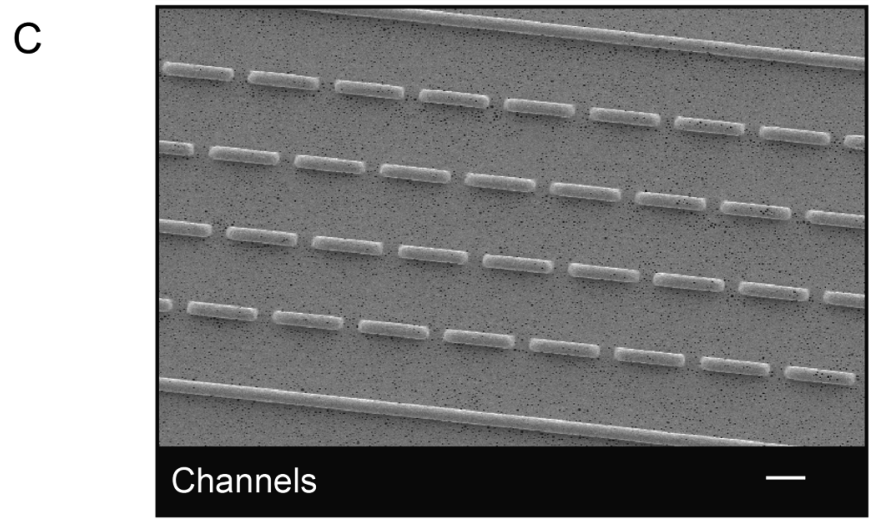

Figure 7.1: Different micropattern configurations of the porous membrane for vascularization: Non - patterned (A), bricks (B), and channels (C). (Scale bars $200 \mu \mathrm{m}$ ) 


\subsection{Materials and Methods}

\subsubsection{Membrane fabrication}

A 15 wt\% poly-(ether sulfone) (PES) (Ultrason, the Netherlands) 5 wt\% poly- (vinyl pyrrolidone) (PVP) (Sigma-Aldrich) polymer solution in N-methylpyrrolidone (NMP) (Sigma-Aldrich) was used to cast membranes. The polymer was casted on a glass plate (for flat membranes) or on a micropatterend silicon wafer for the creating of the different micropatterns. Micropatterns were $40 \mu \mathrm{m}$ in height and $100 \mu \mathrm{m}$ apart and the bricks had a length of $100 \mu \mathrm{m}$. When, directly after casting, the polymer was submerged in a water coagulation bath, phase separation occurred and porous membranes were formed. In order to obtain dense, flat membranes, the polymer was left on the glass plate for $1.5 \mathrm{~h}$ for precipitation in the air. A top layer of the polymer film became turbid and subsequently the glass plate was submerged in the water coagulation bath, where membranes with a dense skin layer were formed. Finally, all the membranes were rinsed with demineralized water in order to remove remaining solvent traces and stored in demineralized water till further use.

\subsubsection{Animal housing and cell culture}

The ethical committee of the University Medical Center Utrecht approved the animal experiments. The care and operative procedure of the rats were performed conform the regulation of the central laboratory animal institute in Utrecht. All animal studies were performed at the University of Twente. Rat bone marrow derived MSCs were harvested from two 10-11 week old female Lewis rats (Harlan, the Netherlands). Rats were euthanized with $\mathrm{CO}_{2}$, shaved, and the skin was sterilized using $70 \%$ ethanol. Both femurs were resected and placed in sterile PBS with $200 \mathrm{U} / \mathrm{mL}$ Penicillin and $2 \mathrm{mg} / \mathrm{mL}$ Streptomycin (Gibco) for at least $15 \mathrm{~min}$. The epiphysis were cut off and the femur was flushed with Minimum Essential Medium $\alpha$ ( $\alpha$-MEM, Life Technologies) with $2 \mathrm{~mm}$ GlutaMAX, $100 \mathrm{U} / \mathrm{mL}$ penicillin and $1 \mathrm{mg} / \mathrm{mL}$ streptomycin (Gibco), and $0.2 \mathrm{~mm}$ L-ascorbic acid-2-phosphate (ASAP) using a $22 \mathrm{G}$ needle and syringe. The cell suspension per femur was plated in 1 flask. FBS was added to the cell suspension 
with a final concentration of $10 \%$. After three days, the medium was refreshed. MSCs were grown to $80 \%$ confluence using Minimum Essential Medium $\alpha$ ( $\alpha$-MEM, Life Technologies) with 10\% FBS, $2 \mathrm{~mm}$ GlutaMAX, $100 \mathrm{U} / \mathrm{mL}$ penicillin and $1 \mathrm{mg} / \mathrm{mL}$ streptomycin (Gibco), and 0.2 mM L-ascorbic acid-2-phosphate (ASAP).

\subsubsection{Coating of membranes}

Scaffolds were coated with fibronectin (Sanquin, Amsterdam) to enable cell attachment. Membranes were cut fit for a 24-wellplate and fixed with o-rings (Eriks), they were sterilized with $70 \%$ Ethanol for 30 min after which they were washed with PBS twice. Membranes were then kept in PBS and washed $3 \mathrm{x}$ with $\mathrm{dH}_{2} \mathrm{O}$ before use. Fibronectin solution of $1 \mathrm{mg} / \mathrm{mL}$ or $200 \mu \mathrm{g} / \mathrm{mL}$ was prepared in PBS. The solution was put on the membranes and incubated for $30 \mathrm{~min}$ at $37^{\circ} \mathrm{C}$. After incubation with fibronectin membranes were incubated with culture medium for $1 \mathrm{~h}$, after which cells were seeded on top.

\subsubsection{Cell attachment on membranes}

Cell attachment was assessed on dense and porous membranes using uncoated or fibronectin $(200 \mu \mathrm{g} / \mathrm{mL}$ or $1 \mathrm{mg} / \mathrm{mL})$ coated PES/PVP membranes. MSCs were seeded with a density of 10.000 cells $/ \mathrm{cm}^{2}$ and kept in culture for 1 and 4 days. Subsequently, samples were fixed in $10 \%$ buffered formalin for $10 \mathrm{~min}$ and stained with methylene blue. Directly after staining images were taken using a Nikon SMZ800 microscope. Quantification of the amount of cells on fibronectin coated membranes was done by taking 3 pictures of each membrane and counting the amount of cells.

\subsubsection{Cell alignment on micropatterned membranes}

MSCs were seeded on micropatterned membranes (bricks and channels) to assess if these cells align with the micropatterns $(n=3)$. Similar to the cell attachment experiments cells were seeded on $200 \mu \mathrm{g} / \mathrm{mL}$ fibronectin coated membranes (10.000 cells $/ \mathrm{cm}^{2}$ ). After 7 days samples were fixed in $10 \%$ formalin for $10 \mathrm{~min}$ and stained us- 
ing DAPI (Invitrogen, 1:100). Images were taken using a BDpathway 435 microscope and analyzed using CellProfiler (v 2.1.1). Using this method the nucleus alignment was estimated. The orientation of the nucleus was defined as: the angle between the $\mathrm{x}$-axis and the major axis of the ellipse of the nuclei.

\subsubsection{Micropatterned membranes and MSCs for in vivo vascularization in female Lewis rats}

In vivo vascularization of the micropatterned membranes and the addition of MSCs were tested by subcutaneous implantation in female Lewis rats. In short; nonpatterned, bricks, and channels PES/PVP membranes $\left(0.79 \mathrm{~cm}^{2}\right)$ were sterilized in $70 \%$ ethanol, was in PBS and coated with $200 \mu \mathrm{g} / \mathrm{mL}$ fibronectin. MSCs isolated from female Lewis rats were seeded on the membranes (Pooled from 4 femurs, Passage 2, 3.000 cells $\left./ \mathrm{cm}^{2}\right)$. After 4 days of culture membranes were ready for implantation. Control membranes were fixed and stained for methylene blue to confirm the presence of a monolayer upon implantation.

11-12 week old female Lewis rats $(n=6)$ (Harlan, the Netherlands), were injected subcutaneously with Carprofen $(5 \mathrm{mg} / \mathrm{kg} 30 \mathrm{~min}$ before surgery. Then they were anesthetized using isoflurane, their back was shaved and sterilized using $70 \%$ ethanol and Betadine. During the entire surgery their temperature was monitored rectally. Six subcutaneous pockets were created on the back of each rat. In each pocket a membrane was implanted. Each condition was implanted in each rat in a randomized order to correct for a possible influence of location. The incisions were first closed intracutaneously and finally the skin was sutured. After 14 days, the rats were euthanized with $\mathrm{CO}_{2}$, samples were explanted, fixed in $4 \%$ buffered paraformaldehyde $\left(\mathrm{ON}, 4^{\circ} \mathrm{C}\right.$, Sigma Aldrich), and processed for immunohistochemistry. From each sample three locations with at least $125 \mu \mathrm{m}$ between the samples were used for analysis. Sections were stained for Toluidine Blue to detect mast cells. In short: Toluidine blue (Sigma Aldrich) was dissolved in $70 \%$ ethanol. At the day of staining, the stock solution was 10x diluted in $1 \%$ sodium chloride, after which the $\mathrm{pH}$ was set at 2.3. Deparaffinized 
and hydrated sections were stained with the working solution for 3 min. Finally samples were dehydrated, cleared with xylene and mounted in Tissue Tex. A Masson Goldner Trichrome staining was performed to detect vessels using the manufacture?s protocol (Merck Chemicals, Darmstadt, Germany). Stained microscopy slides were scanned using a Nanozoomer slide scanner 2.0 RS (Hamamatsu, Hamamatsu City, Japan). Trichrome stained sections from day 14 samples (with a folded configuration upon explantation) were scored by three blinded individuals, independently to assess the extent of vessel formation. Sections were scored with,,-+ or ++ for vessel formation.

\subsubsection{Statistical analysis}

To determine the effect of fibronectin concentration on cell attachment the following analysis was performed. From each sample three pictures were taken, since all used cell types have the tendency to grow in clusters after initial attachment, pictures were taken of the densest, least dense and average covered areas. Average cell numbers on $1 \mathrm{~mm}^{2}$ were determined for each sample. Statistical differences in cell numbers between the conditions and control were determined by a Welch t-test $(\mathrm{p}<0.05=$ $*, \mathrm{p}<0.01=* *$ and $\mathrm{p}<0.001=* * *)$. Fleiss'kappa was used to establish agreement between the three observers of the Trichrome staining. The overall obtained kappa was 0.32 (fair agreement) and there was a moderate agreement $(\kappa=0.63)$ for the ++ classification.

\subsection{Results}

\subsubsection{Cell attachment of MSCs to PES/PVP porous membranes}

The first step was to induce cell attachment to the membranes as PES/PVP does not have good cell adhesive properties. Rat bone marrow derived MSCs were seeded on dense and porous PES/PVP membranes (Figure 7.2). MSCs seeded on dense membranes (left panel) were able to attach to PES/PVP membranes. A slight increase in cell attachment was seen when dense membranes were coated with fibronectin 
$(1 \mathrm{mg} / \mathrm{mL})$ compared to uncoated membranes. Comparing dense and porous membranes, an increase in cell attachment was observed on the porous membranes compared to the dense membranes. On the porous membranes better cell attachment of MSCs was seen on the fibronectin coated membranes compared to uncoated membranes.
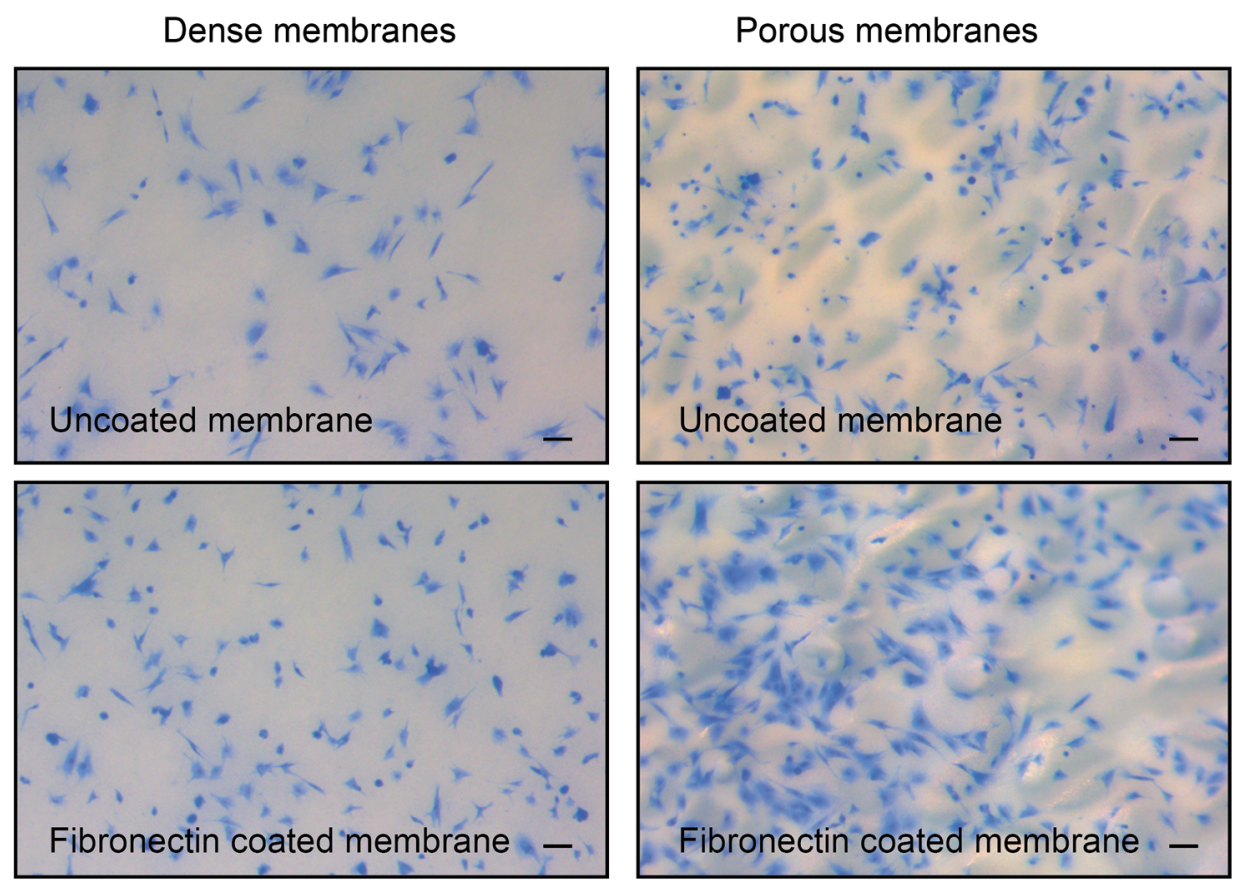

Figure 7.2: MSC attachment to PES/PVP membranes visualized by methylene blue staining after 1 day of culture. MSCs (10.000 cells $/ \mathrm{cm}^{2}$ ) were seeded on dense (left panel) and porous (right panel) PES/PVP membranes. Membranes were either uncoated (top) or coated with fibronectin ( $1 \mathrm{mg} / \mathrm{mL}$, bottom). (Scale bars $100 \mu \mathrm{m})$.

An optimal fibronectin concentration was further determined by seeding MSCs on porous membranes coated with two different concentrations of fibronectin $(200 \mu \mathrm{g} / \mathrm{mL}$ and $1 \mathrm{mg} / \mathrm{mL}$ ). Figure 7.3 shows the effect of fibronectin on MSC attachment on porous PES/PVP membranes. On day 1 a significant effect of $200 \mu \mathrm{g} / \mathrm{mL}$ fibronectin coating was seen on cell attachment compared to the uncoated membrane. After four days, equal numbers of cells were attached to uncoated and fibronectin coated 
membranes.

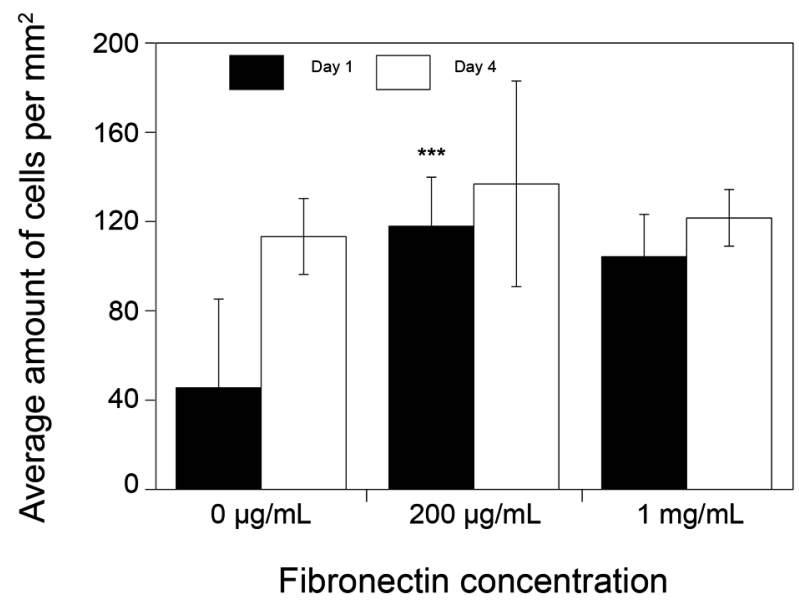

Figure 7.3: Figure 3: Optimization of the fibronectin concentration on cell attachment of MSCs to PES/PVP dense porous membranes. MSCs were seeded $(10.000$ cells $/ \mathrm{cm} 2)$ onto membranes coated with $0 \mu \mathrm{g} / \mathrm{mL}, 200 \mu \mathrm{g} / \mathrm{mL}$, and $1 \mathrm{mg} / \mathrm{mL}$ fibronectin, after 1 day (black) and 4 days (white) of culture the total amount of cells per $\mathrm{mm}^{2}$ was determined. Error $=$ SD

\subsubsection{MSC nucleus alignment on micropatterned membranes}

As alignment and organization of cells has shown to increase vessel formation, we assessed if the MSCs could sense the micropatterns and if they would then align to the micropatterns. Figure 7.4 shows that both the bricks and channels micropatterned membranes induced MSC alignment to the micropatterns. On the contrary when seeded on the flat membranes, MSCs showed random organization as there nucleus orientation was equally distributed in all directions. 


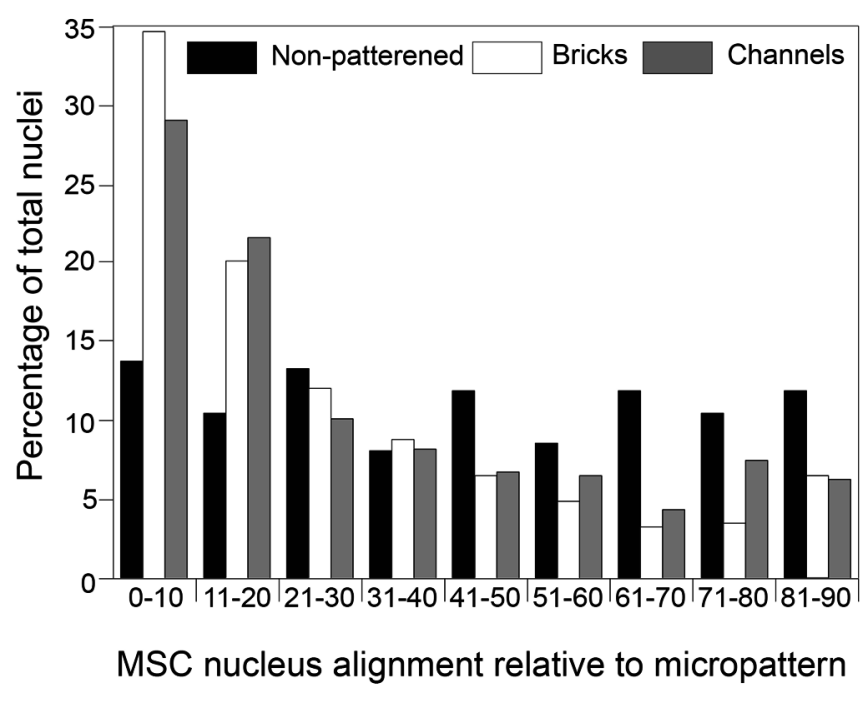

Figure 7.4: MSC nucleus alignment relative to micropatterns, where 0 degrees means that the nucleus was oriented parallel to the micropattern. Alignment to flat (black), bricks (white), and channel (grey) membranes was determined.

\subsubsection{MSCs and micropatterns for in vivo vascularization in female Lewis rats}

We assessed the effect the two strategies on vessel formation in detail, by analyzing the effect of MSCs compared to no cells and the effect of non-patterend and micropatterend membranes on vessel formation in vivo. Finally, we tested the additive effect of the combination of the micropatterned membranes and MSCs on the formation of vessels in vivo. Thereby discriminating between intermittent micropatterns and intermittent patterns in combination with continuous lines.

After four days of culture, samples were either fixed for methylene blue staining to show the presence of a cell layer (Fig 7.5A) or implanted subcutaneously on the back of female Lewis rats. As shown in figure 7.5A, MSCs were present on each type of membrane. Similar to figure 7.4, cells were aligned to the micropatterns whereas cells were not organized in one direction on non-patterned membranes. After 14 days of implantation, the majority of the membranes could be explanted easily (64\%). 
A

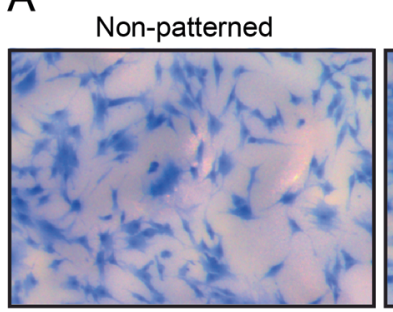

B

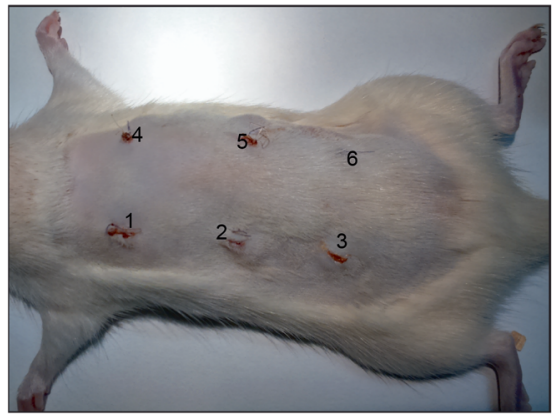

Bricks

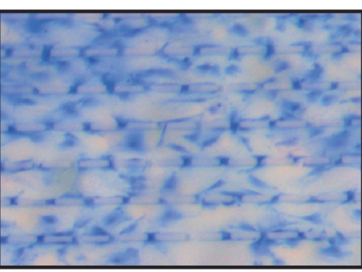

C

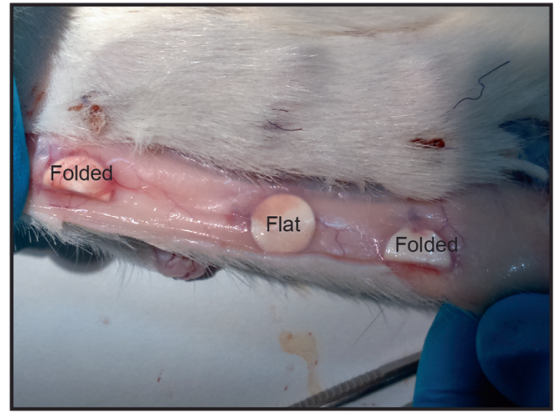

Figure 7.5: A) MSCs stained with methylene blue on non-patterned (left), bricks (middle), and channels (right) membranes after 4 days of cell culture. B) Example of the six implantation pockets at day 1. C) The different configurations upon explantation (Folded and Flat).

Although the samples were implanted flat (Fig 7.5C), some membranes were folded upon explantation. We observed that most of the samples that were flat during explantation had usually less tissue compared to the samples that were folded in vivo. Figure $7.5 \mathrm{~B}$ shows the six pockets on the back of a rat (left) and different configurations upon explantation (right). Only $45 \%$ of the samples were still in a flat configuration upon explantation. Only 25\% of these flat membranes were difficult to explant, whereas $45 \%$ of the folded samples were difficult to explant due to the presence of more dense tissue surrounding the implant.

A Masson-Goldner Trichrome staining was used to determine vessel formation in day 14 samples. Vessel formation was independently scored by 3 blinded observers. Samples were categorized into three classifications of vessel densities ranging from 
hardly any vessels (-), some vessels $(+)$, to many vessels $(++)$. Figure 7.6 shows representative pictures of Trichrome stained sections with different vessel densities (from top till bottom) in samples without cells (left panel) and with MSCs (right panel) all with the channel micropatterns (examples of vessel are indicated with a red star). Representative pictures of non-patterned and brick membranes are depicted in figure 7.7 and 7.8 .

Figure 7.9A shows the trend of vessel formation between the samples precultured with or without samples irrespective of the micropattern. There is a clear difference between samples precultured with MSCs and samples without cells (Fig 7.9A). The majority of the samples $(>50 \%)$ without cells were classified with - whereas more than $50 \%$ of the samples with MSCs were classified with ++ implying that the majority of the samples without cells contained hardly any vessels, whereas the samples with MSCs showed abundant vessel recruitment.

Figure 7.9B depicts the effect of micropatterns on vessel formation. In this analysis, the channel and brick membranes were combined and scored as micropatterned membranes. Additionally, samples were also divided according to the presence or absence of cells during preculture. Non-patterned membranes without precultured cells hardly showed vessel formation as more than $60 \%$ was scored with the lowest classification (-) and the rest with only few vessels $(+)$. In contrast, the micropatterned membranes showed an even distribution of samples among the three classifications. This indicated that the micropatterns promoted vessel formation independently of the presence of MSCs. However, figure 7.9C shows no effect of the micropatterns on vessel formation when MSCs were seeded on the membrane, as both non-patterned and patterned membranes showed similar scores on vessel formation.

In figure 7.9D a discrimination was made between the two different micropatterned membranes. When no cells were seeded on the membranes a beneficial effect of micropatterns was seen compared to the non-patterend membranes. For both micropatterned membranes all classifications were seen in same amounts. This indicated that both micropatterns influenced vessel formation to a similar extent. 
No cells
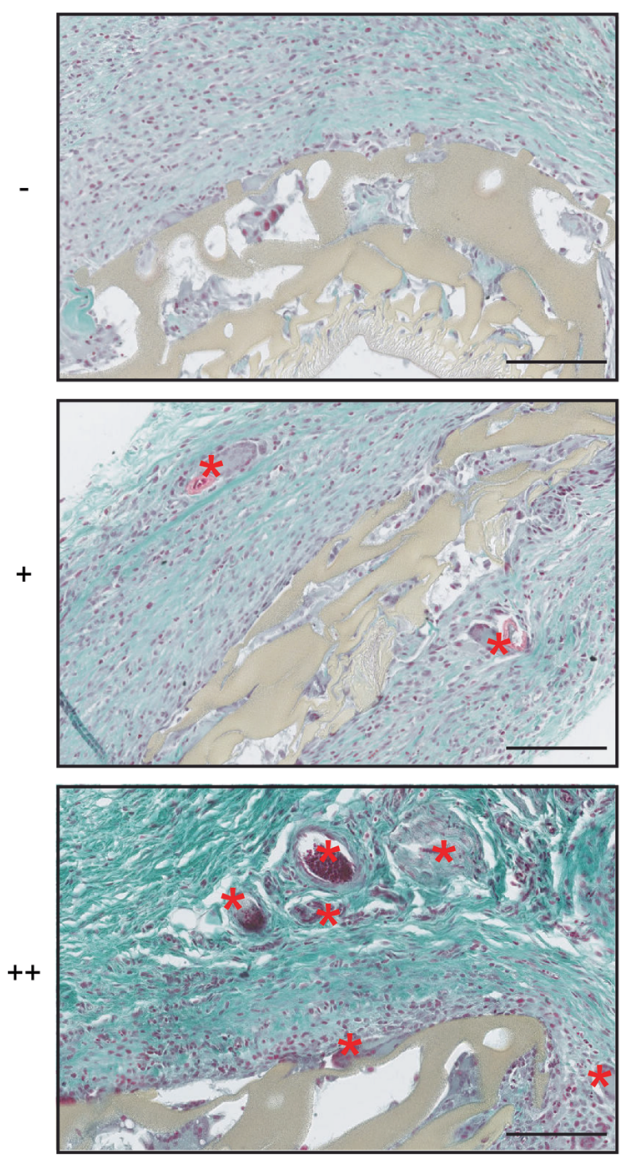

MSCs
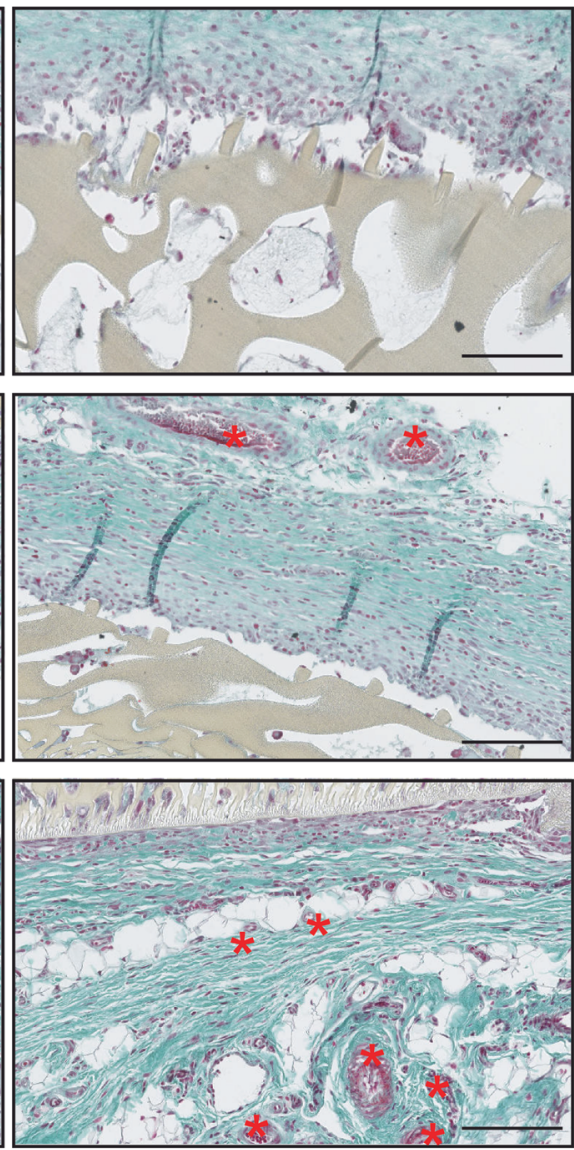

Figure 7.6: MSCs for in vivo vascularization in female Lewis rats, examples of Trichrome stained sections from channels membranes. The left panel shows the samples without cells and the panel on the right the samples with MCSs. From each sample an example of each classification was depicted; - top, + middle, and ++ bottom. Examples of vessels are indicated with a red star. Scale bars $125 \mu \mathrm{m}$. 


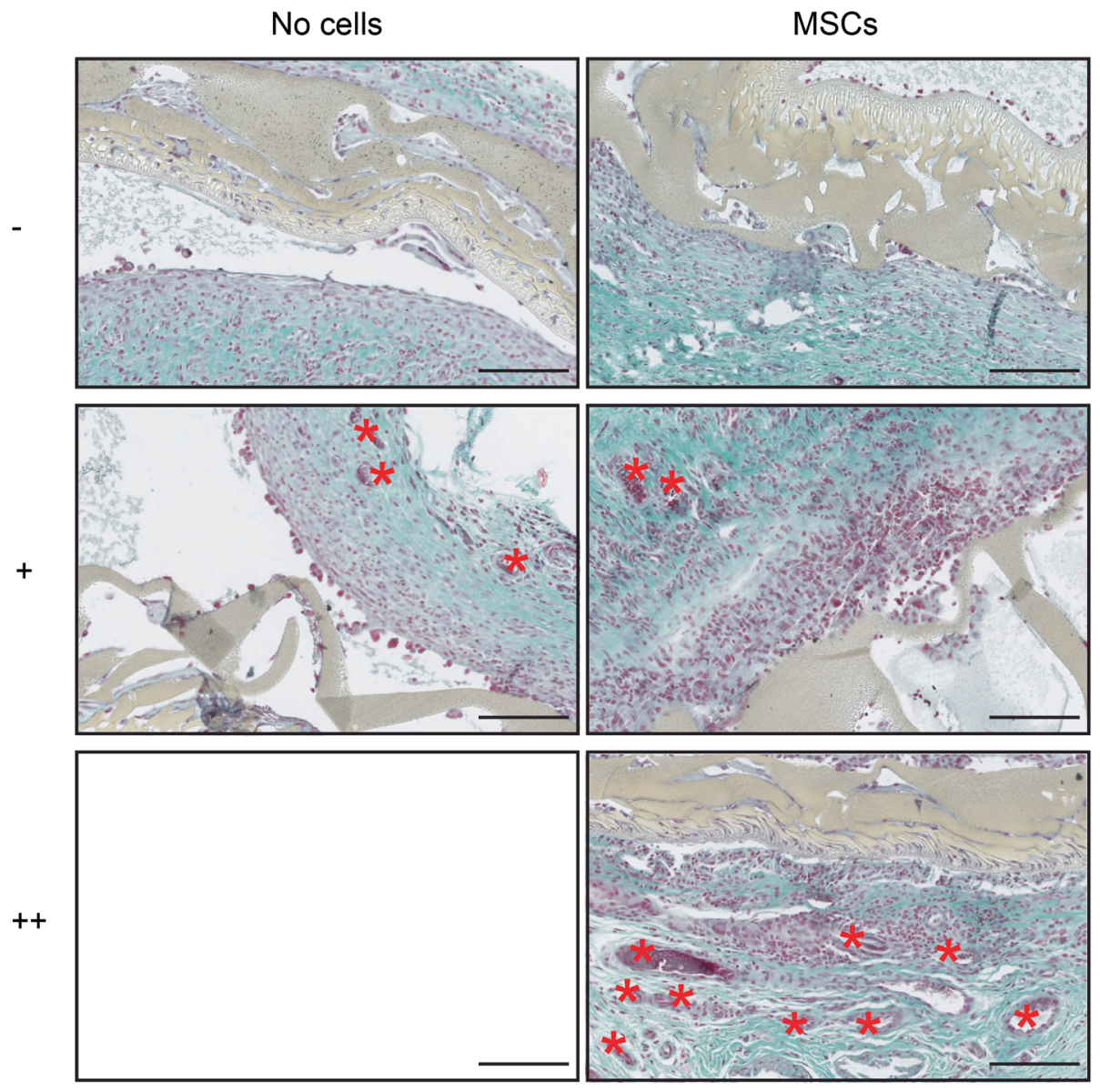

Figure 7.7: MSCs for in vivo vascularization in female Lewis rats, examples of Trichrome stained sections from non-patterned membranes. The left panel shows the samples without cells and the panel on the right the samples with MCSs. From each sample an example of each classification was depicted; - top, + middle, and ++ bottom. Examples of vessels are indicated with a red star. Scale bars $125 \mu \mathrm{m}$. 
No cells
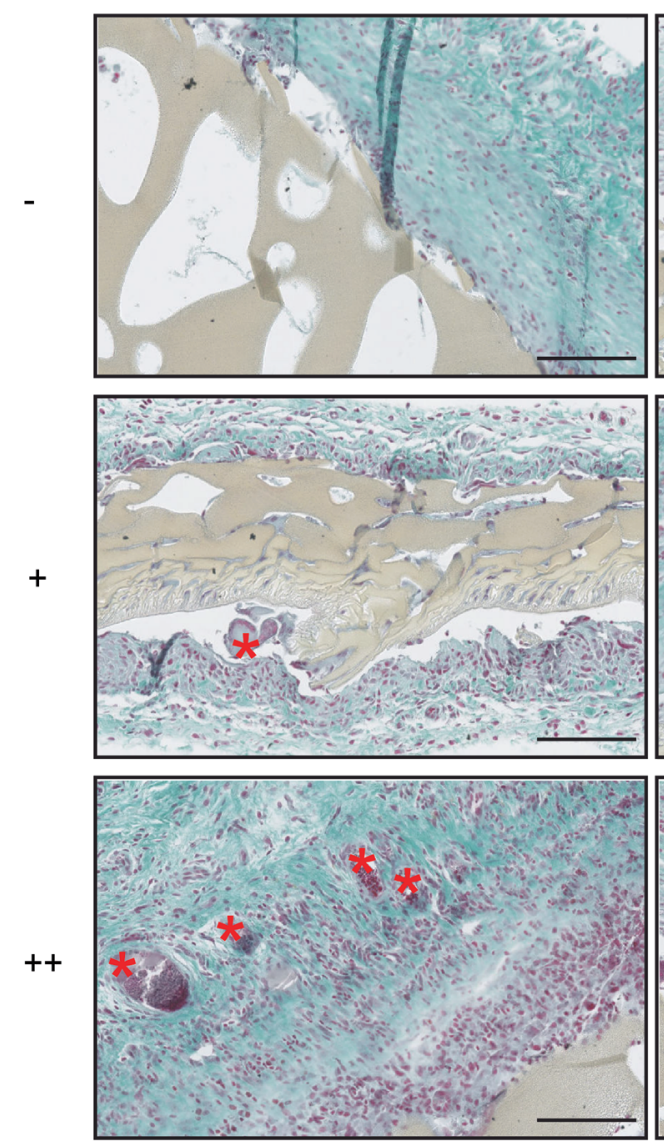

MSCs
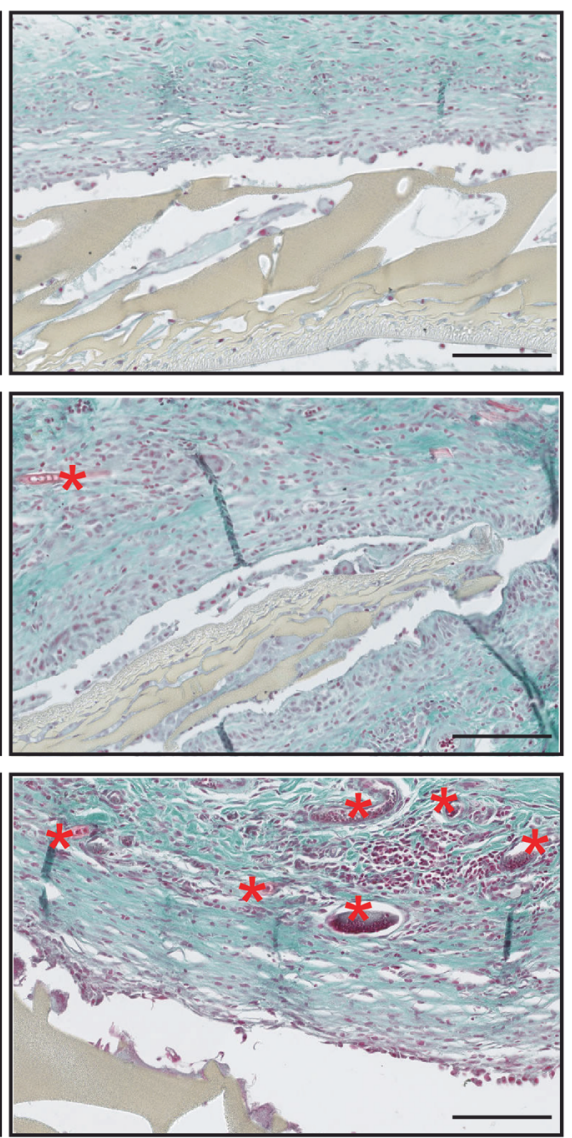

Figure 7.8: MSCs for in vivo vascularization in female Lewis rats, examples of Trichrome stained sections from bricks membranes. The left panel shows the samples without cells and the panel on the right the samples with MCSs. From each sample an example of each classification was depicted; - top, + middle, and ++ bottom. Examples of vessels are indicated with a red star. Scale bars $125 \mu \mathrm{m}$. 
When MSCs were seeded on these membranes, the vessel formation changed completely (Fig 7.9E). In non-patterend, bricks, and channels membranes with MSC we observed samples with the highest classification of vessel formation $(++)$. This corresponds to the data shown in figure $6 \mathrm{~A}$. When cells were seeded on the bricks micropatterned membranes more that $80 \%$ of the sections showed high vessel formation $(++)$. On the contrary when channels micropatterned membranes were used, only $13 \%$ of the samples were scored with ++ . Still, the bricks in combination with the MSCs do seem to have the highest vessel formation.

Finally, a Toluidine blue staining was performed on all samples to assess infiltration of mast cells in the tissue surrounding the membranes. No infiltration of mast cells was seen in the tissue surrounding the scaffolds in all samples (data not shown). 


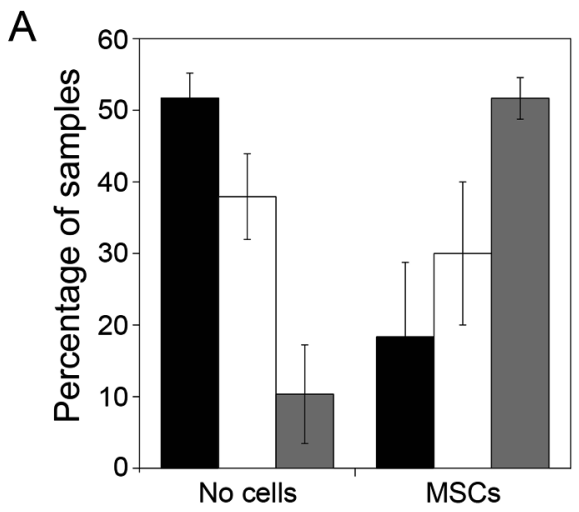

B

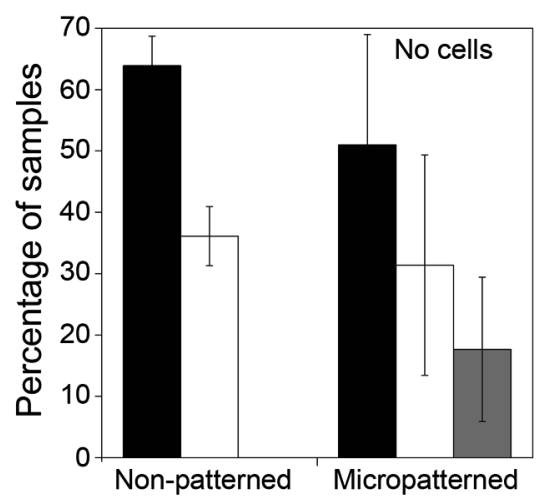

D

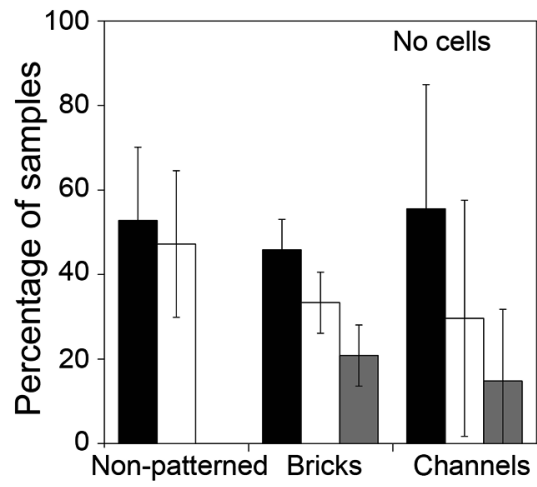

C

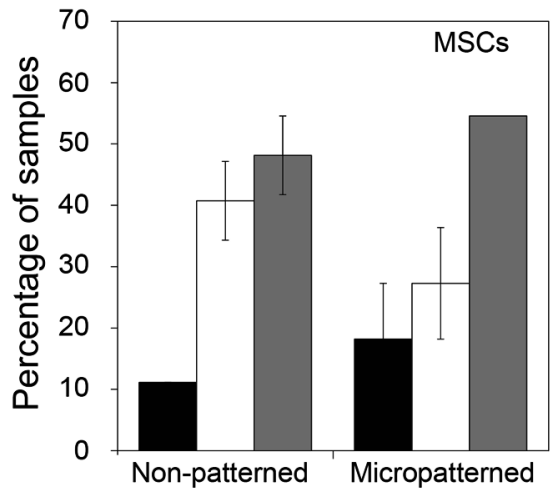

E

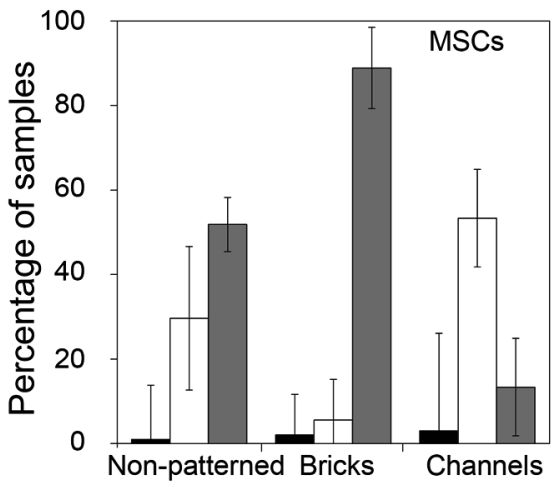

Figure 7.9: Analysis of vessel formation of in vivo samples, samples classified in three categories; hardly any vessels (- black), some vessels ( + white), and lot of vessel infiltration (++ grey). A) Vessel formation in samples without cells and with MSCs. B) Difference in vessel formation between non-patterned and micro pattern membranes in samples without cells. C) The difference in vessel formation between non- patterned and micropattern membranes precultured with cells. D) The effect of non-patterned, bricks and channels on vessel formation in samples without cells. E) In samples with MSCs the effect of vessel formation of non-patterned, bricks, and channels. Error $=\mathrm{SD}$ 


\subsection{Discussion}

Survival of islets of Langerhans encapsulated in an immune-protective device is often hampered by diffusion limitations, lack of oxygen, and lack of vascularization. Proper vascularization for islets is extremely important as they are highly vascularized by themselves while they reside in their native environment. Although only $1 \%$ of the pancreas consists of islets, they receive $5-15 \%$ of the total blood supply to the pancreas(17-19). After islet isolation and encapsulation the pancreatic islets are separated from their native vasculature and have no direct access to the blood supply.

Many different possibilities to enhance vascularization have shown to be promising varying from addition of angiogenic factors, the combination with cells like MSCs or endothelial cells or to the use of micropatterns $(15,24,25,28-30)$. In this study we hypothesized, that the use of micropatterned PES/PVP membranes in combination with rat bone marrow derived MSCs would have an additive effect on scaffold vascularization of PES/PVP membranes in vivo. We therefore investigated the effect of MSCs and micropatterns on vessel formation seperatly and finally the combined effect of both.

We showed that MSCs were able to attach to the PES/PVP membranes, with a difference in cell attachment depending on the surface structures. MSCs attached better on porous membranes than dense membranes. This could be explained by the difference in surface roughness between dense and porous membranes. It is known that cells attach better when the surface roughness is increased(40,41). Fibronectin was used to enhance cell attachment to PES/PVP membranes. A positive effect of fibronectin on MSC attachment has already been described in literature. MSCs are able to attach to fibronectin via RGD binding integrins, and more specifically ?v-containing integrins(42-44). Cell adhesion via integrins to ECM molecules, like fibronectin, activates intracellular signaling pathways that direct cell viability, proliferation and differentiation(45, 46). Culture of MSCs with ECM molecules such as fibronectin also showed to enhance cell proliferation(47). We noticed that coating 
porous PES/PVP membranes with fibronectin, accelerated attachment of MSCs significantly in the 24 hours after cell seeding. However, after four days of culture both coated and uncoated membranes contained similar amounts of cells.

The effect of micropatterned membranes and MSCs on vascularization was assessed by implanting PES/PVP membranes subcutaneously in female Lewis rats. After 14 days membranes were explanted. During explantation we noticed different configurations of the membranes, they were either still flat or they were folded. This might be due to movement of the rats and the flexibility of the membranes, as thin sheets could easy be folded. The different configurations (flat or folded) during explantation influenced the amount of tissue in the explant. Most of the samples were easy to explant, however the folded samples contained more tissue. On the other hand, when the membranes were still flat hardly any tissue attached to the membrane. Indicating that the membranes did not cause a severe tissue response.

We noticed that after 14 days of implantation the membranes containing MSCs supported better vessel recruitment than the samples without cells. This was as expected, as it is well known that MSCs have a positive influence on vessel formation in vivo(29, 48). Additionally, also as expected we noticed a positive influence on vessel formation when micropatterned membranes were used compared to non-patterned membranes. Song et al. showed that their $10 \mu \mathrm{m}$ micropost-textured PDMS scaffolds combined with MSCs had a positive effect on vessel formation in vivo(22). The scope of their study was not to discriminate between the effect of micropatterns and MSCs on vessel formation. They only showed that MSCs on a patterned scaffold in combination with a biochemical stimuli induced vessel formation. We, however, analyzed the effects of the two strategies separately and combined. Although separately, both MSCs and micropatterned membranes induced more vessel formation than membranes without cells or without patterns. However, we did not see an additive effect of both on vessel formation. We did see that MSCs seeded on the bricks membranes induced the highest vessel formation score $(++)$ in $80 \%$ of the sections. This could be connected to the alignment of cells and interconnectivity of the bricks pattern on the membranes. As 
alignment and organization is known to be of great influence on vessel formation(23). However, this effect should be further explored in bigger in vivo studies.

Besides the induction of vascularization by MSCs in vivo, MSCs are also known have an immune-modulatory effect when implanted in vivo. It is known that MSCs have a great influence on a variety of immune cells(33-37). When transplanting islets in an immune protective device in combination with MSCs, we can assess the immune modulatory effects of the MSCs in the system. In this study we only assessed the presence of mast cells, however no infiltration of mast cells was seen. Additionally, we did not observe a dense fibrous capsule, indicating that the PES/PVP membranes induce only a small immune response. This could confirm the inert properties of PES/PVP, showing that it is a good material for an implantable device.

In conclusion, we showed the possibility to attach rat bone marrow derived MSCs to PES/PVP membranes. With the addition of fibronectin the cell attachment was enhanced. MSCs appeared to attach better on porous micropatterned membranes. When transplanted subcutaneously, we noticed the positive effect of MSCs on vascularization. Additionally, the micropatterned membranes showed to enhance vascularization. However, the question remains if there is indeed an additive effect of MSCs and micropatterns on vessel formation in vivo. 


\section{References}

1. Barshes, N.R., Wyllie, S., and Goss, J.A. Inflammation-mediated dysfunction and apoptosis in pancreatic islet transplantation: Implications for intrahepatic grafts. J Leukocyte Biol 77, 587, 2005.

2. Grundfest-Broniatowski, S.F., Tellioglu, G., Rosenthal, K.S., Kang, J., Erdodi, G., Yalcin, B., Cakmak, M., Drazba, J., Bennett, A., Lu, L., and Kennedy, J.P. A new bioartificial pancreas utilizing amphiphilic membranes for the immunoisolation of porcine islets a pilot study in the canine. ASAIO Journal 55, 400, 2009.

3. Kort, H.D., Koning, E.J.D., Rabelink, T.J., Bruijn, J.a., and Bajema, I.M. Islet transplantation in type 1 diabetes. Bmj 342, d217, 2011.

4. Ozmen, L., Ekdahl, K.N., Elgue, G., Larsson, R., Korsgren, O., and Nilsson, B. Inhibition of thrombin abrogates the instant blood-mediated inflammatory reaction triggered by isolated human islets: Possible application of the thrombin inhibitor Melagatran in clinical islet transplantation. DIABETES 51, 1779, 2002.

5. Nanji, S.A., and Shapiro, A.M.J. Advances in pancreatic islet transplantation in humans. Diabetes Obes Metab 8, 15, 2006.

6. Moberg, L., Johansson, H., Lukinius, A., Berne, C., Foss, A., Kallen, R., Ostraat, O., Salmela, K., Tibell, A., Tufveson, G., Elgue, G., Nilsson Ekdahl, K., Korsgren, O., and Nilsson, B. Production of tissue factor by pancreatic islet cells as a trigger of detrimental thrombotic reactions in clinical islet transplantation. Lancet 360, 2039, 2002.

7. Citro, A., Cantarelli, E., and Piemonti, L. Anti-inflammatory strategies to enhance islet engraftment and survival. Curr Diabetes Rep 13, 733, 2013.

8. Harlan, D.M., Kenyon, N.S., Korsgren, O., and Roep, B.O. Current advances and travails in islet transplantation. Diabetes 58, 2175, 2009.

9. Azzi, J., Geara, A.S., El-Sayegh, S., and Abdi, R. Immunological aspects of pancreatic islet cell transplantation. Expert Rev Clin Immunol 6, 111, 2010.

10. Beck, J., Angus, R., Madsen, B., Britt, D., Vernon, B., and Nguyen, K.T. Islet encapsulation: Strategies to enhance islet cell functions. Tissue Eng 13, 589, 2007. 
11. Silva, A.I., de Matos, A.N., Brons, I.G., and Mateus, M. An overview on the development of a bio-artificial pancreas as a treatment of insulin-dependent diabetes mellitus. Medicinal Research Reviews 26, 181, 2006.

12. Silva, A.I., andMateus, M. Development of a polysulfone hollow fiber vascular bio-artificial pancreas device for in vitro studies. Journal of Biotechnology 139, 236, 2009.

13. Lacy, P.E., Hegre, O.D., Gerasimidi-vazeou, A., Gentile, F.T., Dionne, E., Science, S., Series, N., Dec, N., and Dionne, K.E. Maintenance of Normoglycemia in Diabetic Mice by Subcutaneous Xenografts of Encapsulated Islets Science 254, 1782, 1991.

14. Risbud, M.V., and Bhonde, R.R. Islet immunoisolation: Experience with biopolymers. J Biomater Sci Polym Ed 12, 1243, 2001. 15. Colton, C.K. Oxygen supply to encapsulated therapeutic cells. Adv Drug Deliv Rev 67-68, 93, 2014.

16. Tilakaratne, H.K., Hunter, S.K., Andracki, M.E., Benda, J.A., and Rodgers, V.G.J. Characterizing short-term release and neovascularization potential of multiprotein growth supplement delivered via alginate hollow fiber devices. Biomaterials 28, 89, 2007.

17. Ballian, N., and Brunicardi, F.C. Islet vasculature as a regulator of endocrine pancreas function. World J Surg 31, 705, 2007.

18. Homo-Delarche, F., and Boitard, C. Autoimmune diabetes: The role of the islets of Langerhans. IMMUNOL TODAY 17, 456, 1996.

19. Trivedi, N., Steil, G.M., Colton, C.K., Bonner-Weir, S., and Weir, G.C. Improved vascularization of planar membrane diffusion devices following continuous infusion of vascular endothelial growth factor. Cell Transplant 9, 115, 2000.

20. Daoud, J., Petropavlovskaia, M., Rosenberg, L., and Tabrizian, M. The effect of extracellular matrix components on the preservation of human islet function in vitro. Biomaterials 31, 1676, 2010.

21. Bloch, K., Papismedov, E., Yavriyants, K., Vorobeychik, M., Beer, S., and Vardi, P. Photosynthetic oxygen generator for bioartificial pancreas. Tissue Engineering 12, $337,2006$. 
22. Song, S., Kim, E.J., Bahney, C.S., Miclau, T., Marcucio, R., and Roy, S. The synergistic effect of micro-topography and biochemical culture environment to promote angiogenesis and osteogenic differentiation of human mesenchymal stem cells. Acta Biomater 18, 100, 2015.

23. Auger, F.A., Gibot, L., and Lacroix, D. The pivotal role of vascularization in tissue engineering. Annual Review of Biomedical Engineering2013. pp. 177.

24. Kheradmand, T., Wang, S., Gibly, R.F., Zhang, X., Holland, S., Tasch, J., Graham, J.G., Kaufman, D.B., Miller, S.D., Shea, L.D., and Luo, X. Permanent protection of PLG scaffold transplanted allogeneic islet grafts in diabetic mice treated with ECDI-fixed donor splenocyte infusions. Biomaterials 32, 4517, 2011

. 25. Borg, D.J., and Bonifacio, E. The use of biomaterials in islet transplantation. Curr Diabetes Rep 11, 434, 2011.

26. Vallbacka, J.J., and Sefton, M.V. Vascularization and improved in vivo survival of VEGF-secreting cells microencapsulated in HEMA-MMA. Tissue Engineering 13, $2259,2007$.

27. Teramura, Y., and Iwata, H. Bioartificial pancreas. Microencapsulation and conformal coating of islet of Langerhans. Advanced Drug Delivery Reviews 62, 827, 2010. 28. Kang, S., Park, H.S., Jo, A., Hong, S.H., Lee, H.N., Lee, Y.Y., Park, J.S., Jung, H.S., Chung, S.S., and Park, K.S. Endothelial progenitor cell cotransplantation enhances islet engraftment by rapid revascularization. Diabetes 61, 866, 2012.

29. Veriter, S., Gianello, P., Igarashi, Y., Beaurin, G., Ghyselinck, A., Aouassar, N., Jordan, B., Gallez, B., and Dufrane, D. Improvement of subcutaneous bioartificial pancreas vascularization and function by coencapsulation of pig islets and mesenchymal stem cells in primates. Cell Transplant 23, 1349, 2014.

30. Veriter, S., Aouassar, N., Adnet, P.Y., Paridaens, M.S., Stuckman, C., Jordan, B., Karroum, O., Gallez, B., Gianello, P., and Dufrane, D. The impact of hyperglycemia and the presence of encapsulated islets on oxygenation within a bioartificial pancreas in the presence of mesenchymal stem cells in a diabetic Wistar rat model. Biomaterials 32, 5945, 2011.

31. Penko, D., Rojas-Canales, D., Mohanasundaram, D., Peiris, H.S., Sun, W.Y., 
Drogemuller, C.J., Keating, D.J., Coates, P.T.H., Bonder, C.S., andJessup, C.F. Endothelial progenitor cells enhance islet engraftment, influence $\beta$-cell function, and modulate islet connexin 36 expression. Cell Transplant 24, 37, 2015.

32. Deters, N.A., Stokes, R.A., andGunton, J.E. Islet transplantation: Factors in short-term islet survival. Arch Immunol Ther Exp 59, 421, 2011.

33. Brusko, T.M. Mesenchymal stem cells: A potential border patrol for transplanted islets? DIABETES 58, 1728, 2009.

34. Ding, Y., Bushell, A., andWood, K.J. Mesenchymal stem-cell immunosuppressive capabilities: Therapeutic implications in islet transplantation. TRANSPLANTATION 89, 270, 2010.

35. Ding, Y., Xu, D., Feng, G., Bushell, A., Muschel, R.J., andWood, K.J. Mesenchymal stem cells prevent the rejection of fully allogenic islet grafts by the immunosuppressive activity of matrix metalloproteinase-2 and -9. DIABETES 58, 1797, 2009.

36. Jiang, X.X., Zhang, Y., Liu, B., Zhang, S.X., Wu, Y., Yu, X.D., andMao, N. Human mesenchymal stem cells inhibit differentiation and function of monocyte-derived dendritic cells. Blood 105, 4120, 2005.

37. Spaggiari, G.M., Capobianco, A., Becchetti, S., Mingari, M.C., andMoretta, L. Mesenchymal stem cell-natural killer cell interactions: Evidence that activated NK cells are capable of killing MSCs, whereas MSCs can inhibit IL-2-induced NK-cell proliferation. Blood 107, 1484, 2006.

38. Krishnan, L., Chang, C.C., Nunes, S.S., Williams, S.K., Weiss, J.A., andHoying, J.B. Manipulating the microvasculature and its microenvironment. Critical Reviews in Biomedical Engineering 41, 91, 2013.

39. Chang, C.C., Krishnan, L., Nunes, S.S., Church, K.H., Edgar, L.T., Boland, E.D., Weiss, J.A., Williams, S.K., andHoying, J.B. Determinants of microvascular network topologies in implanted neovasculatures. Arterioscler Thromb Vasc Biol 32, 5, 2012. 40. Lalwani, G., Gopalan, A., D’Agati, M., Srinivas Sankaran, J., Judex, S., Qin, Y.X., andSitharaman, B. Porous three-dimensional carbon nanotube scaffolds for tissue engineering. J Biomed Mater Res Part A 103, 3212, 2015.

41. Oliveira, S.M., Alves, N.M., andMano, J.F. Cell interactions with superhy- 
drophilic and superhydrophobic surfaces. J Adhes Sci Technol 28, 843, 2014.

42. Zwolanek, D., Flicker, M., Kirstatter, E., Zaucke, F., van Osch, G.J., andErben, R.G. beta1 Integrins Mediate Attachment of Mesenchymal Stem Cells to Cartilage Lesions. BioResearch open access 4, 39, 2015.

43. Vohra, S., Hennessy, K.M., Sawyer, A.A., Zhuo, Y., andBellis, S.L. Comparison of mesenchymal stem cell and osteosarcoma cell adhesion to hydroxyapatite. J Mater Sci Mater Med 19, 3567, 2008.

44. Kilpadi, K.L., Sawyer, A.A., Prince, C.W., Chang, P.L., andBellis, S.L. Primary human marrow stromal cells and Saos-2 osteosarcoma cells use different mechanisms to adhere to hydroxylapatite. J Biomed Mater Res Part A 68, 273, 2004.

45. Hynes, R.O. Integrins: Bidirectional, allosteric signaling machines. Cell 110, 673, 2002.

46. Giancotti, F.G., andRuoslahti, E. Integrin signaling. Science 285, 1028, 1999.

47. Lindner, U., Kramer, J., Behrends, J., Driller, B., Wendler, N.O., Boehrnsen, F., Rohwedel, J., andSchlenke, P. Improved proliferation and differentiation capacity of human mesenchymal stromal cells cultured with basement-membrane extracellular matrix proteins. Cytotherapy 12, 992, 2010.

48. Tang, Y.L., Zhao, Q., Zhang, Y.C., Cheng, L., Liu, M., Shi, J., Yang, Y.Z., Pan, C., Ge, J., andPhillips, M.I. Autologous mesenchymal stem cell transplantation induce VEGF and neovascularization in ischemic myocardium. Regulatory Peptides $117,3,2004$. 


\section{Chapter 8}

\section{Oxygen generation for extrahepatic islet of Langerhans transplantation}

Milou Groot Nibbelink, Maria Coronel, Katarzyna Skrzypek, Marcel Karperien, Dimitrios Stamatialis, Cherie Stabler, Aart van Apeldoorn 


\subsection{Abstract}

Encapsulating islets inside an immune protective device is still a challenge as lack of direct vascularization and diffusion distances often lead to graft failure. The lack of proper vascularization especially in the period directly after transplantation leads to hypoxia. This often results in islet necrosis after transplantation. When islets become hypoxic, their responsiveness to glucose changes already in an early state. A relative easy solution to overcome hypoxia, is the combination of oxygen generation materials to the immune protective device. Using solid peroxides, like calcium peroxide $\left(\mathrm{CaO}_{2}\right)$, has shown to be effective in the generation of oxygen. When Pedraza et al. incorporated $\mathrm{CaO}_{2}$ particles in hydrophobic Polydimethylsiloxane (PDMS), they showed that the reaction kinetics could be controlled. No toxic byproducts were produced, and rat islets were able to survive and function under hypoxic conditions. They also observed that oxygen was released over a period of at least 6 weeks. Therefore in this study we studied the effect of adding an oxygen generation disk, based on PDMS and $\mathrm{CaO}_{2}$, to the PES/PVP microwell membrane for islet encapsulation on viability an function of rat islets. Our findings match those published by Pedraza et al., showing a similar positive effect of the oxygen generating disk on islets viability and function when cultured under hypoxia. 


\subsection{Introduction}

Islets transplanted into the portal vein are exposed to relative hypoxic conditions due to disruption of their vasculature and the exposure to only venous blood in the first days after transplantation(1-4). When encapsulating islets, this hypoxic state remains present and might be exacerbated due to the barrier of the encapsulation device. One of the main problems is the timeframe in which angiogenesis usually starts, which takes at least 7 days. Therefore islets remain in a hypoxic state in the first week after implantation which is known to cause islets death and dysfunction(5-9). Different approaches to enhance survival of encapsulated islets in this critical period after transplantation include oxygen generation, induction of vascularization or the addition of drug delivery systems(1). In an early stage, hypoxia already influences the glucose homeostasis in islets, as the glucose pathway thrives on oxidative phosphorylation $(2,3,10)$. Consequently, hypoxia or other mechanisms that reduce the aerobic capacity of an islet will most likely have an negative effect on insulin secretion once stimulated with glucose $(2,3,10-12)$. Various genes, regulated by hypoxia-inducible factor-1 (HIF1), are expressed under the influence of hypoxia(13). HIF-1 consists of two subunits; HIF $1 \alpha$ and HIF $1 \beta$. HIF $1 \alpha$ activates target genes and is involved in the secretion of $\operatorname{VEGF}(2,4,12,13)$.

Different approaches have been tried to overcome hypoxia. A few examples are the introduction of Polyethyleenglycol (PEG)-conjugated hemoglobin as an oxygen carrier or an oxygen generator based on electrolysis of water to form oxygen and hydrogen, or the use of microalgae-based photosynthetic oxygen generators(1, 3, 11, 14-16). Even gene therapy to overcome hypoxia and thereby enhance islet survival has been applied by for example increasing HIF-1 $\alpha$ levels(3). These solutions often introduce components that create a more complex device, produce toxic byproducts, or increase the size of the implant significantly and thus hamper clinical translation. Another relative simple and very interesting method is the incorporation of so-called oxygen generating materials in an immune protective device $(15,17,18)$. Decomposition of solid peroxides is a potent source of oxygen generation. Solid peroxides like calcium perox- 
ide $\left(\mathrm{CaO}_{2}\right)$ and sodium percarbonate, both react upon contact with water, thereby generating oxygen $(15,17,18)$. This occurs according to the following reaction(15):

$2 \mathrm{CaO}_{2}+4 \mathrm{H}_{2} \mathrm{O} \rightarrow 2 \mathrm{Ca}(\mathrm{OH})_{2}+2 \mathrm{H}_{2} \mathrm{O}_{2} \rightarrow 2 \mathrm{Ca}(\mathrm{OH})_{2}+2 \mathrm{H}_{2} \mathrm{O}+\mathrm{O}_{2}$

Hydration of solid peroxide is too rapid, leading to hyperoxide conditions creating toxic byproducts and heat(19). Therefore, to be effective as oxygen generating biomaterials, these solid peroxides were incorporated into polymers $(15,17,18)$. Harrison et al. incorporated sodium percarbonate into films and 3D scaffolds of Poly $(\mathrm{D}, \mathrm{L}-$ lactide- co-glycolide (PLGA) and determined the release profile of oxygen. Although, as expected, oxygen was generated, this reaction was short-lived $(24 \mathrm{~h})$ likely due to rapid hydration when PLGA is brought into contact with water. Additionally, the reaction kinetics was not optimal due to the degradation of PLGA induced by the free radicals that were formed when $\mathrm{CaO}_{2}$ reacted with water(18).

In order to obtain better control of the reaction kinetics, Pedraza et al.(15) used a hydrophobic and biostable material for the incorporation of $\mathrm{CaO}_{2}$ particles. They created an oxygen generating material based on Polydimethylsiloxane (PDMS) and $\mathrm{CaO}_{2}(15)$. Upon reaction with water, $\mathrm{CaO}_{2}$ particles generate oxygen.

A PDMS $\mathrm{CaO}_{2}$ disk, of $1 \mathrm{~mm}$ thickness and $10 \mathrm{~mm}$ in diameter, generated oxygen for more than 6 weeks with an average rate of $0.026 \mathrm{~mm}$ per day. Due to the biostable and hydrophobic material properties of the PDMS, they were able to control the reaction kinetics. This material had a positive effect on both MIN6 $\beta$-cells and rat islets survival and function during co-culture under hypoxic conditions (15).

In this work, we show the effect of addition of the PDMS $\mathrm{CaO}_{2}$ disk of Pedraza et al to the PES/PVP microwell membrane for islet encapsulation (Chapter 6). We tested if the oxygen generated by the disk had an effect on rat islets inside the open device as depicted in figure 8.1. Islets inside the device were cultured for $24 \mathrm{~h}$ at either $1 \%$ or $20 \%$ oxygen in the presence of a PDMS disk with or without $\mathrm{CaO}_{2}$. After $24 \mathrm{~h}$ we tested islets viability, metabolic activity, and responsiveness to glucose. All results showed a positive effect of the oxygen-generating disk on islet survival and function. 


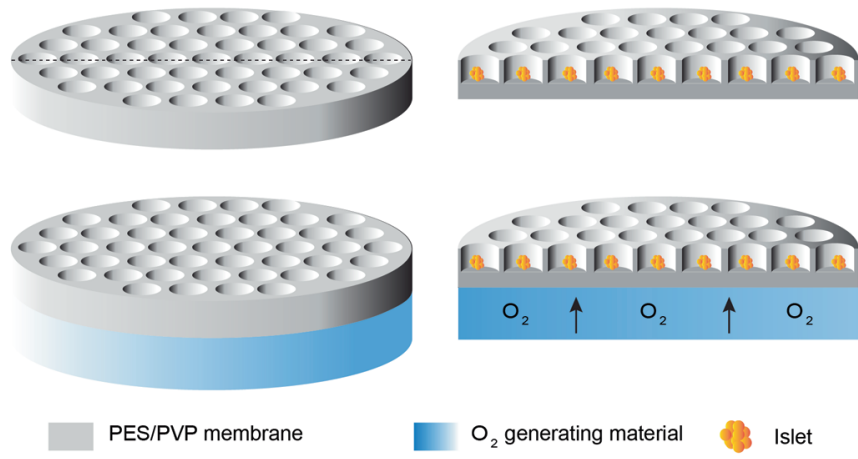

Figure 8.1: The PES/PVP microwell device for islet encapsulation in combination with the oxygen generating biomaterials of Pedraza et al.(15).

\subsection{Materials and methods}

\subsubsection{Pancreatic islet isolation and culture}

Rat islets were isolated from male Lewis rat (Harlan Laboratoy, Indianapolis, IN, USA) donor pancreata via mechanically enhanced enzymatic digestion followed by density gradient purification, as previously described(20). Isolated islets were cultured in CMRL -1066 medium (Gibco Invitrogen) supplemented with 10\% FBS, 1\% Penicillin/Streptavidin, and 1\% L-glutamine in non tissue-culture petri dishes.

\subsubsection{Microwell membrane fabrication}

Micropatterned membranes were fabricated using phase separation micro-molding method (PSmuM)(21-23). Membranes were prepared using a 15 wt\% polyethersulfone (PES)(Ultrason, E6020P) and a $5 \mathrm{wt} \%$ polyvinylpyrrolidone (PVP)(MW= 40000, Sigma Aldrich) in N-Methylpyrrolidone (NMP)(Acros organic) polymer solution which was stirred at the roller bank (overnight at RT). The polymer solution was casted on a custom made, silicon, micropatterned mold (Chapter 6, figure 2). A casting knife with micrometric screws to regulate the casting thickness was used 
to obtain a casting thickness of $250 \mu \mathrm{m}$. Casting was followed by immersion into the demineralized water coagulation bath. When the polymer became turbid and precipitated, membranes were demolded from the wafer. Finally, the membranes were rinsed with demineralized water in order to remove remaining solvent traces and stored in demineralized water till further use.

\subsection{3 $\mathrm{PDMS}-\mathrm{CaO}_{2}$ disk fabrication}

PDMS discs were fabricated using the method described by Pedraza et al.(15). In short: twenty-four hours before use, PDMS- $\mathrm{CaO}_{2}$ disks were prepared by mixing calcium peroxide particles of maximally $74 \mu \mathrm{m}$ with uncured PDMS (4:1 vol/vol PDMS silicone/platinum catalyst) (Nusil MED-6215) in 1:4 ratio (wt/wt). After degassing the mixture was poured in a plastic petridish $(88 \mathrm{~mm}$ in diameter) to settle for $30 \mathrm{~min}$ and cure for $1 \mathrm{~h}$ at $85^{\circ} \mathrm{C}$. Disks of $1 \mathrm{~mm}$ thickness and $10 \mathrm{~mm}$ in diameter were then stored at $50{ }^{\circ} \mathrm{C}(\mathrm{ON})$.

\subsubsection{Islet seeding and co-culture with PDMS disk}

Both the PES/PVP microwell membrane and PDMS-disk (with and without $\mathrm{CaO}_{2}$ ) were sterilized in $70 \%$ ethanol for $30 \mathrm{~min}$ and washed 3 times $5 \mathrm{~min}$ in PBS. Subsequently, the PES/PVP microwell was carefully placed inside inserts (Millipore, $4.0 \mu \mathrm{m})$ in a 24 well plate and incubated in supplemented CMRL-1066 for at least $2 \mathrm{~h}$. Islets were seeded on top of the microwell membrane by pipetting $50 \mu \mathrm{L}$ of cell suspension (1800 IEQ) onto the membrane and centrifuging (1000 rpm, $1 \mathrm{~min}$ ). After seeding PDMS- $\mathrm{CaO}_{2}$ disks were placed under the inserts and $700 \mu \mathrm{L}$ culture medium was added to the well and $300 \mu \mathrm{L}$ in the insert. Samples were left to settle for $1 \mathrm{~h}$ before placing them under hypoxia $\left(1 \% \mathrm{O}_{2}\right)$ for $24 \mathrm{~h}$. Islets in the microwells with a PDMS disk without calcium peroxide, were cultured under normoxia were used as a positive control. Islets in microwells with a PDMS disk without calcium peroxide cultured under hypoxia were used as a negative control. After $24 \mathrm{~h}$ of culture, islets were flushed out of the microwells and spun down. Medium samples were collected 
for Lactate Dehydrogenase (LDH). Subsequently, islets were divided and assessed for viability, metabolic activity, and glucose induced insulin secretion.

\subsubsection{In vitro assessment of islet viability and metabolic activity}

Flushed out islets were assessed for viability by a Live Dead assay. In short, islets were incubated in $8 \mu \mathrm{M}$ Ethidium homodimer and $4 \mu \mathrm{M}$ Calcein-AM (Invitrogen) diluted in PBS for $30 \mathrm{~min}$ at $37^{\circ} \mathrm{C}$. Subsequently, live and dead cells were visualized using confocal imaging. Lactate dehydrogenase (LDH) was determined in the collected medium samples using the cytotoxicity Detection LDH kit (Roche) according to manufacturer's protocol. In short; samples were plated in triplicate in a flat bottom 96 well plate. Reagent was added in a 1:1 ratio. The plate was incubated for 30 minutes at room temperature and absorbance was measured at $492 \mathrm{~nm}$. A MTT assay (Promega) was performed to determine the metabolic activity of the islets following manufacturer's protocol, $48 \mathrm{~h}$ after the addition of the stop solution absorbance was measured at $570 \mathrm{~nm}$. Gene expression of LDH (LDHa Rn00820751_g1) and GLUT1 (GLUT 1 Rn01417099_m1) was determined via PCR. First RNAlater (Ambion) was added to the islets and stored at $4^{\circ} \mathrm{C}$ for $24 \mathrm{~h}$ and then at $-80^{\circ} \mathrm{C}$ till RNA isolation. RNA was then isolated using a mirVANa isolation kit (Life technologies) following manufacturer's protocol, followed by DNAase treatment using Ambion RNA turbo DNA-free. Gene expression was normalized against Actinb (Rn00667869_m1).

\subsubsection{In vitro assessment of glucose induced insulin secretion}

Functionality of islets was assessed by a glucose induced insulin secretion test (GIIST). Glucose buffers for the GIIST were prepared as follows; a Krebs buffer $\left(99 \mu \mathrm{M} \mathrm{NaCl}_{2}\right.$, $5 \mu \mathrm{M} \mathrm{KCL}, 1.2 \mu \mathrm{M} \mathrm{KH}_{2} \mathrm{PO}_{4}, 1.2 \mu \mathrm{M} \mathrm{MgSO}_{4}, 2.6 \mu \mathrm{M} \mathrm{CaCl}_{2}, 26 \mu \mathrm{M} \mathrm{NaHCO}_{3}$, and $0.2 \%$ $\mathrm{w} / \mathrm{v}(\mathrm{g} / \mathrm{mL}) \mathrm{BSA}$ ) was supplemented with $25 \mu \mathrm{M}$ Hepes ( $\mathrm{pH} 7.4)$ and sterilized through filtering. For the low glucose buffer, $40 \mathrm{mg} / \mathrm{dL}$ glucose was added to the Krebs buffer. Whereas for the high glucose buffer, $300 \mathrm{mg} / \mathrm{dL}$ glucose was added. Sephadex G 10 beads (Sigma Aldrich) were boiled in PBS and after cooling loaded $(400 \mu \mathrm{L})$ onto Biorad Microchromatography $10 \mathrm{~mL}$ columns (Biorad Hercules, CA). After settling 
of the Sephadex beads, 150 IEQs were loaded in the column. Finally, Sephadex beads were added to a final volume of $1 \mathrm{~mL}$. Before starting the GIIST, the columns were flushed with $4 \mathrm{~mL}$ of low glucose buffer, and islets were preincubated with low glucose buffer for $1 \mathrm{~h}$ to bring them to basal insulin secretion level. They were stimulated for $1 \mathrm{~h}$ in low, high, and low glucose buffers consecutively. After each step, samples were collected in low glucose buffer by adding $1 \mathrm{~mL}$ to the column and stored at $-80^{\circ} \mathrm{C}$. After the GIIST, DNA was collected by first removing all liquid from the columns, and the addition of DNA extraction buffer $\left(1 \mathrm{~N} \mathrm{NH}_{4} \mathrm{OH}, 0.2 \%\right.$ Triton $\left.\mathrm{X}-100\right)$. Samples underwent at least 2 freeze thaw cycles, before DNA analysis via Picogreen assay. Insulin concentration was determined by a rat insulin ELISA (Mercodia).

\subsubsection{Statistical analysis}

A two paired Student's t-test was performed to assess statistical differences $(\mathrm{p}<0.05)$.

\subsection{Results}

\subsubsection{In vitro assessment of islet viability and metabolic activity}

After 24 hours of culture at either $20 \%$ oxygen or $1 \%$ oxygen, we stained islets with a live/dead assay to assess islet viability (Fig 8.2A). The positive control (20\% oxygen with PDMS disk) showed viable islets, while the negative control (cultured at $1 \%$ oxygen) clearly showed many dead cells. The live dead images of the islets cultured at $1 \%$ oxygen in the presence of a $\mathrm{PDMS} \mathrm{CaO}_{2}$ disk, showed similar viability to the positive control. Indicating the positive effect of $\mathrm{PDMS} \mathrm{CaO}_{2}$ on islet survival when cultured under hypoxic conditions. The results of the live dead assay were confirmed by analyzing the amount of $\mathrm{LDH}$ released by the islets in the supernatant of the medium (Fig 8.2B). Again PDMS $\mathrm{CaO}_{2}$ disk were used to overcome the hypoxic environment the islets were cultured in. In figure 8.2B an increased release of LDH in the negative control group $(37.5 \pm 8.6 \mathrm{AU} / \mathrm{\mu g} / \mathrm{mL} \mathrm{DNA})$ was seen compared to both the positive control $(19.7 \pm 0.1 \mathrm{AU} / \mu \mathrm{g} / \mathrm{mL} \mathrm{DNA}, \mathrm{p}<0.002)$ and the samples cultured at $1 \%$ oxygen in combination with a PDMS $\mathrm{CaO}_{2}$ disk $(24.0 \pm 1.3 \mathrm{AU} / \mathrm{\mu g} / \mathrm{mL} \mathrm{DNA}$, 
$\mathrm{p}<0.019$ ). Furthermore, the islets cultured at $20 \%$ oxygen did release less LDH than the $\mathrm{CaO}_{2}$ group $(\mathrm{p}<0.016)$.
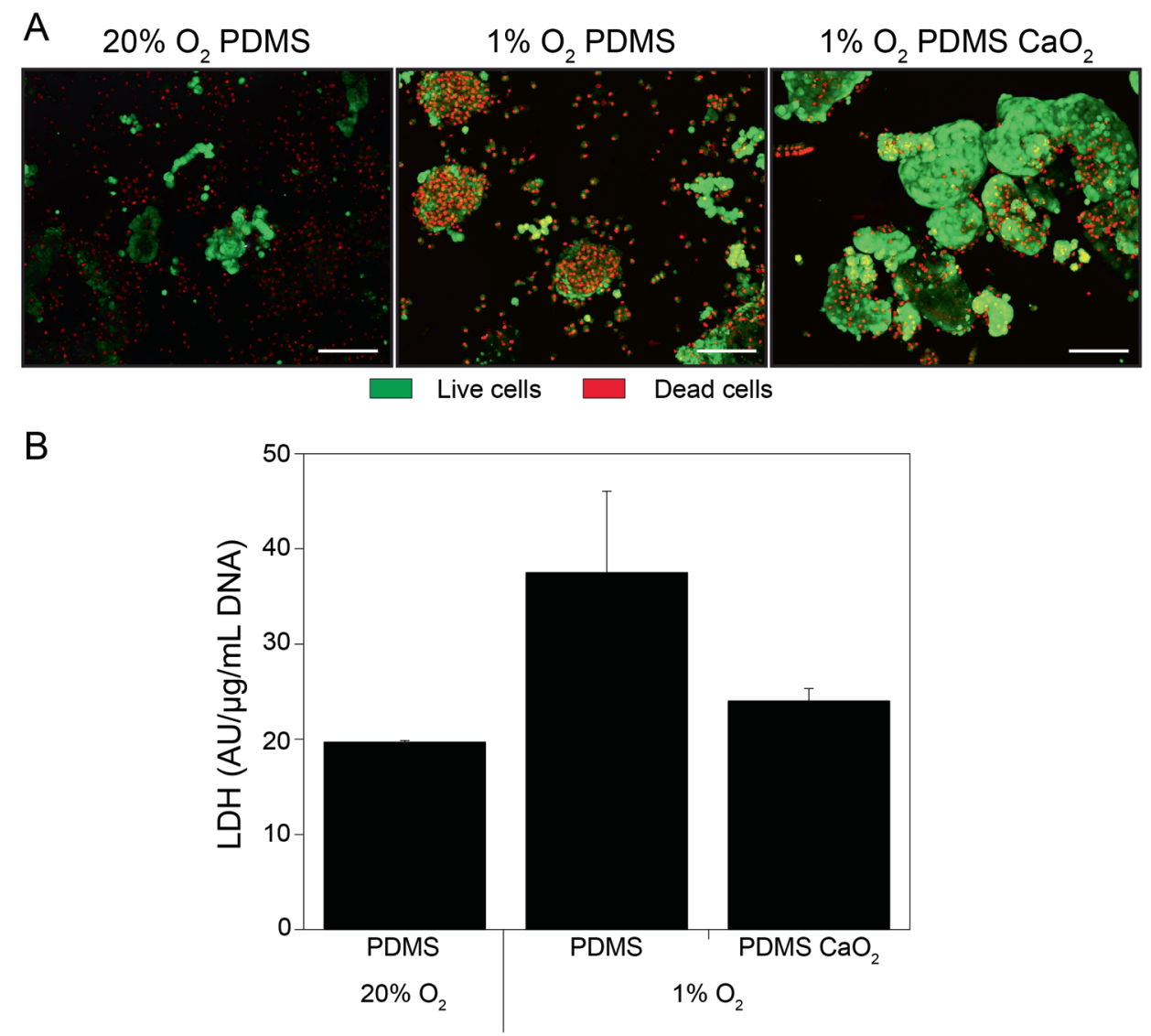

Figure 8.2: In vitro assessment of islet viability, live dead assay and LDH release. Rat islets were cultured in the PES/PVP device in the presence of a PDMS disk or PDMS $\mathrm{CaO}_{2}$ disk at $20 \%$ oxygen or 1\% oxygen. A) After $24 \mathrm{~h}$, islets were flushed from the scaffolds and stained with Calcein (live cells in green) and Ethidium homodimer (dead cells in red) to assess cell viability. Scale bar $100 \mu \mathrm{m}$. B) Collected medium was analyzed for $\mathrm{LDH}$ release and corrected for DNA. Error $=$ SD.

Besides the effect of the oxygen generating disk on islet viability, we determined the metabolic activity of the islets via an MTT assay and gene expression of LDH and 
GLUT1 (Fig 8.3). The MTT assay showed that the islets in the negative control were least metabolic active $(2.0 \pm 0.9 \mathrm{AU} / \mathrm{\mu g} / \mathrm{mL} \mathrm{DNA})$ compared to the positive control $(5.4 \pm 1.2 \mathrm{AU} / \mathrm{\mu g} / \mathrm{mL} \mathrm{DNA})$ and the islets cultured in the presence of $\mathrm{CaO}_{2}(4.8 \pm$ $1.7 \mathrm{AU} / \mu \mathrm{g} / \mathrm{mL}$ DNA) $(\mathrm{p}<0.019)($ Fig $8.3 \mathrm{~A})$.

LDH and GLUT1 gene expression was determined via a RT-PCR to confirm the previous results. Upregulation indicates activation of anaerobic glycolysis. In figure $3 \mathrm{~B}$ the fold change in gene expression over the $1 \%$ control (white bars) is shown, normalized to the hypoxic control. A fold change of $0.46 \pm 0.02$ for $\mathrm{LDH}$ and $0.51 \pm 0.03$ for GLUT1 in the $1 \%$ oxygen PDMS $\mathrm{CaO}_{2}$ group (black bars). The gene expression of the PDMS $\mathrm{CaO}_{2}$ group was significantly decreased for both $\mathrm{LDH}(\mathrm{p}<0.0019)$ and GLUT1 $(\mathrm{p}<0.0007)$. These results confirmed the positive effect of $\mathrm{PDMS}^{\mathrm{CaO}} \mathrm{O}_{2}$ on islet survival and metabolic activity. 
A

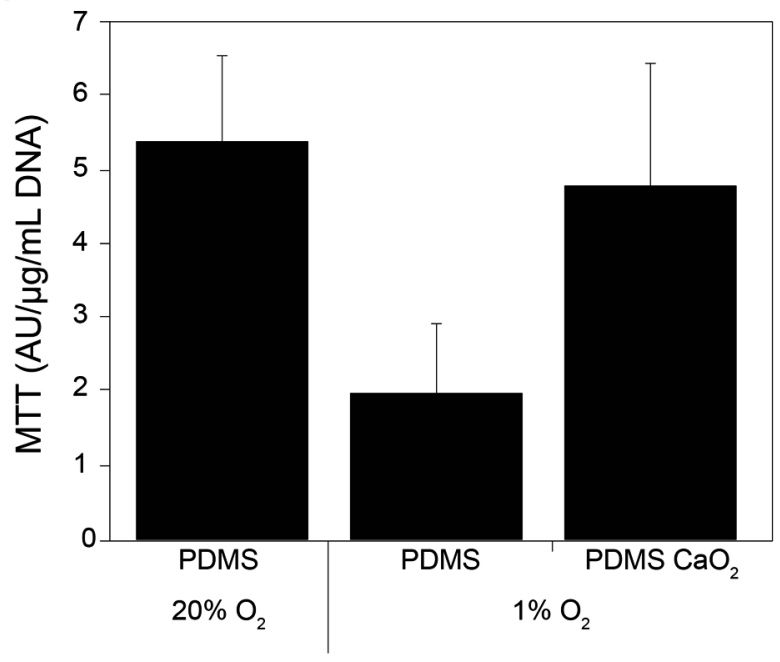

$\mathrm{B}$

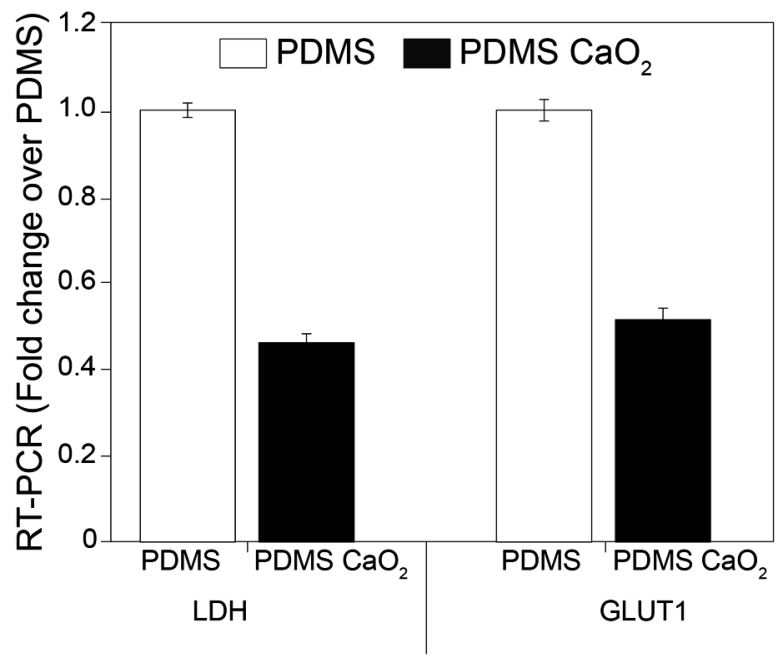

Figure 8.3: In vitro assessment of metabolic activity of islets. Rat islets, 1800 IEQ per scaffold, were seeded inside PES/PVP scaffold. The islets were then either cultured at $20 \%$ oxygen with a PDMS disk (positive control) or at $1 \%$ oxygen with a PDMS disk (negative control) or with a PDMS $\mathrm{CaO}_{2}$ disk. A) A MTT was performed on flushed out islets after $24 \mathrm{~h}$ of culture and corrected for DNA. B) Gene expression of LDH and GLUT1 was determined by RT PCR from islets cultured at $1 \%$ oxygen with (black bars) and without (white bars) oxygen generating disk. Gene expression is depicted as fold change over $1 \%$ control (PDMS disk). Errors=SD 


\subsubsection{In vitro assessment of glucose induced insulin secretion}

Since islets were viable and metabolic active when cultured under hypoxia in the presence of a PDMS $\mathrm{CaO}_{2}$ disk, the next step was to test the glucose responsiveness of the rat islets cultured under the same conditions. Rat islets seeded in the PES/PVP microwell membrane were cultured in presence of a PDMS disk with or without $\mathrm{CaO}_{2}$ for 24 hours at either $20 \%$ oxygen or $1 \%$ oxygen. After this we assessed if hypoxia would induce a change in function and if the presence of an oxygen generating material could overcome this effect.

In figure 8.4 the stimulation index of the GIIST is shown. Free floating islets (FF) at 0 hours, showed a response to high glucose with an average stimulation index above 3. After $24 \mathrm{~h}$ this response had clearly decreased, but still a low-high-low pattern of insulin secretion was observed when islets were cultured at 20\% oxygen (stimulation index $1.6 \pm 0.5)$. The negative control, islets cultured on flat membranes at $1 \%$ oxygen with a PDMS disks without $\mathrm{CaO}_{2}$, did not show any response to a glucose stimulation (stimulation index $0.7 \pm 0.1$ ). This shows that hypoxia had a detrimental effect on islet functionality. In contrast, when islets were cultured under hypoxia in the presence of an oxygen generating PDMS disc a clear low-high-low pattern in insulin secretion was observed with a significant $(p<0.01)$ higher insulin secretion upon high glucose stimulation. The low-high-low pattern was comparable to the pattern observed in the positive control (stimulation index $1.7 \pm 0.2$ ). The $\mathrm{PDMS}^{\mathrm{CaO}} \mathrm{O}_{2}$ disk was not only able to keep islets viable and metabolic active but also still responsive to glucose stimulation. 


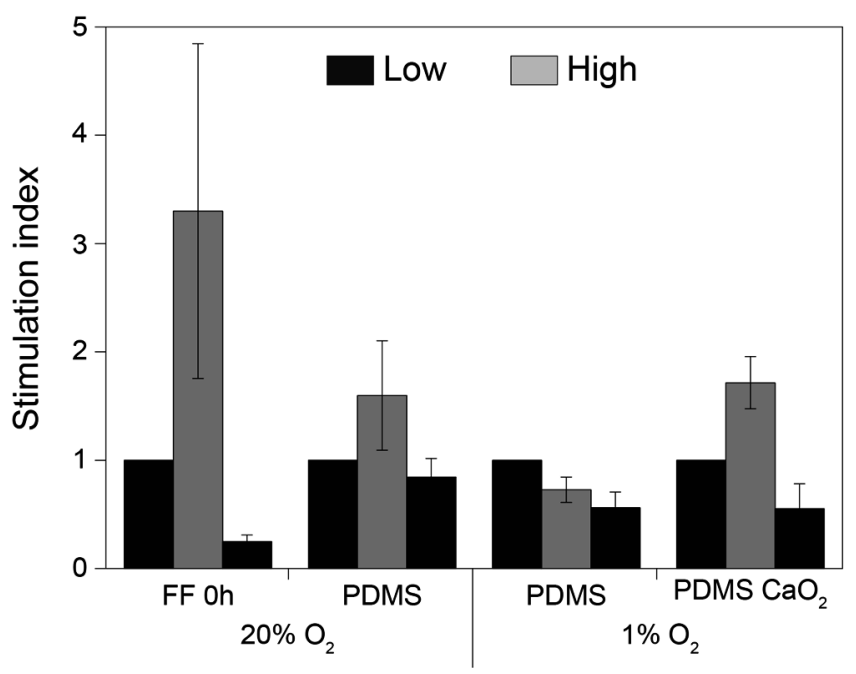

Figure 8.4: In vitro assessment of glucose induced insulin secretion. Glucose induced insulin secretion was determined for normoxic conditions; free floating (FF) islets at $0 \mathrm{~h}$ and islets cultured at $\mathbf{2 0 \%}$ oxygen for $24 \mathrm{~h}$ in the presence of a PDMS disk. Additionally, islets were cultured for $24 \mathrm{~h}$ at $1 \%$ oxygen in the presence of a PDMS disk (negative control) or a PDMS $\mathrm{CaO}_{2}$ disk, after which a GIIST was performed. Errors $=$ SD

\subsection{Discussion}

Encapsulating islets inside an immune protective device is still a challenge as lack of direct vascularization and diffusion distances often lead to graft failure. The lack of proper vascularization especially in the period directly after transplantation leads to hypoxia. This often results in islet necrosis after transplantation. When islets become hypoxic, their responsiveness to glucose changes already in an early state(5-9). Therefore, ways to overcome hypoxia have been studied from many years. Different options, from vascularization to gene therapy have shown to aid in cell survival(1, 3, $11,14,16)$. A relative easy solution however, is the combination of oxygen generation materials to the immune protective device. Using solid peroxides, like $\mathrm{CaO}_{2}$, has shown to be effective in the generation of oxygen $(15,17,18)$. One of the difficulties of using peroxides as oxygen generating agents is the reaction kinetics. When not 
properly controlled this reaction goes too fast with toxic byproducts, such as hydrogenperoxide, as a result $(15,17,18)$. When Pedraza et al. incorporated $\mathrm{CaO}_{2}$ particles in hydrophobic PDMS, they showed that the reaction kinetics could be controlled. No toxic byproducts were produced, and rat islets were able to survive and function under hypoxic conditions. They also observed that oxygen was released over a period of at least 6 weeks(15).

We developed an immune-protective device for islet encapsulation based on PES/PVP microwell membranes. This platform was based on work by Buitinga et al.(24) (Chapter 6) who developed a microwell array device in which islets are captured and kept separated. We showed that islets encapsulated in a PES/PVP microwell membrane sealed device with a $0.45 \mu \mathrm{m}$ lid for immune protection, remained functional after at least 7 days of culture(Chapter 6 ). In order to overcome the immediate period after transplantation, when vascularization around the implant has not occurred yet, a local oxygen delivery source can decrease cell death and loss of function. Therefore in this study we studied the effect of adding an oxygen generation disk, based on PDMS and $\mathrm{CaO}_{2}$, to the PES/PVP microwell membrane for islet encapsulation on viability an function of rat islets.

After culturing rat islets under hypoxic conditions, islets captured in the microwell device showed a similar amount of viable islets compared to islets cultured under normoxic conditions, while in the negative control group (1\% oxygen) many dead cells were observed. These results were confirmed by the LDH release measured in the supernatant of the medium. As the LDH release by the negative control (hypoxia) was significantly higher than both the positive control (normoxia) and the islets cultured under hypoxia in the presence of the PDMS $\mathrm{CaO}_{2}$ disk.

Besides the increase in viability the metabolic activity of the islets in the membrane in the presence of PDMS $\mathrm{CaO}_{2}$, measured by an MTT assay, was also significantly increased compared to the islets cultured at $1 \%$ oxygen. Additionally, the gene expression of LDH and GLUT1 was approximately a 0.5 fold less in the oxygen generating material group than the negative control group. These results indicate that an oxygen 
generating material can support islet survival under hypoxia.

Glucose responsiveness was increased to a comparable level of the positive control group when an oxygen generating disk was used at $1 \%$ oxygen. Islets cultured at $20 \%$ oxygen and $1 \%$ oxygen with an oxygen generating disk showed a similar stimulation index (1.6 and 1.7). The negative control group, however, showed a stimulation index of 0.7. Although both a stimulation indices are not extremely high, these results did indicate the supportive effect of the oxygen generating disk on islet function.

The findings in this study match those published by Pedraza et al., showing a similar positive effect of the oxygen generating disk on islets viability and function when cultured under hypoxia(15). The in vitro data presented in this work clearly show that the negative influence of hypoxia on cell survival and beta cell function can be overcome when a PDMS $\mathrm{CaO}_{2}$ disk is used in combination with an immune-protective microwell device within $24 \mathrm{~h}$. The question remains of course if this effect is sustained when cultured for longer periods.Pedraza et al. showed in their studies that these disks can generate a relevant amount of oxygen for a period of at least 6 weeks $(15)$. We can assume a similar positive effect is potentially present when islets are cultured for longer periods than $24 \mathrm{~h}$ in a microwell macroencapsulation device.

In this study only an open construct was used and oxygen was allowed to diffuse unhindered to the islets. The next step would be to combine the disk with a sealed construct, using a lid with pores of $0.45 \mu \mathrm{m}$ in diameter. Simply stacking the PDMS $\mathrm{CaO}_{2}$ disk onto the macroencapsulation device would mean that at least one side is inaccessible for the surrounding vasculature to grow in close proximity to the membrane surface. This potentially leads to considerable diffusion limitations, as PDMS is not very permeable to water blocking the influx of nutrients towards the islets on one side of the membrane. An alternative design, were the oxygen generating material is placed at the rim of the macroencapsulation device in an open ring structure would still allow for the formation of a dense vascular bed on both sides of the macroencapsulation device. This design could help to minimize the diffusion pathway length across the device for nutrients to reach the encapsulated islets and insulin to reach 
the blood stream in a more efficient manner. 


\section{References}

1. Bloch, K., Papismedov, E., Yavriyants, K., Vorobeychik, M., Beer, S., and Vardi, P. Photosynthetic oxygen generator for bioartificial pancreas. Tissue Engineering 12, $337,2006$.

2. Cantley, J., Grey, S.T., Maxwell, P.H., and Withers, D.J. The hypoxia response pathway and $\beta$-cell function. Diabetes Obes Metab 12, 159, 2010.

3. Colton, C.K. Oxygen supply to encapsulated therapeutic cells. Adv Drug Deliv Rev 67-68, 93, 2014.

4. Moritz, W., Meier, F., Stroka, D.M., Giuliani, M., Kugelmeier, P., Nett, P.C., Lehmann, R., Candinas, D., Gassmann, M., and Weber, M. Apoptosis in hypoxic human pancreatic islets correlates with HIF-1alpha expression. FASEB J 16, 745, 2002.

5. Silva, A.I., de Matos, A.N., Brons, I.G., and Mateus, M. An overview on the development of a bio-artificial pancreas as a treatment of insulin-dependent diabetes mellitus. Medicinal Research Reviews 26, 181, 2006.

6. Beck, J., Angus, R., Madsen, B., Britt, D., Vernon, B., and Nguyen, K.T. Islet encapsulation: Strategies to enhance islet cell functions. Tissue Engineering 13, 589, 2007.

7. Daoud, J., Petropavlovskaia, M., Rosenberg, L., and Tabrizian, M. The effect of extracellular matrix components on the preservation of human islet function in vitro. Biomaterials 31, 1676, 2010.

8. Barshes, N.R., Wyllie, S., and Goss, J.A. Inflammation-mediated dysfunction and apoptosis in pancreatic islet transplantation: Implications for intrahepatic grafts. J Leukocyte Biol 77, 587, 2005.

9. Grundfest-Broniatowski, S.F., Tellioglu, G., Rosenthal, K.S., Kang, J., Erdodi, G., Yalcin, B., Cakmak, M., Drazba, J., Bennett, A., Lu, L., and Kennedy, J.P. A new bioartificial pancreas utilizing amphiphilic membranes for the immunoisolation of porcine islets a pilot study in the canine. ASAIO Journal 55, 400, 2009.

10. Sato, Y., Endo, H., Okuyama, H., Takeda, T., Iwahashi, H., Imagawa, A., Ya- 
magata, K., Shimomura, I., and Inoue, M. Cellular hypoxia of pancreatic $\beta$-cells due to high levels of oxygen consumption for insulin secretion in vitro. J Biol Chem 286, $12524,2011$.

11. Chae, S.Y., Kim, S.W., and Bae, Y.H. Effect of cross-linked hemoglobin on functionality and viability of microencapsulated pancreatic islets. Tissue Engineering 8, 379, 2002.

12. Bensellam, M., Duvillie, B., Rybachuk, G., Laybutt, D.R., Magnan, C., Guiot, Y., Pouyssegur, J., and Jonas, J.C. Glucose-induced O 2 consumption activates hypoxia inducible factors 1 and 2 in rat insulin-secreting pancreatic beta-cells. PLoS ONE 72012.

13. Miao, G., Ostrowski, R.P., Mace, J., Hough, J., Hopper, A., Peverini, R., Chinnock, R., Zhang, J., and Hathout, E. Dynamic production of hypoxia-inducible factor$1 \alpha$ in early transplanted islets. Am J Transplant 6, 2636, 2006.

14. Wu, H., Avgoustiniatos, E.S., Swette, L., Bonner-Weir, S., Weir, G.C., and Colton, C.K. In situ electrochemical oxygen generation with an immunoisolation device. Annals of the New York Academy of Sciences1999. pp. 105.

15. Pedraza, E., Coronel, M.M., Fraker, C.A., Ricordi, C., and Stabler, C.L. Preventing hypoxia-induced cell death in beta cells and islets via hydrolytically activated, oxygen-generating biomaterials. Proc Natl Acad Sci U S A 109, 4245, 2012.

16. Evron, Y., Zimermann, B., Ludwig, B., Barkai, U., Colton, C.K., Weir, G.C., Arieli, B., Maimon, S., Shalev, N., Yavriyants, K., Goldman, T., Gendler, Z., Eizen, L., Vardi, P., Bloch, K., Barthel, A., Bornstein, S.R., and Rotem, A. Oxygen supply by photosynthesis to an implantable islet cell device. Horm Metab Res 47, 24, 2015. 17. Boudreau, N., Sympson, C.J., Werb, Z., and Bissell, M.J. Suppression of ICE and apoptosis in mammary epithelial cells by extracellular matrix. Science 267, 891, 1995.

18. Chennazhy, K.P., and Krishnan, L.K. Effect of passage number and matrix characteristics on differentiation of endothelial cells cultured for tissue engineering. Biomaterials 26, 5658, 2005.

19. Hynes, R.O. Integrins: Bidirectional, allosteric signaling machines. Cell 110, 673, 
2002.

20. Lindner, U., Kramer, J., Behrends, J., Driller, B., Wendler, N.O., Boehrnsen, F., Rohwedel, J., and Schlenke, P. Improved proliferation and differentiation capacity of human mesenchymal stromal cells cultured with basement-membrane extracellular matrix proteins. Cytotherapy 12, 992, 2010.

21. Papenburg, B.J., Vogelaar, L., Bolhuis-Versteeg, L.A.M., Lammertink, R.G.H., Stamatialis, D., and Wessling, M. One-step fabrication of porous micropatterned scaffolds to control cell behavior. Biomaterials 28, 1998, 2007.

22. Vogelaar, L., Barsema, J.N., Van Rijn, C.J.M., Nijdam, W., and Wessling, M. Phase Separation Micromolding - PSM. Adv Mater 15, 1385, 2003.

23. Vogelaar, L., Lammertink, R.G.H., Barsema, J.N., Nijdam, W., Bolhuis-Versteeg, L.A.M., Van Rijn, C.J.M., and Wessling, M. Phase separation micromolding: A new generic approach for microstructuring various materials. Small 1, 645, 2005.

24. Giancotti, F.G., and Ruoslahti, E. Integrin signaling. Science 285, 1028, 1999. 



\section{Chapter 9}

\section{Summary and outlook}

Milou Groot Nibbelink, Katarzyna Skrzypek, Lisanne Karbaat, Jéré van Lente, Cherie Stabler, Maria Coronel, Marcel Karperien, Dimitrios Stamatialis, Aart van Apeldoorn 


\subsection{Summary}

A crucial parameter for evaluation of biomaterials used for an islet macro encapsulation device is the interaction of beta cells with the biomaterials of which the device consists. Although primary cells are always preferred, they are not widely available on demand. A reliable $\beta$ cell line, although not exactly mimicking primary beta cell behavior, is a valuable tool to investigate basic concepts in immune protective encapsulation devices. We developed a protocol to use pseudo-islets assembled from mouse MIN6 insulinoma cells to overcome the donor shortage issue (chapter 3). In this chapter we showed that with an optimized cell culture protocol using theophylline we were able to obtain reliable insulin secretory behavior and glucose responsiveness comparable to donor islets using these pseudo-islets.

We used this method as a tool to develop two different immune protective strategies. Concept A is based on the use of multibore hollow fiber membranes and concept B is based on the assembly of microtextured flat membranes into an enclosing nanoporous envelop, both to protect islets direct interaction with the host's immune-system. In chapter 4 and 5 we investigated the possibility to use a commercial available PESM multibore hollow fiber, normally used for water purification, as a potential macroencapsulation device for islets. The main advantage of this system is that the different bores in the fiber can provide different functionality. For example one bore can serve for encapsulating islets, while an adjacent bore can guide bloodvessel formation, or be filled with an oxygen generating biomaterial for controlled oxygen delivery. In chapter $\mathbf{4}$ and $\mathbf{5}$ we showed that we were capable to seed and physically separate islets using agarose macrospheres in the different channels of the immunoprotective islet delivery device. However, encapsulated pseudo-islets and human islets showed no functional behavior (chapter 4). As this might be due to a lack of oxygen, an oxygen generating material was added to the device. Although oxygen was generated, this was only short lived (chapter 4). Since the multibore hollow fiber device is optically non transparent, we used photoacoustic imaging to follow cell behavior over time during cell culture in the bores of this particular macroencapsulation de- 
vice (chapter 5). In order to monitor cells within these tissue engineered constructs we designed tailor made cell culture containers which allowed for photoacoustic (PA) imaging in a sterile manner. In addition, we evaluated a number of cell labels to visualize cells within the device. An important outcome of this study was that aggregates containing carbon nanoparticle labelled cells gave rise to the highest PA signal. Using these particles, we were able to follow cell behavior over a period of 7 days without destruction of the sample. PA imaging could also be used for a broader application in Tissue Engineering, cells thick dense scaffolds could be imaged using this technique. In this thesis we only showed PA imaging on the multibore hollow fiber, however the flat membranes from chapter 6, also highly light scattering could benefit from PA imaging.

The second concept consists of two thin layers of polyethersulfone/polyvinylpyrrolidone (PES/PVP) nanoporous membranes. One layer comprises a dense array of microwells produced by phase separation solvent-non solvent casting on silicon-oxide wafers. In each microwell one or two islets can be captured, which prevents islets from accumulating and aggregating in the device. This design ensured a good control over islet distribution throughout the macroencapsulation device. This microwell array layer was closed with a porous lid ( $0.45 \mathrm{\mu m}$ pores) with a custom made hot press to seal only the rim, while leaving the internal microarchitecture intact (chapter 6).

Islets in the pancreas are normally innervated by a dense almost glomeruli-like vascular network to provide pancreatic islet cells, and $\beta$ cells in particular, with a very efficient supply of nutrients and oxygen, and release of pancreatic hormones in the opposite direction. It is commonly accepted and shown by numerous groups that a lack of oxygen in the environment of $\beta$ cells, due to impaired vascularization after islet isolation and encapsulation afterwards, can directly lead to significant loss of function, and islet necrosis over time.

In chapter 7 we show that the addition of a well-defined micropattern to the flat membrane macroencapsulation device can influence the behavior and direct cell growth of rat mesenchymal stem cells (MSCs) along the surface of the implant in order to 
potentially enhance vascularization in vivo. In the final chapter (chapter 8) oxygen generating materials, developed by our collaborators at the Diabetes Research institute in Miami, FL, USA, consisting of a combination of polydimethylsiloxane (PDMS) and calcium peroxide $\left(\mathrm{CaO}_{2}\right)$ particles, were combined with the flat membrane macroencapsulation device. We showed an enhanced effect on islet viability, metabolic activity, and function when cultured under hypoxia in the presence of the oxygen generating disk.

During this research we made the first steps towards a working immune protective islet encapsulation device. Although successful in many aspects additional work is needed to further optimize the devices developed during this project.

\subsection{Multibore hollow fiber for extrahepatic islet transplantation}

In chapter 4 a commercial PESM multibore hollow fiber was used as a macroencapsulation device for islets. Hollow fibers have previously been shown to be a potential interesting technique to shield allogeneic islets from the immune system. The main advantages of this design is that the device is relatively compact with a large surface area, can be produced from inert, non fouling and non-degradable biomaterials, and the shape and size as well as membrane properties can be easily adjusted to meet the requirements for islet encapsulation.

In our studies we chose for a multibore bore hollow fiber since they have higher mechanical stability that allows for easier handling and implantation and the different bores can be used to incorporate different functionalities like islet encapsulation, vascularization, drug delivery, and controlled oxygen delivery (chapter 4 fig 1).

We showed that both glucose and insulin can diffuse relatively unhindered across the membrane of the commercial available multibore hollow fiber. However, after encapsulation islets could not respond accurately to changes in glucose with no to minimal insulin release. After thorough histological evaluation we conclude that the 
dimensions of the bores do not accommodate islets. As the diameter of the bore is already $900 \mu \mathrm{m}$ and the membrane thickness itself adds to the pathway length for nutrients to diffuse towards the islets. Although, connective tissue ingrowth seemed not to be hindered by the majority of the pores in these constructs, the length of the bores in a clinically relevant sized device, could potentially lead to suboptimal vascularization of the construct. Based on these results a change in basic design of the multibore macroencapsulation device is necessary in order to serve as immune protective islet delivery device.

An important step is to increase the permeability of these membranes without compromising immune protection. Similar to the optimization of the flat membrane device in chapter 6, composition and treatment of PES/PVP could be optimized in order to achieve a higher porosity leading to better diffusion of glucose and insulin. We showed that washing out PVP after casting with sodium hyperchlorite increased the porosity and even changed the device from non-functional to a functional device.

Changing the geometry of the device could very well aid in a successful multibore hollow fiber, as the diffusion distance for the islets towards to outside of the membrane should be as thin as possible. It is known that diffusion distances exceeding $200 \mu \mathrm{m}$ cell viability could be negatively affected $(1,2)$. In chapter $\mathbf{6}$, we already noticed that islets encapsulated in a membrane with $250 \mu \mathrm{m}$ thickness had a significant decrease in glucose responsiveness compared to the free floating. The shows how important diffusion distances are. Designing a spinneret and optimizing the spinning process in such a way that the walls could be as thin as possible as well as creating smaller bores could be a step in a good direction. The most optimal would be if the size of the bores is maximally the size of the biggest islet. These changes, although most likely necessary to create a successful device, do possess some difficulties. Thinner walls for example will decrease the stability of the device, although still stronger than a single fiber would be. Also the seeding might become more difficult as the bores are reduced in size. A new seeding method might need to be developed.

As shown in chapter 4, the oxygen generated from three bores filled with PDMS 
$\mathrm{CaO}_{2}$ was not sufficient as this lasted for merely a day. In table 2 of chapter 4 we showed the differences between volume and surface of the disk used by Pedraza et al.(3), and the PDMS-CaO ${ }_{2}$-cylinders incorporated into the multibore device. The cylinders comprise $16 \%$ of the total volume and only $8 \%$ of the total surface of the disk published in their study. We therefore concluded that the size of these oxygen generating cylinders should be increased in order to achieve sufficient oxygen supply similar to the disk. We propose to use the middle bore of the multibore hollow fiber for this, by increasing the size of this bore, both volume and surface will increase. This could be achieved by doubling the size of the middle bore. This on itself will of course increase the total diameter of the multibore hollow fiber. However, by decreasing the size of the other bores and the wall thickness, this might not pose a problem.

In figure 9.1 we present the design differences between the commercial PESM multibore hollow fiber from chapter 4 with a proposed new multibore hollow fiber. 


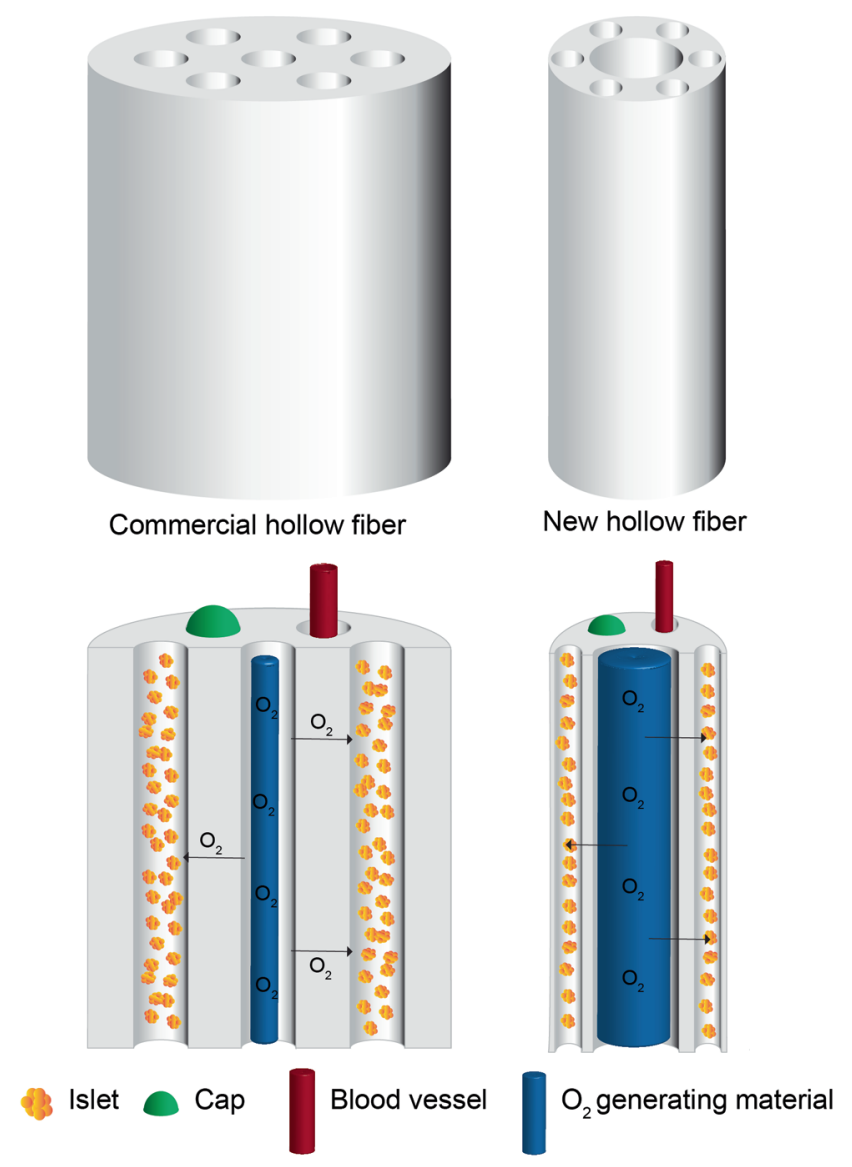

Figure 9.1: A schematic of the commercial PESM multibore hollow fiber on the left and the proposed design of a new multibore hollow fiber on the right. 
We also indicate the possibility to use bores for vascular ingrowth (Fig 9.1). Biodegradable hollow fibers have previously been used as a support to guide vascularization. Support cells can be seeded on the outside of the hollow fibers(4-6). In the most optimal design one would like to seed cells within one or multiple bores of each fiber before implantation to stimulate neoageogenesis. Mercado-Pagán et al. showed that they were able to seed human umbilical vein endothelial cells (HUVECs) in the bore of the hollow fiber, so technically this should be possible(6).

A more straight forward solution would be to induce vascularization in vivo by the introduction of growth factors into these vascularization bores. One of the most used angiogenic growth factors is vascular endothelial growth factor (VEGF)(7, 8). Numerous studies have shown that the addition or incorporation of VEGF a tissue engineered device can enhance the formation of new bloodvessels in close vicinity to the implant $(7,9,10)$. Other options of angiogenic factors are; endothelial cell growth factor, and basic fibroblast growth factor(8). Combining these factors with a tailored release pattern, maybe in combination with a hydrogel or another drug delivery system, could aid in sufficient vessel formation inside the bore of the multibore hollow fiber.

\subsection{Outlook}

\subsubsection{Improving the transplantation outcome by the induction of vessel formation}

In chapter 7 we showed that MSCs and the two different micropatterned membranes, the bricks and channels (chapter 7 fig 1), enhanced vascularization in vivo. This vascularization is of great importance for an immune protective device for clinical islet transplantation. As the isolation process disrupts the vasculature of islets and as islets are normally highly vascularized in the pancreas. Proper vascularization of islets is important as they receive $5-15 \%$ of the total blood supply of the pancreas while they only consist of $1 \%$ of the entire pancreas $(9,11,12)$. As for many cells and tissues, when 
islets are not in contact with blood vessels, they will become hypoxic. Subsequently this leads to a loss of viability and glucose responsiveness(13-18). Still we should keep in mind that with islets encapsulated in an immune protective membrane, we will never vascularize the islets themselves. However, the aim would be to implant a device in a highly vascularized environment.

There are many different ways to enhance vascularization of the encapsulated islets, either by prevascularization of the device or by induction of vascularization in vivo ( 9 , 19). In general prevascularization is referred to the formation of a capillary network before implantation(20). Prevascularization could shorten the vascularization of the implant(20). in vitro prevascularization has shown to be effective for fast in vivo vessel formation. Pre-culture of endothelial cells on the scaffold has shown to aid in fast vessel formation once implanted in vivo(21-24). Many different cell types with endothelial potential have shown to positively influence the rate of vascularization. Examples of cells used are MSCs, fibroblasts, endothelial (progenitor) cells, and bone marrow progenitor cells(7, 25-32). When using so-called support cells like fibroblasts and MSCs are combined with endothelial like cells, the effect of prevascularization can be more significant $(21,22,24)$. When HUVECs are co-cultured with support cells they can form primitive capillary like structures. This often happens in combination with a hydrogel, like fibrin gel or matrigel $(20,33,34)$. The combination of HUVECs with MSCs, or HUVECs with fibroblast have previously been described to lead to increased blood vessel formation in vivo $(22,24,34)$. The combination of a wellestablished ECM network by the support cells, containing growth factors, and the cell-cell contact yields in a stable microvascular network with subsequently a vast formation of vessels in vivo(34).

When a prevascularization strategy is applied the biomaterial should facilitate cell adhesion(20). By definition synthetic polymers do not contain amino acid sequences, or proteins to which cell receptors can naturally adhere. Cell attachment can only occur in an indirect manner after proteins are adsorbed to the material surface. Non fouling biomaterials such as PES/PVP show little to no protein adsorption which 
often leads to poor cell attachment. Pretreatment of these materials by coating with fibronectin or collagen can greatly improve cell attachment on these polymers $(20,23)$. Fibronectin has shown to be of great importance for angiogenesis as it facilitates cell adhesion, proliferation, and cell migration(23). Cells are able to attach to fibronectin via RGD binding integrins, and more specifically $\alpha \mathrm{v}$-containing integrins $(21,22,35)$. It has been shown that cell adhesion via integrins to ECM molecules, like fibronectin, activates intracellular signaling pathways that direct cell viability, proliferation and differentiation $(23,36)$.

In addition to pretreating materials to enhance cell attachment altering the micropattern of the surface can enhance vascularization even further. Baxter Healthcare discovered that micropatterns could positively influence vessel formation already in 1990 . More recently, Song et al. showed that MSCs on micropatterned PDMS had a positive effect on blood vessel formation in vivo(37). Micropatterns made by casting, soft lithography, photolithography, and micropatterning were shown to promote cell adhesion and alignment(34). The cell alignment and organization was shown to induce vascularization in engineered tissues $(34)$.

In chapter 7 we showed that MSCs combined with micropatterned membranes can be used for in vivo vascularization. However, this effect can likely be enhanced by the use of in vitro prevascularization before implantation. In a conceptual study we investigated the use of MSCs as supporter cells for HUVECs. Although in literature MSCs were proven to be good support cells, we observed that MSCs were not capable to stimulate HUVECs to form tubule like structures (Fig 9.2). 
DAPI

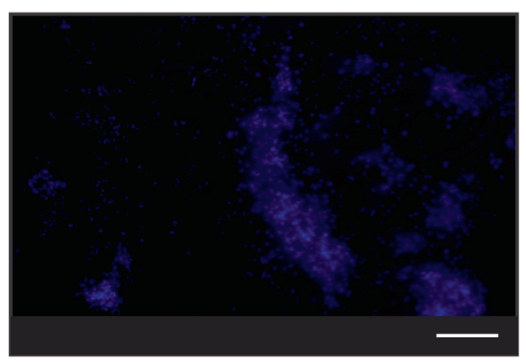

CD31

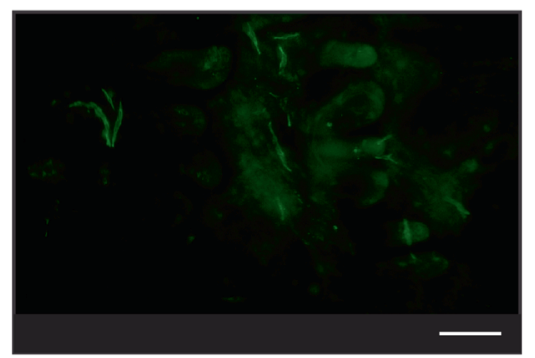

Figure 9.2: Co culture of HUVECs on a confluent layer of MSCs on a non-patterned membrane. All cell nuclei were stained with DAPI (left) and HUVECs were stained for CD31 (right). Scale bars $100 \mu \mathrm{m}$.

As an alternative strategy we investigated the use of normal human dermal fibroblasts (NHDF) and HUVECs for in vitro prevascularization as was described before by Friis et al $(35,38)$. We found that similar to MSCs, both HUVECs and NHDF were able to attach to fibronectin coated PES/PVP membranes. NHDF, albeit to a lesser extent than MSCs, aligned to micropatterned membranes (Fig 9.3A). On the contrary, HUVECs showed only a slight increase in percentage of nuclei aligned with the structures on the micropatterned membranes (Fig 9.3B).

We further investigated if NHDF could serve as support cells for HUVECs and aid in alignment and structure formation of HUVECs. After a confluent layer of NHDF was obtained, HUVECs were seeded on top of this confluent layer. After cell culture the CD31+ HUVECs were visualized by immunofluorescent microscopy (Fig 9.4). For all membranes (non-patterned, bricks, and channels), we observed structure formation of CD31 positive HUVECs (right panel). Where a random organization of these HUVEC structures was seen on non-patterned membranes with a random porous surface architecture, a clear alignment to the micropatterns was seen in both bricks and channels micropatterned membranes. 


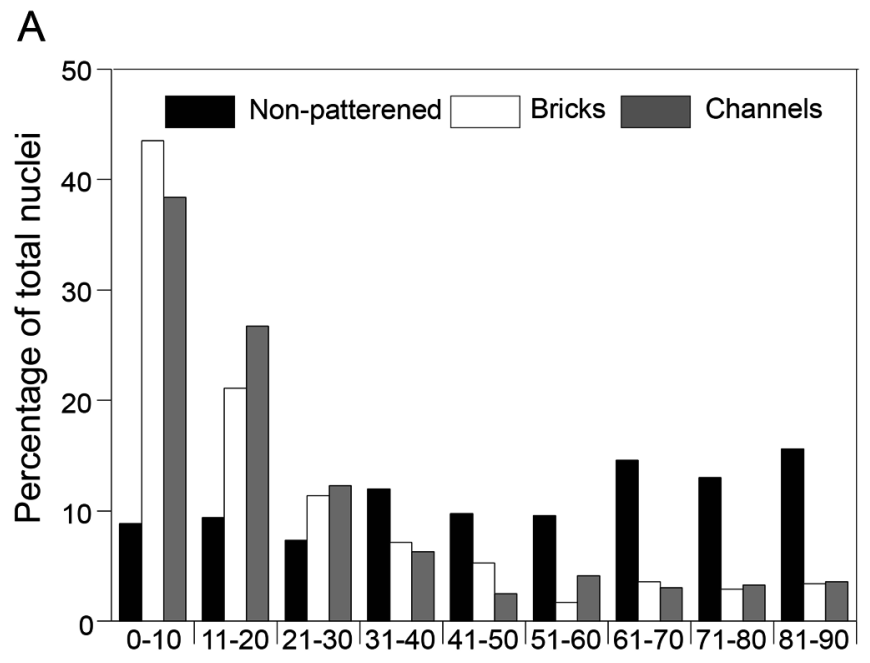

NHDF nucleus alignment relative to micropattern

B

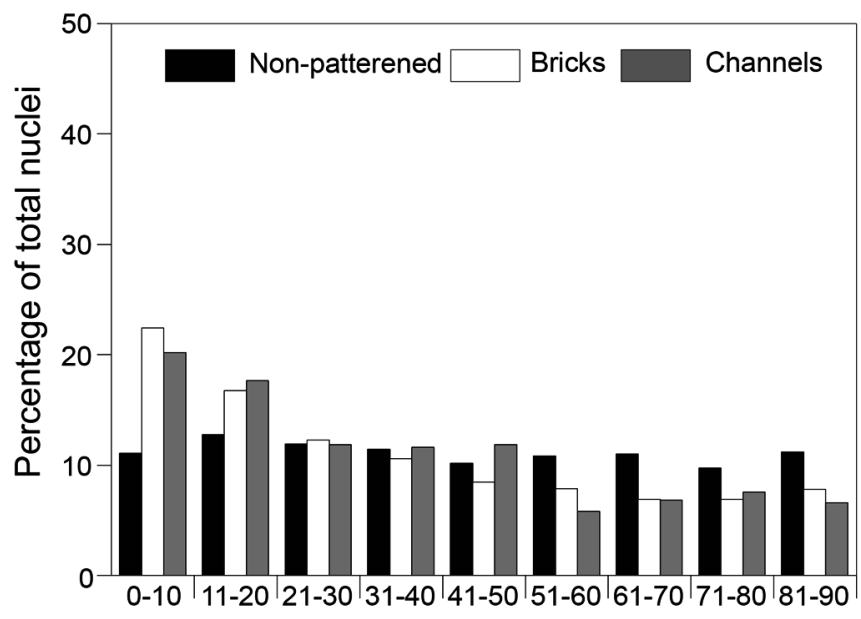

HUVEC nucleus alignment relative to micropat-

Figure 9.3: Nucleus alignment relative to structure. A) NHDF nucleus alignment relative to structure (non-patterned, bricks, and channels). B) HUVEC nucleus alignment relative to structure (nonpatterned, bricks, and channels). 


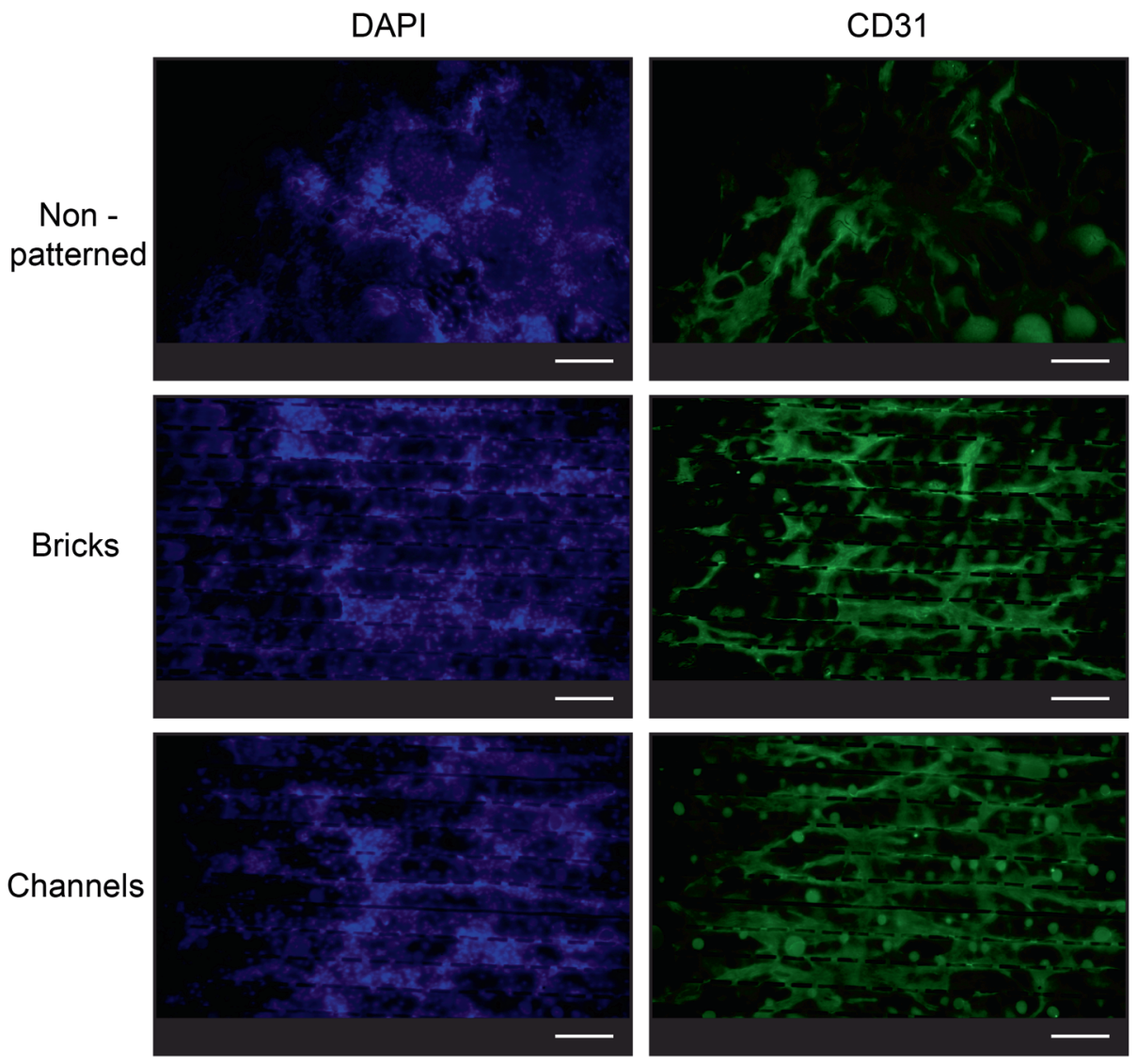

Figure 9.4: Co-Culture of HUVECs and NHDF on PES/PVP membranes. HUVECs were seeded on a confluent layer of NHDF. After culture nuclei were stained with DAPI (left panel) and HUVECs were stained with CD31 (right panel). Three different membrane types were used; flat (top), bricks (middle), and channels (bottom). (Scale bar $500 \mu \mathrm{m}$ ) 
The outcome of this study indicates that by combining micropatterns, and with the seeding of NHDFs organized structures by HUVECs can be formed in vitro without the need for an extracellular matrix like hydrogel. Further in vivo and in vitro studies need to reveal the actual effect on neoangenesis and permeability of the newly developed system.

\subsubsection{Oxygen generating materials}

In chapter 8 we combined a PDMS- $\mathrm{CaO}_{2}$ disk with the flat membrane device from chapter 6. The $\mathrm{CaO}_{2}$ particles containing PDMS disk generates oxygen for at least 6 weeks and has proven to aid in islet function and survival when cultured under hypoxic conditions(3). We showed in chapter 8 that the addition of the PDMS $\mathrm{CaO}_{2}$ disk to the open flat membrane device indeed had a positive effect on islet survival, metabolic activity, and glucose responsiveness. The next step would be to test if the oxygen generated from the PDMS $\mathrm{CaO}_{2}$ disk still boosts islet survival while encapsulated in the sealed device as in chapter 6 we only used an open system. Preliminary data in figure 9.5 shows a live dead stain of islets flushed from the thin flat membrane device that was closed off with a $0.45 \mu \mathrm{m}$ lid in a transwell system. Similar to the data presented in chapter $\mathbf{8}$, islets survive better under hypoxia when co cultured with a PDMS $\mathrm{CaO}_{2}$ disk.

In chapter $\mathbf{8}$, as well as in figure 9.5, we placed the disk at the bottom of a wells plate with medium in between the disk and the membrane. When this combination would be implanted in vivo, this would mean that the disk would be attached to the bottom of the membrane. This could potentially induce diffusion limitations, as the disk might (partially) block the membrane. We therefore propose to change the design of the oxygen generating flat membrane device to overcome this issue. In figure 9.6A a schematic of the new design is depicted. We developed a mold for this (Fig 9.6B). The mold consist of a reservoir for PDMS in the shape of a ring and a holder for the flat membranes. Besides generation of oxygen, the purpose of this PDMS ring would be to seal the lid and the bottom membrane together. The complete device was engineered 


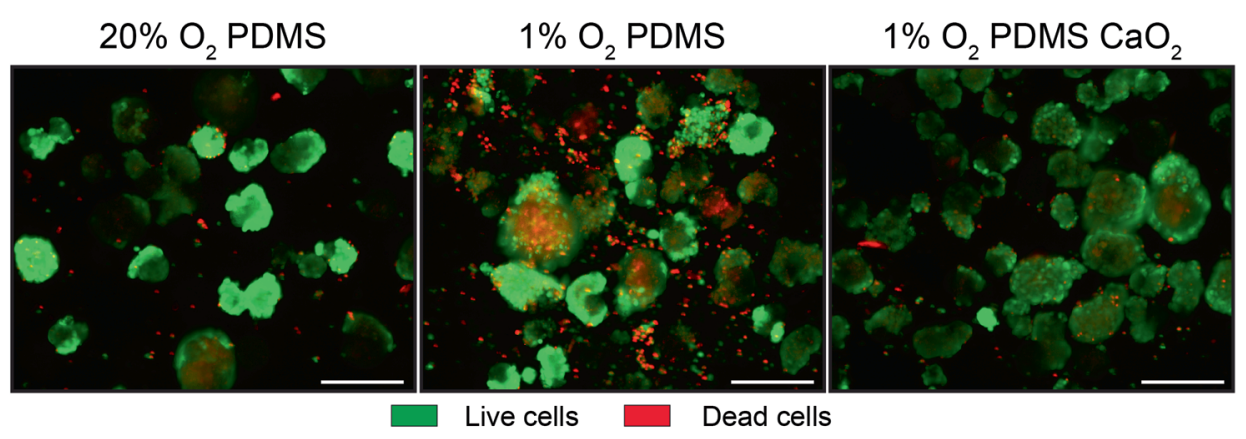

Figure 9.5: Islets were encapsulated in a flat membrane device with a $0.45 \mathrm{\mu m}$ lid on top. After 1 day of culture at either $20 \%$ oxygen or $1 \%$ oxygen in the presence of a PDMS or PDMS $\mathrm{CaO}_{2}$ disk, islets were flushed out and stained with a live (green) dead (red) stain. Scale bars $200 \mu \mathrm{m}$

as follows; both the lid and the bottom membrane were placed in the middle of the mold. The mold was closed, and degassed PDMS was pipetted into the mold. As the mold had a tight seal, no PDMS could leak into part of the membranes where islets would be encapsulated. After curing of the PDMS, the mold was taken apart and the device was ready for use (Fig 9.6C). The final result is shown in figure 9.6D. The two membranes are on top of each other, with a ring of PDMS around them, immediately providing a seal. As depicted in figure 9.6D, a small opening was created in the PDMS ring. Through this opening, islets will be seeded. When using PDMS with $\mathrm{CaO}_{2}$ the PDMS ring has a brown color (Fig 9.6E).

The PDMS ring has an outer diameter of $16 \mathrm{~mm}$, an inner diameter of $10 \mathrm{~mm}$ and is $2 \mathrm{~mm}$ in height. This correlates to a volume of $245 \mathrm{~mm}^{3}\left(\operatorname{disk}=78.5 \mathrm{~mm}^{3}\right)$ and a surface area of $408 \mathrm{~mm}^{2}\left(\right.$ disk $\left.=188.5 \mathrm{~mm}^{2}\right)$. Compared to the small cylinders in chapter 4 , where oxygen generation was not sufficient, this will probably not be the case for this PDMS ring. Oxygen generation data and finally cell data will give us an answer if this construct could be used as an oxygen generating immune protective device for islet encapsulation. 
A

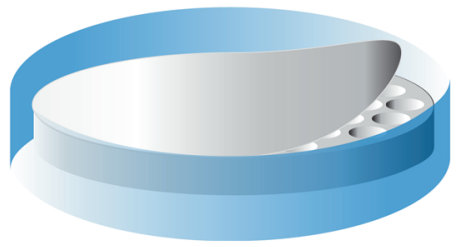

PES/PVP membrane

B

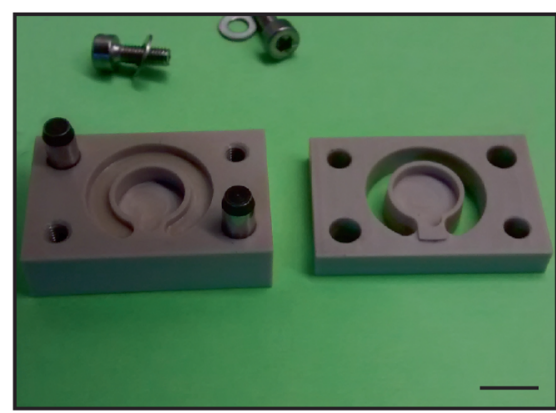

D

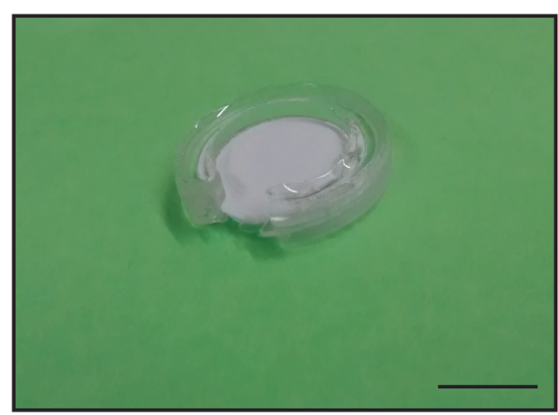

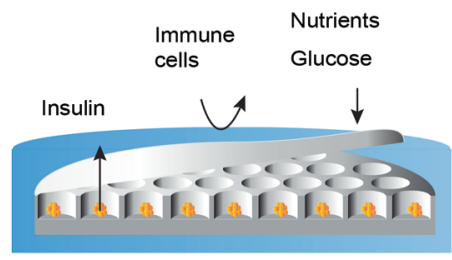

$\mathrm{O}_{2}$ generating material

Islet

C

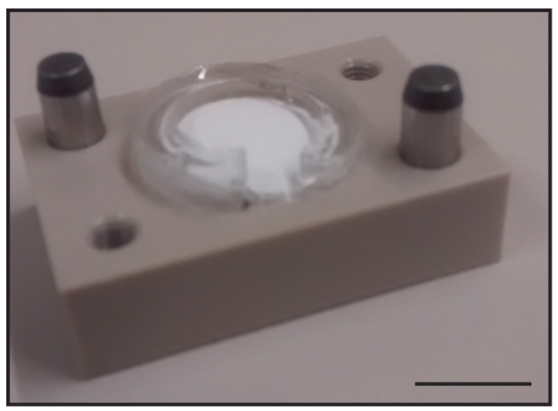

E

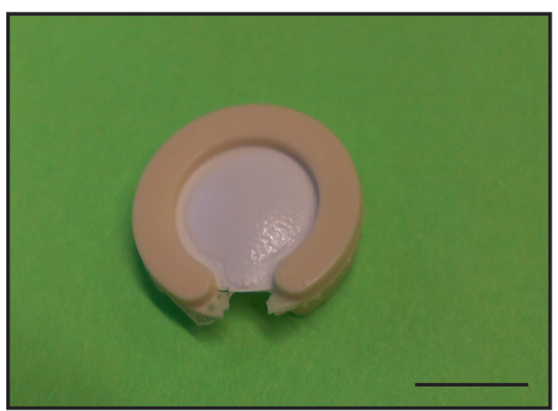

Figure 9.6: A) A schematic representation of the newly developed oxygen generation flat membrane device, which consists of the flat microwell membrane with on top a lid, both sealed with a ring of oxygen generating materials. B) the mold to create the device. The outer ring is the PDMS reservoir, with an outer diameter of $16 \mathrm{~mm}$ and an inner diameter of $10 \mathrm{~mm}$. Both membranes are placed in the middle of the mold. After curing of the PDMS, a seal of PDMS is formed around the membranes in the shape of a ring (C). D) The final device, a PDMS ring around the membranes with an inlet for seeding. E) The final device, with a PDMS $\mathrm{CaO}_{2}$ ring around the membranes with an inlet for seeding. Scale bars $8 \mathrm{~mm}$ 


\subsubsection{Immune protection}

We aimed to develop not only an encapsulation device for extrahepatic islet transplantation but to develop an immune protective device. As discussed in chapter 2 the question remains what the most optimal molecular weight cut off or pore size for an immune protective device is. The molecular weight cut off usually lies between $50-150 \mathrm{kDa}(39)$. A $150 \mathrm{kDa}$ cut off is based on the size of $\operatorname{IgG}$ which is the smallest immunoglobulin. Loudovaris et al showed that an $0.45 \mu \mathrm{m}$ pore size comprising membrane was successful in shielding allogeneic cells from the immune system(40). A very well-known device in the field of islet encapsulation is the Baxter immunoisolation device, otherwise known as the TheraCyte ${ }^{\mathrm{TM}}$ system, where islets are shielded by a $0.4 \mu \mathrm{m}$ pore membrane laminated to a $5 \mu \mathrm{m}$ pore membrane to allow for vascularization(41-43). With these pore sizes, IgG and IgM were still able to infiltrate the device while the allogenic tissue survived(40-43). In this thesis we did not show any experiments concerning immune protection. However, based on the device of Loudovaris et al. and the TheraCyte ${ }^{\mathrm{TM}}$ system, we believe the flat membrane device could potentially be immune protective. As the flat membrane device has a maximum pore size of $0.45 \mu \mathrm{m}$.

If the device is indeed immune protective should clearly be established via experiments. in vitro assays should be selected on the parameters of the device. Interesting would be to check for complement-dependent cytotoxicity (CDC), cytokine cytotoxicity, mixed lymphocyte reaction, reactive T cells, and reactive NK cells. These assays could give an indication about the immune protective properties of the device, however an allogeneic transplantation in immune competent animals should give more conclusive data.

\subsubsection{The multibore hollow fiber or a flat microwell membrane?}

In this thesis we described two different immune protective strategies. Concept $\mathrm{A}$ is based on the use of multibore hollow fiber membranes and concept B is based on the assembly of microtextured flat membranes into an enclosing nanoporous envelop, both 
to protect islets direct interaction with the host's immune-system. For both strategies we showed the need for additional work. For the multibore hollow fiber the diffusion distance has shown to be a great issue, leading to a non functional device. When we used a casting thickness of $250 \mu \mathrm{m}$ for the microwell membrane, we observed that this distance reduced the functionality of the device. However, at $100 \mu \mathrm{m}$ the islets remained functional although still somewhat less than the free floating. Comparing the thickness of the membrane of the hollow fiber to the thickness of the multibore it seems logic that the commercial multibore hollow fiber from chapter 4 was not functional. In order for a multibore hollow fiber to be successful, the thickness of the membrane should not exceed $100 \mu \mathrm{m}$. Decreasing the thickness of the membrane of the multibore to $100 \mu \mathrm{m}$ is possible. However, one should also consider the diameter of the bores, this needs to be added to the diffusion length. When we take this into consideration, the microwell membrane might be the best solution for an immune protective device. Additionally, the physical separation achieved by the microwells is easier than in the multibore hollow fiber, as additional materials should be added when islets are encapsulated in the bores. These materials might negatively influence the diffusion of nutrients to the islets.

For both strategies we discussed the option to (pre-) vascularize the constructs. For the flat microwell membranes we already showed in chapter 7 that we were able to induce vessel formation. When upscaling the device, the method to induce vessel formation does not need to change, as it would still consist of a cell layer and micropatterned surface. Using a bore for vessel formation in the multibore hollow fiber strategy on the other hand, would be more problematic when the device needs to be upscaled. As the cells and vessels need to travel for a much longer distance in the bore.

The solution for oxygen generation on the other hand might be easier in the multibore hollow fiber. The geometry of the device, the diameter of the middle bore, can easily be adapted. Therefore, oxygen will be generated homogeneously throughout the multibore. The ring used as a seal in the microwell strategy as discussed in this 
chapter, has the disadvantage that the islets in the periphery are the furthest away from the oxygen generating materials. When using a disk as decribed in chapter $\mathbf{8}$, the diffusion of nutrients might be blocked. Therefore, oxygen generation for all islets in the device might be easier in a multibore hollow fiber.

In conclusion, in this thesis we presented two strategies for an immune protective encapsulation device for the extrahepatic transplantation of islets; the multibore hollow fiber and flat membranes. We showed the possibilities to enhance the devices by vascularization and oxygen generation. Although in chapter 6 we presented a functional device, these results were purely based on in vitro data. In the final chapter we presented several possibilities and focus points to take the next step towards a true immune protective device. The most optimal device would include physical separation of islets, thin membranes, a vascular network surrounding the device, and oxygen generating materials to overcome the first period after transplantation. Combining the flat membranes with the oxygen generating ring and the MSCs on the with bricks micropatterened lid of this construct might lead to a functional immune protective membrane based scaffold for islet encapsulation. 


\section{References}

1. Pareta, R.A., Farney, A.C., and Opara, E.C. Design of a bioartificial pancreas. Pathobiology 80, 194, 2013.

2. Schweicher, J., Nyitray, C., and Desai, T.A. Membranes to achieve immunoprotection of transplanted islets. Front Biosci Landmark 19, 49, 2014.

3. Pedraza, E., Coronel, M.M., Fraker, C.A., Ricordi, C., and Stabler, C.L. Preventing hypoxia-induced cell death in beta cells and islets via hydrolytically activated, oxygen-generating biomaterials. Proc Natl Acad Sci U S A 109, 4245, 2012.

4. Ellis, M.J., and Chaudhuri, J.B. Poly(lactic-co-glycolic acid) hollow fibre membranes for use as a tissue engineering scaffold. Biotechnol Bioeng 96, 177, 2007.

5. Bettahalli, N.M.S., Steg, H., Wessling, M., and Stamatialis, D. Development of poly(l-lactic acid) hollow fiber membranes for artificial vasculature in tissue engineering scaffolds. Journal of Membrane Science 371, 117, 2011.

6. Mercado-Pagan A, E., Kang, Y., Findlay, M.W., and Yang, Y. Development and evaluation of elastomeric hollow fiber membranes as small diameter vascular graft substitutes. Materials Science and Engineering C 49, 541, 2015.

7. Colton, C.K. Oxygen supply to encapsulated therapeutic cells. Adv Drug Deliv Rev 67-68, 93, 2014.

8. Tilakaratne, H.K., Hunter, S.K., Andracki, M.E., Benda, J.A., and Rodgers, V.G.J. Characterizing short-term release and neovascularization potential of multiprotein growth supplement delivered via alginate hollow fiber devices. Biomaterials 28, 89, 2007.

9. Trivedi, N., Steil, G.M., Colton, C.K., Bonner-Weir, S., and Weir, G.C. Improved vascularization of planar membrane diffusion devices following continuous infusion of vascular endothelial growth factor. Cell Transplant 9, 115, 2000.

10. Vallbacka, J.J., and Sefton, M.V. Vascularization and improved in vivo survival of VEGF-secreting cells microencapsulated in HEMA-MMA. Tissue Engineering 13, $2259,2007$.

11. Ballian, N., and Brunicardi, F.C. Islet vasculature as a regulator of endocrine 
pancreas function. World J Surg 31, 705, 2007.

12. Homo-Delarche, F., and Boitard, C. Autoimmune diabetes: The role of the islets of Langerhans. IMMUNOL TODAY 17, 456, 1996.

13. Silva, A.I., de Matos, A.N., Brons, I.G., and Mateus, M. An overview on the development of a bio-artificial pancreas as a treatment of insulin-dependent diabetes mellitus. Medicinal Research Reviews 26, 181, 2006.

14. Beck, J., Angus, R., Madsen, B., Britt, D., Vernon, B., and Nguyen, K.T. Islet encapsulation: Strategies to enhance islet cell functions. Tissue Engineering 13, 589, 2007.

15. Daoud, J., Petropavlovskaia, M., Rosenberg, L., and Tabrizian, M. The effect of extracellular matrix components on the preservation of human islet function in vitro. Biomaterials 31, 1676, 2010.

16. Barshes, N.R., Wyllie, S., and Goss, J.A. Inflammation-mediated dysfunction and apoptosis in pancreatic islet transplantation: Implications for intrahepatic grafts. J Leukocyte Biol 77, 587, 2005.

17. Grundfest-Broniatowski, S.F., Tellioglu, G., Rosenthal, K.S., Kang, J., Erdodi, G., Yalcin, B., Cakmak, M., Drazba, J., Bennett, A., Lu, L., and Kennedy, J.P. A new bioartificial pancreas utilizing amphiphilic membranes for the immunoisolation of porcine islets a pilot study in the canine. ASAIO Journal 55, 400, 2009.

18. Kort, H.D., Koning, E.J.D., Rabelink, T.J., Bruijn, J.a., and Bajema, I.M. Islet transplantation in type 1 diabetes. Bmj 342, d217, 2011.

19. Bloch, K., Papismedov, E., Yavriyants, K., Vorobeychik, M., Beer, S., and Vardi, P. Photosynthetic oxygen generator for bioartificial pancreas. Tissue Engineering 12, 337, 2006.

20. Tian, L., andGeorge, S.C. Biomaterials to prevascularize engineered tissues. J Cardiovasc Transl Res 4, 685, 2011.

21. Mishra, R., Roux, B.M., Posukonis, M., Bodamer, E., Brey, E.M., Fisher, J.P., and Dean, D. Effect of prevascularization on in vivo vascularization of poly(propylene fumarate)/fibrin scaffolds. Biomaterials 77, 255, 2016.

22. Baiguera, S., and Ribatti, D. Endothelialization approaches for viable engineered 
tissues. Angiogenesis 16, 1, 2013.

23. Sarker, M., Chen, X.B., and Schreyer, D.J. Experimental approaches to vascularisation within tissue engineering constructs. J Biomater Sci Polym Ed 26, 683, 2015. 24. Novosel, E.C., Kleinhans, C., and Kluger, P.J. Vascularization is the key challenge in tissue engineering. Adv Drug Deliv Rev 63, 300, 2011.

25. Teramura, Y., andIwata, H. Bioartificial pancreas. Microencapsulation and conformal coating of islet of Langerhans. Adv Drug Deliv Rev 62, 827, 2010.

26. Kang, S., Park, H.S., Jo, A., Hong, S.H., Lee, H.N., Lee, Y.Y., Park, J.S., Jung, H.S., Chung, S.S., and Park, K.S. Endothelial progenitor cell cotransplantation enhances islet engraftment by rapid revascularization. Diabetes 61, 866, 2012.

27. Veriter, S., Gianello, P., Igarashi, Y., Beaurin, G., Ghyselinck, A., Aouassar, N., Jordan, B., Gallez, B., and Dufrane, D. Improvement of subcutaneous bioartificial pancreas vascularization and function by coencapsulation of pig islets and mesenchymal stem cells in primates. Cell Transplant 23, 1349, 2014.

28. Veriter, S., Aouassar, N., Adnet, P.Y., Paridaens, M.S., Stuckman, C., Jordan, B., Karroum, O., Gallez, B., Gianello, P., and Dufrane, D. The impact of hyperglycemia and the presence of encapsulated islets on oxygenation within a bioartificial pancreas in the presence of mesenchymal stem cells in a diabetic Wistar rat model. Biomaterials 32, 5945, 2011.

29. Wang, X., Meloche, M., Verchere, C.B., Ou, D., Mui, A., and Warnock, G.L. Improving islet engraftment by gene therapy. Journal of transplantation 20112011.

30. Penko, D., Rojas-Canales, D., Mohanasundaram, D., Peiris, H.S., Sun, W.Y., Drogemuller, C.J., Keating, D.J., Coates, P.T.H., Bonder, C.S., and Jessup, C.F. Endothelial progenitor cells enhance islet engraftment, influence $\beta$-cell function, and modulate islet connexin 36 expression. Cell Transplant 24, 37, 2015.

31. Borg, D.J., and Bonifacio, E. The use of biomaterials in islet transplantation. Curr Diabetes Rep 11, 434, 2011.

32. Deters, N.A., Stokes, R.A., and Gunton, J.E. Islet transplantation: Factors in short-term islet survival. Arch Immunol Ther Exp 59, 421, 2011.

33. Samal, J., Weinandy, S., Weinandy, A., Helmedag, M., Rongen, L., Hermanns- 
Sachweh, B., Kundu, S.C., and Jockenhoevel, S. Co-Culture of Human Endothelial Cells and Foreskin Fibroblasts on 3D Silk-Fibrin Scaffolds Supports Vascularization. Macromolecular Bioscience 15, 1433, 2015.

34. Auger, F.A., Gibot, L., and Lacroix, D. The pivotal role of vascularization in tissue engineering. Annual Review of Biomedical Engineering2013. pp. 177.

35. Friis, T., Hansen, A.B., Houen, G., and Engel, A.M. Influence of angiogenesis inhibitors on endothelial cell morphology in vitro. APMIS 114, 211, 2006.

36. Duttenhoefer, F., Lara De Freitas, R., Meury, T., Loibl, M., Benneker, L.M., Richards, R.G., Alini, M., and Verrier, S. 3D scaffolds co-seeded with human endothelial progenitor and mesenchymal stem cells: Evidence of prevascularisation within 7 days. Eur Cells and Mater 26, 49, 2013.

37. Kannan, R.Y., Salacinski, H.J., Sales, K., Butler, P., and Seifalian, A.M. The roles of tissue engineering and vascularisation in the development of micro-vascular networks: A review. Biomaterials 26, 1857, 2005.

38. Friis, T., Sorensen, B.K., Engel, A.M., Rygaard, J., and Houen, G. A quantitative ELISA-based co-culture angiogenesis and cell proliferation assay. APMIS 111, 658, 2003.

39. Li, R.H. Materials for immunoisolated cell transplantation. Adv Drug Deliv Rev 33, 87, 1998.

40. Loudovaris, T., Charlton, B., Hodgson, R.J., and Mandel, T.E. Destruction of xenografts but not allografts within cell impermeable membranes. Transplant Proc 24, 2291, 1992.

41. Loudovaris, T., Jacobs, S., Young, S., Maryanov, D., Brauker, J., and Johnson, R.C. Correction of diabetic nod mice with insulinomas implanted within Baxter immunoisolation devices. J Mol Med 77, 219, 1999.

42. Brauker, J., Martinson, L.A., Young, S.K., and Johnson, R.C. Local inflammatory response around diffusion chambers containing xenografts: Nonspecific destruction of tissues and decreased local vascularization. Transplantation 61, 1671, 1996.

43. Barkai, U., Weir, G.C., Colton, C.K., Ludwig, B., Bornstein, S.R., Brendel, M.D., Neufeld, T., Bremer, C., Leon, A., Evron, Y., Yavriyants, K., Azarov, D., Zimermann, 
B., Maimon, S., Shabtay, N., Balyura, M., Rozenshtein, T., Vardi, P., Bloch, K., De Vos, P., and Rotem, A. Enhanced oxygen supply improves islet viability in a new bioartificial pancreas. Cell Transplant 22, 1463, 2013. 


\section{Samenvatting}

Patiënten met Diabetes Type I zijn afhankelijk van insuline omdat hun eigen afweersysteem de beta cellen in de eilandjes van Langerhans aanvallen. De meest gebruikte behandeling is de injectie van insuline met daarbij nauwe controle van de glucose spiegels in het bloed. Wanneer dit niet goed onder controle is, kan dit voor veel complicaties zorgen. Een andere optie om Diabetes te behandelen is de transplantatie van de eilandjes van Langerhans. Deze worden in de poort ader van de patient gespoten waar zij hun functie zullen uitoefenen. Ondanks dat deze therapie erg succesvol is, is het donor tekort een groot probleem en sterven er vele eilandjes na de transplantatie. Daarom wordt er veel onderzoek gedaan naar het gebruik van dragermaterialen om deze eilanden op een andere plek te transplanteren met de hoop op een betere uitkomst.

Een belangrijke parameter voor de evaluatie van biomaterialen die gebruikt worden als een dragermateriaal voor eilandjes van Langerhans is de interactie van beta cellen met deze biomaterialen. Het gebruik van primaire cellen heeft altijd de voorkeur, maar helaas zijn deze niet beschikbaar wanneer nodig. Daarom is een betrouwbare beta cellijn, ondanks dat deze niet exact de primaire beta cellen nabootst, belangrijk om basis concepten te testen in immuun beschermende dragermaterialen. Wij hebben daarom een protocol ontwikkeld om zogenoemde model-eilandjes bestaande uit MIN6 insulinoma cellen te gebruiken om het probleem van donor tekort te overbruggen (hoofdstuk 3). In dit hoofdstuk hebben we laten zien dat we met dit geoptimaliseerde protocol, waarbij we gebruik maken van theophylline en de model-eilanden, in staat waren om betrouwbare insuline secretie en glucose respons te verkrijgen die 
vergelijkbaar is met donor eilanden.

We hebben deze methode gebruikt om twee verschillende immuun beschermende strategieën te ontwikkelen. Concept $\mathrm{A}$ is gebaseerd op het gebruikt van een mutlibore hollow fiber en concept B is gebaseerd op vlakke membranen met microstructuren die samen een soort envelop vormen om eilanden in te beschermen tegen het immuun systeem. In hoofdstuk 4 en $\mathbf{5}$ hebben we onderzocht of er een mogelijkheid was om een commerciële multibore hollow fiber te gebruiken. Waar de verschillende bores (kanalen) gebruikt kunnen worden voor bijvoorbeeld de eilanden, bloedvat vorming of zuurstof generende materialen. In hoofdstuk 4 en 5 hebben we laten zien dat we in staat waren om de eilanden van elkaar te scheiden door agarose bolletjes te gebruiken in de verschillende kanalen van de multibore hollow fiber. Maar zowel de model-eilandjes als de humane donor eilanden lieten geen functioneel gedrag zien (hoofdstuk 4). Dit zou het gevolg kunnen zijn geweest van een gebrek aan zuurstof. Daarom hebben we een zuurstof genererend materiaal toegevoegd aan de mutibore hollow fiber (hoofdstuk 4). Ondanks dat zuurstof gegenereerd werd, was dit maar voor korte duur. Aangezien de multibore hollow fiber niet transparant is, hebben we beeldvorming op basis van fotoakoestiek gebruikt om het gedrag van de cellen over de tijd te volgen (hoofdstuk 5). Om cellen die in de multibore hollow fiber zaten te kunnen monitoren, moest er een houder ontwikkeld worden die de beeldvorming op basis van fotoakoestiek toe liet in een steriele omgeving. Daarnaast hebben we een aantal cel labels geëvalueerd om cellen zichtbaar te maken. Een belangrijke uitkomst van deze studie was dat wanneer cellen koolstof nanodeeltjes bevatten het fotoakoestiek signaal het hoogst was. Door deze deeltjes te gebruiken, waren we in staat om het gedrag van de cellen te volgen over een periode van 7 dagen zonder de multibore hollow fiber kapot te maken. Deze beeldvormende techniek zou toegepast kunnen worden voor veel meer applicaties in het veld van Tissue Engineering. Behalve de multibore hollow fiber, zou onderzoek naar de vlakke membrane van hoofdstuk 6 ook baat kunnen hebben bij deze beeldvormende techniek, aangezien deze vlakke membranen ook niet transparant zijn. 
Concept B bestaat uit twee dunne lagen van polyethersulfone/polyvinylpyrrolidone (PES/PVP) nanoporeuze membranen. De ene laag bestaat uit een dichte laag van microbakjes. In elk bakje kunnen 1 of 2 eilandjes gehouden worden. Dit voorkomt het samenklonteren van eilanden in dit dragermateriaal. Het ontwerp zorgde voor een goede controle over de distributie van eilanden. Deze laag werd afgesloten met een poreuze deksel (0.45 um porien) en gesealed door middel van een eigen ontwikkelde seal constructie (hoofdstuk 6).

Eilandjes van Langerhans in de pancreas zijn normaal gesproken omgeven door een vaatnetwerk die de cellen in een eilandje, waaronder de beta cellen, op een efficiënte wijze van nutriënten en zuurstof voorzien. Waarbij de cellen in een eilandje op hun beurt snel hormonen kunnen afgeven aan het bloed. Het is bewezen dat het gebrek aan zuurstof in de omgeving van de beta cellen door een slecht vaatnetwerk (door de isolatie om de embedding van eilanden in een dragermateriaal) direct kan leiden tot een verlies in functie en de dood van eilandjes na verloop van tijd.

In hoofdstuk $\mathbf{7}$ hebben we laten zien dat een micropatroon op een vlak membraan de groei van mesenchymale stam cellen (MSCs) van de rat beïnvloed kan worden. Waarbij de cellen langs deze patronen opgroeien wat mogelijk de vascularisatie kan verhogen in vivo. In hoofdstuk $\mathbf{8}$ hebben we laten zien dat de zuurstof generende materialen, welke ontwikkeld zijn door onze collega's in het Diabetes Research Institute in Miami Amerika, gecombineerd konden worden met onze vlakke membranen van hoofdstuk 6. Deze zuurstof generende materialen lieten een positief effect op de overleving van eilandjes zien, hun metabole activiteit, en hun functie wanneer ze under lage zuurstof concentraties gekweekt werden.

Gedurende deze studies hebben we de eerste stappen gezet naar een werkend immuun beschermend dragermateriaal. Ondanks dat er succes geboekt is bij vele aspecten, moet er nog meer onderzoek gedaan worden om de dragermaterialen verder te optimaliseren. 



\section{Curriculum Vitae}

Milou Groot Nibbelink was born in Apeldoorn, the Netherlands, on March $18^{\text {th }} 1986$. In 2005 after receiving her high school diploma at the Koninklijke Scholen Gemeenschap (Apeldoorn), she started Technical Medicine at the University of Twente. Milou started her master's degree program in Regenerative Medicine, after completing her bachelor's degree at University of Twente in 2008. For her master thesis project, Immune-protective membrane based scaffolds for extra hepatic islet transplantation, she collaborated with four different research groups; the Developmental BioEngineering group, Biomaterial Science and Technology group, and BioMedical Photonic Imaging group at University of Twente and the department of Nephrology at Leiden University Medical Center. After finishing her master's, she started as a PhD student in the Developmental BioEngineering group of Marcel Karperien in 2013. In close collaboration with the Biomaterial Science and Technology group, she worked on a new immune protective islet of Langerhans encapsulation device for the cure of Type I Diabetes. During her PhD, she collaborated with a group at the Diabetes Research Institute to combine their oxygen generating material with her encapsulation device. As part of this collaboration, she worked as a research scholar for 3 months at the Diabetes Research Institute of Miami Florida.

After finishing her PhD in the beginning of 2016, she continued working at the University of Twente. She started as a post-doc at the Molecular Nanofabrication group. As a post-doc, she is part of the team that will bring LipoCoat technology to the market. 



\section{List of Publications}

\section{Peer-reviewed papers}

Milou Groot Nibbelink, Marcel Karperien, Aart van Apeldoorn. Immune protection in clinical islet of Langerhans transplantation. Submitted

Milou Groot Nibbelink*, Giulia Marchioli*, Lorenzo Moroni, Marcel Karperien, Aart van Apeldoorn. A protocol to enhance INS1E and MIN6 functionality; the use of theophylline. Submitted

Milou Groot Nibbelink, Khalid Daoudi, Sanne Slegers, Diederik Grootendorst, Maura Dantuma, Wiendelt Steenbergen, Marcel Karperien, Srirang Manohar, and Aart van Apeldoorn. Opening the 'white box' in tissue engineering: visualization of cell aggregates in optically scattering scaffolds. Accepted in Tissue Engineering Part C, April 2016

Katarzyna Skrzypek, Milou Groot Nibbelink, Maria Coronel, Irayme Labrada, Cherie Stabler, Jr van Lente, Marcel Karperien, Aart van Apeldoorn, Dimitrios Stamatialis. Evaluation of microwell PES/PVP membranes for islet encapsulation: A novel strategy for immune protection. In preparation

Milou Groot Nibbelink, Katarzyna Skrzypek, Lisanne Karbaat, Sanne Both, Jacqueline Plass, Bettie Klomphaar, Jr van Lente, Sieger Henke, Marcel Karperien, 
Dimitrios Stamatialis, Aart van Apeldoorn. Mesenchymal stem cells and micropatterns of poly(ether sulfone) / poly(vinylpyrrolidone) membranes accelerates vascularization.Submitted

\section{Abstract selected for poster presentation}

The Netherlands Society for Biomaterials and Tissue Engineering annual meeting 2013, Bilthoven, the Netherlands. M Groot Nibbelink, K Skrzypek, EJP de Koning, M Karperien, D Stamatialis, AA van Apeldoorn. Immuno-protective Membrane Based Scaffolds For Extra Hepatic Islet Transplantation

\section{Abstract selected for oral presentation}

The 4th joint EPITA and AIDPIT winter symposium, 2014, Igls, Austria. M Groot Nibbelink, K Skrzypek, EJP de Koning, M Karperien, D Stamatialis, AA van Apeldoorn. Immuno-protective Membrane Based Scaffolds For Extra Hepatic Islet Transplantation 


\section{Acknowledgements}

It is a strange feeling to finalize your thesis, thinking about lay-out, the cover, and now the acknowledgements. For three years you are working towards the final product of your $\mathrm{PhD}$; your thesis. However, these three years were not about these final aspects. During these final steps, I realize, like every other $\mathrm{PhD}$, how fast these years have past and how many people I have had the joy to meet.

I would like to thank Marcel, Aart and Dimitrios for the opportunity to work on the JDRF project and thereby the change to go abroad to Miami. There are many things I have learned from you over these years, that helped me become the researcher I am today. I want to thank as well Prof. W. Steenbergen, Prof. P. de Vos, Dr. S. le Gac, Prof D.W. Grijpma, Dr. L. Moroni, and Dr. F. Carlotti for being part of my graduation committee. For sure I would not have been able to get to this point without my colleague in the JDRF project Kasia. I really enjoyed our time together and the support I received. All the project plans we created, the supervision of our time-share students, the many (really many) function tests we performed together starting earlier each time, I was lucky to have you as my partner in crime. I still feel guilty leaving you behind during your final months without an extra set of hands in the lab.

Of course I would like to thank the Islet group; Janneke, Mijke, Sieger, Giulia, and Don. Thank you for all your help, already starting at my master assignment. I really enjoyed our chats, tea breaks, and laughter throughout the years. Furthermore, I really appreciate that you were there when things were not going according to plan. 
Helping me to get back on track and keep faith that everything would be turn out okay. Finally, of course the shared care of our precious islets at the most inconvenient times.

Maurice and Brenda, thanks for being my paranymphs, I can always count on your positive note. Sorry for all the times I kept you from your work when I was stressed, frustrated, not motivated to write or overexcited about results, the upcoming wedding or my trip to Miami. Maurice, I really got the know you during our trip to Italy. I truly had a great time driving through the hills of Italy, creating a traffic jam and of course my first diving experience. From then on it was nice to have someone around to joke around with in between al the seriousness of research. Brenda, we got to share an office which I truly enjoyed. I lost track of how many cups of tea we much have drunk together and hours we lost in chatting about everything and nothing. The best thing about you is your positive view on things and your ability to help people relax and relieve stress. Let's dance and jump up and down a couple of times before my defense.

During my PhD I had the opportunity to transfer my neurotic tics and my tendency to over organize to several students. Jéré, Lisanne, Pinak, Cindy, Maaike, Alise, Roelof, and Maura thank you for all the hard work you did during your internships or graduation projects. I hope I was able to transfer my enthusiasm about research to you guys.

Of course all my colleagues from DBE, I really enjoyed my time at DBE thanks to you. Thank you for all your help, scientific suggestions and discussions but also the many tea and lunch breaks at the red couches, and of the course the nice borrels. With a special thanks to Sanne and Jacqueline for your listening ear and help in the lab. During the last months of my contract I got extra help from Piet, thank you for your help with writing and editing of chapter 4. I am really happy with the end result.

Thank you Bettie for your time and patience with the animals. You helped me overcome my fears with small steps each time. I would have never imagined to enjoy 
the presence of these small creatures as I do now.

The collaboration with BMPI started already during my master assignment with Srirang, Diederink, and Sanne. I was very pleased we could continue this part of my master assignment during my PhD. I would like to thank everyone who helped during this project at BMPI. Everyone in research knows the struggle of submission and publication, therefore my special thanks to Srirang and Khalid for all the effort and time they spend helping me with my first manuscript.

I had the pleasure of spending 3 months at the Diabetes Research Institute in Miami Florida as part of the JDRF project. Living in Miami was a fantastic experience; the location and the weather were amazing. Foremost, I got to experience the knowledge at the DRI and the kindness of everyone at the DRI. With a special thanks to Cherie, Maria, and Irayme, I cannot thank you enough for all your help. Maria, I truly enjoyed working together, you are a great researcher. I still miss the Colombian hotdog.

Since February I started a new adventure as a post-doc at the MnF group, or maybe more specifically as a researcher at LipoCoat. I would like to thank Jasper, Marcel, and Pascal for this great opportunity, I would have never imagined a door like this would open in Enschede. Thanks to all my new colleagues for your very warm welcome.

Finally, I would like to thank my family and friends. Thank you for all your support during these years. Sorry for being less present at times or fully occupied with my research. Because of you guys I was able to reset my mind, relax and continue my PhD. The one person I would like to thank the most of all is Marcel. I know me working with "living things" was not always easy for you. Strange working hours, appointments to be rescheduled or only finalized at the very last moment. Short stops at the University, a medium change or check up on the animals, before heading for family and friends. I could not have done this without you. I love you and cannot wait to start our new chapter in life. 


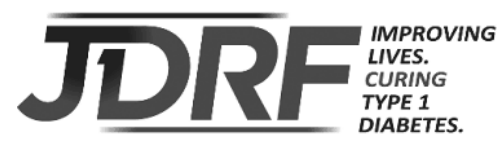

The research described in this thesis was supported by the Juvenile Diabetes Research Foundation (JDRF).

Grant title: New islet encapsulation method for ideal masstransport and immunoprotection

Grant key: 17-2013-303

Call name: JDRF Encapsulation Consortium Fall 2012 

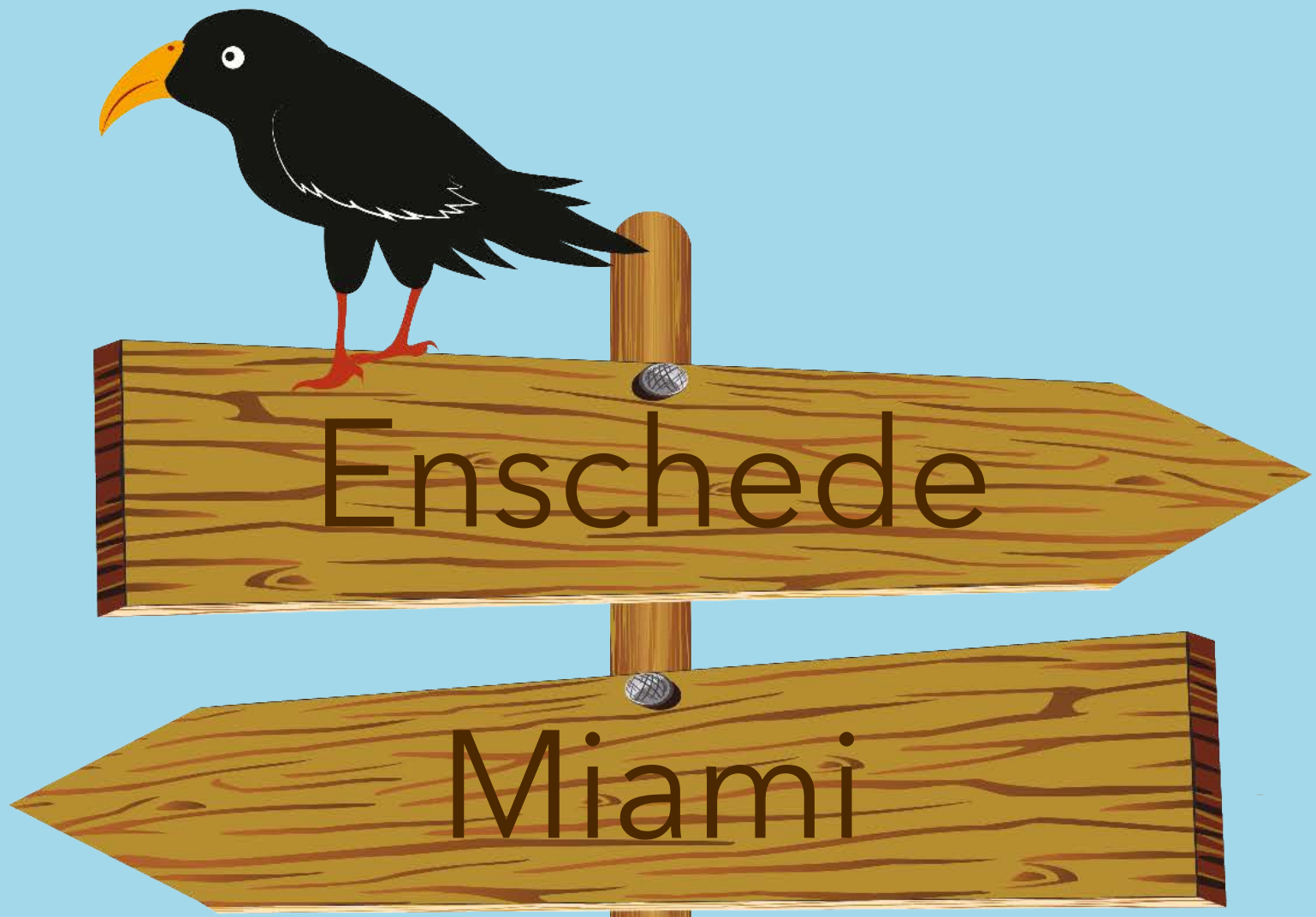

Milou Groot Nibbelink 